\title{
The fish egg microbiome: diversity and activity against the oomycete pathogen Saprolegnia
}

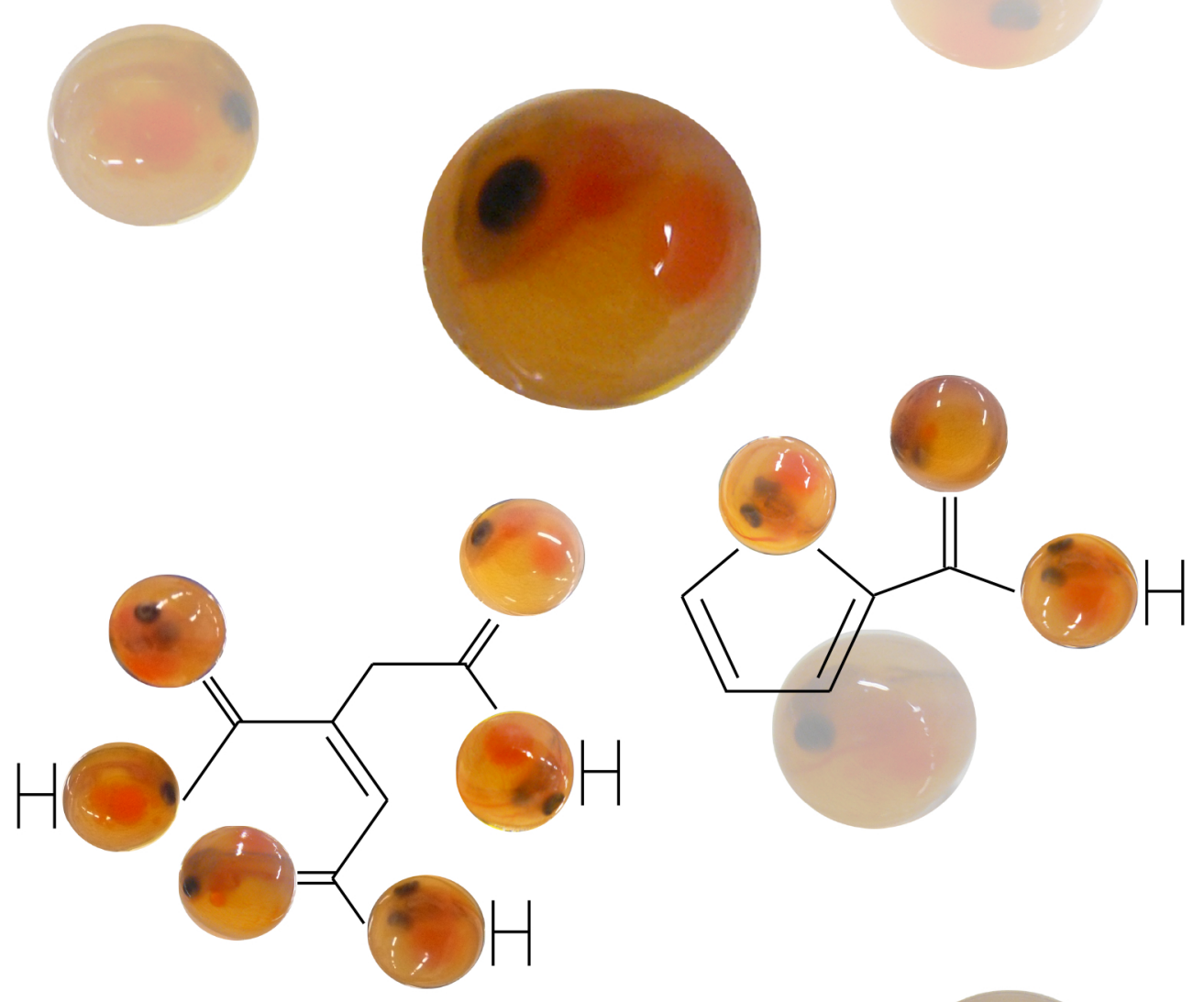




\section{The fish egg microbiome:}

diversity and activity against the oomycete pathogen Saprolegnia 


\section{Thesis committee}

\section{Promotors}

Prof. Dr F.P.M. Govers

Personal chair at the Laboratory of Phytopathology

Wageningen University

Prof. Dr J.M. Raaijmakers

Professor of Microbial Ecology

Netherlands Institute of Ecology (NIOO-KNAW), Wageningen

\section{Co-promotor}

Dr I. de Bruijn

Researcher Microbial Ecology

Netherlands Institute of Ecology (NIOO-KNAW), Wageningen

Other members

Prof. Dr G.F. Wiegertjes, Wageningen University

Prof. Dr P. Bossier, Ghent University, Belgium

Prof. Dr H. Spaink, Leiden University

Prof. Dr H. Smidt, Wageningen University

This research was conducted under the auspices of the Graduate School of Experimental Plant Sciences. 


\section{The fish egg microbiome:}

\section{diversity and activity against the oomycete pathogen Saprolegnia}

\section{Yiying Liu}

\section{Thesis}

submitted in fulfilment of the requirements for the degree of doctor at Wageningen University

by the authority of the Rector Magnificus

Prof. Dr A.P.J. Mol,

in the presence of the

Thesis Committee appointed by the Academic Board

to be defended in public

on Monday 13 June 2016

at 1.30 p.m. in the Aula. 
Yiying Liu

The fish egg microbiome: diversity and activity against the oomycete pathogen Saprolegnia, 170 pages.

$\mathrm{PhD}$ thesis, Wageningen University, Wageningen, NL (2016) With references, with summaries in English and Dutch

ISBN 978-94-6257-767-1

DOI: http://dx.doi.org/10.18174/377064 
Table of contents

$\begin{array}{lll}\text { Chapter } 1 & \text { General Introduction and thesis outline } & 7\end{array}$

Chapter 2 Deciphering microbial landscapes of fish eggs to 45 mitigate emerging diseases

Chapter 3 Phenotypic, genomic and metabolic characterization of 75 aquatic Frondihabitans with activity against the oomycete fish pathogen Saprolegnia diclina

Chapter 4 Diversity of aquatic Pseudomonas species and their activity against the fish pathogenic oomycete Saprolegnia

Chapter 5 Elucidating the diversity of aquatic Microdochium and 129 Trichoderma species and their activity against the fish pathogen Saprolegnia diclina

Chapter 6 Summarizing discussion and future perspectives

Summary

Samenvatting 161

Acknowledgements 163

Curriculum vitae 166

Publications 167

Education statement of the Graduate School 168 



\section{Chapter 1}

General introduction and thesis outline 
Aquaculture is the fastest-growing animal food sector and will further increase to feed the growing human population. Along with this growth, aquaculture is suffering more and more from emerging diseases caused by viruses, bacteria, fungi, oomycetes and parasites. To mitigate these infectious diseases in a sustainable manner, there is an increasing interest in habitat bioaugmentation or introduction of beneficial microbes to protect fish and amphibians against emerging pathogens. To this end, a profound understanding of the diversity and temporal-spatial dynamics of the microbiomes of aquatic organisms and their impact on growth and health of their hosts is required. The research described in this thesis focuses on the characterisation of fungal, oomycete and bacterial communities associated with Atlantic salmon (Salmo salar) eggs, the isolation of potential beneficial microbes, and the efficacy of several bacterial and fungal isolates and their metabolites to mitigate oomycete diseases. This introductory chapter will first give an overview of common and emerging infectious diseases in aquatic environments and the measures that are currently used to control these diseases. The current state-ofthe-art in fish microbiome research is summarized and the potential functions of the fish microbiome and its role in disease protection are highlighted. Finally, I will present the outline of my thesis.

\section{Aquaculture: opportunities and threats}

Aquaculture is defined as 'the farming of aquatic organisms' (FAO, 2002). In many parts of the world, fish contribute substantially to the total animal protein supply, in some cases even more than $20 \%$ (FAO, 2014). In 2013, the world aquaculture production (70 million tonnes excluding aquatic plants) overtook bovine production (68 million tonnes) and accounted for USD 151 billion (FAO, 2015, 2016). The major aquaculture groups include fish, crustaceans (such as shrimps and lobsters) and molluscs (such as mussels, oysters and scallops) (FAO, 2014). Aquaculture is yet a more environmentally-friendly food producing industry than livestock farming in agriculture due to the natural efficiency of fish in converting feed into animal protein (FAO, 2014). Aquaculture comprised $43 \%$ of total world fisheries in 2013 and this proportion is foreseen to exceed $60 \%$ by 2030 due to the reduction of capture fisheries and the raise in demand of fish products (FAO, 2014, 2015). Therefore, optimizing the health and growth of aquaculture animals is key to ensure sustainability and profitability of the industry. However, several factors are harmful to the long-term development of aquaculture, such as water pollution by aquaculture wastes, variability of water temperature due to climate change and emerging diseases (Cheung et al., 2010; FAO, 2014).

Besides the common 'lingering' aquaculture diseases, such as Vibriosis and Pancreas Disease, other diseases are emerging (FAO, 2014; WHO, 2016). The 
major causes proposed for this emergence include changes in environment and climate (e.g. temperature fluctuation), microbial evolution (e.g. resistance to antibiotics), anthropogenic activities (e.g. transmission of pathogens between different regions via transport/trade), changes in aquacultural practices (e.g. hygienic management or restricted regulations of chemical control measures), and social and cultural factors (e.g. consumption of contaminated raw food and subsequent release of manure in the water) (Harvell et al., 1999; Murray and Peeler, 2005; Adlard et al., 2015; WHO, 2016). Pathogenic microorganisms are commonly present in aquatic ecosystems but when the commensal microbial and plankton community is disturbed or the ambient environment (e.g. temperature and season) varies, pathogens can become more prevalent and cause infection (Turner et al., 2009; Romero et al., 2014a). Aquaculture is enormously diverse, including more than 560 species (FAO, 2014), and also has very diverse farming practices. Therefore, it is no surprise that also many infectious diseases are threatening the aquaculture industry, such as diseases caused by viruses, bacteria, fungi, oomycetes, and parasites including protists and metazoans (Table 1).

Disease outbreaks can impact a species' economic value by either reduction in yield by mortality or reduction in growth. Also, a bad taste or appearance will reduce the marketability of the products (Lafferty et al., 2015). For example, outbreaks of white spot syndrome virus and yellow head disease virus led to economic losses of around USD 6.5 billion in shrimp aquaculture in Asia from 1991 to 1993 (Lightner, 2011). Sea lice infection causes more than USD 100 million worldwide every year (Johnson et al., 2004). Worldwide, lots of money is invested to minimize the detrimental impact of aquatic diseases, largely by purchasing parasiticides, equipments and feed, but also on research (Costello, 2009). 


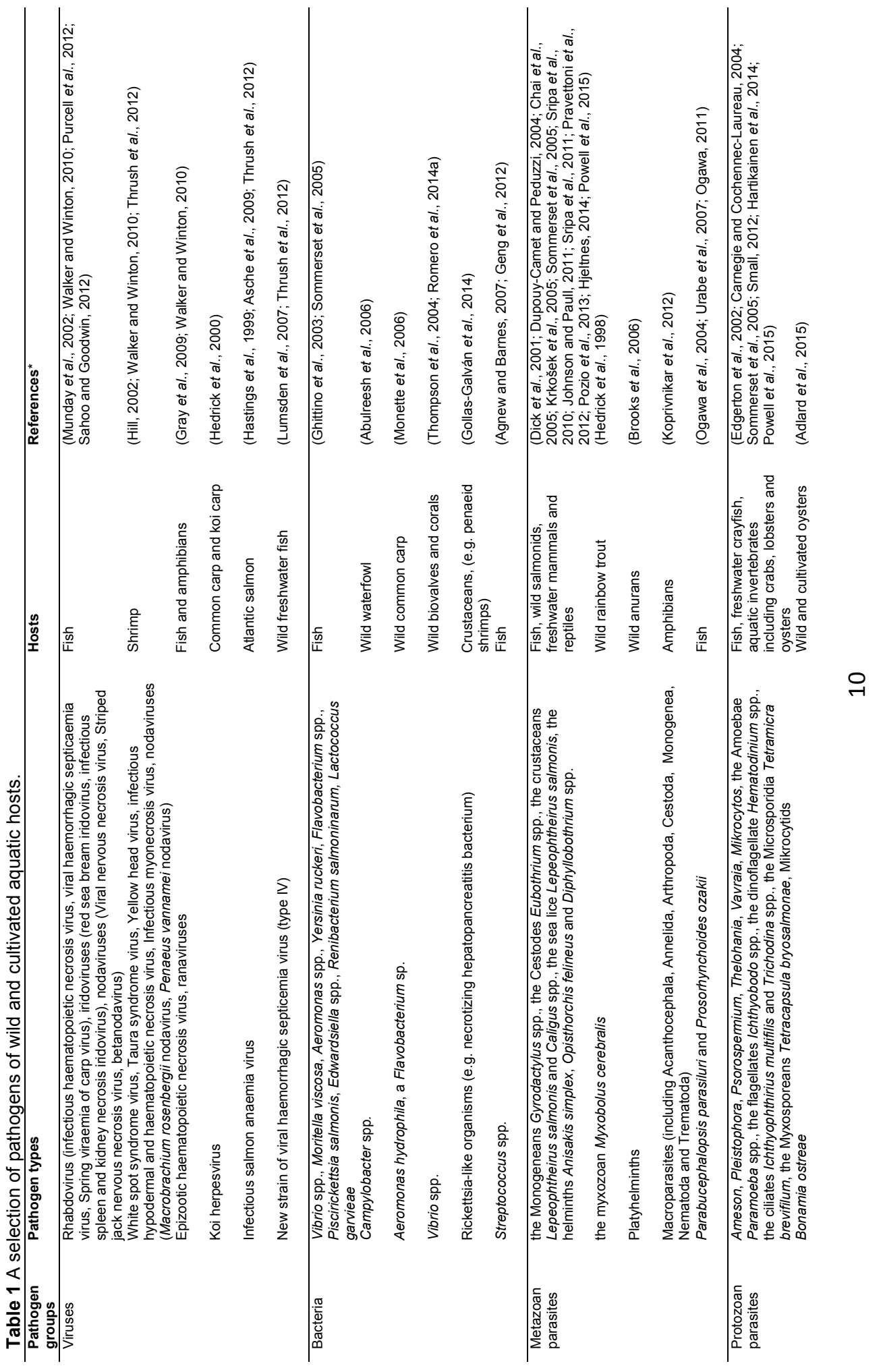




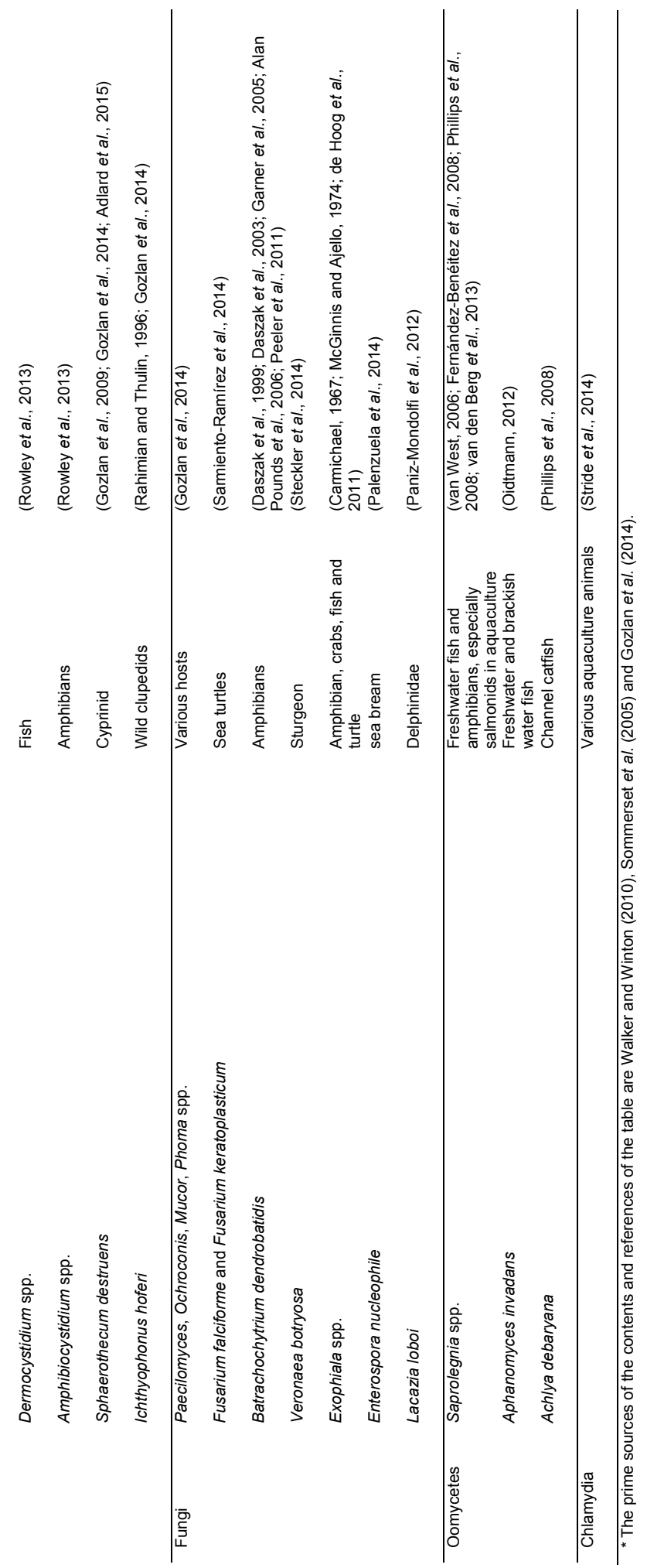




\section{Control measures of aquatic diseases}

Several measures are taken to prevent or cure aquatic diseases, including vaccinations, breeding for resistance, control by chemicals and antibiotics, and biological control.

\section{Vaccination}

Vaccines are globally applied to trigger immunity of fish to infectious diseases, mainly because they have high efficacy and low cost (Komar et al., 2004). Traditional antigen vaccines are prepared by attenuating or killing microbes. They are applied by immersion, injection or oral uptake and mainly effective against bacterial and viral diseases (Heppell and Davis, 2000; Plant and LaPatra, 2011). Vaccines are used for preventing instead of curing diseases (Yanong, 2009) and therefore they are not applicable for controlling sudden disease outbreaks. Other disadvantages of vaccination are the labour intensiveness of applying vaccines by injection (Yanong, 2009), the need for re-application in the case of immersion vaccination and the instability of oral vaccines (Komar et al., 2004). Moreover, injection can cause stress on fish and make them more susceptible to other pathogens (Yanong, 2009). DNA vaccines, which consist of encoding sequences expressing the antigens directly in the recipients, have been developed because of easier production, low production cost, stability, easy modification and lower risk of accidental infection due to incomplete attenuation (Davis and McCluskie, 1999; Heppell and Davis, 2000; Evensen and Leong, 2013). DNA vaccines can effectively protect rainbow trout (Oncorhynchus mykiss) from infectious hematopoietic necrosis and viral haemorrhagic septicaemia (Anderson et al., 1996; Lorenzen et al., 1998), and exerted a high effect against fish rhabdoviruses (Kurath, 2008).

\section{Breeding for disease resistance}

In the past decades, many fish breeding programs have been launched to improve disease resistance in aquaculture. To date, however, only a small percentage of aquaculture production is based on genetically improved stocks because of a low success rate of selective breeding (Gjedrem, 2012). Nevertheless, selective breeding has recently achieved resistance against the grass carp reovirus in grass carp (Ctenopharyngodon idellus) (Huang et al., 2015) and against sea lice in Atlantic salmon (Gharbi et al., 2015). In addition, crossing a brown trout (Salmo trutta) female with an Atlantic salmon male has resulted in resistance against 
amoebic gill disease (Maynard et al., 2016). However, to our knowledge, breeding has not yet resulted in fish species, with genetic resistance against fungal or oomycete diseases.

\section{Control by chemicals and antibiotics}

Chemicals like formalin, hydrogen peroxide and $\mathrm{NaCl}$ are widely used to control aquaculture diseases (Plumb, 1991; Harikrishnan et al., 2010; Bruno et al., 2011; Harikrishnan et al., 2011). However, for many chemicals there are concerns on safety for the farmers and their adverse environmental effects. Therefore, formalin is foreseen to be banned soon (Bruno et al., 2011). Antibiotics, such as ampicillin, tetracycline and streptomycin, are commonly used to control aquaculture diseases (Defoirdt et al., 2011; Romero et al., 2012). Concerns on the application of antibiotics have risen due to the development of antibiotic resistance in several aquatic pathogens, the putative risk of transfer of antibiotic resistance to human or animal pathogens, and the detrimental effects of residues of antibiotics in food products on human health (Cabello, 2006; Heuer et al., 2009; Cabello et al., 2013). To evaluate the efficacy of a new chemical therapy, a profound knowledge on the ecology and pathogenicity of the pathogen is required, as well as extensive toxicity testing and environmental risk assessment before application of the treatment in the aquaculture industry.

\section{Biological control}

Biological control, defined as 'the use of living organisms as control agents for pests, weeds and diseases' (Waage, 2007), has been proposed as a promising measure to tackle aquaculture diseases in a more sustainable manner. The majority of the biological control in aquaculture includes potential probiotic bacteria but also parameciidae, bacteriophages, fungi, yeasts and microalgae are considered (Neospark; Scholz et al., 1999; Marques et al., 2006; Khairnar et al., 2013; Schmeller et al., 2014). The potential probiotic bacteria to date mostly include species in the genera Vibrio, Bacillus, Pseudomonas and Lactobacillus (Table 2), which were randomly selected and explored for their effects on fish growth and disease (Verschuere et al., 2000; Newaj-Fyzul et al., 2014; Hai, 2015; Newaj-Fyzul and Austin, 2015). Additionally, natural products like short-chain fatty acids, polyhydroxy-alkanoates, bacterial-derived cyclic lipopeptide biosurfactants, and plant and fungal extracts are being investigated as potential measures to suppress aquaculture diseases (Immanuel et al., 2004; Harikrishnan et al., 2012; Reverter et al., 2014; Liu et al., 2015). Several compounds (i.e. quorum sensing 
antagonists) can inhibit the expression of the virulence genes of bacterial pathogens and are applied as antivirulence therapy (Defoirdt et al., 2004; Clatworthy et al., 2007; Defoirdt et al., 2011).

The underlying modes of action of probiotics include boosting the immune response, improving nutrient uptake, enhancing growth and survival, disease suppression by producing pathogen-inhibitory compounds, prohibiting pathogen colonization by competitive exclusion, and optimizing water quality by eliminating harmful elements like ammonium and nitrite (Verschuere et al., 2000; Martínez Cruz et al., 2012; Newaj-Fyzul et al., 2014; Hai, 2015; Newaj-Fyzul and Austin, 2015). Microbes can be applied directly in culture water or conveyed by (live) feed. For many promising candidates, however, only a few are commercialized or licensed. These include Bacillus, Lactobacillus, Enterococcus, Paracoccus, Pediococcus and Thiobacillus species marketed as a.o. BioMar, Biomin ${ }^{\circledR}$ or SporeGen ${ }^{\circledR}$. Constraints for commercial application of probiotics are concerns with long-term safety for the environment, limited shelf-life, high production costs and stringent storage and transport conditions of the microbial inoculants. Also consistency of performance under different environmental conditions, their relatively narrow activity spectrum and compatibility with other applications are points of concern to the industry. Even though probiotics are considered as promising candidates in sustainable control of diseases in aquaculture, patenting, registration and commercialization of probiotics are complicated due to the strict rules and regulations involved.

\section{Microbiomes of aquatic animals}

In recent years, many microbiome studies have described the composition of microbial communities in humans, insects, plants, soils and water. These studies clearly point to the importance of microbiomes for pathogen protection of their eukaryotic hosts (Round et al., 2010; Mendes et al., 2011; Weiss and Aksoy, 2011; Everard et al., 2013; Stecher et al., 2013; Turner et al., 2013; Liu et al., 2014). As a result, habitat bioaugmentation has been proposed as a promising approach to mitigate emerging diseases of fish and amphibians in natural ecosystems and commercial aquaculture. This requires profound understanding of the diversity and activity of the microbiomes associated with their aquatic hosts. In the next paragraphs the current status of fish microbiome research, including investigations into the diversity, dynamics and functions of microbiomes for their host (Figure 1) will be described. 


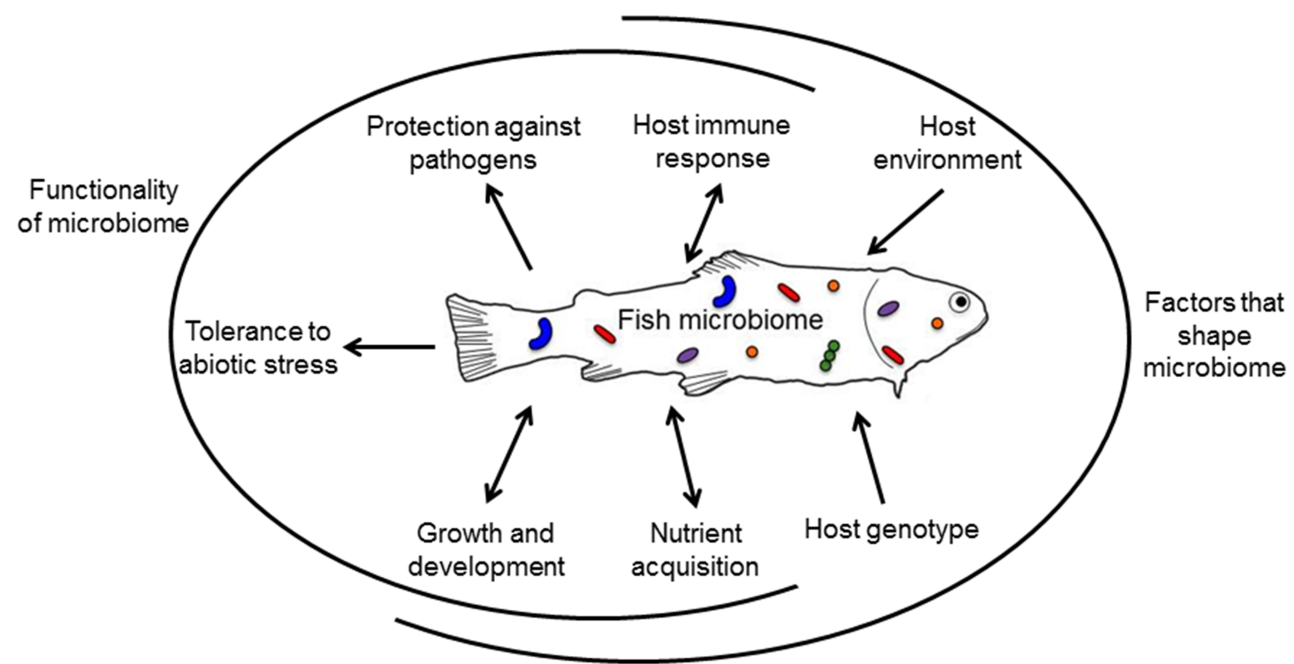

Figure 1 Schematic overview of different life-support functions of the fish microbiome and the impact of the host and ambient environment on microbiome diversity, assembly and functions.

\section{The fish microbiome - who is there?}

The composition of microbiomes of aquatic animals is highly dependent on the ambient aquatic habitat. To study microbiomes associated with aquatic animals and their environment, culture-dependent methods such as plating on general and selective culture media have been widely used. Due to the awareness that presumably less than $1 \%$ of the viable microbes in various aquatic environments are culturable (Amann et al., 1995), culture-independent methods have been developed. Besides quantitative PCR, denaturing gradient gel electrophoresis (DGGE), terminal restriction fragment length polymorphism (T-RFLP), clone library sequencing, and 16S rRNA gene sequencing, more and more advanced 'omics techniques are being used to study the composition and functions of microbiomes of a wide variety of eukaryotic hosts including aquatic hosts (Wang et al., 2010; Leonard et al., 2014; Liu et al., 2014; Merrifield and Rodiles, 2015).

The skin, gill and gastrointestinal $(\mathrm{Gl})$ tract are considered as the major portals for microbes from external to internal tissues (Merrifield and Rodiles, 2015). These mucosal tissues are important physical barriers against pathogen invasion and provide a unique environment for commensal microbes. The majority of the mucosal microbes is coated with host immunoglobulins (IGs). The immunoglobulins are the antibodies that recognize and bind to the microbes and activating the immune response. Therefore IGs are suggested to be important for the adaptive immune response differentiating between commensal bacterial microbiota and pathogens (Zhang et al., 2010; Xu et al., 2013). In fish, each 
mucosal tissue has its own specific adaptive immune system (Salinas, 2015) and therefore it is likely that the microbiota are coated with different $\mathrm{lg}$ isotypes depending on the tissue type (Tacchi et al., 2014). Moreover, as described below, also the microbiomes of the different mucosal tissues vary.

\section{Skin}

The slimy and viscous epidermal mucus of the skin of aquatic animals is the natural primary guardian against the external environmental influences and also provides a home for the commensal bacteria to live and to form a shield against invasive pathogens (Hansen and Olafsen, 1999; Merrifield and Rodiles, 2015). The mucus and the protective scales of the fish skin contain more aerobic than anaerobic microbes (Merrifield and Rodiles, 2015). In general, the fish skin houses $10^{2}-10^{4}$ bacteria per $\mathrm{cm}^{2}$ (Austin, 2006). Fish from warm waters tend to harbour more Gram-positive bacteria in their skin such as Bacillus and Micrococcus spp., while in the skin of fish from temperate waters, Gram-negative bacteria, including Acinetobacter, Flavobacterium, Moraxella, Photobacterium, Pseudomonas and Vibrio spp. are more abundant. Skins of fish from tropical waters have higher numbers of Enterobacteriaceae (Hansen and Olafsen, 1999; Gram and Ringø, 2005). The skin microbiome of aquatic animals is influenced by the ambient environment, including water quality, load of potential pathogens, oxygen level, $\mathrm{pH}$ and temperature (Horsley, 1973, 1977), but also host genotype appeared to be important for the composition of skin specific microbiome (Boutin et al., 2014). It was argued that the skin microbiomes are simply present on the cuticle surface without substantial interference with the skin (Crouse-Eisnor et al., 1985). However, more studies are showing that skin microbes are playing a role in defence and immune responses (Xu et al., 2013; Lowrey et al., 2015). In rainbow trout, the highest diversity in bacterial community was found on the skin when compared to the gills and gut, and several skin isolates inhibited the growth of the aquatic pathogens Saprolegnia australis and Mucor hiemalis in vitro (Lowrey et al., 2015; Salinas, 2015). The skin microbiome can produce polymers to reduce friction generated between the skin and water during swimming and to facilitate locomotion of fish (Sar and Rosenberg, 1989). Compared to the bacterial microbiome, the fungal microbiome of skin is less studied. It was reported that the fungal and yeast population represented less than $2.3 \%$ whereas bacteria represented more than $97.7 \%$ of the total culturable microbial community of Atlantic salmon (LandeiraDabarca et al., 2013). Alternaria, Aspergillus, Cladosporium and Fusarium represented the most dominant fungal genera in the exoskeleton of crayfish (Procambarus clarkii) (Dörr et al., 2012). 
Fish gills contain a high diversity and richness of microbiota, the composition of which is mainly affected by water quality, seasonal environmental changes and host genotype (Merrifield and Rodiles, 2015). The gill microbiome functions as primary barrier against external pathogens (Larsen and Arias, 2014). Due to the consistent water exchange in the gills, many gill-associated bacteria and fungi have attachment structures and they tend to colonize in protected niches of the gill rather than the surface exposed areas (Mudarris and Austin, 1988; Hansen and Olafsen, 1999; Wang et al., 2010). Typically, the aerobic bacterial population ranges from $10^{3}$ to $10^{6} \mathrm{CFU}$ per gram of gill tissue in various fish species (Merrifield and Rodiles, 2015). Anaerobic bacteria are rarely present in fish gill or skin. Facultative anaerobic bacteria, mainly Vibrio species, are found in pelagic fish (Lougovois and Kyrana, 2005). The core bacterial microbiome of the gills of at least 19 fish species is composed of Achromobacter, Aeromonas, Bacillus, Corynebacterium, Flavobacterium, Micrococcus, Pseudomonas and Vibrio species (Cahill, 1990). For Atlantic salmon, the gill microbiome was similar to the skin microbiome and also reflected the microbiome of the ambient water (Horsley, 1973). In contrast, the gill microbiome of healthy turbot (Scophthalmus maximus) was distinct from the ambient water (Mudarris and Austin, 1988). So far, studies on the fungal microbiome of fish gills are limited. Wang et al. (2010) reported that the Ascomycota as the most dominant fungal phyla of gibel carp (Carassius auratus gibelio) and bluntnose black bream (Megalobrama amblycephala Yih) (Wang et al., 2010).

\section{Gastrointestinal tract}

Of the mucosal microbiomes of fish, the gut bacterial microbiome is studied most intensely. In general, the fish GI tract houses up to $10^{8}$ aerobic heterotrophic bacteria and up to $10^{5}$ anaerobic bacteria per gram of tissue wet weight (Austin, 2006). It has been commonly agreed that the GI tract of newly hatched fish larvae is nearly sterile. The microbial population is acquired from the water, live and artificial feed, and establishes shortly after hatching (Ringø and Birkbeck, 1999).

Besides the bacterial microbiome, the yeast microbiome of fish gut has attracted wide attention, mainly due to the fact that several yeasts can stimulate the host immune response, growth, development and metabolism of the hosts (Gatesoupe, 2007). The population density of yeast in fish gut ranges from undetectable quantities to $10^{7} \mathrm{CFU}$ per gram of gut matter and the two most reported fungal phyla are the Ascomycota and Basidiomycota (Gatesoupe, 2007; Romero et al., 2014b). Concerning filamentous fungi, only little is known: a 
Trichoderma sp. was found in catfish Hypostomus strigaticeps (Cardone et al., 2006) and Cladosporium, Dothideomycetes and Pseudocercospora species were found in rainbow trout (Geurden et al., 2014).

It should be noted that the gut is also a habitat for potential pathogenic microbes. Among these are bacteria such as Aeromonas, Edwardsiella, Mycobacterium, Photobacterium, Piscirickettsia, Pseudomonas, Vibrio and Yersinia species, and Alteromonas, Flavobacterium, Moraxella that are associated with diseases in early developmental stage of fish (eggs, larvae or juveniles) (Hansen and Olafsen, 1999; Bøgwald and Dalmo, 2014). Besides, yeasts, such as Candida, Cryptococcus and Trichosporon species, are known to cause diseases on e.g. Oncorhynchus rhodurus, Oncorhynchus tshawytscha, Sparus aurata and Tinca tinca (Gatesoupe, 2007).

The commensal GI tract microbes play a role in nutrition acquisition (Nayak, 2010; Montalban-Arques et al., 2015), as was shown for gnotobiotic zebrafish (Danio rerio) that were defect in the uptake of protein macromolecules (Bates et al., 2006). The microbes can produce exogenous enzymes to facilitate the digestibility of food and degradation of large and complex molecules, such as chitin, protein and starch (Austin, 2006; Nayak, 2010; Ray et al., 2012; Merrifield and Rodiles, 2015; Montalban-Arques et al., 2015). The gut microbes can also produce vitamins and eicosapentaenoic acid to enhance the health of the host (Yazawa et al., 1988; Austin, 2006). Moreover, the microbiome of the Gl tract can also be the main food source for its hosts, as was shown for Asian silver carp (Hypophthalmichthys molitrix) and gizzard shad (Dorosoma cepedianum) where the Cyanobacteria were most abundant in the GI tract (Ye et al., 2014). It is well known from studies in humans and animals that nutrients can alter the microbiome composition of the $\mathrm{GI}$ tract (Kau et al., 2011; Kostic et al., 2013) and this is also the case in fish as was shown in Arctic charr (Salvelinus alpinus) when fed with low or high level of carbohydrate (Ringø and Olsen, 1999). Besides nutritional uptake, the commensal GI tract microbiomes play an important role in defence against pathogens by enhancing and maintaining immune functions (Nayak, 2010; Maynard et al., 2012; Montalban-Arques et al., 2015). For example, commensal microbiomes of zebrafish larvae were shown to exhibit immunoregulatory activity, via for example stimulating genes encoding antiviral components, against viral infection before the adaptive immunity became mature (Galindo-Villegas et al., 2012). Moreover, starved seabass showed the enrichment of genes encoding antimicrobial compounds in the $\mathrm{Gl}$ tract microbiome indicating that the microbiome can protect the host from invasion of pathogens under stressed conditions (Xia et al., 2014). Various studies have shown that several members of the $\mathrm{Gl}$ tract microbiome are capable of producing inhibitory compounds against pathogens, including Carnobacterium against Aeromonas salmonicida, Acinetobacter against Vibrio 
campbellii, Vibrio sp. against Pasteurella piscicida, and yeasts against Vibrio anguillarum (Sugita et al., 1997; Ringø et al., 2000; Liu et al., 2010; Caruffo et al., 2015).

Compared to research on bacterial microbiomes, much less studies have been conducted on archaeal and protozoan microbiomes of the $\mathrm{Gl}$ tract of fish. Archaeal species were found in several aquatic organisms, including the $\mathrm{Gl}$ tract of flounder (Platichthys flesus) and grey mullet (Mugil cephalus) (van der Maarel et al., 1998). Also protozoa belonging to the genera Balantidium and Paracichlidotherus were found in the GI tract of surgeonfishes (family Acanthuridae) (Grim et al., 2002). Protozoa are hypothesized as a potential ecological contributor to the fish gut, but clearly more research is needed to prove their exact functions for their hosts (Romero et al., 2014b).

\section{The fish microbiome: for better or for worse?}

Besides the commensal microbes, the fish microbiome can also be a source of pathogens as they can utilize the aquatic environment not only to disperse, but also to propagate (Hansen and Olafsen, 1999). Climate change, anthropogenic activity, disturbance of ecosystems, introduction of pathogens, and evolution of pathogens are some of the factors that can enhance the frequencies of existing and (re-) emerging pathogens (De Silva and Soto, 2009; Pulkkinen et al., 2010; Engering et al., 2013; Liu et al., 2014; Tomova et al., 2015). For example, the spread of parasitic protozoans Haplosporidium nelsoni and Perkinsus marinus in Eastern oyster (Crassostrea virginica), and the bacterial pathogen Vibrio parahaemolyticus were triggered by increased temperatures in seafood products in the south of Chile and in oysters in Alaska (Hofmann et al., 2001; De Silva and Soto, 2009).

Next to true fish pathogens, aquatic ecosystems and fish can also act as a vector for human pathogens which can be transmitted via direct contact and handling of fish or via consumption (Novotny et al., 2004; Austin, 2006). It has been shown for example, that consumption of filter feeders, like bivalves, is an important path to acquire human pathogens including Vibrio fluvialis and Vibrio damsela (Olafsen, 2001; Ramamurthy et al., 2014). Human pathogens that are transmitted via direct contact include Erysipelothrix rhusiopathiae, Photobacterium damselae, Streptococcus iniae, Vibrio alginolyticus, Vibrio vulnificus and Mycobacterium species, while pathogens known to be transferred by consumption

of contaminated seafood comprise Campylobacter jejuni, Clostridium botulinum, Clostridium perfringens, Escherichia coli, Listeria monocytogenes, Staphylococcus aureus, Vibrio cholerae, Vibrio parahaemolyticus, and Aeromonas and Salmonella species (Novotny et al., 2004). Subsequent infections are dependent on the health 
condition and eating habit (e.g. consuming uncooked food) of the consumer and pathogen load (Novotny et al., 2004).

\section{Toward pathogen control}

A major challenge for aquaculture is to find sustainable methods to control infectious diseases that (re-)emerged in the last decades. Exploiting the 'good guys' in the microbiome to combat the 'bad guys', the pathogens, could be a way forward. However to do so, a profound insight in the composition and functioning of the microbiomes is not sufficient. We also need to learn more about the fundamental mechanisms underlying the intimate interactions between host and pathogen. Similar to animal and plant pathogens, aquatic pathogens use various strategies to invade their hosts. They can, for example, manipulate the metabolic processes in the host, as shown in Atlantic salmon where infection by Piscirickettsia salmonis resulted in a change in protein metabolism in muscle and liver (Tacchi et al., 2011). Or they can avoid host immune defences or other biotic and abiotic perturbations, as shown in the late stage of amoebic gill disease, where the pathogen infects the host via evading the cell-mediated killing mechanisms or inducing an allergic reaction on the host (Benedicenti et al., 2015). Also via coevolution with hosts pathogens can acquire properties that enable them to avoid defence of their hosts. Another strategy exploited by for example Staphylococcus aureus and Pseudomonas aeruginosa, is destroying physical barriers of the host by producing proteases that lyse host proteins (Finlay and Falkow, 1997). Also other lytic enzymes, such as chitinases and lipases that are produced by fish pathogens, such as Aeromonas spp., are potential virulence factors that destroy the tissue of fish or the chorion and zona radiata of eggs (Olafsen, 2001; Defoirdt, 2014; Arslan and Küçüksari, 2015). Last but not least pathogens can compete with their hosts for chemical elements. This mechanism is for example exploited by Vibrio anguillarum, via sequestering iron from its hosts via siderophores, thereby limiting the iron availability for the host (Naka and Crosa, 2011; Defoirdt, 2014). A better fundamental understanding of these processes will be needed to identify critical steps in the disease cycle as potential targets for disease control. 


\section{How to use microbiome analyses to mitigate emerging diseases?}

As part of the innate immunity, the microbiome harbours beneficial microbes that form the first line of defence in protection of their aquatic hosts. The microbial community composition is affected by external and intrinsic factors, such as feed ingredients, feeding regime, environment (water quality, temperature, $\mathrm{pH}$, salinity, perturbation), genetics, stress level and density of the host (Landeira-Dabarca et al., 2013; Merrifield and Rodiles, 2015). This was also shown for humans, where infections or changes of environment can substantially affect the gut microbiome by causing overgrowth of microbes that otherwise are present at low abundance (Stecher et al., 2013), thereby boosting the propagation of specific beneficial or pathogenic microbes.

Microbiome analysis has evolved as an informative tool to understand the diversity, dynamics, richness, abundance and functions of the aquatic animalassociated microbes. The results from microbiome studies can, on the one hand, be used for decision making to control or prevent diseases, in particular by predicting potential disease outbreak based on the load and seasonal changes of (potential) native and non-native pathogens; and on the other hand, for evaluating the efficacy and toxicity of pharmaceutical or biological control treatments. Large multidisciplinary international programs should be launched to exchange experiences on farming and knowledge on disease control. Additionally, largescale tests in farming conditions should accompany the culture-independent microbiome analyses to demonstrate the efficacy of microbiomes on disease control.

Aquaculture is sensitive to infectious pathogens and environmental perturbations. Therefore a suitable rearing system can maintain the beneficial microbes at a stable level. For example, recirculation aquaculture systems (RASs) are capable of stabilizing microbiome composition and maintaining microbial diversity within the rearing system, which subsequently inhibits the growth of harmful microbes and enhances the growth and survival of Atlantic cod (Gadus morhua) larvae (Attramadal et al., 2012a; Attramadal et al., 2012b; Attramadal et al., 2014). To combat common and emerging aquatic diseases, a comprehensive understanding of the dynamics, richness, abundance and functions of microbiomes associated with their aquatic hosts and environment is pivotal to obtain the right bioaugmentation candidates for application. 


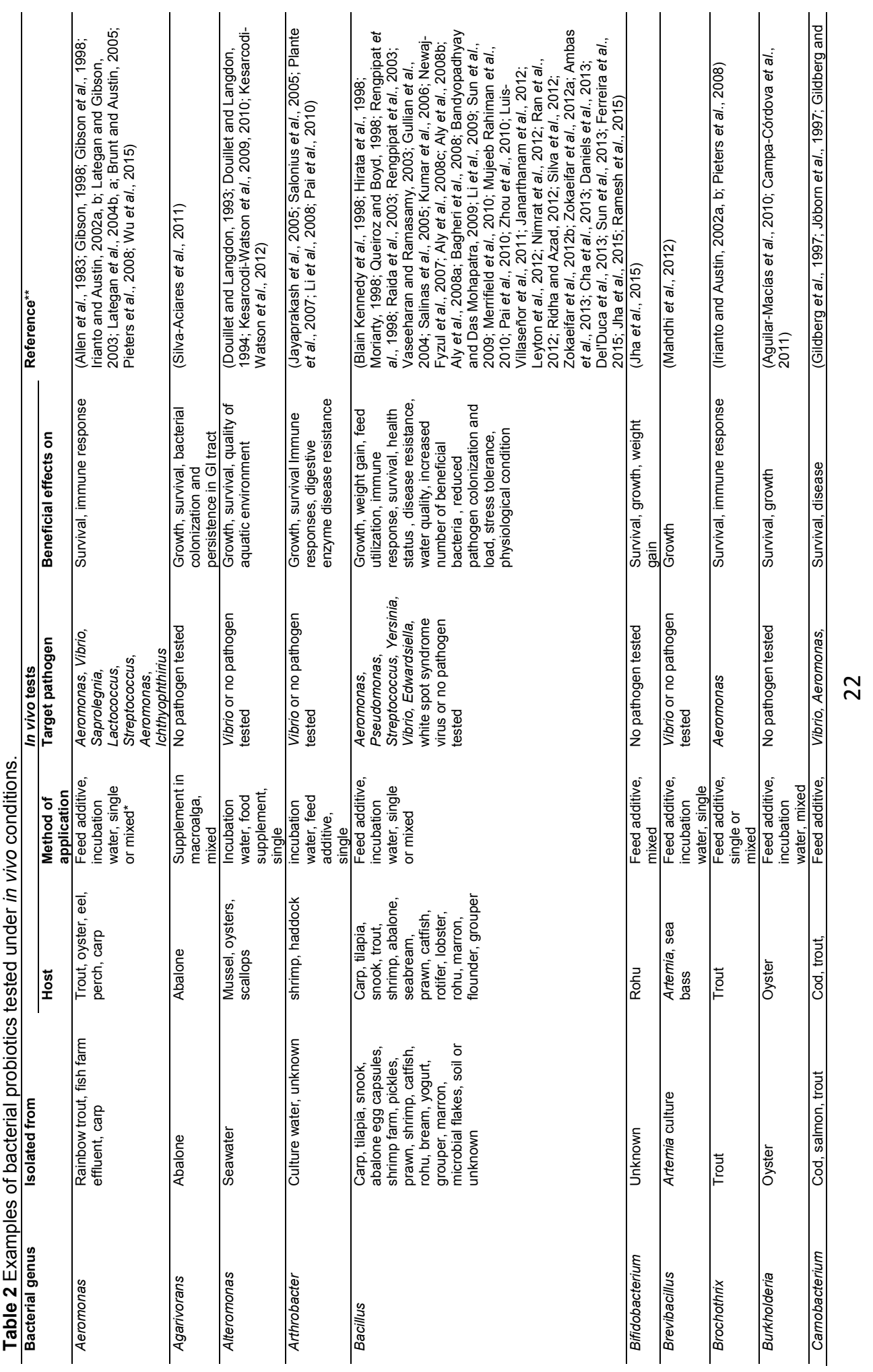




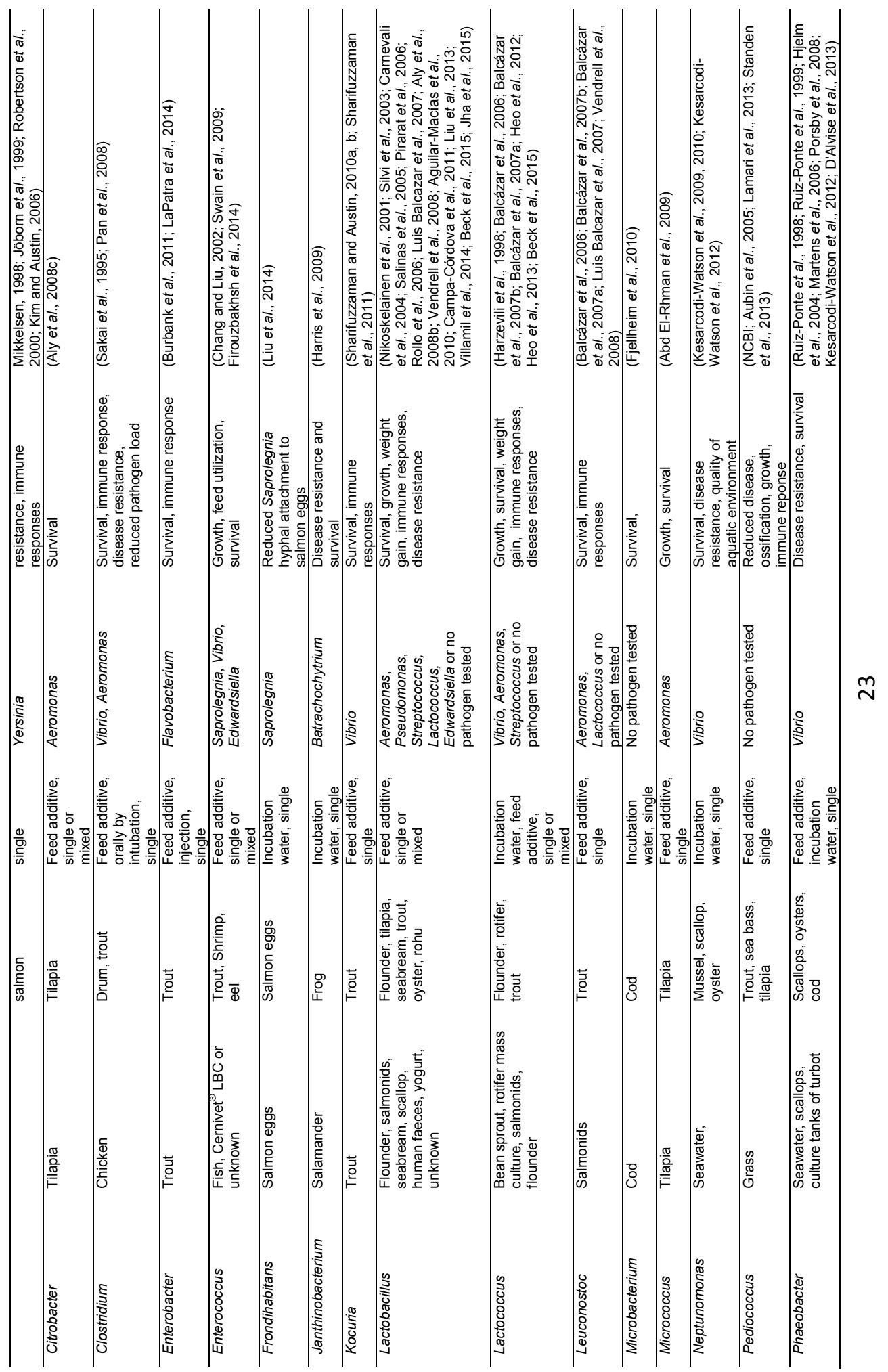




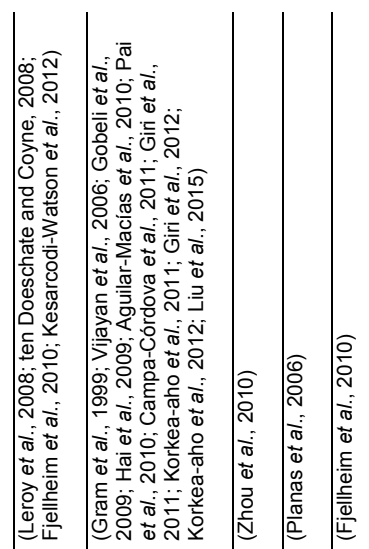

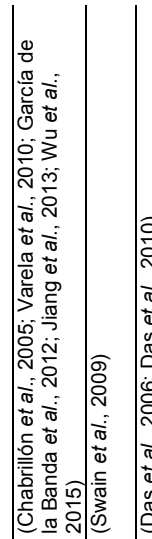

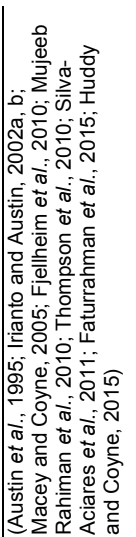

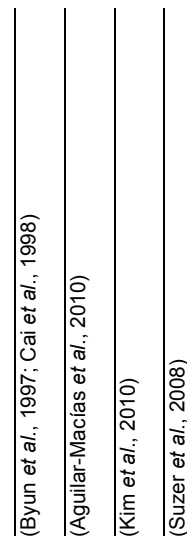
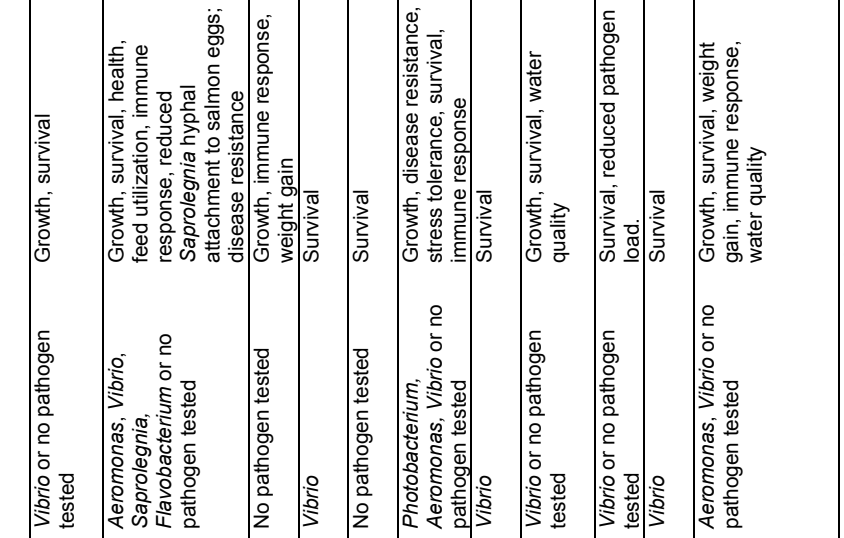

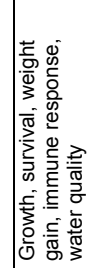

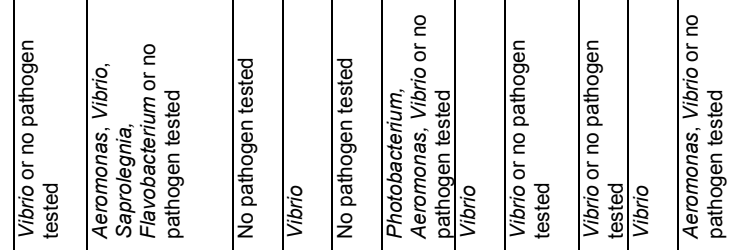

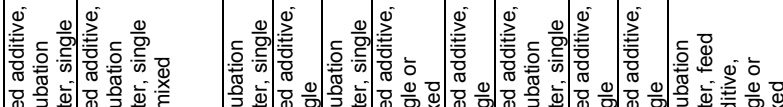

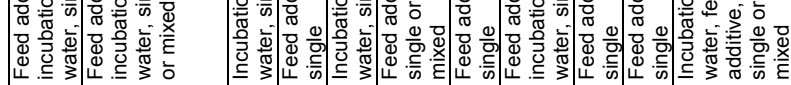

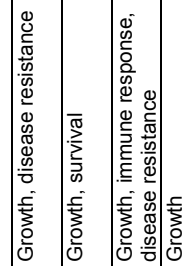

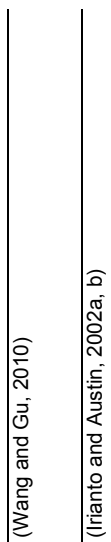

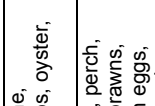

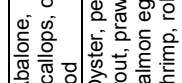

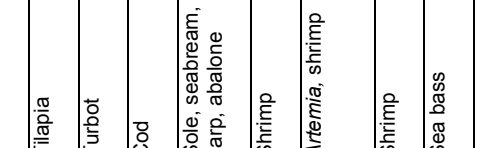

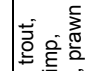

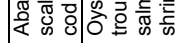

更

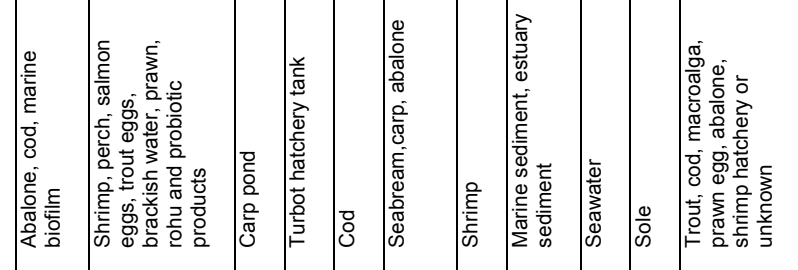

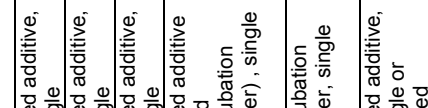

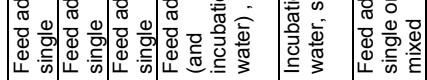

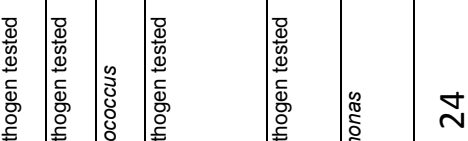

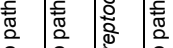

$\underset{\sim}{ }$ 
*Mixed: in combination with other microbes or chemical compounds

** The prime sources of the contents and references of the table are Newaj-Fyzul et al. (2014), Hai (2015) and Verschuere et al. (2000).

\section{Thesis outline}

Among the emerging diseases, Saprolegniosis is causing substantial declines in fish and amphibian populations in natural ecosystems and aquaculture. The overall aim of the research described in this thesis was to decipher the microbiome of Atlantic salmon eggs and to investigate the diversity and activity of commensal microbes of fish eggs. This knowledge is instrumental for designing strategies to combat Saprolegniosis and other emerging diseases in aquaculture and natural habitats.

In this introductory chapter (Chapter 1) I gave an overview of the current status of common and emerging aquatic diseases and the current control measures. To mitigate emerging aquaculture diseases in a sustainable manner, there is an increasing interest in habitat bioaugmentation to protect fish against emerging pathogens. Understanding the impact of microbiomes on growth and health of their aquatic hosts might provide solutions to mitigate aquatic diseases. I have summarized the current state-of-the-art of fish microbiome research with a focus on the role of microbiomes in protection of fish and other aquatic animals against common and emerging diseases.

Chapter 2 presents the meta-taxonomic analyses of the oomycete, fungal, bacterial and archaeal communities associated with Saprolegnia-infected (diseased) and non-infected Atlantic salmon (Salmo salar) eggs from a commercial fish hatchery. While pathogenic Saprolegnia species were identified in both diseased and healthy salmon egg samples, a low incidence of Saprolegniosis was strongly correlated with a high abundance and richness of commensal Actinobacteria. Subsequent isolation of Actinobacteria and functional bioassays showed that an Actinobacterial isolate, classified as Frondihabitans (Microbacteriaceae), significantly inhibited hyphal attachment of $S$. diclina to live salmon eggs while other bacterial genera were not able to provide protection.

Chapter 3 describes the results of a more comprehensive study aimed at unravelling the diversity, bioactivity and phylogeny of aquatic Frondihabitans bacteria associated with healthy salmon eggs. The results showed that most Frondihabitans isolates inhibited growth in vitro of $S$. diclina, formed biofilms and had extracellular protease and lipase activity at low temperature $\left(5{ }^{\circ} \mathrm{C}\right)$. The Frondihabitans sp. $762 \mathrm{G} 35$ that inhibited hyphal attachment of S. diclina to salmon eggs was selected for genome sequencing. An in-depth study was conducted to further analyse the genome, metabolite profile and bioactive compounds of Frondihabitans sp. 762 G35. 
Since the meta-taxonomic analyses in chapter 2 revealed that the Proteobacteria (Pseudomonas) represented one of the most abundant bacterial genera associated with salmon eggs, the diversity and activity of aquatic Pseudomonas species and their metabolic potential to suppress Saprolegniosis on salmon eggs were investigated. As shown in Chapter 4, no distinct difference was observed in the frequencies of Pseudomonas isolates from diseased or healthy salmon eggs with in vitro activities against Saprolegnia. However, a significantly higher frequency of biosurfactant-producing Pseudomonas was found among the isolates from healthy salmon eggs. Pseudomonas isolate $\mathrm{H} 6$ consistently inhibited hyphal attachment of Saprolegnia diclina to live salmon eggs and significantly reduced salmon egg mortality caused by Saprolegnia. Pseudomonas $\mathrm{H} 6$ produces a viscosin-like biosurfactant, which inhibited hyphal growth of $S$. diclina and $S$. parasitica in vitro, but lacked significant effects in vivo.

Chapter 5 describes the isolation and characterization of salmon eggassociated fungi. The results showed that most isolates were closely related to Microdochium lycopodinum/Microdochium phragmitis, and also to Trichoderma viride. The analyses revealed both qualitative and quantitative differences in the Trichoderma community associated with diseased and healthy salmon eggs, with a higher abundance on healthy salmon eggs. These differences were not observed for the Microdochium community and only few isolates showed in vitro antagonistic activity against $S$. diclina. For most Trichoderma isolates, the typical mycoparasitic coiling around and/or formation of papilla-like structures on $S$. diclina hyphae were observed, suggesting attachment of Trichoderma to $S$. diclina hyphae and mycoparasitism.

In Chapter 6, the major findings of this research are summarized and the potential application of beneficial microbes to mitigate Saprolegniosis and other emerging aquatic diseases is discussed.

\section{References}

Abd El-Rhman, A.M., Khattab, Y.A.E., and Shalaby, A.M.E. (2009) Micrococcus luteus and Pseudomonas species as probiotics for promoting the growth performance and health of Nile tilapia, Oreochromis niloticus. Fish \& Shellfish Immunology 27: 175-180.

Abulreesh, H.H., Paget, T.A., and Goulder, R. (2006) Campylobacter in waterfowl and aquatic environments: incidence and methods of detection. Environ Sci Technol 40: 7122-7131.

Adlard, R.D., Miller, T.L., and Smit, N.J. (2015) The butterfly effect: parasite diversity, environment, and emerging disease in aquatic wildlife. Trends Parasitol 31: 160-166.

Agnew, W., and Barnes, A.C. (2007) Streptococcus iniae: An aquatic pathogen of global veterinary significance and a challenging candidate for reliable vaccination. Veterinary Microbiology 122: 1-15.

Aguilar-Macías, O.L., Ojeda-Ramírez, J.J., Campa-Córdova, A.I., and Saucedo, P.E. (2010) Evaluation of natural and commercial probiotics for improving growth and survival of the pearl oyster, 
Pinctada mazatlanica, during late hatchery and early field culturing. Journal of the World Aquaculture Society 41: 447-454.

Alan Pounds, J., Bustamante, M.R., Coloma, L.A., Consuegra, J.A., Fogden, M.P.L., Foster, P.N. et al. (2006) Widespread amphibian extinctions from epidemic disease driven by global warming. Nature 439: 161-167.

Allen, D.A., Austin, B., and Colwell, R.R. (1983) Aeromonas media, a new species isolated from river water. International Journal of Systematic Bacteriology 33: 599-604.

Aly, S.M., Mohamed, M.F., and John, G. (2008a) Effect of probiotics on the survival, growth and challenge infection in Tilapia nilotica (Oreochromis niloticus). Aquaculture Research 39: 647-656.

Aly, S.M., Abdel-Galil Ahmed, Y., Abdel-Aziz Ghareeb, A., and Mohamed, M.F. (2008b) Studies on Bacillus subtilis and Lactobacillus acidophilus, as potential probiotics, on the immune response and resistance of Tilapia nilotica (Oreochromis niloticus) to challenge infections. Fish \& Shellfish Immunology 25: 128-136.

Aly, S.M., Abd-El-Rahman, A.M., John, G., and Mohamed, M.F. (2008c) Characterization of some bacteria isolated from Oreochromis niloticus and their potential use as probiotics. Aquaculture 277: 1-6.

Amann, R.I., Ludwig, W., and Schleifer, K.H. (1995) Phylogenetic identification and in situ detection of individual microbial cells without cultivation. Microbiological Reviews 59: 143-169.

Ambas, I., Suriawan, A., and Fotedar, R. (2013) Immunological responses of customised probioticsfed marron, Cherax tenuimanus, (Smith 1912) when challenged with Vibrio mimicus. Fish Shellfish Immunol 35: 262-270.

Anderson, E.D., Mourich, D.V., Fahrenkrug, S.C., LaPatra, S., Shepherd, J., and Leong, J.A. (1996) Genetic immunization of rainbow trout (Oncorhynchus mykiss) against infectious hematopoietic necrosis virus. Mol Mar Biol Biotechnol 5: 114-122.

Arslan, S., and Küçüksari, R. (2015) Phenotypic and genotypic virulence factors and antimicrobial resistance of motile Aeromonas spp. from fish and ground beef. Journal of Food Safety 35: 551-559.

Asche, F., Hansen, H., Tveteras, R., and Tveteras, S. (2009) The salmon disease crisis in chile. Marine Resource Economics 24: 405-411.

Attramadal, K.J.K., Oie, G., Storseth, T.R., Alver, M.O., Vadstein, O., and Olsen, Y. (2012a) The effects of moderate ozonation or high intensity UV-irradiation on the microbial environment in RAS for marine larvae. Aquaculture 330: 121-129.

Attramadal, K.J.K., Thi My Hanh, T., Bakke, I., Skjermo, J., Olsen, Y., and Vadstein, O. (2014) RAS and microbial maturation as tools for K-selection of microbial communities improve survival in cod larvae. Aquaculture 432: 483-490.

Attramadal, K.J.K., Salvesen, I., Xue, R., Oie, G., Storseth, T.R., Vadstein, O., and Olsen, Y. (2012b) Recirculation as a possible microbial control strategy in the production of marine larvae. Aquacultural Engineering 46: 27-39.

Aubin, J., Gatesoupe, F.-J., Labbé, L., and Lebrun, L. (2005) Trial of probiotics to prevent the vertebral column compression syndrome in rainbow trout (Oncorhynchus mykiss Walbaum). Aquaculture Research 36: 758-767.

Austin, B. (2006) The bacterial microflora of fish, revised. ScientificWorldJournal 6: 931-945.

Austin, B., Stuckey, L.F., Robertson, P.A.W., Effendi, I., and Griffith, D.R.W. (1995) A probiotic strain of Vibrio alginolyticus effective in reducing diseases caused by Aeromonas salmonicida, Vibrio anguillarum and Vibrio ordalii. Journal of Fish Diseases 18: 93-96.

Bagheri, T., Hedayati, S.A., Yavari, V., Alizade, M., and Farzanfar, A. (2008) Growth, survival and gut microbial load of rainbow trout (Onchorhynchus mykiss) fry given diet supplemented with probiotic during the two months of first feeding. Turkish Journal of Fisheries and Aquatic Sciences 8: 43-48.

Balcázar, J.L., Vendrell, D., de Blas, I., Ruiz-Zarzuela, I., Gironés, O., and Muzquiz, J.L. (2006) Immune modulation by probiotic strains: quantification of phagocytosis of Aeromonas salmonicida by leukocytes isolated from gut of rainbow trout (Oncorhynchus mykiss) using a radiolabelling assay. Comp Immunol Microbiol Infect Dis 29: 335-343. 
Balcázar, J.L., de Blas, I., Ruiz-Zarzuela, I., Vendrell, D., Gironés, O., and Muzquiz, J.L. (2007a) Enhancement of the immune response and protection induced by probiotic lactic acid bacteria against furunculosis in rainbow trout (Oncorhynchus mykiss). FEMS Immunol Med Microbiol 51: 185-193.

Balcázar, J.L., de Blas, I., Ruiz-Zarzuela, I., Vendrell, D., Calvo, A.C., Márquez, I. et al. (2007b) Changes in intestinal microbiota and humoral immune response following probiotic administration in brown trout (Salmo trutta). Br J Nutr 97: 522-527.

Bandyopadhyay, P., and Das Mohapatra, P.K. (2009) Effect of a probiotic bacterium Bacillus circulans PB7 in the formulated diets: on growth, nutritional quality and immunity of Catla catla (Ham.). Fish Physiol Biochem 35: 467-478.

Bates, J.M., Mittge, E., Kuhlman, J., Baden, K.N., Cheesman, S.E., and Guillemin, K. (2006) Distinct signals from the microbiota promote different aspects of zebrafish gut differentiation. Developmental Biology 297: 374-386.

Beck, B.R., Kim, D., Jeon, J., Lee, S.-M., Kim, H.K., Kim, O.-J. et al. (2015) The effects of combined dietary probiotics Lactococcus lactis BFE920 and Lactobacillus plantarum FGL0001 on innate immunity and disease resistance in olive flounder (Paralichthys olivaceus). Fish \& Shellfish Immunology 42: 177183.

Benedicenti, O., Collins, C., Wang, T., McCarthy, U., and Secombes, C.J. (2015) Which Th pathway is involved during late stage amoebic gill disease? Fish \& Shellfish Immunology 46: 417-425.

BioMar. URL http://www.biomar.com/en/BioMar-Denmark/.

Biomin $^{\circledR}$. URL http://www.biomin.net/en/products/aquastar/.

Blain Kennedy, S., Tucker, J.J.W., Neidig, C.L., Vermeer, G.K., Cooper, V.R., Jarrell, J.L., and Sennett, D.G. (1998) Bacterial management strategies for stock enhancement of warmwater marine fish: a case study with common snook (Centropomus Undecimalis). Bulletin of Marine Science 62: 573588.

Bøgwald, J., and Dalmo, R.A. (2014) Gastrointestinal pathogenesis in aquatic animals. In Aquaculture Nutrition: John Wiley \& Sons, Ltd, pp. 53-74.

Boutin, S., Sauvage, C., Bernatchez, L., Audet, C., and Derome, N. (2014) Inter individual variations of the fish skin microbiota: host genetics basis of mutualism? PLOS ONE 9: e102649.

Brooks, D.R., Leon-Regagnon, V., McLennan, D.A., and Zelmer, D. (2006) Ecological fitting as a determinant of the community structure of platyhelminth parasites of anurans. Ecology 87: S76-S85.

Bruno, D., van West, P., and Beakes, G. (2011) Saprolegnia and other oomycetes. In Fish Diseases and Disorders, Viral, Bacterial and Fungal Infections. Woo, P., and Bruno, D. (eds). Wallingford, UK: CABI: Wallingford, UK, pp. 669-720.

Brunt, J., and Austin, B. (2005) Use of a probiotic to control lactococcosis and streptococcosis in rainbow trout, Oncorhynchus mykiss (Walbaum). Journal of Fish Diseases 28: 693-701.

Burbank, D.R., Shah, D.H., LaPatra, S.E., Fornshell, G., and Cain, K.D. (2011) Enhanced resistance to coldwater disease following feeding of probiotic bacterial strains to rainbow trout (Oncorhynchus mykiss). Aquaculture 321: 185-190.

Byun, J.W., Park, S.C., Benno, Y., and Oh, T.K. (1997) Probiotic effect of Lactobacillus sp. DS-12 in flounder (Paralichthys olivaceus). J Gen Appl Microbiol 43: 305-308.

Cabello, F.C. (2006) Heavy use of prophylactic antibiotics in aquaculture: a growing problem for human and animal health and for the environment. Environ Microbiol 8: 1137-1144.

Cabello, F.C., Godfrey, H.P., Tomova, A., Ivanova, L., Dolz, H., Millanao, A., and Buschmann, A.H. (2013) Antimicrobial use in aquaculture re-examined: its relevance to antimicrobial resistance and to animal and human health. Environ Microbiol 15: 1917-1942.

Cahill, M. (1990) Bacterial flora of fishes: A review. Microbial Ecology 19: 21-41.

Cai, Y., Benno, Y., Nakase, T., and Oh, T.K. (1998) Specific probiotic characterization of Weissella hellenica DS-12 isolated from flounder intestine. J Gen Appl Microbiol 44: 311-316. 
Campa-Córdova, A.I., Luna-González, A., Mazón-Suastegui, J.M., Aguirre-Guzmán, G., Ascencio, F., and González-Ocampo, H.A. (2011) Effect of probiotic bacteria on survival and growth of Cortez oyster larvae, Crassostrea corteziensis (Bivalvia: Ostreidae). Rev Biol Trop 59: 183-191.

Cardone, I.B., Lima-Junior, S.E., and Goitein, R. (2006) Diet and capture of Hypostomus strigaticeps (Siluriformes, Loricariidae) in a small brazilian stream: relationship with limnological aspects. Brazilian Journal of Biology 66: 25-33.

Carmichael, J.W. (1967) Cerebral mycetoma of trout due to a Phialophora-like fungus. Sabouraudia: Journal of Medical and Veterinary Mycology 5: 120-123.

Carnegie, R.B., and Cochennec-Laureau, N. (2004) Microcell parasites of oysters: Recent insights and future trends. Aquat Living Resour 17: 519-528.

Carnevali, O., Zamponi, M.C., Sulpizio, R., Rollo, A., Nardi, M., Orpianesi, C. et al. (2004) Administration of probiotic strain to improve sea bream wellness during development. Aquaculture International 12: 377-386.

Caruffo, M., Navarrete, N., Salgado, O., Díaz, A., López, P., García, K. et al. (2015) Potential probiotic yeasts isolated from the fish gut protect zebrafish (Danio rerio) from a Vibrio anguillarum challenge. Frontiers in Microbiology 6: 1093.

Cha, J.-H., Rahimnejad, S., Yang, S.-Y., Kim, K.-W., and Lee, K.-J. (2013) Evaluations of Bacillus spp. as dietary additives on growth performance, innate immunity and disease resistance of olive flounder (Paralichthys olivaceus) against Streptococcus iniae and as water additives. Aquaculture 402 403: 50-57.

Chabrillón, M., Rico, R.M., Balebona, M.C., and Moriñigo, M.A. (2005) Adhesion to sole, Solea senegalensis Kaup, mucus of microorganisms isolated from farmed fish, and their interaction with Photobacterium damselae subsp. piscicida. Journal of Fish Diseases 28: 229-237.

Chai, J.Y., Murrell, K.D., and Lymbery, A.J. (2005) Fish-borne parasitic zoonoses: Status and issues. International Journal for Parasitology 35: 1233-1254.

Chang, C.I., and Liu, W.Y. (2002) An evaluation of two probiotic bacterial strains, Enterococcus faecium SF68 and Bacillus toyoi, for reducing edwardsiellosis in cultured European eel, Anguilla anguilla L. Journal of Fish Diseases 25: 311-315.

Cheung, W.W.L., Lam, V.W.Y., Sarmiento, J.L., Kearney, K., Watson, R.E.G., Zeller, D., and Pauly, D. (2010) Large-scale redistribution of maximum fisheries catch potential in the global ocean under climate change. Global Change Biology 16: 24-35.

Clatworthy, A.E., Pierson, E., and Hung, D.T. (2007) Targeting virulence: a new paradigm for antimicrobial therapy. Nat Chem Biol 3: 541-548.

Costello, M.J. (2009) The global economic cost of sea lice to the salmonid farming industry. Journal of Fish Diseases 32: 115-118.

Crouse-Eisnor, R.A., Cone, D.K., and Odense, P.H. (1985) Studies on relations of bacteria with skin surface of Carassius auratus L. and Poecilia reticulata. Journal of Fish Biology 27: 395-402.

D'Alvise, P.W., Lillebø, S., Wergeland, H.I., Gram, L., and Bergh, Ø. (2013) Protection of cod larvae from vibriosis by Phaeobacter spp.: A comparison of strains and introduction times. Aquaculture 384387: 82-86.

Daniels, C.L., Merrifield, D.L., Ringø, E., and Davies, S.J. (2013) Probiotic, prebiotic and synbiotic applications for the improvement of larval European lobster (Homarus gammarus) culture. Aquaculture 416-417: 396-406.

Das, S., Lyla, P.S., and Khan, S.A. (2006) Application of streptomyces as a probiotic in the laboratory culture of Penaeus monodon (Fabricius). Israeli Journal of Aquaculture-Bamidgeh 58: 198204.

Das, S., Ward, L.R., and Burke, C. (2010) Screening of marine Streptomyces spp. for potential use as probiotics in aquaculture. Aquaculture 305: 32-41.

Daszak, P., Cunningham, A.A., and Hyatt, A.D. (2003) Infectious disease and amphibian population declines. Diversity and Distributions 9: 141-150. 
Daszak, P., Berger, L., Cunningham, A.A., Hyatt, A.D., Green, D.E., and Speare, R. (1999) Emerging infectious diseases and amphibian population declines. Emerging Infectious Diseases 5: 735748.

Davis, H.L., and McCluskie, M.J. (1999) DNA vaccines for viral diseases. Microbes and Infection 1: 7-21.

de Hoog, G.S., Vicente, V.A., Najafzadeh, M.J., Harrak, M.J., Badali, H., and Seyedmousavi, S. (2011) Waterborne Exophiala species causing disease in cold-blooded animals. Persoonia : Molecular Phylogeny and Evolution of Fungi 27: 46-72.

De Silva, S.S., and Soto, D. (2009) Climate change and aquaculture: potential impacts, adaptation and mitigation. In Climate change implications for fisheries and aquaculture: overview of current scientific knowledge. Cochrane, K., De Young, C., Soto, D., and Bahri, T. (eds). Rome: FAO Fisheries and Aquaculture Technical Paper. No. 530. FAO., pp. 151-212.

Defoirdt, T. (2014) Virulence mechanisms of bacterial aquaculture pathogens and antivirulence therapy for aquaculture. Reviews in Aquaculture 6: 100-114.

Defoirdt, T., Sorgeloos, P., and Bossier, P. (2011) Alternatives to antibiotics for the control of bacterial disease in aquaculture. Curr Opin Microbiol 14: 251-258.

Defoirdt, T., Boon, N., Bossier, P., and Verstraete, W. (2004) Disruption of bacterial quorum sensing: an unexplored strategy to fight infections in aquaculture. Aquaculture 240: 69-88.

Del'Duca, A., Evangelista Cesar, D., Galuppo Diniz, C., and Abreu, P.C. (2013) Evaluation of the presence and efficiency of potential probiotic bacteria in the gut of tilapia (Oreochromis niloticus) using the fluorescent in situ hybridization technique. Aquaculture 388-391: 115-121.

Dick, T.A., Nelson, P.A., and Choudhury, A. (2001) Diphyllobothriasis: update on human cases, foci, patterns and sources of human infections and future considerations. The Southeast Asian journal of tropical medicine and public health 32 Suppl 2: 59-76.

Dörr, A.J.M., Elia, A.C., Rodolfi, M., Garzoli, L., Picco, A.M., D'Amen, M., and Scalici, M. (2012) A model of co-occurrence: segregation and aggregation patterns in the mycoflora of the crayfish Procambarus clarkii in Lake Trasimeno (central Italy). Journal of Limnology 71: 135-143.

Douillet, P., and Langdon, C.J. (1993) Effects of marine bacteria on the culture of axenic oyster Crassostrea gigas (Thunberg) Larvae. The Biological Bulletin 184: 36-51.

Douillet, P.A., and Langdon, C.J. (1994) Use of a probiotic for the culture of larvae of the Pacific oyster (Crassostrea gigas Thunberg). Aquaculture 119: 25-40.

Dupouy-Camet, J., and Peduzzi, R. (2004) Current situation of human diphyllobothriasis in Europe. Euro surveillance : bulletin Europeen sur les maladies transmissibles = European communicable disease bulletin 9: 31-35.

Edgerton, B.F., Evans, L.H., Stephens, F.J., and Overstreet, R.M. (2002) Synopsis of freshwater crayfish diseases and commensal organisms. Aquaculture 206: 57-135.

Engering, A., Hogerwerf, L., and Slingenbergh, J. (2013) Pathogen-host-environment interplay and disease emergence. Emerg Microbes Infect 2: e5.

Evensen, O., and Leong, J.-A.C. (2013) DNA vaccines against viral diseases of farmed fish. Fish \& Shellfish Immunology 35: 1751-1758.

Everard, A., Belzer, C., Geurts, L., Ouwerkerk, J.P., Druart, C., Bindels, L.B. et al. (2013) Cross-talk between Akkermansia muciniphila and intestinal epithelium controls diet-induced obesity. Proc Natl Acad Sci U S A 110: 9066-9071.

FAO (2002) CWP handbook of fishery statistical standards, section J: aquaculture. CWP Data Collection. In. Rome: FAO Fisheries and Aquaculture Department.

FAO (2014) The state of world fisheries and aquaculture 2014. Rome, Italy.

FAO (2015) Food outlook, biannual report on global food markets.

FAO (2016). Global aquaculture production 1950-2013. URL http://www.fao.org/fishery/statistics/global-aquaculture-production/query/en. 
Faturrahman, Rohyati, I.S., and Sukiman, d. (2015) Improved of growth rate of abalone Haliotis Asinine fed pudding probiotic-enriched protein. Procedia Environmental Sciences 23: 315-322.

Fernández-Benéitez, M.J., Ortiz-Santaliestra, M.E., Lizana, M., and Diéguez-Uribeondo, J. (2008) Saprolegnia diclina: another species responsible for the emergent disease 'Saprolegnia infections' in amphibians. FEMS Microbiol Lett 279: 23-29.

Ferreira, G.S., Bolívar, N.C., Pereira, S.A., Guertler, C., Vieira, F.d.N., Mouriño, J.L.P., and Seiffert, W.Q. (2015) Microbial biofloc as source of probiotic bacteria for the culture of Litopenaeus vannamei. Aquaculture 448: 273-279.

Finlay, B.B., and Falkow, S. (1997) Common themes in microbial pathogenicity revisited. Microbiol Mol Biol Rev 61: 136-169.

Firouzbakhsh, F., Mehrabi, Z., Heydari, M., Khalesi, M.K., and Tajick, M.A. (2014) Protective effects of a synbiotic against experimental Saprolegnia parasitica infection in rainbow trout (Oncorhynchus mykiss). Aquaculture Research 45: 609-618.

Fjellheim, A.J., Klinkenberg, G., Skjermo, J., Aasen, I.M., and Vadstein, O. (2010) Selection of candidate probionts by two different screening strategies from Atlantic cod (Gadus morhua L.) larvae. Vet Microbiol 144: 153-159.

Galindo-Villegas, J., Garcia-Moreno, D., de Oliveira, S., Meseguer, J., and Mulero, V. (2012) Regulation of immunity and disease resistance by commensal microbes and chromatin modifications during zebrafish development. Proceedings of the National Academy of Sciences of the United States of America 109: E2605-E2614.

García de la Banda, I., Lobo, C., Chabrillón, M., León-Rubio, J.M., Arijo, S., Pazos, G. et al. (2012) Influence of dietary administration of a probiotic strain Shewanella putrefaciens on senegalese sole (Solea senegalensis, Kaup 1858) growth, body composition and resistance to Photobacterium damselae subsp piscicida. Aquaculture Research 43: 662-669.

Garner, T.W.J., Walker, S., Bosch, J., Hyatt, A.D., Cunningham, A.A., and Fisher, M.C. (2005) Chytrid fungus in Europe. Emerging Infectious Diseases 11: 1639-1641.

Gatesoupe, F.J. (2007) Live yeasts in the gut: Natural occurrence, dietary introduction, and their effects on fish health and development. Aquaculture 267: 20-30.

Geng, Y., Wang, K.Y., Huang, X.L., Chen, D.F., Li, C.W., Ren, S.Y. et al. (2012) Streptococcus agalactiae, an emerging pathogen for cultured ya-fish, Schizothorax prenanti, in China. Transbound Emerg Dis 59: 369-375.

Geurden, I., Mennigen, J., Plagnes-Juan, E., Veron, V., Cerezo, T., Mazurais, D. et al. (2014) High or low dietary carbohydrate:protein ratios during first-feeding affect glucose metabolism and intestinal microbiota in juvenile rainbow trout. Journal of Experimental Biology 217: 3396-3406.

Gharbi, K., Matthews, L., Bron, J., Roberts, R., Tinch, A., and Stear, M. (2015) The control of sea lice in Atlantic salmon by selective breeding. Journal of the Royal Society Interface 12.

Ghittino, C., Latini, M., Agnetti, F., Panzieri, C., Lauro, L., Ciappelloni, R., and Petracca, G. (2003) Emerging pathologies in aquaculture: effects on production and food safety. Vet Res Commun 27 Suppl 1: 471-479.

Gibson, L.F. (1998) Bacteriocin activity and probiotic activity of Aeromonas media. Journal of Applied Microbiology 85: 243S-248S.

Gibson, L.F., Woodworth, J., and George, A.M. (1998) Probiotic activity of Aeromonas media on the Pacific oyster, Crassostrea gigas, when challenged with Vibrio tubiashii. Aquaculture 169: 111-120.

Gildberg, A., and Mikkelsen, H. (1998) Effects of supplementing the feed to Atlantic cod (Gadus morhua) fry with lactic acid bacteria and immuno-stimulating peptides during a challenge trial with Vibrio anguillarum. Aquaculture 167: 103-113.

Gildberg, A., Mikkelsen, H., Sandaker, E., and Ringø, E. (1997) Probiotic effect of lactic acid bacteria in the feed on growth and survival of fry of Atlantic cod (Gadus morhua). Hydrobiologia 352: 279-285. 
Giri, S., Sukumaran, V., Sen, S., Vinumonia, J., Banu, B.N., and Jena, P. (2011) Antagonistic activity of cellular components of potential probiotic bacteria, isolated from the gut of Labeo rohita, Against Aeromonas hydrophila. Probiotics and Antimicrobial Proteins 3: 214-222.

Giri, S.S., Sen, S.S., and Sukumaran, V. (2012) Effects of dietary supplementation of potential probiotic Pseudomonas aeruginosa VSG-2 on the innate immunity and disease resistance of tropical freshwater fish, Labeo rohita. Fish Shellfish Immunol 32: 1135-1140.

Gjedrem, T. (2012) Genetic improvement for the development of efficient global aquaculture: A personal opinion review. Aquaculture 344-349: 12-22.

Gobeli, S., Goldschmidt-Clermont, E., Frey, J., and Burr, S.E. (2009) Pseudomonas chlororaphis strain JF3835 reduces mortality of juvenile perch, Perca fluviatilis L., caused by Aeromonas sobria. J Fish Dis 32: 597-602.

Gollas-Galván, T., Angélica Avila-Villa, L., Martínez-Porchas, M., and Hernandez-Lopez, J. (2014) Rickettsia-like organisms from cultured aquatic organisms, with emphasis on necrotizing hepatopancreatitis bacterium affecting penaeid shrimp: an overview on an emergent concern. Reviews in Aquaculture 6: 256-269.

Gozlan, R.E., Whipps, C.M., Andreou, D., and Arkush, K.D. (2009) Identification of a rosette-like agent as Sphaerothecum destruens, a multi-host fish pathogen. Int $J$ Parasitol 39: 1055-1058.

Gozlan, R.E., Marshall, W.L., Lilje, O., Jessop, C.N., Gleason, F.H., and Andreou, D. (2014) Current ecological understanding of fungal-like pathogens of fish: what lies beneath? Frontiers in Microbiology 5.

Gram, L., and Ringø, E. (2005) Prospects of fish probiotics. In Microbial ecology in growing animals. Holzapfel, W.H., and Naughton, P.J. (eds): Elsevier, pp. 379-417.

Gram, L., Melchiorsen, J., Spanggaard, B., Huber, I., and Nielsen, T.F. (1999) Inhibition of Vibrio anguillarum by Pseudomonas fluorescens $\mathrm{AH} 2$, a possible probiotic treatment of fish. Appl Environ Microbiol 65: 969-973.

Gray, M.J., Miller, D.L., and Hoverman, J.T. (2009) Ecology and pathology of amphibian ranaviruses. Dis Aquat Organ 87: 243-266.

Grim, J.N., Clements, K.D., and Byfield, T. (2002) New species of Balantidium and Pamcichttdotherus (Ciliophora) inhabiting the intestines of four surgeonfish species from the Tuvalu Islands, Pacific Ocean. Journal of Eukaryotic Microbiology 49: 146-153.

Gullian, M., Thompson, F., and Rodriguez, J. (2004) Selection of probiotic bacteria and study of their immunostimulatory effect in Penaeus vannamei. Aquaculture 233: 1-14.

Hai, N.V. (2015) The use of probiotics in aquaculture. Journal of Applied Microbiology 119: 917-935.

Hai, N.V., Buller, N., and Fotedar, R. (2009) Effects of probiotics (Pseudomonas synxantha and Pseudomonas aeruginosa) on the growth, survival and immune parameters of juvenile western king prawns (Penaeus latisulcatus Kishinouye, 1896). Aquaculture Research 40: 590-602.

Hansen, G.H., and Olafsen, J.A. (1999) Bacterial interactions in early life stages of marine cold water fish. Microb Ecol 38: 1-26.

Harikrishnan, R., Balasundaram, C., and Heo, M.-S. (2010) Scuticociliatosis and its recent prophylactic measures in aquaculture with special reference to South Korea Taxonomy, diversity and diagnosis of scuticociliatosis: Part I Control strategies of scuticociliatosis: Part II. Fish \& Shellfish Immunology 29: 15-31.

Harikrishnan, R., Balasundaram, C., and Heo, M.-S. (2011) Fish health aspects in grouper aquaculture. Aquaculture 320: 1-21.

Harikrishnan, R., Balasundaram, C., and Heo, M.-S. (2012) Effect of Inonotus obliquus enriched diet on hematology, immune response, and disease protection in kelp grouper, Epinephelus bruneus against Vibrio harveyi. Aquaculture 344-349: 48-53.

Harris, R.N., Brucker, R.M., Walke, J.B., Becker, M.H., Schwantes, C.R., Flaherty, D.C. et al. (2009) Skin microbes on frogs prevent morbidity and mortality caused by a lethal skin fungus. Isme $j$ 3: 818824. 
Hartikainen, H., Stentiford, G.D., Bateman, K.S., Berney, C., Feist, S.W., Longshaw, M. et al. (2014) Mikrocytids are a broadly distributed and divergent radiation of parasites in aquatic invertebrates. Current Biology 24: 807-812.

Harvell, C.D., Kim, K., Burkholder, J.M., Colwell, R.R., Epstein, P.R., Grimes, D.J. et al. (1999) Emerging marine diseases--climate links and anthropogenic factors. Science 285: 1505-1510.

Harzevili, A.R.S., Van Duffel, H., Dhert, P., Swings, J., and Sorgeloos, P. (1998) Use of a potential probiotic Lactococcus lactis AR21 strain for the enhancement of growth in the rotifer Brachionus plicatilis (Muller). Aquaculture Research 29: 411-417.

Hastings, T., Olivier, G., Cusack, R., Bricknell, I., Nylund, A., Binde, M. et al. (1999) Infectious salmon anaemia. Bulletin of the European Association of Fish Pathologists 19: 286-288.

Hedrick, R.P., el-Matbouli, M., Adkison, M.A., and MacConnell, E. (1998) Whirling disease: reemergence among wild trout. Immunol Rev 166: 365-376.

Hedrick, R.P., Gilad, O., Yun, S., Spangenberg, J.V., Marty, G.D., Nordhausen, R.W. et al. (2000) A herpesvirus associated with mass mortality of juvenile and adult koi, a strain of common carp. Journal of Aquatic Animal Health 12: 44-57.

Heo, W.-S., Kim, Y.-R., Kim, E.-Y., Bai, S.C., and Kong, I.-S. (2013) Effects of dietary probiotic, Lactococcus lactis subsp. lactis 12, supplementation on the growth and immune response of olive flounder (Paralichthys olivaceus). Aquaculture 376-379: 20-24.

Heo, W.S., Kim, E.Y., Kim, Y.R., Hossain, M.T., and Kong, I.S. (2012) Salt effect of nisin Z isolated from a marine fish on the growth inhibition of Streptococcus iniae, a pathogen of streptococcosis. Biotechnol Lett 34: 315-320.

Heppell, J., and Davis, H.L. (2000) Application of DNA vaccine technology to aquaculture. Advanced Drug Delivery Reviews 43: 29-43.

Heuer, O.E., Kruse, H., Grave, K., Collignon, P., Karunasagar, I., and Angulo, F.J. (2009) Human health consequences of use of antimicrobial agents in aquaculture. Clinical Infectious Diseases 49: 1248-1253.

Hill, B. (2002) National and international impacts of white spot disease of shrimp. Bulletin of the European Association of Fish Pathologists 22: 58-65.

Hirata, H., Murata, O., Yamada, S., Ishitani, H., and Wachi, M. (1998) Probiotic culture of the rotifer Brachionus plicatilis. Hydrobiologia 387-388: 495-498.

Hjelm, M., Bergh, O., Riaza, A., Nielsen, J., Melchiorsen, J., Jensen, S. et al. (2004) Selection and identification of autochthonous potential probiotic bacteria from turbot larvae (Scophthalmus maximus) rearing units. Syst Appl Microbiol 27: 360-371.

Hjeltnes, B. (2014) The health situation in Norwegian Aquaculture 2013. In. Hjeltnes, B. (ed). Oslo, Norway: Norwegian Veterinary Institute, p. 41.

Hofmann, E., Ford, S., Powell, E., and Klinck, J. (2001) Modeling studies of the effect of climate variability on MSX disease in eastern oyster (Crassostrea virginica) populations. Hydrobiologia 460: 195-212.

Horsley, R.W. (1973) The bacterial flora of the Atlantic salmon (Salmo salar L.) in relation to its environment. Journal of Applied Bacteriology 36: 377-386.

Horsley, R.W. (1977) A review of the bacterial flora of teleosts and elasmobranchs, including methods for its analysis. Journal of Fish Biology 10: 529-553.

Huang, R., Sun, J., Luo, Q., He, L., Liao, L., Li, Y. et al. (2015) Genetic variations of body weight and GCRV resistance in a random mating population of grass carp. Oncotarget 6: 35433-35442.

Huddy, R.J., and Coyne, V.E. (2015) Characterisation of the role of an alkaline protease from Vibrio midae SY9 in enhancing the growth rate of cultured abalone fed a probiotic-supplemented feed. Aquaculture 448: 128-134.

Immanuel, G., Vincybai, V.C., Sivaram, V., Palavesam, A., and Marian, M.P. (2004) Effect of butanolic extracts from terrestrial herbs and seaweeds on the survival, growth and pathogen (Vibrio parahaemolyticus) load on shrimp Penaeus indicus juveniles. Aquaculture 236: 53-65. 
Irianto, A., and Austin, B. (2002a) Use of probiotics to control furunculosis in rainbow trout, Oncorhynchus mykiss (Walbaum). Journal of Fish Diseases 25: 333-342.

Irianto, A., and Austin, B. (2002b) Probiotics in aquaculture. Journal of Fish Diseases 25: 633-642.

Janarthanam, K., George, M.R., John, K.R., and Jeyaseelan, M.J.P. (2012) In vitro and in vivo biocontrol of Vibrio harveyi using indigenous bacterium, Bacillus spp. Indian Journal of Geo-Marine Sciences 41: 83-89.

Jayaprakash, N.S., Pai, S.S., Anas, A., Preetha, R., Philip, R., and Singh, I.S. (2005) A marine bacterium, Micrococcus MCCB 104, antagonistic to vibrios in prawn larval rearing systems. Dis Aquat Organ 68: 39-45.

Jha, D.K., Bhujel, R.C., and Anal, A.K. (2015) Dietary supplementation of probiotics improves survival and growth of Rohu (Labeo rohita Ham.) hatchlings and fry in outdoor tanks. Aquaculture 435: 475-479.

Jiang, H.F., Liu, X.L., Chang, Y.Q., Liu, M.T., and Wang, G.X. (2013) Effects of dietary supplementation of probiotic Shewanella colwelliana WA64, Shewanella olleyana WA65 on the innate immunity and disease resistance of abalone, Haliotis discus hannai Ino. Fish Shellfish Immunol 35: 8691.

Jöborn, A., Olsson, J.C., Westerdahl, A., Conway, P.L., and Kjelleberg, S. (1997) Colonization in the fish intestinal tract and production of inhibitory substances in intestinal mucus and faecal extracts by Carnobacterium sp. strain K1. Journal of Fish Diseases 20: 383-392.

Jöborn, A., Dorsch, M., Olsson, J.C., Westerdahl, A., and Kjelleberg, S. (1999) Carnobacterium inhibens sp. nov., isolated from the intestine of Atlantic salmon (Salmo salar). Int $J$ Syst Bacteriol $49 \mathrm{Pt}$ 4: 1891-1898.

Johnson, P.T.J., and Paull, S.H. (2011) The ecology and emergence of diseases in fresh waters. Freshwater Biology 56: 638-657.

Johnson, S.C., Treasurer, J.W., Bravo, S., Nagasawa, K., and Kabata, Z. (2004) A review of the impact of parasitic copepods on marine aquaculture. Zoological Studies 43: 229-243.

Kau, A.L., Ahern, P.P., Griffin, N.W., Goodman, A.L., and Gordon, J.I. (2011) Human nutrition, the gut microbiome, and immune system: envisioning the future. Nature 474: 327-336.

Kesarcodi-Watson, A., Kaspar, H., Lategan, M.J., and Gibson, L. (2009) Screening for probiotics of

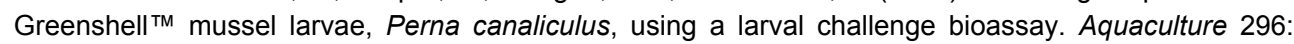
159-164.

Kesarcodi-Watson, A., Kaspar, H., Lategan, M.J., and Gibson, L. (2010) Alteromonas macleodii 0444 and Neptunomonas sp. 0536, two novel probiotics for hatchery-reared Greenshell ${ }^{\mathrm{TM}}$ mussel larvae, Perna canaliculus. Aquaculture 309: 49-55.

Kesarcodi-Watson, A., Miner, P., Nicolas, J.-L., and Robert, R. (2012) Protective effect of four potential probiotics against pathogen-challenge of the larvae of three bivalves: Pacific oyster (Crassostrea gigas), flat oyster (Ostrea edulis) and scallop (Pecten maximus). Aquaculture 344-349: 29-34.

Khairnar, K., Raut, M.P., Chandekar, R.H., Sanmukh, S.G., and Paunikar, W.N. (2013) Novel bacteriophage therapy for controlling metallo-beta-lactamase producing Pseudomonas aeruginosa infection in catfish. Bmc Veterinary Research 9.

Kim, D.-H., and Austin, B. (2006) Innate immune responses in rainbow trout (Oncorhynchus mykiss, Walbaum) induced by probiotics. Fish \& Shellfish Immunology 21: 513-524.

Kim, J.S., Harikrishnan, R., Kim, M.C., Balasundaram, C., and Heo, M.S. (2010) Dietary administration of Zooshikella sp. enhance the innate immune response and disease resistance of Paralichthys olivaceus against Sreptococcus iniae. Fish Shellfish Immunol 29: 104-110.

Komar, C., Enright, W.J., Grisez, L., and Tan, Z. (2004) Understanding fish vaccination. In AQUA Culture AsiaPacific Magazine.

Koprivnikar, J., Marcogliese, D.J., Rohr, J.R., Orlofske, S.A., Raffel, T.R., and Johnson, P.T. (2012) Macroparasite infections of amphibians: what can they tell us? Ecohealth 9: 342-360. 
Korkea-aho, T.L., Heikkinen, J., Thompson, K.D., von Wright, A., and Austin, B. (2011) Pseudomonas sp. M174 inhibits the fish pathogen Flavobacterium psychrophilum. J Appl Microbiol 111: 266-277.

Korkea-aho, T.L., Papadopoulou, A., Heikkinen, J., von Wright, A., Adams, A., Austin, B., and Thompson, K.D. (2012) Pseudomonas M162 confers protection against rainbow trout fry syndrome by stimulating immunity. J App/ Microbiol 113: 24-35.

Kostic, A.D., Howitt, M.R., and Garrett, W.S. (2013) Exploring host-microbiota interactions in animal models and humans. Genes \& Development 27: 701-718.

Krkošek, M., Lewis, M.A., and Volpe, J.P. (2005) Transmission dynamics of parasitic sea lice from farm to wild salmon. Proceedings of the Royal Society of London B: Biological Sciences 272: 689-696.

Kumar, R., Mukherjee, S.C., Prasad, K.P., and Pal, A.K. (2006) Evaluation of Bacillus subtilis as a probiotic to Indian major carp Labeo rohita (Ham.). Aquaculture Research 37: 1215-1221.

Kurath, G. (2008) Biotechnology and DNA vaccines for aquatic animals. Rev Sci Tech 27: 175-196.

Lafferty, K.D., Harvell, C.D., Conrad, J.M., Friedman, C.S., Kent, M.L., Kuris, A.M. et al. (2015) Infectious diseases affect marine fisheries and aquaculture economics. Annual Review of Marine Science 7: 471-496.

Lamari, F., Castex, M., Larcher, T., Ledevin, M., Mazurais, D., Bakhrouf, A., and Gatesoupe, F.-J. (2013) Comparison of the effects of the dietary addition of two lactic acid bacteria on the development and conformation of sea bass larvae, Dicentrarchus labrax, and the influence on associated microbiota. Aquaculture 376-379: 137-145.

Landeira-Dabarca, A., Sieiro, C., and Álvarez, M. (2013) Change in food ingestion induces rapid shifts in the diversity of microbiota associated with cutaneous mucus of Atlantic salmon Salmo salar. Journal of Fish Biology 82: 893-906.

LaPatra, S.E., Fehringer, T.R., and Cain, K.D. (2014) A probiotic Enterobacter sp. provides significant protection against Flavobacterium psychrophilum in rainbow trout (Oncorhynchus mykiss) after injection by two different routes. Aquaculture 433: 361-366.

Larsen, A.M., and Arias, C.R. (2014) More than mucus: the hidden world of the fish microbiota. Fisheries 39: 154-154.

Lategan, M.J., and Gibson, L.F. (2003) Antagonistic activity of Aeromonas media strain A199 against Saprolegnia sp., an opportunistic pathogen of the eel, Anguilla australis Richardson. Journal of Fish Diseases 26: 147-153.

Lategan, M.J., Torpy, F.R., and Gibson, L.F. (2004a) Control of saprolegniosis in the eel Anguilla australis Richardson, by Aeromonas media strain A199. Aquaculture 240: 19-27.

Lategan, M.J., Torpy, F.R., and Gibson, L.F. (2004b) Biocontrol of saprolegniosis in silver perch Bidyanus bidyanus (Mitchell) by Aeromonas media strain A199. Aquaculture 235: 77-88.

Leonard, A., Carlson, J., Bishoff, D., Sendelbach, S., Yung, S., Ramzanali, S. et al. (2014) The skin microbiome of Gambusia affinis is defined and selective. Advances in Microbiology 4: 335-343.

Leroy, C., Delbarre, C., Ghillebaert, F., Compere, C., and Combes, D. (2008) Influence of subtilisin on the adhesion of a marine bacterium which produces mainly proteins as extracellular polymers. Journal of Applied Microbiology 105: 791-799.

Leyton, Y.E., Varas- Psijas, R.A., and Riquelme, C.E. (2012) Probiotic activity of bacteria associated with egg capsules of Concholepas concholepas (common name 'Loco'). Aquaculture Research 43: 1089-1095.

Li, J., Tan, B., and Mai, K. (2009) Dietary probiotic Bacillus OJ and isomaltooligosaccharides influence the intestine microbial populations, immune responses and resistance to white spot syndrome virus in shrimp (Litopenaeus vannamei). Aquaculture 291: 35-40.

Li, J., Tan, B., Mai, K., Ai, Q., Zhang, W., Liufu, Z., and Xu, W. (2008) Immune responses and resistance against Vibrio parahaemolyticus induced by probiotic bacterium Arthrobacter XE-7 in Pacific white shrimp, Litopenaeus vannamei. Journal of the World Aquaculture Society 39: 477-489. 
Lightner, D.V. (2011) Virus diseases of farmed shrimp in the Western Hemisphere (the Americas): A review. Journal of Invertebrate Pathology 106: 110-130.

Liu, W., Ren, P., He, S., Xu, L., Yang, Y., Gu, Z., and Zhou, Z. (2013) Comparison of adhesive gut bacteria composition, immunity, and disease resistance in juvenile hybrid tilapia fed two different Lactobacillus strains. Fish Shellfish Immunol 35: 54-62.

Liu, Y., De Schryver, P., Van Delsen, B., Maignien, L., Boon, N., Sorgeloos, P. et al. (2010) PHBdegrading bacteria isolated from the gastrointestinal tract of aquatic animals as protective actors against luminescent vibriosis. FEMS Microbiology Ecology 74: 196-204.

Liu, Y., Rzeszutek, E., van der Voort, M., Wu, C.-H., Thoen, E., Skaar, I. et al. (2015) Diversity of aquatic Pseudomonas species and their activity against the fish pathogenic oomycete Saprolegnia. PLOS ONE 10: e0136241.

Liu, Y., de Bruijn, I., Jack, A.L.H., Drynan, K., van den Berg, A.H., Thoen, E. et al. (2014) Deciphering microbial landscapes of fish eggs to mitigate emerging diseases. ISME J 8: 2002-2014.

Lorenzen, N., Lorenzen, E., Einer-Jensen, K., Heppell, J., Wu, T., and Davis, H. (1998) Protective immunity to VHS in rainbow trout (Oncorhynchus mykiss, Walbaum) following DNA vaccination. Fish \& Shellfish Immunology 8: 261-270.

Lougovois, V.P., and Kyrana, V.R. (2005) Freshness quality and spoilage of chill-stored fish. In Food Policy, Control, and Research. Riley, A.P. (ed): Nova Biomedical Books, pp. 35-86.

Lowrey, L., Woodhams, D.C., Tacchi, L., and Salinas, I. (2015) Topographical mapping of the rainbow trout (Oncorhynchus mykiss) microbiome reveals a diverse bacterial community with antifungal properties in the skin. Appl Environ Microbiol 81: 6915-6925.

Luis-Villaseñor, I.E., Macías-Rodríguez, M.E., Gómez-Gil, B., Ascencio-Valle, F., and CampaCórdova, Á.l. (2011) Beneficial effects of four Bacillus strains on the larval cultivation of Litopenaeus vannamei. Aquaculture 321: 136-144.

Luis Balcazar, J., de Blas, I., Ruiz-Zarzuela, I., Vendrell, D., Girones, O., and Luis Muzquiz, J. (2007) Sequencing of variable regions of the 16S rRNA gene for identification of lactic acid bacteria isolated from the intestinal microbiota of healthy salmonids. Comparative Immunology Microbiology and Infectious Diseases 30: 111-118.

Lumsden, J.S., Morrison, B., Yason, C., Russell, S., Young, K., Yazdanpanah, A. et al. (2007) Mortality event in freshwater drum Aplodinotus grunniens from Lake Ontario, Canada, associated with viral haemorrhagic septicemia virus, type IV. Dis Aquat Organ 76: 99-111.

Macey, B.M., and Coyne, V.E. (2005) Improved growth rate and disease resistance in farmed Haliotis midae through probiotic treatment. Aquaculture 245: 249-261.

Mahdhi, A., Kamoun, F., Messina, C., Santulli, A., and Bakhrouf, A. (2012) Probiotic properties of Brevibacillus brevis and its influence on sea bass (Dicentrarchus labrax) larval rearing. African Journal of Microbiology Research 6: 6487-6495.

Marques, A., Thanh, T.H., Sorgeloos, P., and Bossier, P. (2006) Use of microalgae and bacteria to enhance protection of gnotobiotic Artemia against different pathogens. Aquaculture 258: 116-126.

Martens, T., Heidorn, T., Pukall, R., Simon, M., Tindall, B.J., and Brinkhoff, T. (2006) Reclassification of Roseobacter gallaeciensis Ruiz-Ponte et al. 1998 as Phaeobacter gallaeciensis gen. nov., comb. nov., description of Phaeobacter inhibens sp. nov., reclassification of Ruegeria algicola (Lafay et al. 1995) Uchino et al. 1999 as Marinovum algicola gen. nov., comb. nov., and emended descriptions of the genera Roseobacter, Ruegeria and Leisingera. Int J Syst Evol Microbiol 56: 12931304.

Martínez Cruz, P., Ibáñez, A.L., Monroy Hermosillo, O.A., and Ramírez Saad, H.C. (2012) Use of probiotics in aquaculture. ISRN Microbiology 2012: 916845.

Maynard, B.T., Taylor, R.S., Kube, P.D., Cook, M.T., and Elliott, N.G. (2016) Salmonid heterosis for resistance to amoebic gill disease (AGD). Aquaculture 451: 106-112.

Maynard, C.L., Elson, C.O., Hatton, R.D., and Weaver, C.T. (2012) Reciprocal interactions of the intestinal microbiota and immune system. Nature 489: 231-241. 
McGinnis, M.R., and Ajello, L. (1974) A new species of Exophiala isolated from channel catfish. Mycologia 66: 518-520.

Mendes, R., Kruijt, M., de Bruijn, I., Dekkers, E., van der Voort, M., Schneider, J.H. et al. (2011) Deciphering the rhizosphere microbiome for disease-suppressive bacteria. Science 332: 1097-1100.

Merrifield, D.L., and Rodiles, A. (2015) 10 - The fish microbiome and its interactions with mucosal tissues. In Mucosal Health in Aquaculture. Peatman, B.H.B. (ed). San Diego: Academic Press, pp. 273295.

Merrifield, D.L., Bradley, G., Baker, R.T.M., and Davies, S.J. (2010) Probiotic applications for rainbow trout (Oncorhynchus mykiss Walbaum) II. Effects on growth performance, feed utilization, intestinal microbiota and related health criteria postantibiotic treatment. Aquaculture Nutrition 16: 496503.

Monette, S., Dallaire, A.D., Mingelbier, M., Groman, D., Uhland, C., Richard, J.P. et al. (2006) Massive mortality of common carp (Cyprinus carpio carpio) in the St. Lawrence River in 2001: diagnostic investigation and experimental induction of lymphocytic encephalitis. Vet Pathol 43: 302-310.

Montalban-Arques, A., De Schryver, P., Bossier, P., Gorkiewicz, G., Mulero, V., Gatlin III, D.M., and Galindo-Villegas, J. (2015) Selective manipulation of the gut microbiota improves immune status in vertebrates. Frontiers in Immunology 6.

Moriarty, D.J.W. (1998) Control of luminous Vibrio species in penaeid aquaculture ponds. Aquaculture 164: 351-358.

Mudarris, M., and Austin, B. (1988) Quantitative and qualitative studies of the bacterial microflora of turbot, Scophthalmus maximus L., gills. Journal of Fish Biology 32: 223-229.

Mujeeb Rahiman, K.M., Jesmi, Y., Thomas, A.P., and Mohamed Hatha, A.A. (2010) Probiotic effect of Bacillus NL110 and Vibrio NE17 on the survival, growth performance and immune response of Macrobrachium rosenbergii (de Man). Aquaculture Research 41: e120-e134.

Munday, B.L., Kwang, J., and Moody, N. (2002) Betanodavirus infections of teleost fish: a review. Journal of Fish Diseases 25: 127-142.

Murray, A.G., and Peeler, E.J. (2005) A framework for understanding the potential for emerging diseases in aquaculture. Preventive Veterinary Medicine 67: 223-235.

Naka, H., and Crosa, J.H. (2011) Genetic determinants of virulence in the marine fish pathogen Vibrio anguillarum. Fish Pathol 46: 1-10.

Nayak, S.K. (2010) Role of gastrointestinal microbiota in fish. Aquaculture Research 41: 1553-1573.

NCBI. URL http://www.ncbi.nlm.nih.gov/nuccore/AGKB01000008.1.

Neospark. URL http://www.neospark.com/hetronex-abtp.html.

Newaj-Fyzul, A., and Austin, B. (2015) Probiotics, immunostimulants, plant products and oral vaccines, and their role as feed supplements in the control of bacterial fish diseases. Journal of Fish Diseases 38: 937-955.

Newaj-Fyzul, A., Al-Harbi, A.H., and Austin, B. (2014) Review: Developments in the use of probiotics for disease control in aquaculture. Aquaculture 431: 1-11.

Newaj-Fyzul, A., Adesiyun, A.A., Mutani, A., Ramsubhag, A., Brunt, J., and Austin, B. (2007) Bacillus subtilis AB1 controls Aeromonas infection in rainbow trout (Oncorhynchus mykiss, Walbaum). $J$ Appl Microbiol 103: 1699-1706.

Nikoskelainen, S., Ouwehand, A., Salminen, S., and Bylund, G. (2001) Protection of rainbow trout (Oncorhynchus mykiss) from furunculosis by Lactobacillus rhamnosus. Aquaculture 198: 229-236.

Nimrat, S., Suksawat, S., Boonthai, T., and Vuthiphandchai, V. (2012) Potential Bacillus probiotics enhance bacterial numbers, water quality and growth during early development of white shrimp (Litopenaeus vannamei). Veterinary Microbiology 159: 443-450.

Novotny, L., Dvorska, L., Lorencova, A., Beran, V., and Pavlik, I. (2004) Fish: a potential source of bacterial pathogens for human beings. Veterinarni Medicina 49: 343-358. 
Ogawa, K. (2011) Significant and emerging parasitic diseases of finfish. In Diseases in Asian Aquaculture VII. Bondad-Reantaso, M.G., Jones, J.B., Corsin, F., and Aoki, T. (eds): Fish Health Section, Asian Fisheries Society, Selangor, Malaysia. 385 pp, pp. 3-12.

Ogawa, K., Nakatsugawa, T., and Yasuzaki, M. (2004) Heavy metacercarial infections of cyprinid fishes in Uji River. Fisheries Science 70: 132-140.

Oidtmann, B. (2012) Review of biological factors relevant to import risk assessments for epizootic ulcerative syndrome (Aphanomyces invadans). Transbound Emerg Dis 59: 26-39.

Olafsen, J.A. (2001) Interactions between fish larvae and bacteria in marine aquaculture. Aquaculture 200: 223-247.

Pai, S.S., Anas, A., Jayaprakash, N.S., Priyaja, P., Sreelakshmi, B., Preetha, R. et al. (2010) Penaeus monodon larvae can be protected from Vibrio harveyi infection by pre-emptive treatment of a rearing system with antagonistic or non-antagonistic bacterial probiotics. Aquaculture Research 41: 847860 .

Palenzuela, O., Redondo, M.J., Cali, A., Takvorian, P.M., Alonso-Naveiro, M., Alvarez-Pellitero, P., and Sitjà-Bobadilla, A. (2014) A new intranuclear microsporidium, Enterospora nucleophila n. sp., causing an emaciative syndrome in a piscine host (Sparus aurata), prompts the redescription of the family Enterocytozoonidae. International Journal for Parasitology 44: 189-203.

Pan, X., Wu, T., Song, Z., Tang, H., and Zhao, Z. (2008) Immune responses and enhanced disease resistance in Chinese drum, Miichthys miiuy (Basilewsky), after oral administration of live or dead cells of Clostridium butyrium CB2. Journal of Fish Diseases 31: 679-686.

Paniz-Mondolfi, A., Talhari, C., Sander Hoffmann, L., Connor, D.L., Talhari, S., Bermudez-Villapol, L. et al. (2012) Lobomycosis: an emerging disease in humans and delphinidae. Mycoses 55: 298-309.

Peeler, E., Oidtmann, B., Midtlyng, P., Miossec, L., and Gozlan, R. (2011) Non-native aquatic animals introductions have driven disease emergence in Europe. Biological Invasions 13: 1291-1303.

Phillips, A.J., Anderson, V.L., Robertson, E.J., Secombes, C.J., and van West, P. (2008) New insights into animal pathogenic oomycetes. Trends in Microbiology 16: 13-19.

Pieters, N., Brunt, J., Austin, B., and Lyndon, A.R. (2008) Efficacy of in-feed probiotics against Aeromonas bestiarum and Ichthyophthirius multifilis skin infections in rainbow trout (Oncorhynchus mykiss, Walbaum). Journal of Applied Microbiology 105: 723-732.

Pirarat, N., Kobayashi, T., Katagiri, T., Maita, M., and Endo, M. (2006) Protective effects and mechanisms of a probiotic bacterium Lactobacillus rhamnosus against experimental Edwardsiella tarda infection in tilapia (Oreochromis niloticus). Veterinary Immunology and Immunopathology 113: 339-347.

Planas, M., Pérez-Lorenzo, M., Hjelm, M., Gram, L., Uglenes Fiksdal, I., Bergh, Ø., and Pintado, J. (2006) Probiotic effect in vivo of Roseobacter strain 27-4 against Vibrio (Listonella) anguillarum infections in turbot (Scophthalmus maximus L.) larvae. Aquaculture 255: 323-333.

Plant, K.P., and LaPatra, S.E. (2011) Advances in fish vaccine delivery. Developmental \& Comparative Immunology 35: 1256-1262.

Plante, S., Pernet, F., Haché, R., Ritchie, R., Ji, B., and McIntosh, D. (2007) Ontogenetic variations in lipid class and fatty acid composition of haddock larvae Melanogrammus aeglefinus in relation to changes in diet and microbial environment. Aquaculture 263: 107-121.

Plumb, J.A. (1991) Major diseases of striped bass and redfish. Veterinary and Human Toxicology 33: 34-39.

Porsby, C.H., Nielsen, K.F., and Gram, L. (2008) Phaeobacter and Ruegeria species of the Roseobacter clade colonize separate niches in a Danish Turbot (Scophthalmus maximus)-rearing farm and antagonize Vibrio anguillarum under different growth conditions. Applied and Environmental Microbiology 74: 7356-7364.

Powell, M.D., Reynolds, P., and Kristensen, T. (2015) Freshwater treatment of amoebic gill disease and sea-lice in seawater salmon production: Considerations of water chemistry and fish welfare in Norway. Aquaculture 448: 18-28. 
Pozio, E., Armignacco, O., Ferri, F., and Morales, M.A.G. (2013) Opisthorchis felineus, an emerging infection in Italy and its implication for the European Union. Acta Tropica 126: 54-62.

Pravettoni, V., Primavesi, L., and Piantanida, M. (2012) Anisakis simplex: current knowledge. European annals of allergy and clinical immunology 44: 150-156.

Preetha, R., Jayaprakash, N.S., and Singh, I.S. (2007) Synechocystis MCCB 114 and 115 as putative probionts for Penaeus monodon post-larvae. Dis Aquat Organ 74: 243-247.

Pulkkinen, K., Suomalainen, L.R., Read, A.F., Ebert, D., Rintamäki, P., and Valtonen, E.T. (2010) Intensive fish farming and the evolution of pathogen virulence: the case of columnaris disease in Finland. Proceedings of the Royal Society B: Biological Sciences 277: 593-600.

Purcell, M.K., Laing, K.J., and Winton, J.R. (2012) Immunity to fish rhabdoviruses. Viruses 4: 140.

Queiroz, J.F., and Boyd, C.E. (1998) Effects of a bacterial inoculum in channel catfish ponds. Journal of the World Aquaculture Society 29: 67-73.

Rahimian, H., and Thulin, J. (1996) Epizootiology of Ichthyophonus hoferi in herring populations off the Swedish west coast. Diseases of Aquatic Organisms 27: 187-195.

Raida, M.K., Larsen, J.L., Nielsen, M.E., and Buchmann, K. (2003) Enhanced resistance of rainbow trout, Oncorhynchus mykiss (Walbaum), against Yersinia ruckeri challenge following oral administration of Bacillus subtilis and B. licheniformis (BioPlus2B). J Fish Dis 26: 495-498.

Ramamurthy, T., Chowdhury, G., Pazhani, G.P., and Shinoda, S. (2014) Vibrio fluvialis: an emerging human pathogen. Frontiers in Microbiology 5: 91.

Ramesh, D., Vinothkanna, A., Rai, A.K., and Vignesh, V.S. (2015) Isolation of potential probiotic Bacillus spp. and assessment of their subcellular components to induce immune responses in Labeo rohita against Aeromonas hydrophila. Fish \& Shellfish Immunology 45: 268-276.

Ran, C., Carrias, A., Williams, M.A., Capps, N., Dan, B.C.T., Newton, J.C. et al. (2012) Identification of Bacillus strains for biological control of catfish pathogens. PLOS ONE 7: e45793.

Ray, A.K., Ghosh, K., and Ringø, E. (2012) Enzyme-producing bacteria isolated from fish gut: a review. Aquaculture Nutrition 18: 465-492.

Rengpipat, S., Phianphak, W., Piyatiratitivorakul, S., and Menasveta, P. (1998) Effects of a probiotic bacterium on black tiger shrimp Penaeus monodon survival and growth. Aquaculture 167: 301-313.

Rengpipat, S., Tunyanun, A., Fast, A.W., Piyatiratitivorakul, S., and Menasveta, P. (2003) Enhanced growth and resistance to Vibrio challenge in pond-reared black tiger shrimp Penaeus monodon fed a Bacillus probiotic. Diseases of Aquatic Organisms 55: 169-173.

Reverter, M., Bontemps, N., Lecchini, D., Banaigs, B., and Sasal, P. (2014) Use of plant extracts in fish aquaculture as an alternative to chemotherapy: Current status and future perspectives. Aquaculture 433: 50-61.

Ridha, M.T., and Azad, I.S. (2012) Preliminary evaluation of growth performance and immune response of Nile tilapia Oreochromis niloticus supplemented with two putative probiotic bacteria. Aquaculture Research 43: 843-852.

Ringø, E., and Birkbeck, T.H. (1999) Intestinal microflora of fish larvae and fry. Aquaculture Research 30: 73-93.

Ringø, E., and Olsen, R.E. (1999) The effect of diet on aerobic bacterial flora associated with intestine of Arctic charr (Salvelinus alpinus L.). Journal of Applied Microbiology 86: 22-28.

Ringø, E., Bendiksen, H.R., Wesmajervi, M.S., Olsen, R.E., Jansen, P.A., and Mikkelsen, H. (2000) Lactic acid bacteria associated with the digestive tract of Atlantic salmon (Salmo salar L.). J Appl Microbiol 89: 317-322.

Robertson, P.A.W., O'Dowd, C., Burrells, C., Williams, P., and Austin, B. (2000) Use of Carnobacterium sp. as a probiotic for Atlantic salmon (Salmo salar L.) and rainbow trout (Oncorhynchus mykiss, Walbaum). Aquaculture 185: 235-243.

Rollo, A., Sulpizio, R., Nardi, M., Silvi, S., Orpianesi, C., Caggiano, M. et al. (2006) Live microbial feed supplement in aquaculture for improvement of stress tolerance. Fish Physiology and Biochemistry 32: 167-177. 
Romero, A., Costa, M., Forn-Cuni, G., Balseiro, P., Chamorro, R., Dios, S. et al. (2014a) Occurrence, seasonality and infectivity of Vibrio strains in natural populations of mussels Mytilus galloprovincialis. Dis Aquat Organ 108: 149-163.

Romero, J., Feijoó, C.G., and Navarrete, P. (2012) Antibiotics in aquaculture - use, abuse and alternatives In Health and environment in aquaculture. Carvalho, E. (ed): InTech.

Romero, J., Ringø, E., and Merrifield, D.L. (2014b) The gut microbiota of fish. In Aquaculture Nutrition: John Wiley \& Sons, Ltd, pp. 75-100.

Round, J.L., O'Connell, R.M., and Mazmanian, S.K. (2010) Coordination of tolerogenic immune responses by the commensal microbiota. J Autoimmun 34: J220-225.

Rowley, J.J.L., Gleason, F.H., Andreou, D., Marshall, W.L., Lilje, O., and Gozlan, R. (2013) Impacts of mesomycetozoean parasites on amphibian and freshwater fish populations. Fungal Biology Reviews 27: $100-111$.

Ruiz-Ponte, C., Cilia, V., Lambert, C., and Nicolas, J.L. (1998) Roseobacter gallaeciensis sp. nov., a new marine bacterium isolated from rearings and collectors of the scallop Pecten maximus. International Journal of Systematic Bacteriology 48: 537-542.

Ruiz-Ponte, C., Samain, J.F., Sánchez, J.L., and Nicolas, J.L. (1999) The Benefit of a Roseobacter species on the survival of scallop larvae. Marine Biotechnology 1: 52-59.

Sahoo, P.K., and Goodwin, A.E. (2012) Viruses of freshwater finfish in the Asian-Pacific Region. Indian Journal of Virology 23: 99-105.

Sakai, M., Yoshida, T., Atsuta, S., and Kobayashi, M. (1995) Enhancement of resistance to vibriosis in rainbow trout, Oncorhynchus mykiss (Walbaum), by oral administration of Clostridium butyricum bacterin. Journal of Fish Diseases 18: 187-190.

Salinas, I. (2015) The mucosal immune system of teleost fish. Biology 4: 525.

Salinas, I., Cuesta, A., Esteban, M.A., and Meseguer, J. (2005) Dietary administration of Lactobacillus delbrueckii and Bacillus subtilis, single or combined, on gilthead seabream cellular innate immune responses. Fish Shellfish Immunol 19: 67-77.

Salonius, K., Siderakis, C., MacKinnon, A.M., and Griffiths, S.G. (2005) Use of Arthrobacter davidanieli as a live vaccine against Renibacterium salmoninarum and Piscirickettsia salmonis in salmonids. Dev Biol (Basel) 121: 189-197.

Sar, N., and Rosenberg, E. (1989) Fish skin bacteria: Production of friction-reducing polymers. Microb Ecol 17: 27-38.

Sarmiento-Ramírez, J.M., Abella-Perez, E., Phillott, A.D., Sim, J., van West, P., Martin, M.P. et al. (2014) Global distribution of two fungal pathogens threatening endangered sea turtles. Plos One 9.

Schmeller, Dirk S., Blooi, M., Martel, A., Garner, Trenton W.J., Fisher, Matthew C., Azemar, F. et al. (2014) Microscopic aquatic predators strongly affect infection dynamics of a globally emerged pathogen. Current Biology 24: 176-180.

Scholz, U., Garcia Diaz, G., Ricque, D., Cruz Suarez, L.E., Vargas Albores, F., and Latchford, J. (1999) Enhancement of vibriosis resistance in juvenile Penaeus vannamei by supplementation of diets with different yeast products. Aquaculture 176: 271-283.

Sharifuzzaman, S.M., and Austin, B. (2010a) Kocuria SM1 controls vibriosis in rainbow trout (Oncorhynchus mykiss, Walbaum). J Appl Microbiol 108: 2162-2170.

Sharifuzzaman, S.M., and Austin, B. (2010b) Development of protection in rainbow trout (Oncorhynchus mykiss, Walbaum) to Vibrio anguillarum following use of the probiotic Kocuria SM1. Fish \& Shellfish Immunology 29: 212-216.

Sharifuzzaman, S.M., Abbass, A., Tinsley, J.W., and Austin, B. (2011) Subcellular components of probiotics Kocuria SM1 and Rhodococcus SM2 induce protective immunity in rainbow trout (Oncorhynchus mykiss, Walbaum) against Vibrio anguillarum. Fish Shellfish Immunol 30: 347-353.

Silva-Aciares, F.R., Carvajal, P.O., Mejías, C.A., and Riquelme, C.E. (2011) Use of macroalgae supplemented with probiotics in the Haliotis rufescens (Swainson, 1822) culture in Northern Chile. Aquaculture Research 42: 953-961. 
Silva, E.F., Soares, M.A., Calazans, N.F., Vogeley, J.L., do Valle, B.C., Soares, R., and Peixoto, S. (2012) Effect of probiotic (Bacillus spp.) addition during larvae and postlarvae culture of the white shrimp Litopenaeus vannamei. Aquaculture Research 44: 13-21.

Silvi, S., Verdenelli, M.C., Orpianesi, C., and Cresci, A. (2003) EU project Crownalife: functional foods, gut microflora and healthy ageing - Isolation and identification of Lactobacillus and Bifidobacterium strains from faecal samples of elderly subjects for a possible probiotic use in functional foods. Journal of Food Engineering 56: 195-200.

Small, H.J. (2012) Advances in our understanding of the global diversity and distribution of Hematodinium spp. - significant pathogens of commercially exploited crustaceans. J Invertebr Pathol 110: 234-246.

Sommerset, I., Krossoy, B., Biering, E., and Frost, P. (2005) Vaccines for fish in aquaculture. Expert Rev Vaccines 4: 89-101.

Sorroza, L., Padilla, D., Acosta, F., Roman, L., Grasso, V., Vega, J., and Real, F. (2012) Characterization of the probiotic strain Vagococcus fluvialis in the protection of European sea bass (Dicentrarchus labrax) against vibriosis by Vibrio anguillarum. Vet Microbiol 155: 369-373.

SporeGen ${ }^{\circledR}$. URL http://www.sporegen.com/research-pipeline/probiotics-and-novel-foods/.

Sripa, B., Kaewkes, S., Intapan, P.M., Maleewong, W., and Brindley, P.J. (2010) Food-borne trematodiases in southeast Asia: epidemiology, pathology, clinical manifestation and control. In Advances in Parasitology, Vol 72: Important Helminth Infections in Southeast Asia: Diversity and Potential for Control and Elimination, Pt A. Zhou, X.N., Bergquist, R., Olveda, R., and Utzinger, J. (eds), pp. 305-350.

Sripa, B., Bethony, J.M., Sithithaworn, P., Kaewkes, S., Mairiang, E., Loukas, A. et al. (2011) Opisthorchiasis and Opisthorchis-associated cholangiocarcinoma in Thailand and Laos. Acta Tropica 120: S158-S168.

Standen, B.T., Rawling, M.D., Davies, S.J., Castex, M., Foey, A., Gioacchini, G. et al. (2013) Probiotic Pediococcus acidilactici modulates both localised intestinal- and peripheral-immunity in tilapia (Oreochromis niloticus). Fish Shellfish Immunol 35: 1097-1104.

Stecher, B., Maier, L., and Hardt, W.-D. (2013) 'Blooming' in the gut: how dysbiosis might contribute to pathogen evolution. Nat Rev Micro 11: 277-284.

Steckler, N.K., Yanong, R.P.E., Pouder, D.B., Nyaoke, A., Sutton, D.A., Lindner, J.R. et al. (2014) New disease records for hatchery-reared sturgeon. II. Phaeohyphomycosis due to Veronaea botryosa. Diseases of Aquatic Organisms 111: 229-238.

Stride, M.C., Polkinghorne, A., and Nowak, B.F. (2014) Chlamydial infections of fish: diverse pathogens and emerging causes of disease in aquaculture species. Vet Microbiol 170: 19-27.

Sugita, H., Matsuo, N., Hirose, Y., Iwato, M., and Deguchi, Y. (1997) Vibrio sp. strain NM 10, isolated from the intestine of a Japanese coastal fish, has an inhibitory effect against Pasteurella piscicida. Applied and Environmental Microbiology 63: 4986-4989.

Sun, Y.-Z., Yang, H.-L., Huang, K.-P., Ye, J.-D., and Zhang, C.-X. (2013) Application of autochthonous Bacillus bioencapsulated in copepod to grouper Epinephelus coioides larvae. Aquaculture 392-395: 44-50.

Sun, Y., Yang, H., Ling, Z., Chang, J., and Ye, J. (2009) Gut microbiota of fast and slow growing grouper Epinephelus coioides. African Journal of Microbiology Research 3: 713-720.

Suzer, C., Coban, D., Kamaci, H.O., Saka, S., Firat, K., Otgucuoglu, O., and Kucuksari, H. (2008) Lactobacillus spp. bacteria as probiotics in gilthead sea bream (Sparus aurata, L.) larvae: Effects on growth performance and digestive enzyme activities. Aquaculture 280: 140-145.

Swain, S., Singh, C., and Arul, V. (2009) Inhibitory activity of probiotics Streptococcus phocae PI80 and Enterococcus faecium MC13 against Vibriosis in shrimp Penaeus monodon. World Journal of Microbiology and Biotechnology 25: 697-703. 
Tacchi, L., Bron, J.E., Taggart, J.B., Secombes, C.J., Bickerdike, R., Adler, M.A. et al. (2011) Multiple tissue transcriptomic responses to Piscirickettsia salmonis in Atlantic salmon (Salmo salar). Physiological Genomics 43: 1241-1254.

Tacchi, L., Musharrafieh, R., Larragoite, E.T., Crossey, K., Erhardt, E.B., Martin, S.A.M. et al. (2014) Nasal immunity is an ancient arm of the mucosal immune system of vertebrates. Nature communications 5: 5205-5205.

ten Doeschate, K.I., and Coyne, V.E. (2008) Improved growth rate in farmed Haliotis midae through probiotic treatment. Aquaculture 284: 174-179.

Thompson, F.L., lida, T., and Swings, J. (2004) Biodiversity of vibrios. Microbiol Mol Biol Rev 68: 403-431, table of contents.

Thompson, J., Gregory, S., Plummer, S., Shields, R.J., and Rowley, A.F. (2010) An in vitro and in vivo assessment of the potential of Vibrio spp. as probiotics for the Pacific white shrimp, Litopenaeus vannamei. J Appl Microbiol 109: 1177-1187.

Thrush, M.A., Dunn, P.L., and Peeler, E.J. (2012) Monitoring emerging diseases of fish and shellfish using electronic sources. Transbound Emerg Dis 59: 385-394.

Tomova, A., Ivanova, L., Buschmann, A.H., Rioseco, M.L., Kalsi, R.K., Godfrey, H.P., and Cabello, F.C. (2015) Antimicrobial resistance genes in marine bacteria and human uropathogenic Escherichia coli from a region of intensive aquaculture. Environmental Microbiology Reports 7: 803-809.

Turner, J.W., Good, B., Cole, D., and Lipp, E.K. (2009) Plankton composition and environmental factors contribute to Vibrio seasonality. Isme $j$ 3: 1082-1092.

Turner, T.R., James, E.K., and Poole, P.S. (2013) The plant microbiome. Genome Biology 14.

Urabe, M., Ogawa, K., Nakatsugawa, T., Nakai, K., Tanaka, M., and Wang, G. (2007) Morphological description of two bucephalid trematodes collected from freshwater fishes in the Uji River, Kyoto, Japan. Parasitology International 56: 269-272.

van den Berg, A.H., McLaggan, D., Diéguez-Uribeond, J., and van West, P. (2013) The impact of the water moulds Saprolegnia diclina and Saprolegnia parasitica on natural ecosystems and the aquaculture industry. Fungal Biology Reviews 27: 33-42.

van der Maarel, M.J.E.C., Artz, R.R.E., Haanstra, R., and Forney, L.J. (1998) Association of marine archaea with the digestive tracts of two marine fish species. Applied and Environmental Microbiology 64: 2894-2898.

van West, P. (2006) Saprolegnia parasitica, an oomycete pathogen with a fishy appetite: new challenges for an old problem. Mycologist 20: 99-104.

Varela, J.L., Ruiz-Jarabo, I., Vargas-Chacoff, L., Arijo, S., León-Rubio, J.M., García-Millán, I. et al. (2010) Dietary administration of probiotic Pdp11 promotes growth and improves stress tolerance to high stocking density in gilthead seabream Sparus auratus. Aquaculture 309: 265-271.

Vaseeharan, B., and Ramasamy, P. (2003) Control of pathogenic Vibrio spp. by Bacillus subtilis BT23, a possible probiotic treatment for black tiger shrimp Penaeus monodon. Lett Appl Microbiol 36: 83-87.

Vendrell, D., Balcazar, J.L., de Blas, I., Ruiz-Zarzuela, I., Girones, O., and Luis Muzquiz, J. (2008) Protection of rainbow trout (Oncorhynchus mykiss) from lactococcosis by probiotic bacteria. Comp Immunol Microbiol Infect Dis 31: 337-345.

Verschuere, L., Rombaut, G., Sorgeloos, P., and Verstraete, W. (2000) Probiotic bacteria as biological control agents in aquaculture. Microbiology and Molecular Biology Reviews 64: 655-+.

Vijayan, K.K., Bright Singh, I.S., Jayaprakash, N.S., Alavandi, S.V., Somnath Pai, S., Preetha, R. et al. (2006) A brackishwater isolate of Pseudomonas PS-102, a potential antagonistic bacterium against pathogenic vibrios in penaeid and non-penaeid rearing systems. Aquaculture 251: 192-200.

Villamil, L., Reyes, C., and Martínez-Silva, M.A. (2014) In vivo and in vitro assessment of Lactobacillus acidophilus as probiotic for tilapia (Oreochromis niloticus, Perciformes:Cichlidae) culture improvement. Aquaculture Research 45: 1116-1125. 
Waage, J. (2007) The sustainable management of biodiversity for biological control in food and agriculture: status and needs. In Background study paper No 38. FAO (ed).

Walker, P.J., and Winton, J.R. (2010) Emerging viral diseases of fish and shrimp. Veterinary Research 41.

Wang, W., Zhou, Z., He, S., Liu, Y., Cao, Y., Shi, P. et al. (2010) Identification of the adherent microbiota on the gills and skin of poly-cultured gibel carp (Carassius auratus gibelio) and bluntnose black bream (Megalobrama amblycephala Yih). Aquaculture Research 41: e72-e83.

Wang, Y., and Gu, Q. (2010) Effect of probiotics on white shrimp (Penaeus vannamei) growth performance and immune response. Marine Biology Research 6: 327-332.

Weiss, B., and Aksoy, S. (2011) Microbiome influences on insect host vector competence. Trends Parasitol 27: 514-522.

WHO (2016). Emerging zoonoses. URL http://www.who.int/zoonoses/emerging_zoonoses/en/.

Wu, Z.-Q., Jiang, C., Ling, F., and Wang, G.-X. (2015) Effects of dietary supplementation of intestinal autochthonous bacteria on the innate immunity and disease resistance of grass carp (Ctenopharyngodon idellus). Aquaculture 438: 105-114.

Xia, J.H., Lin, G., Fu, G.H., Wan, Z.Y., Lee, M., Wang, L. et al. (2014) The intestinal microbiome of fish under starvation. Bmc Genomics 15.

Xu, Z., Parra, D., Gomez, D., Salinas, I., Zhang, Y.-A., Jorgensen, L.v.G. et al. (2013) Teleost skin, an ancient mucosal surface that elicits gut-like immune responses. Proceedings of the National Academy of Sciences of the United States of America 110: 13097-13102.

Yanong, R.P.E. (2009) Use of vaccines in finfish aquaculture FA156. Published by Fisheries and Aquatic Sciences Department, UF/IFAS Extension, USA.

Yazawa, K., Araki, K., Watanabe, K., Ishikawa, C., Inoue, A., Kondo, K. et al. (1988) Eicosapentaenoic acid productivity of the bacteria isolated from fish intestines. Nippon Suisan Gakkaishi 54: 1835-1838.

Ye, L., Amberg, J., Chapman, D., Gaikowski, M., and Liu, W.T. (2014) Fish gut microbiota analysis differentiates physiology and behavior of invasive Asian carp and indigenous American fish. Isme $j$ 8: 541-551.

Zhang, Y.-A., Salinas, I., Li, J., Parra, D., Bjork, S., Xu, Z. et al. (2010) IgT, a primitive immunoglobulin class specialized in mucosal immunity. Nat Immunol 11: 827-835.

Zhou, X., Tian, Z., Wang, Y., and Li, W. (2010) Effect of treatment with probiotics as water additives on tilapia (Oreochromis niloticus) growth performance and immune response. Fish Physiol Biochem 36: 501-509.

Zokaeifar, H., Luis Balcazar, J., Kamarudin, M.S., Sijam, K., Arshad, A., and Saad, C.R. (2012a) Selection and identification of non-pathogenic bacteria isolated from fermented pickles with antagonistic properties against two shrimp pathogens. J Antibiot 65: 289-294.

Zokaeifar, H., Balcazar, J.L., Saad, C.R., Kamarudin, M.S., Sijam, K., Arshad, A., and Nejat, N. (2012b) Effects of Bacillus subtilis on the growth performance, digestive enzymes, immune gene expression and disease resistance of white shrimp, Litopenaeus vannamei. Fish Shellfish Immunol 33: 683-689. 



\section{Chapter 2}

\section{Deciphering microbial landscapes of fish eggs to mitigate emerging diseases}

Yiying Liu, Irene de Bruijn, Allison L.H. Jack, Keith Drynan, Albert H. van den Berg, Even Thoen, Vladimir Sandoval-Sierra, Ida Skaar, Pieter van West, Javier Diéguez-Uribeondo, Menno van der Voort, Rodrigo Mendes, Mark Mazzola and Jos M. Raaijmakers

This chapter has been published as:

Yiying Liu', Irene de Bruijn ${ }^{1}$, Allison L.H. Jack, Keith Drynan, Albert H. van den Berg, Even Thoen, Vladimir Sandoval-Sierra, Ida Skaar, Pieter van West, Javier Diéguez-Uribeondo, Menno van der Voort, Rodrigo Mendes, Mark Mazzola and Jos M. Raaijmakers. (2014). Deciphering microbial landscapes of fish eggs to mitigate emerging diseases. The ISME Journal 8 (10), 2002-2014; doi:10.1038/ismej.2014.44.

${ }^{1}$ Shared first authors. 


\begin{abstract}
Animals and plants are increasingly suffering from diseases caused by fungi and oomycetes. These emerging pathogens are now recognized as a global threat to biodiversity and food security. Among oomycetes, Saprolegnia species cause significant declines in fish and amphibian populations. Fish eggs have an immature adaptive immune system and depend on nonspecific innate defences to ward off pathogens. Here, meta-taxonomic analyses revealed that Atlantic salmon eggs are home to diverse fungal, oomycete and bacterial communities. Although virulent Saprolegnia isolates were found in all salmon egg samples, a low incidence of Saprolegniosis was strongly correlated with a high richness and abundance of specific commensal Actinobacteria, with the genus Frondihabitans (Microbacteriaceae) effectively inhibiting attachment of Saprolegnia to salmon eggs. These results highlight that fundamental insights into microbial landscapes of fish eggs may provide new sustainable means to mitigate emerging diseases.
\end{abstract}

\title{
Introduction
}

Fungal diseases that were previously not considered as major threats to ecosystem functioning are now causing severe ecological disruption (Fisher et al., 2012). Among the fungi, Fusarium solani is causing mass mortality in eggs of endangered sea turtles in Cape Verde (Sarmiento-Ramirez et al., 2010), and Batrachochytrium dendrobatidis and Batrachochytrium salmandrivorans are involved in major amphibian declines worldwide (Woodhams et al., 2011; Martel et al., 2013). Among the fungal-like oomycetes, Aphanomyces astaci, Aphanomyces invadans and Saprolegnia species are causing significant reductions in crayfish, fish and amphibian populations (Fernández-Benéitez et al., 2008; Phillips et al., 2008; Krugner-Higby et al., 2010; Bruno et al., 2011; Van den Berg et al., 2013), respectively. Saprolegniosis is a major disease problem in different wild and farmed fish species, including salmonid species such as Atlantic salmon, rainbow and brown trout, and non-salmonid species including perch, eels and catfish (Bruno et al., 2011). This disease is characterized by white and grey patches of mycelial growth on the skin and fins of adult fish, and cotton-like filamentous mycelium on eggs. In fish, death often occurs from disruption of the osmotic balance (haemodilution) following destruction of large areas of the epidermis by massive, invasive hyphal growth (Bruno et al., 2011). Fish eggs on the other hand are thought to be killed by hyphal breaching of the chorionic membrane regulating the osmosis of the embryo. Saprolegnia species can produce flagellated zoospores to disperse in the aquatic environment. Saprolegnia also forms secondary zoospores and secondary cysts that, for some species, contain boathooks that are 
presumed to aid in attachment to the fish skin or promote floating (buoyancy) in water (Van den Berg et al., 2013). Losses resulting from Saprolegniosis average $10 \%$ in eggs and young fish, but losses of up to $50 \%$ have been reported (Hatai and Hoshiai, 1992, 1994; Bruno et al., 2011; Van den Berg et al., 2013).

To control and prevent the spread of emerging pathogens, several conservation and disease mitigation strategies have been proposed because a singular solution is doubtful given the rich diversity of fish and amphibian habitats (Woodhams et al., 2011). In aquaculture, immunization and chemical control are among the preferred approaches to mitigate diseases (Bruno et al., 2011; Van den Berg et al., 2013). For Saprolegniosis, however, no effective immunization is currently available and nonspecific chemical agents such as malachite green and formalin have been or will be banned, leading to a dramatic re-emergence of Saprolegniosis. Habitat bioaugmentation and introduction of protective microbiota have been proposed as potential strategies to rescue and protect fish and amphibians from emerging disease. Over the past years, several studies have unequivocally shown that microbes play a pivotal role in the protection of eukaryotes (humans, plants, insects) against pathogens (Round et al., 2010; Mendes et al., 2011; Weiss and Aksoy, 2011; Everard et al., 2013; Stecher et al., 2013; Turner et al., 2013). For fish and amphibians, microbiome studies have only been initiated recently (Cahill, 1990; Hansen and Olafsen, 1999; Schulze et al., 2006; McKenzie et al., 2012). Several studies have indicated that specific bacteria can contribute to the protection of fish and amphibians against fungal and oomycete pathogens. This was shown for Janthinobacterium lividum, a bacterium that was isolated from frog skin and provided protection against $B$. dendrobatidis (Harris et al., 2009).

Here, we deciphered the microbiome of Atlantic salmon eggs and determined how Saprolegniosis affects the structure (richness, evenness) of fungal, oomycete and bacterial communities, with the ultimate goal to identify commensal microbes that prevent or delay disease onset and/or development.

\section{Materials and Methods}

\section{Salmon egg sample collection for microbial community analysis}

Atlantic salmon (Salmo salar L.) eyed eggs and the incubation water from each of the tanks were collected separately from a commercial hatchery in Scotland. The eggs were spawned in November 2010 and incubated in a flow-through system at a flow rate of $25-30 \mathrm{I} \mathrm{s}^{-1}$ at $3-5^{\circ} \mathrm{C}$. The water source for the incubation of the salmon eggs is a catchment area that is an upland peat moor with conifer plantations, grazing cattle, sheep and wild animals, $\sim 3 \mathrm{~km}$ from the hatchery and is delivered via a hydroelectric scheme using a hill loch as a source. Before the water enters the egg incubators, it is filtered through a $10-\mu \mathrm{m}$ filter and a carbon filter and is subsequently treated with ultraviolet light for a few seconds. Eggs received a 1-h 1000 p.p.m. formalin bath treatment weekly, and were collected on 14 February 2011. For more details on each of the 12 egg samples, see Table S1. The microbial community was obtained by shaking the eggs and incubator water at 180 r.p.m. at $6{ }^{\circ} \mathrm{C}$ for $12 \mathrm{~h}$, and subsequent centrifugation of the water at $24000 \times g$ at $4{ }^{\circ} \mathrm{C}$ for $20 \mathrm{~min}$. Cell pellets were resuspended in sterile demineralized water, concentrating the original sample $30-80$ times, and stored at $-80{ }^{\circ} \mathrm{C}$ 
before DNA isolation. One aliquot was stored at $-80{ }^{\circ} \mathrm{C}$ in $20 \%(\mathrm{v} / \mathrm{v})$ glycerol for bacterial isolation (Figure S1).

\section{Scanning electron microscopy}

A selection of salmon egg samples showing visual signs of Saprolegnia infection were collected and stored in a $1 \%$ gluteraldehyde and $4 \%$ formalin solution. Subsequently, samples were fixed in $2.5 \%$ gluteraldehyde and then treated with $1 \%$ osmium tetroxide for $1 \mathrm{~h}$. Samples were dehydrated with alcohol and subsequently dried using hexamethyldisilazane. Dried samples were coated in gold using an EMitech Limited (Ashford, UK) K550 sputter coater. Coated samples were viewed in a Zeiss (Oberkochen, Germany) EVO MA10 scanning electron microscope at $10 \mathrm{kV}$.

\section{Metagenomic DNA isolation and storage}

DNA was isolated from the pellet suspensions (described above) in duplicate with PowerSoil DNA isolation kit (MO BIO Laboratories, Inc., Carlsbad, CA, USA) according to the manufacturer's instructions. Duplicate DNA extracts were pooled and an aliquot was analysed on a $0.8 \%(\mathrm{w} / \mathrm{v})$ agarose gel with SmartLadder MW-1700-10 (Eurogentec, Seraing, Belgium) as a size marker. The DNA concentration was measured with a NanoDrop 1000 Spectrophotometer (Thermo Fisher Scientific Inc., Waltham, MA, USA). DNA samples were stored at $-80^{\circ} \mathrm{C}$.

\section{PhyloChip analysis}

PhyloChip analysis of the bacterial and archaeal community structure of each sample ( 0.5 $\mu \mathrm{g}$ DNA) was conducted at Second Genome (South San Francisco, CA, USA). Sample and data processing and data reduction were performed as described previously (Hazen et al., 2010). Annotation of operational taxonomic units (OTUs) was performed based on the Greengenes database (McDonald et al., 2012). Cluster analysis with Bray-Curtis similarity measures was performed in Primer-E v6.1.13 (Primer-E Ltd, Ivybridge, UK). Nonmetric multi-dimensional scaling and analysis of similarity (Ramette, 2007) were performed in Paleontological Statistics freeware package (PAST v2.10, http://folk.uio.no/ohammer/past/) (Hammer et al., 2001).

\section{Clone library sequencing of oomycete and fungal communities}

The internal transcribed spacer (ITS) region of fungal and oomycete rRNA genes was PCR-amplified with primers ITS1F and ITS4 (White et al., 1990; Gardes and Bruns, 1993), and Oom-Up5.8S (5'TGCGATACGTAATGCGAATT-3') and Oom-Lo28S (5'-ACTTGTTCGCTATCGGTCTCGCA-3') (Mazzola et al., 2002; Tambong et al., 2006), respectively. Amplification reactions were conducted in 50 $\mu \mathrm{l}$ volumes with Taq DNA polymerase (Invitrogen, Grand Island, NY, USA) according to the manufacturer's instructions with $1 \mu \mathrm{l}$ DNA $(5-10 \mathrm{ng}), 1 \mathrm{cycle}$ at $94^{\circ} \mathrm{C}$ for $3 \mathrm{~min}, 40$ cycles at $94^{\circ} \mathrm{C}$ for 1 min, $50{ }^{\circ} \mathrm{C}$ for $45 \mathrm{~s}, 72{ }^{\circ} \mathrm{C}$ for $1 \mathrm{~min}$ and $1 \mathrm{cycle}$ at $72{ }^{\circ} \mathrm{C}$ for $7 \mathrm{~min}$. The dominant representatives of fungal and oomycete populations were determined by sequencing clone libraries. Amplicons were cloned into the TOPO-TA vector and transformed into chemically competent Escherichia coli Top10 cells according to the manufacturer's protocol (Invitrogen). Inserts were PCR amplified from intact cells using primer pair M13F/M13R and purified with ExoSAP-IT (USB, Cleveland, OH, USA) according to the manufacturer's instructions. A total of 20 and 5-6 clones per sample were selected for fungal and oomycete amplicon sequencing, respectively, with primer T7 and GenomeLab DTCS Quick Start Kit using the Beckman Coulter CEQ 8000 Genetic Analysis system (Beckman Coulter, Brea, CA, USA). Sequences of at least 400 bp were analysed by BLASTn (Altschul et al., 1990) on the National Center for Biotechnology Information (NCBI) database website (www.ncbi.nlm.nih.gov/). A cutoff of $>93 \%$ identity and a 400-bp alignment length were used for identification (Pounder et al., 2007; Nilsson et al., 2008). 


\section{T-RFLP analysis of fungal community}

Fluorescently labelled PCR products of the ITS region were generated using the D4-labelled ITS1F primer in conjunction with D3-labelled ITS4 primer. PCR was performed in quadruplicate $25 \mu \mathrm{l}$ reactions containing $1 \times$ Promega PCR Master mix (Promega, Madison, WI, USA), $200 \mathrm{mM}$ primer, $4 \mu \mathrm{g} \mathrm{I}^{-1}$ bovine serum albumin and 0.1-0.5 $\mu$ DNA template $(0.5-5 \mathrm{ng})$ with above-mentioned cycling conditions. PCR products were digested in duplicate reactions with $10 \mathrm{U}$ of the restriction endonucleases HaellI and Hhal at $37^{\circ} \mathrm{C}$ for $6 \mathrm{~h}$. Restriction enzymes were heat inactivated at $80^{\circ} \mathrm{C}$ for $10 \mathrm{~min}$. Restriction fragments were purified by ethanol precipitation and fragments were resuspended in $40 \mu \mathrm{l}$ of sample loading solution and $0.25 \mu \mathrm{l} 600$ size standards. Terminal restriction fragment length polymorphism (TRFLP) fragments were separated using the CEQ 8000 Genetic Analysis System with denaturation for $120 \mathrm{~s}$ at $90{ }^{\circ} \mathrm{C}$, injection for $15 \mathrm{~s}$ at $2 \mathrm{kV}$, separation for $90 \mathrm{~min}$ at $4.8 \mathrm{kV}$ and a capillary temperature of $50{ }^{\circ} \mathrm{C}$. T-RFLP profiles were analysed using the Fragment Analysis Module of the CEQ 8000 Genetic Analysis Software, with a slope threshold of $10,1 \%$ relative peak height threshold, $95 \%$ confidence level, quartic calibration curve with PA, ver. 1 , dye mobility calibration and calculated dye spectra. The baseline value was set to exclude background peaks that commonly occurred in tandem with the DNA standard peaks. Fragments were binned with a 1-bp margin using the AFLP tool in the Fragment Analysis software. Profiles that consisted of mean fragment length and fluorescence intensities were generated for each sample. As different amounts of DNA were used for amplification between samples, no accurate analysis of T-RF abundance could be carried out and we analysed the data only on the presence/absence of T-RF peaks. Cluster analysis was performed as mentioned above.

\section{Isolation of oomycetes and fungi from salmon eggs}

Per sample, one to two salmon eggs were placed on potato dextrose agar (PDA, Oxoid, Hampshire, UK). The cultures were incubated for 2 weeks at room temperature $\left(20 \pm 1^{\circ} \mathrm{C}\right)$ and for $17-18$ days at $18{ }^{\circ} \mathrm{C}$. The oomycete and fungal isolates were purified by subculturing hyphal tips three times on fresh PDA supplemented with $100 \mathrm{\mu g} \mathrm{ml}^{-1}$ streptomycin and $50 \mathrm{\mu g} \mathrm{ml}^{-1}$ tetracycline.

\section{ITS sequencing and phylogenetic analysis of oomycete isolates}

For genomic DNA extraction, hyphae were harvested in $90 \mu \mathrm{l}$ of $0.5 \mathrm{M} \mathrm{NaOH}$ and disrupted by Mixer Mill MM400 (Retsch, Haan, Germany) at a frequency of $30 / \mathrm{s}$ for $35 \mathrm{~s}$ in the presence of one sterile glass bead. The tube was placed at room temperature for $30 \mathrm{~min}$ to $24 \mathrm{~h}$ until complete cell wall disruption. The hyphal suspension was diluted with sterile $0.1 \mathrm{M}$ Tris-HCl $(\mathrm{pH} \mathrm{7.0)}$ and ITS rRNA genes were amplified with ITS1 and ITS4 primers in $25 \mu \mathrm{l}$ volumes, each consisting of $2 \mu \mathrm{l}$ of diluted DNA template with GoTaq DNA polymerase (Promega) according to the manufacturer's protocol. The amplification program consisted of 1 cycle at $94-95^{\circ} \mathrm{C}$ for $2-5 \mathrm{~min}, 30-35$ cycles at $94{ }^{\circ} \mathrm{C}$ for $1 \mathrm{~min}, 55^{\circ} \mathrm{C}, 60^{\circ} \mathrm{C}$ or $65^{\circ} \mathrm{C}$ for $30-60 \mathrm{~s}, 72{ }^{\circ} \mathrm{C}$ for $30-120 \mathrm{~s}$ and $1 \mathrm{cycle}$ at $72{ }^{\circ} \mathrm{C}$ for $5-10 \mathrm{~min}$. PCR products were sequenced by Macrogen Inc. (Amsterdam, The Netherlands). Contigs were created from the sequence fragments using Geneious v6.1.4 (Kearse et al., 2012) and aligned using MAFFT v7.0 with G-INS-i algorithm using default settings (Katoh and Standley, 2013), including previously identified reference sequences (Sandoval-Sierra et al., 2013). Two different approaches were applied: Bayesian inferences and Maximum Likelihood inference. Bayesian inference analysis with Markov-chain Monte Carlo, MrBayes v3.2.1 (Ronquist et al., 2012), was run at temperature parameter of 0.2 , sample frequency of 1000 , and three independent runs with two hot and six cold chains each for 20 million generations. Estimation of the effective samples size in the Markov-chain Monte Carlo and determination of a suitable burn-in time was checked with Tracer v1.5 (Rambaut and Drummond, 2007). A burn-in of 2 million generations was discarded after checking for stability on the log-likelihood curves, and the remaining trees from the independent runs were combined to build a $50 \%$ majority-rule consensus tree. The evolutionary model used for the molecular data in MrBayes was $H K Y+G$ and was obtained by running the data sets in jModelTest 2 (Darriba et al., 2012). Maximum Likelihood inference analysis was carried out with RaxmIGUI v7.4.2 (Silvestro and Michalak, 2012) with a random starting tree, included the GTRGAMMA option and employed the rapid hill-climbing algorithm (Stamatakis et al., 2007). Clade support was assessed with 1000 bootstrap replicates, with the rapid-hill climbing algorithm (Stamatakis et al., 2008). Phylogram trees were visualized with FigTree (tree.bio.ed.ac.uk/software/figtree/). 
Cell pellets obtained from the salmon eggs samples and stored in $20 \%$ glycerol at $-80{ }^{\circ} \mathrm{C}$ were resuspended in sterile demineralized water and dilution plated on humic acid-vitamin (HA) and starch agar (GA) modified from (Zhang, 1990). Plates were incubated at $30^{\circ} \mathrm{C}$ and bacterial colony-forming units were determined after 6 weeks. HA medium, modified from Hayakawa and Nonomura (1987), contained $1.0 \mathrm{~g} \mathrm{l}^{-1}$ humic acid (dissolved in $10 \mathrm{ml}$ of $0.2 \mathrm{~N} \mathrm{NaCl}$ ), $0.5 \mathrm{~g} \mathrm{l}^{-1} \mathrm{Na}_{2} \mathrm{HPO}_{4}, 1.71 \mathrm{~g} \mathrm{l}^{-1} \mathrm{KCl}, 0.05 \mathrm{~g}$ $\mathrm{I}^{-1} \mathrm{MgSO}_{4} .7 \mathrm{H}_{2} \mathrm{O}, 0.01 \mathrm{~g} \mathrm{l}^{-1} \mathrm{FeSO}_{4} .7 \mathrm{H}_{2} \mathrm{O}, 0.02 \mathrm{~g} \mathrm{I}^{-1} \mathrm{CaCO}_{3}$ and $18.0 \mathrm{~g} \mathrm{I}^{-1}$ agar. Starch agar (GA) (Zhang, 1990) contained $15 \mathrm{~g} \mathrm{l}^{-1}$ potato starch (soluble starch), $0.5 \mathrm{~g} \mathrm{I}^{-1} \mathrm{KNO}_{3}, 0.5 \mathrm{~g} \mathrm{I}^{-1} \mathrm{~K}_{2} \mathrm{HPO}_{4}, 0.5 \mathrm{~g} \mathrm{I}^{-1}$ $\mathrm{MgSO}_{4} .7 \mathrm{H}_{2} \mathrm{O}, 5.0 \mathrm{~g} \mathrm{I}^{-1} \mathrm{NaCl}, 5.0 \mathrm{~g} \mathrm{I}^{-1} \mathrm{KCl}, 0.01 \mathrm{~g} \mathrm{I}^{-1} \mathrm{FeSO}_{4} .7 \mathrm{H}_{2} \mathrm{O}$ and $18.0 \mathrm{~g} \mathrm{I}^{-1}$ agar. Both HA and GA were $\mathrm{pH}$ adjusted to 7.0-7.4 and were supplemented with $1 \mathrm{ml} \mathrm{l}^{-1}$ of $B$ vitamin solution, $20 \mu \mathrm{g} \mathrm{ml}^{-1}$ nalidixic acid, $20 \mathrm{\mu g} \mathrm{ml}^{-1}$ Trimethoprim and $100 \mathrm{\mu g} \mathrm{ml}^{-1}$ Delvocid after autoclaving. B vitamin solution (Nonomura and Ohara, 1969) (suspended in Milli-Q water) included $0.5 \mathrm{mg} \mathrm{ml}^{-1}$ of thiamine hydrochloride, riboflavin, nicotinic acid, pyridoxine hydrochloride, myo-inositol, calcium pantothenate and 4-aminobenzoic acid and $0.25 \mathrm{mg} \mathrm{m}^{-1} \mathrm{D}(+)$-biotin. From each sample, 40 single colonies were randomly isolated at different time points from both media and purified on GA or tryptone soya broth (Oxoid) supplemented with $10 \%$ sucrose (TSBS) with or without $1.8 \%(\mathrm{w} / \mathrm{v})$ agar. Isolates were stored at $-20{ }^{\circ} \mathrm{C}$ and $-80{ }^{\circ} \mathrm{C}$ in $20-40 \%$ glycerol. In vitro antagonistic activity of the isolates against Saprolegnia diclina 1152F4 was determined by placing an agar plug of each Actinobacterial isolate at the edge of $1 / 5^{\text {th }}$ strength PDA plates. After incubation at $30^{\circ} \mathrm{C}$ for 7-10 days, an agar plug from a fresh S. diclina $1152 \mathrm{~F} 4$ culture was placed in the centre of the plate. Plates were incubated for $4-5$ days at $25^{\circ} \mathrm{C}$ and inhibition of hyphal growth was scored. For DNA isolation, Actinobacterial cells were disrupted by incubation of $50 \mu \mathrm{l} \mathrm{TSBS}$ culture at $95{ }^{\circ} \mathrm{C}$ for $10 \mathrm{~min}$ and PCR was performed with Actinobacterialspecific primers Com 2xf (5'-AAACTCAAAGGAATTGACGG-3') and Ac1186r (5'CTTCCTCCGAGTTGACCC-3') (Schäfer et al., 2010). Amplification reactions were conducted in $25 \mu \mathrm{l}$ volumes using GoTaq DNA polymerase (Promega) according to manufacturer's instructions, with 1 cycle at $95{ }^{\circ} \mathrm{C}$ for $3 \mathrm{~min}, 35$ cycles of $94^{\circ} \mathrm{C}$ for $30 \mathrm{~s}, 60^{\circ} \mathrm{C}$ for $30 \mathrm{~s}, 72{ }^{\circ} \mathrm{C}$ for $30 \mathrm{~s}$ and $1 \mathrm{cycle}$ at $72{ }^{\circ} \mathrm{C}$ for $15 \mathrm{~min}$. All isolates positive for the amplified fragments were sent for $16 \mathrm{~S}$ rRNA sequencing by Macrogen Inc. Sequence identity was obtained by comparison with sequences deposited in the Greengenes database (McDonald et al., 2012) (http://greengenes.lbl.gov/) and Ribosomal Database Project (Cole et al., 2009) (RDP, http://rdp.cme.msu.edu/). Among the 526 Actinobacterial OTUs with significant differential abundance based on the PhyloChip analyses, the 16S rRNA sequences ( $\geq 850 \mathrm{bp}$ ) of 413 OTUs were downloaded from the Greengenes database. These sequences were subjected to phylogenetic analysis with ClustalW in MEGA5 (Tamura et al., 2011) to generate a neighbour-joining (Saitou and Nei, 1987) consensus tree with 1000 bootstrap replicates (Felsenstein, 1985). The evolutionary distances were analysed by Tamura-Nei model (Tamura and Nei, 1993) and the evolutionary rates among sites were modelled by a gamma distribution.

\section{Salmon eggs for in vivo experiments}

Atlantic salmon (Salmo salar L.) eyed eggs of strain AquaGen Atlantic QTL-innOva IPN from AquaGen AS (Trondheim, Norway) were used for the in vivo experiments. Salmon egg ages at the day of shipment were as follows; for the pathogenicity assay of Saprolegnia isolates, the eggs were 385 degree-days; for the in vivo assays with the Actinobacterial isolates, the eggs were 320 degree-days. All egg batches were disinfected during incubation and before transport with buffodine $(1: 100,10 \mathrm{~min})$ and treated with formalin according to Aquagen's in-house protocols. Upon arrival, blank, pin-eyed and white eggs were removed if observed.

\section{Preparation of Saprolegnia inocula and pathogenicity assays}

Live eggs were placed in $97-98{ }^{\circ} \mathrm{C}$ sterile distilled water or well water and incubated for $80-150 \mathrm{~s}$. The resulting dead eggs were drained and placed on PDA agar plates overgrown with Saprolegnia isolates and incubated overnight at $25^{\circ} \mathrm{C}$. Each egg was then transferred into a well of a 24-well cell-culture plate (Greiner Bio-One, Kremsmünster, Austria) and further incubated for 1 day at $15-25{ }^{\circ} \mathrm{C}$ until Saprolegnia hyphal colonization was visible. The slow-growing Saprolegnia isolates 746F3 and 736F2 were further incubated for 2 and 4 days, respectively. After overnight acclimatization of the live eggs, two Saprolegnia-infected dead salmon eggs (inocula) were added to each cup containing 30 live eggs in a similar setup as described in Figure 4c, with the exception that here $3 \mathrm{I}$ of dechlorinated Norwegian 
tap water, and not well water, was used. Isolate 736F2 was added to the salmon eggs 2 days later as this isolate was a slow grower. Each treatment consisted of an incubator containing three cups with 30 salmon eggs each. In the control treatment no Saprolegnia was added. The water temperature was maintained at $10 \pm 1{ }^{\circ} \mathrm{C}$ by adding ice blocks into each incubation unit every $12 \mathrm{~h}$. After 8 days post inoculation ( 6 days post inoculation for isolate 736F2), the mortality percentage of the salmon eggs was determined visually.

\section{In vivo bioassays to test disease suppression by Actinobacteria}

The incubation setup (Figure S4) was located in a ventilated room of constant $15{ }^{\circ} \mathrm{C}$ ambient temperature. The egg incubation units, containing 2 I of well water (Table S6), were randomly distributed in an incubation tank with circulating water of $5-7^{\circ} \mathrm{C}$. Polystyrene panels were used to cover the incubation tank to maintain darkness and insulation without blocking aeration. Each incubation unit was aerated with an air stone connected to an air pump. Dissolved oxygen levels and temperature, measured with a pH/Oxi 340i multi-parameter instrument (WTW GmbH, Weilheim, Germany), ranged from $101.8-103.4 \%$ and from $5.7{ }^{\circ} \mathrm{C}$ to $6.4{ }^{\circ} \mathrm{C}$, respectively. Within each egg incubation unit, $51 \pm 1$ live eggs were placed in perforated plastic cups in triplicate. The cups were stabilized by placing a petri dish (145 mm diameter) and a weight on top. The eggs were introduced into each incubation unit immediately after arrival from Norway and allowed to acclimatize and rehydrate overnight.

Actinobacterial isolates were inoculated in TSBS and incubated at $30{ }^{\circ} \mathrm{C}$ at 200 r.p.m. for $2-4$ days. Cultures were centrifuged at $3400 \times g$ for 5-15 min at room temperature. The cell pellets were washed and resuspended in sterile well water and $\mathrm{OD}_{600}$ values determined by spectrophotometry for the Frondihabitans sp. and Arthrobacter sp. For the Streptomyces isolates, the $\mathrm{OD}_{600}$ could not be determined because of aggregation of cells. Approximate equal amounts of cells were determined based on an estimate of the size of the cell pellet after centrifugation. On day 1, the Frondihabitans sp. and Arthrobacter sp. were added to the incubation units at a final concentration of $10^{7}$ cells per $\mathrm{ml}$ or 0.5 $\mathrm{ml}$ and $1.5 \mathrm{ml}$ of Streptomyces sp. 1 and 2, respectively. In the consortium of all four isolates, one quarter of the cell suspensions of each bacterium was added. After 3 days of incubation, two S. diclina 1152F4 inocula were placed at opposite sides in each cup. As control treatments, salmon eggs were treated with $S$. diclina only or with malachite green and $S$. diclina. Each treatment was conducted in duplicate, that is, two independent experimental incubation units with three technical replicates per incubation unit. For those eggs that received malachite green treatment, the eggs were placed in $1.5 \mathrm{I}$ of 2 p.p.m. malachite green solution for 60-70 min with aeration. Subsequently, eggs were gently rinsed in $500 \mathrm{ml}$ fresh well water and placed back into their incubation units. This was repeated every 4 days, replacing the incubation unit water with fresh well water. Hyphal expansion was photographed and assessed every other day. Based on the photos of each group of eggs, ImageJ v1.44n (Schneider et al., 2012) was used to measure the diameter of hyphal expansion. As a proxy for infection of salmon eggs by Saprolegnia, we determined hyphal attachment by lifting infection inocula with a pair of tweezers and counting the number of eggs attached to the hyphal patch (Movie S1). Hyphal attachment was determined at day 14 (10 days post inoculation) when attachment in the control, S. diclina only, was $>50 \%$ (Table S5).

\section{Nucleotide sequence accession numbers}

The sequences of the $16 \mathrm{~S}$ rRNA sequences of Frondihabitans sp., Arthrobacter sp. and Streptomyces sp. 1 and 2 have been deposited in GenBank under accession numbers KF741274, KF741275, KF741276 and KF741277, respectively.

\section{Colonization of Actinobacteria on the egg surface}

Colonization of the applied Actinobacterial isolates on the salmon egg surfaces was determined by harvesting one to two eggs from each cup at 0 and 10 days post inoculation, rinsing with $1 \mathrm{ml}$ of sterile well water three times, draining briefly on sterile filter paper and rolling gently over the surface of $\mathrm{HA}$ and GA agar plates (Movie S2). All plates were incubated at $30^{\circ} \mathrm{C}$ for $5-6$ weeks, and $2-8$ colonies that were morphologically similar to each of the four isolates used for inoculation were purified and subjected to $16 \mathrm{~S}$ rRNA sequencing. 
For each experiment, obtained data were tested for normal distribution and homogeneity of variances before conducting parametric or nonparametric statistical analyses. Disease incidence of salmon egg samples was analysed with a Mann-Whitney $U$-test $(P<0.05)$. The pathogenicity of Saprolegnia isolates were compared with one-way analysis of variance and with post hoc Dunnett analysis $(P<0.05)$. Cluster analysis and nonmetric multidimensional scaling and analysis of similarity of T-RFLP-derived data for the fungal community and PhyloChip-derived data for the bacterial and archaeal communities were conducted using Bray-Curtis similarity measures in Primer-E and in PAST. The differences in total number of bacterial and archaeal OTUs associated with diseased versus healthy eggs was analysed by Student's $t$-test $(P>0.05)$. Phylogenetic groups containing OTUs that have a significant differential abundance between diseased and healthy eggs were identified with Student's $t$-test $(P<0.005)$ in Microsoft Excel. Percentage of hyphal attachment was analysed with Kruskal-Wallis one-way analysis of variance $(P<0.05)$. Area under hyphal expansion curve and area under hatching percentage curve of different treatments in the bioassay were compared with Kruskal-Wallis one-way analysis of variance $(P<0.05)$. All statistical analyses were performed in IBM SPSS Statistics v20 (Armonk, NY, USA), unless mentioned otherwise.

\section{Results and discussion}

We conducted a meta-taxonomic microbiome analysis of 12 salmon egg batches from a Scottish salmon hatchery (Figure S1, Supplementary Methods). In hatcheries, certain salmon egg batches become infected with Saprolegnia, whereas others remain unaffected. Here, six of the sampled egg batches were selected based on a high incidence of Saprolegniosis and six based on a low disease incidence (Figure 1 and Figure S1). From this point onwards, these two distinct sample sets are referred to as 'diseased' and 'healthy', respectively. Both sets, containing eggs from the same broodstock, received water from the same source, were all incubated at average temperatures ranging from $3{ }^{\circ} \mathrm{C}$ to $5{ }^{\circ} \mathrm{C}$, and were all sampled at $\sim 85$ days after fertilization (Table S1). Total DNA was extracted from the microbiota present in the pellets obtained from each of the 12 egg samples and subjected to meta-taxonomic analyses (Figure $\mathrm{S} 1$ and Supplementary Methods).

Clone library sequencing of oomycete-specific ribosomal ITS amplicons showed the presence of Saprolegnia, Achlya and Aphanomyces (all belonging to the order Saprolegniales) in both diseased and healthy samples (Figure 2a). Achlya species have been described for diseased fish in natural environments (Jeney and Jeney, 1995; Kales et al., 2007; Sosa et al., 2007), and A. invadans is a notorious pathogen of different natural and farmed fish species worldwide, except in Europe and South America (Oidtmann, 2012). Both Achlya and Aphanomyces spp. have been isolated from eggs of sea trout (Salmo trutta m. trutta) in Polish rivers (Czeczuga et al., 2005) and from eggs of salmonids in Japan (Kitancharoen and Hatai, 1997). To date, however, no reports have indicated that Achlya or Aphanomyces are pathogenic for Atlantic salmon. Achlya or Aphanomyces were not present among the population of oomycetes isolated from the salmon eggs. Therefore, their effects on salmon eggs could not be resolved. 

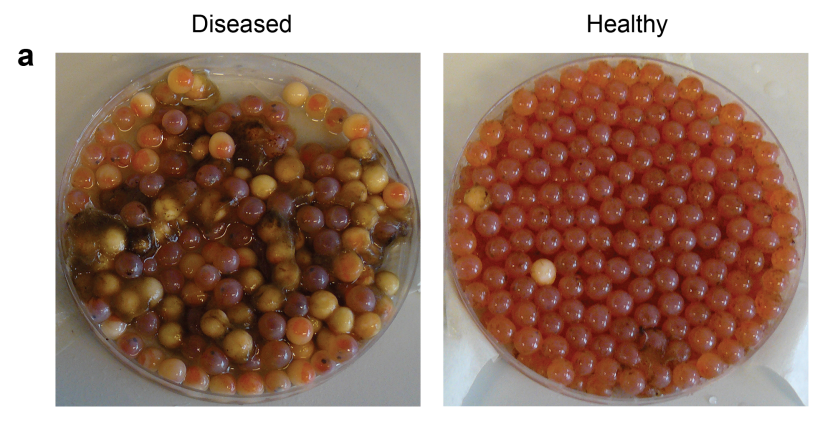

b
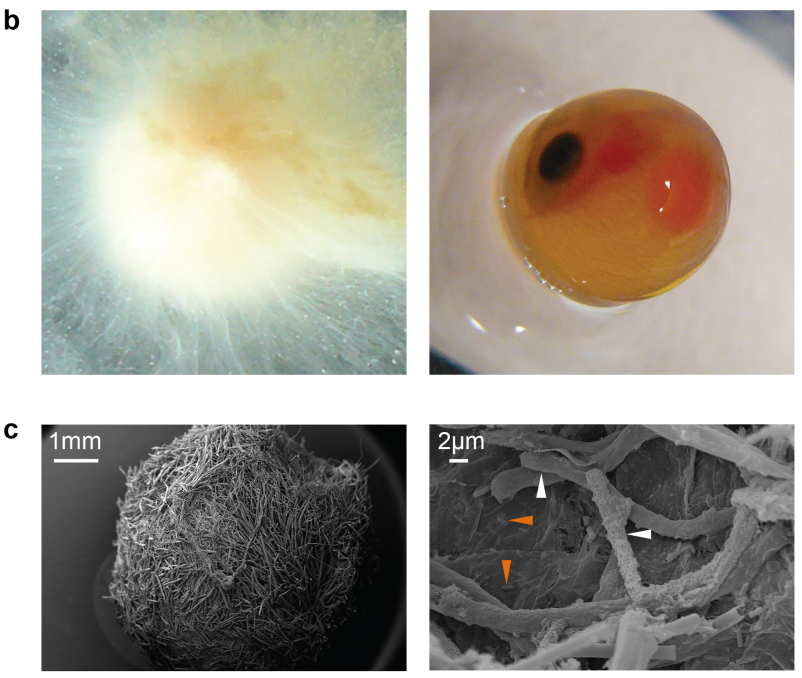

d

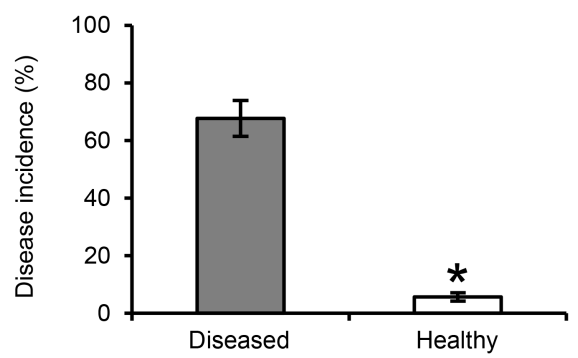

Figure 1 Saprolegniosis in Atlantic salmon (Salmo salar L.) eggs. (a) Diseased and healthy salmon eggs collected from a hatchery $(N=6)$. (b) Close-up picture of diseased and healthy salmon egg. (c) Scanning electron microscopy (SEM) image of Saprolegnia-infected salmon egg showing Saprolegnia hyphae (white arrows) and bacteria (orange arrows) covering the salmon egg surface. (d) Disease incidence of salmon egg samples collected in the hatchery. Error bars indicate s.e.m. $(N=6)$. *Statistically significant difference compared with the diseased samples. 
a

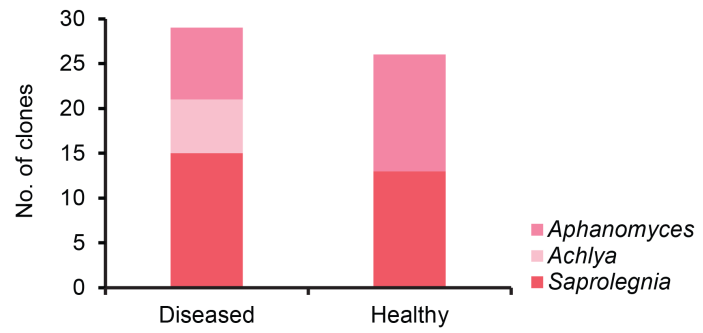

b

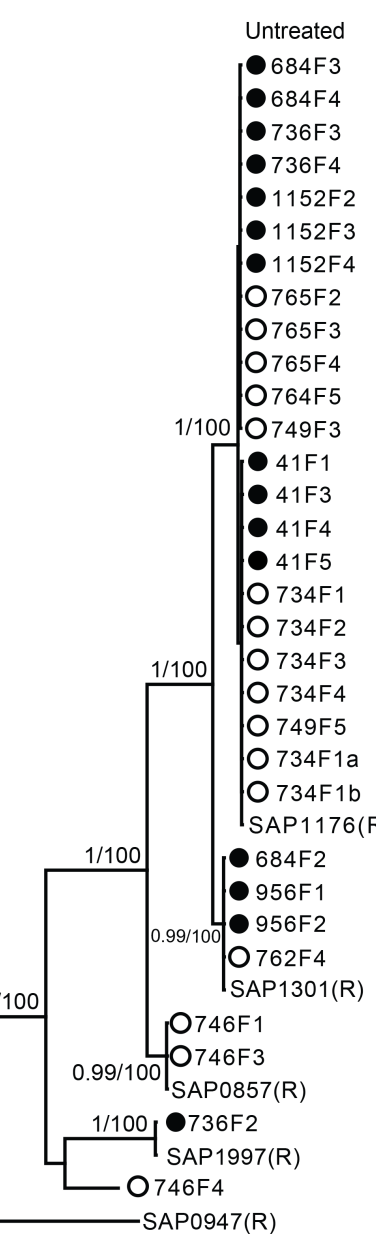

$-0.03$

- Diseased

O Healthy

届

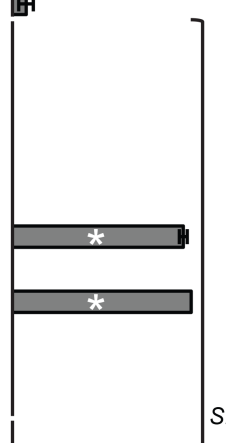

S. diclina

S. parasitica

S. torulosa

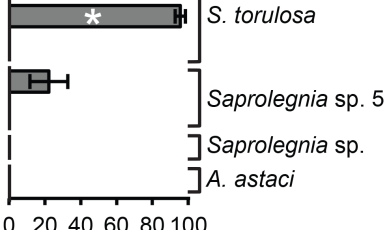

Egg mortality percentage (\%)

Figure 2 Oomycete community on diseased and healthy salmon eggs. (a) Number of clone library sequences obtained with oomycete-specific ITS primers. (b) Phylogenetic tree of ITS sequences of isolated oomycete strains from diseased $(\bullet)$ and healthy $(\circ)$ salmon eggs (left). Bayesian posterior probabilities are shown at nodes followed by estimates of bootstrap support. Pathogenicity (expressed as \% egg mortality (right)) of Saprolegnia isolates obtained from diseased and healthy salmon eggs. Strains that do not have a bar were not tested. Error bars indicate s.e.m. $(N=3)$. * Statistically significant difference compared with the untreated control. $R$, Reference strains. 
For Saprolegnia species, a similar number of sequenced clones was found in diseased and healthy eggs ( $52 \%$ and $50 \%$, respectively; Figure $2 \mathrm{a}$ ). To better characterize the Saprolegnia species, eggs from both sample sets were placed on agar media to allow outgrowth of the oomycetes. Subsequent purification and ITS sequencing of 31 randomly selected oomycete isolates showed that the majority were S. diclina, with no distinct phylogenetic differences between the Saprolegnia isolates from diseased and healthy samples (Figure 2b). Furthermore, when Saprolegnia isolates from the different phylogenetic clades were tested for pathogenicity on salmon eggs, equal levels of mortality were observed for eggs inoculated with Saprolegnia isolates from diseased or from healthy egg samples (Figure 2b). Collectively, these results indicate that the difference in incidence of Saprolegniosis between the two sets of salmon egg samples from the commercial hatchery cannot be explained by differences in population structure or pathogenicity of the Saprolegnia species present in both sample sets.

Hierarchical cluster analyses of T-RFLP data revealed no distinct differences between the fungal community from diseased or healthy salmon eggs (Figure $3 b$, Figure S2a). Further ITS-clone library sequencing showed that the fungal community associated with diseased and healthy salmon egg samples was dominated by the Ascomycota (Figure 3a), mainly Microdochium (Table S2). Microdochium species, known as snow moulds (Matsumoto, 2009), are pathogenic to cereals but also contain endophytic members that may have beneficial effects on plants (Ernst et al., 2011). For aquatic ecosystems, however, no records exist of the presence of Microdochium. Chytriomyces was only detected in the diseased egg samples, and Mortierella and Microdochium species were more abundant in diseased samples (Table S2). These fungi have not been previously associated with salmon eggs or with Saprolegniosis. In addition, Spirosphaera and Saccharicola, the fungal genera that were only detected in healthy egg samples, have not yet been described for salmon eggs. Spirosphaera spp. are known to decompose submerged plant litter (Voglmayr, 2004), whereas some Saccharicola species (S. bicolor) cause disease in sugarcane (Eriksson and Hawksworth, 2003).

PhyloChip (DeAngelis et al., 2009; Hazen et al., 2010)-based meta-taxonomic analysis of the bacterial community revealed a total of 31278 bacterial and 3 archaeal OTUs. Although 16S rDNA amplicon pyrosequencing is less biased towards detecting unknown species (DeSantis et al., 2007; Kunin et al., 2010), the PhyloChip technique allows detection of a large number of bacterial taxa including less abundant taxa. A study on lignin-degrading microbes showed that the microbial community profiles obtained by the PhyloChip technique and pyrosequencing were well comparable (DeAngelis et al., 2011). The overall distribution of the four most dominant bacterial phyla for the salmon egg samples ranged from $9 \%$ for the Bacteroidetes to $12 \%, 24 \%$ and $44 \%$ for the Actinobacteria, 
a
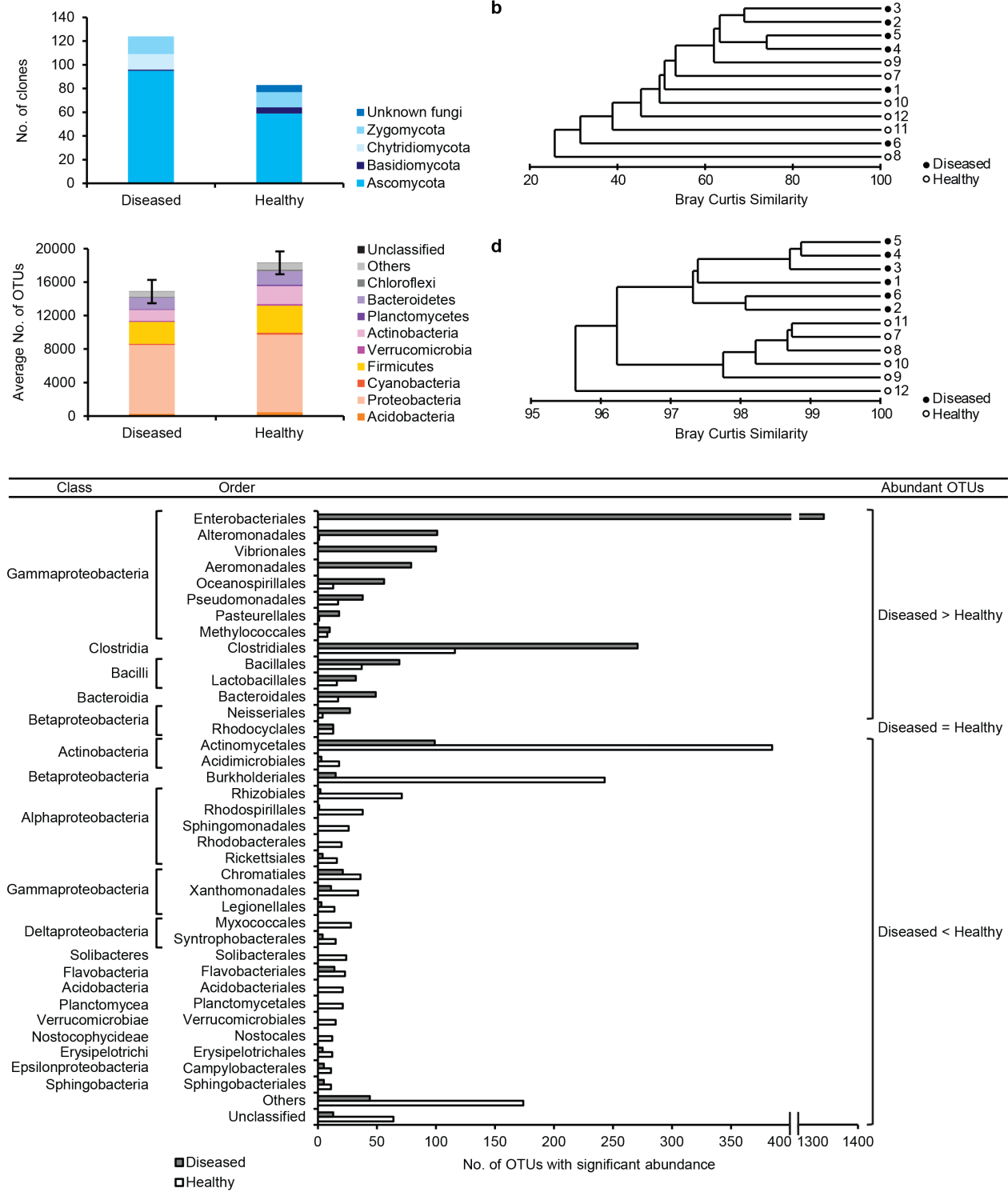

Figure 3 Fungal, bacterial and archaeal community analyses by clone library sequencing, T-RFLP and PhyloChip analyses. (a) Relative abundance of fungal phyla from Saprolegnia diseased and healthy salmon eggs as determined by sequence analysis of clones containing inserts of the ITS region. (b) Cluster analysis (Bray-Curtis similarity) of T-RFLP-derived data for the fungal community associated with diseased $(\bullet)$ and healthy $(\circ)$ salmon eggs. (c) Number of OTUs of bacterial and archaeal taxa in diseased and healthy salmon egg samples as determined by number of OTUs passing stage 1 and 2 PhyCA. Error bars indicate s.e.m. $(N=6)$. (d) Cluster analysis (Bray-Curtis similarity) of bacterial and archaeal OTUs associated with diseased $(\bullet)$ and healthy $(\circ)$ salmon egg samples $(N=6)$. (e) Phylogenetic groups containing OTUs that have a significant differential abundance between diseased and healthy salmon eggs.
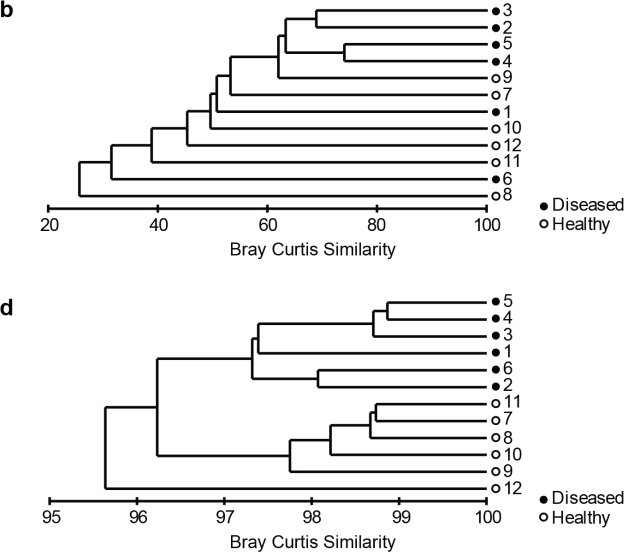
Firmicutes and Proteobacteria, respectively (Figure 3c). A number of OTUs (4684) were exclusively found in healthy samples, especially taxa belonging to the phylum Actinobacteria, that is, Streptomycetaceae, Microbacteriaceae and Micrococcaceae (Figure $3 \mathrm{c}$ and Table S3). Along with differences in richness, the relative abundance of the detected bacterial taxa also resulted in a clear discrimination between the diseased and healthy samples, except for sample 12 (healthy) that appeared to be more distinct from all other (healthy) samples (Figure $3 \mathrm{~d}$ and Figure S2b). A total of 4029 OTUs were significantly different in abundance between the diseased and healthy egg samples (Figure $3 \mathrm{e}$ ). OTUs that were significantly more abundant in the diseased samples belonged to the Enterobacteriales, Clostridiales, Alteromonadales, Vibrionales and Aeromonadales (Figure $3 \mathrm{e}$ ) and comprised several bacterial pathogens, including Vibrio spp. (Frans et al., 2011), Aeromonas spp. (Beaz-Hidalgo and Figueras, 2013) and Yersinia spp. (Tobback et al., 2007) that are common to salmon and other fish species. It is generally believed that Saprolegnia behaves as an opportunistic pathogen, infecting upon injury, stress or other infections (Stueland et al., 2005; Bruno et al., 2011). However, several papers have also reported that Saprolegnia acts as a primary infection agent in eggs and adult fish (Bruno et al., 2011). Thus, whether these potentially pathogenic bacterial taxa were initially present and predisposed the eggs for Saprolegnia infection or infection of the salmon eggs by Saprolegnia led to proliferation of these opportunistic pathogenic bacteria remains to be resolved.

Most of the OTUs that were significantly more abundant in healthy samples belonged to the orders Actinomycetales and Burkholderiales (Figure 3e). In fungal gardens of ants, Actinobacteria were identified that protect the ant colony from a parasitic black fungus (Phialophora sp.) (Caldera et al., 2009). Actinobacteria are prolific producers of an array of antimicrobial compounds and have been suggested as probiotic agents in aquaculture (Verschuere et al., 2000; Das et al., 2008; Dharmaraj, 2010). To study the potential role of the differentially abundant Actinobacterial taxa in protection of salmon eggs against Saprolegnia infections (Figure 3e), a total of 354 Actinobacteria were isolated from the diseased and healthy egg samples on two different media that are semiselective for Actinobacteria (Table S4). Isolates were subcultured, purified, characterized by $16 S$ rRNA sequencing and tested for in vitro and in vivo activity against $S$. diclina. Most of the cultured isolates belonged to the families Microbacteriaceae, Micrococcaceae and Streptomycetaceae and, considering their 16S rRNA-based phylogeny, were in the same clades as the differentially abundant OTUs detected by the culture-independent PhyloChip analysis (Figure S3). OTUs detected only by PhyloChip and not by isolation belonged to Corynebacteriaceae, 
Dermabacteraceae, Thermomonosporaceae and Streptosporangiaceae among others.

The results of the in vitro dual culture plate assays showed that $6.9 \%$ and $12.3 \%$ of the Actinobacterial isolates from diseased and healthy samples, respectively, inhibited hyphal growth of $S$. diclina. For the in vivo assays with salmon eggs, we selected four bacterial isolates from the obtained Actinobacterial collection belonging to clades with OTUs that were significantly more abundant in the healthy salmon egg samples (Figure $3 e$ and Figure S3). Two isolates belonged to the genera Frondihabitans (Microbacteriaceae) and Arthrobacter (Micrococcaceae), and two isolates to Streptomyces (Streptomycetaceae) (Figure 4a). The two Streptomyces isolates inhibited in vitro hyphal growth of S. diclina, whereas Arthrobacter and Frondihabitans were not inhibitory (Figure 4b). For the in vivo assays, salmon eggs were transferred to aerated cups inside a unit cooled to 5-7 ${ }^{\circ} \mathrm{C}$ and preincubated for 3 days with each of the bacterial isolates at an initial density of $\sim 10^{7}$ cells per ml. Two heat-killed eggs overgrown with $S$. diclina were then placed in each cup serving as the inoculum source for pathogen outgrowth and attachment (Figure 4c and Figure S4). After 10 days of incubation, none of the four selected Actinobacterial isolates reduced radial outgrowth of $S$. diclina from the inoculum source (Figure S5a). However, the Frondihabitans isolate significantly inhibited hyphal attachment to the salmon eggs (Figure 4d and Movie S1), even under high disease levels where malachite green treatment did not provide $100 \%$ control (Figure 4d). This suppressive effect was not observed for the Streptomyces and Arthrobacter isolates. When a consortium of all four isolates was tested, hyphal attachment was inhibited to the same level as obtained with the Frondihabitans isolate alone (Figure 4d). Subsequent analysis of the bacterial community associated with the salmon eggs (see movie S2) showed that, based on colony morphology and 16S rRNA sequencing, the majority of the obtained colonies were indeed the Actinobacterial isolates initially applied to the salmon eggs. In the absence of $S$. diclina, stress-associated hatching (Czerkies et al., 2001) of the salmon eggs was observed for one of the Streptomyces isolates but not for Frondihabitans, Arthrobacter or other Streptomyces isolate (Figures S5b and c). None of the bacterial isolates exhibited adverse effects on alevin survival or morphology (data not shown). Collectively, these results highlight that insights into the microbial landscapes of salmon eggs allows for a taxon-targeted selection of specific commensal bacteria from fish eggs with the potential to mitigate Saprolegniosis.

Frondihabitans (previously named Frondicola) was originally isolated from fallen leaf litter from a pine forest in Australia (Zhang et al., 2007; Greene et al., 2009) and has also been isolated from lichens (Cardinale et al., 2011) and the rhizosphere of Peucedanum japonicum (Lee, 2010). However, association with 
a Fror

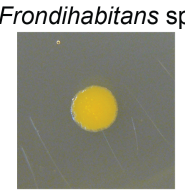

Streptomyces sp.

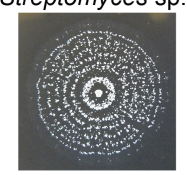

C
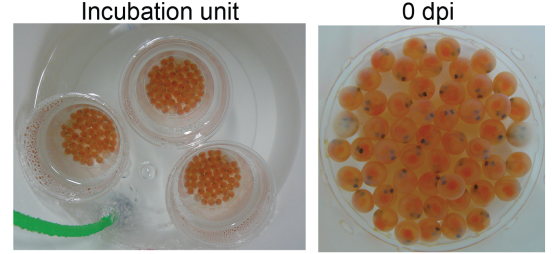

d

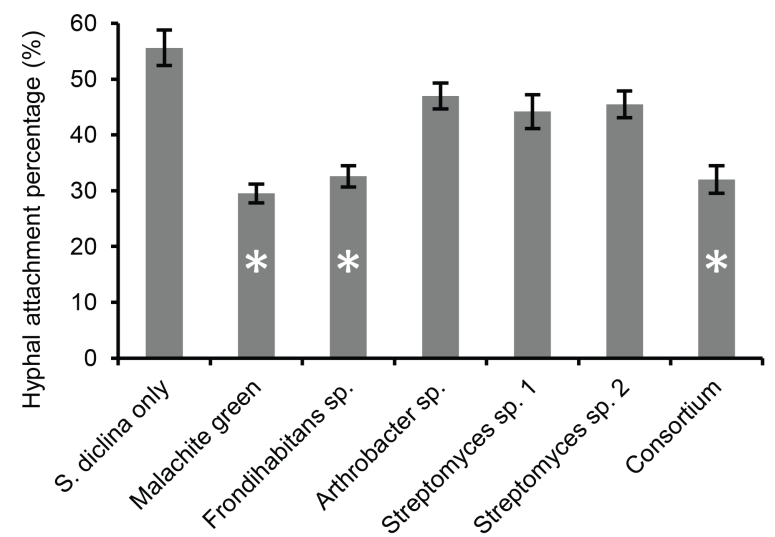

Figure 4 Characteristics and in vivo testing of selected Actinobacterial isolates to control Saprolegniosis on salmon eggs. (a) Morphology of Frondihabitans, Arthrobacter and two Streptomyces isolates. (b) In vitro antagonism against Saprolegnia diclina 1152F4. (c) Setup of in vivo bioassay. Eggs were inoculated with bacteria and after 3 days of incubation, two $S$. diclina-infected salmon eggs were added at opposite ends of each cup. The diameter of hyphal expansion was determined every 2 days as indicated by the double arrow. (d) Percentage of eggs to which Saprolegnia hyphae were attached at 10 days post inoculation of the pathogen (see Movie S1). Error bars indicate the s.e.m. $(N=6)$. * Statistically significant difference with the control, $S$. diclina only (Kruskal-Wallis, $P<0.05$ ).

freshwater environments has not previously been reported. The means by which Frondihabitans limits hyphal attachment of $S$. diclina to the salmon eggs is not known. The observation that hyphal expansion of the pathogen from the inoculum sources was not inhibited by the Frondihabitans isolate (Figure S5a) and that the bacterium did not show in vitro antagonism (Figure 4b) suggests that antibiosis via (water-soluble) secondary metabolites is most likely not a key mechanism of 
pathogen control. Microscopic analysis further demonstrated that zoospores of $S$. diclina were not negatively affected by the presence of Frondihabitans sp. However, the role of zoospores in pathogenesis is unclear as no zoospore-initiated secondary infection was observed throughout the experiment. Successful colonization of salmon egg surfaces by the Frondihabitans isolate may point to competitive niche exclusion as one of the underlying mechanisms of disease suppression.

The impact of the microbiota on host health and development is gaining increasing attention. For humans, environmental changes or infections can substantially influence the gut microbiome by causing blooms of microbes that are otherwise present at low abundance (Stecher et al., 2013). Human gut microbiomes can significantly drive or suppress disease development (Round et al., 2010; Everard et al., 2013). Although less diverse, the gut microbiome of insects also influences host development by increasing nutrient uptake and stimulating host immunity maturation (Weiss and Aksoy, 2011). Similarly for plants, endophytic, rhizospheric and phyllospheric microbiota play an important role in the protection against biotic and abiotic stress factors (Vorholt, 2012; Bulgarelli et al., 2013; Mendes et al., 2013; Turner et al., 2013). Here we showed a significant correlation between the incidence of Saprolegniosis and the richness and evenness of specific bacterial genera associated with salmon eggs. These results indicate that along with established factors influencing disease susceptibility, such as genetic inheritance (broodstock effect), developmental stage of the salmon eggs, environmental and other stress conditions (Hansen and Olafsen, 1999), the microbiota are also a determining factor in health and disease of fish eggs that have an immature adaptive immune system and depend on other defences for protection. In terms of genetic inheritance, components of the complement immune system were shown to be maternally transferred to the eggs for rainbow trout, zebrafish and amphibian eggs (Lovoll et al., 2006; Poorten and Kuhn, 2009; Wang et al., 2009; Walke et al., 2011) and a paternal genetic component contributed to resistance against Saprolegnia in frog eggs (Sagvik et al., 2008). The relative contribution of the genetic inheritance, the fish egg microbiome or their interplay to protect against Saprolegniosis is not clear yet. Hence, our current and future experiments on Saprolegniosis focus on the temporal dynamics of microbial communities on salmon eggs of different broodstocks and how these community changes affect egg and disease development. These studies will give insight into the recruitment of beneficial commensal bacteria, like Frondihabitans and other genera, during egg development and the transfer of specific microbiota via the mother during spawning.

Aquaculture has emerged as the fastest growing animal food-producing sector, in part as a response to regulations that seek to prevent overfishing of wild oceanic 
populations (Bruno et al., 2011). Environmental regulations have restricted the use of chemical control agents (malachite green, formalin) in aquaculture production systems and alternative treatments such as hydrogen peroxide, $\mathrm{NaCl}$ and seawater flushes are not as effective (Bruno et al., 2011; Van den Berg et al., 2013). Given the importance of aquaculture for long-term food security, there is a strong need for sustainable means to mitigate Saprolegniosis and other emerging diseases. Our results provide a strong basis for the selection of beneficial microorganisms that can act as a first line of defence. Similar strategies can be used to mitigate other diseases including those that threaten wild populations of fish and amphibians.

\section{Acknowledgements}

We are grateful to Menno ter Veld and Geert Wiegertjes (Animal Sciences, Wageningen University, The Netherlands) for their advice, help and valuable suggestions for the in vivo experiments. We thank the Laboratory of Jean Beagle Ristraino (North Carolina State University, USA) for the provision of genomic DNA extraction protocol for oomycete isolates. We thank Viviane Cordovez da Cunha (Wageningen University) for her help in culturing and characterization of Actinobacteria. This work was financially supported by SAPRO (Sustainable Approaches to Reduce Oomycete (Saprolegnia) Infections in Aquaculture, 238550), a Marie Curie Initial Training Network funded by the European Commission (EC) under Framework Program 7. Javier Diéguez-Uribeondo was supported by grant of MINECO CGL201239357. PhyloChip hybridizations and initial data analyses were performed at Second Genome, CA, USA. This manuscript is publication number 5586 of Netherlands Institute of Ecology (NIOO-KNAW).

\section{Author contributions}

YL, IdB., MvdV and JMR designed the project. YL set up experiments, performed DNA extractions, strain isolations and characterization, Phylochip data analysis and in vitro and in vivo bioassays. MvdV and RM performed the PhyloChip data analysis. ALHJ contributed to the in vivo bioassay data collection and analysis. Salmon eggs were sampled from a Scottish hatchery by KD and AHvdB. Scanning electron microscopy analysis was performed by $\mathrm{AHvdB}$ and performed in the laboratory of PvW. Pathogenicity assays with the Saprolegnia isolates were designed and performed by $\mathrm{YL}$, ET and IS and performed in the laboratory of IS. Phylogenetic analysis of oomycete isolates was performed by VS-S in the laboratory of JD-U. MM performed fungal and oomycete T-RFLP analysis and clone library sequencing. YL, IdB, MvdV, ALHJ, VS-S, and MM analysed data and created figures. IdB, YL and JMR wrote the manuscript with input from all co-authors.

\section{Conflict of interest}

All authors declare no conflict of interest.

\section{References}

Altschul, S.F., Gish, W., Miller, W., Myers, E.W., and Lipman, D.J. (1990) Basic local alignment search tool. Journal of Molecular Biology 215: 403-410. 
Beaz-Hidalgo, R., and Figueras, M.J. (2013) Aeromonas spp. whole genomes and virulence factors implicated in fish disease. J Fish Dis 36: 371-388.

Bruno, D.W., van West, P., and Beakes, G.W. (2011) Saprolegnia and other oomycetes. In Fish Diseases and Disorders, Viral, Bacterial and Fungal Infections, 2nd edition, Volume 3. Woo, P.T.K. and Bruno, D.W. (eds). Wallingford, UK: CABI, pp 669-720.

Bulgarelli, D., Schlaeppi, K., Spaepen, S., Ver Loren van Themaat, E., and Schulze-Lefert, P. (2013) Structure and functions of the bacterial microbiota of plants. Annual Review of Plant Biology 64: 807838.

Cahill, M.M. (1990) Bacterial flora of fishes - a review. Microbial Ecology 19: 21-41.

Caldera, E.J., Poulsen, M., Suen, G., and Currie, C.R. (2009) Insect symbioses: a case study of past, present, and future fungus-growing ant research. Environmental Entomology 38: 78-92.

Cardinale, M., Grube, M., and Berg, G. (2011) Frondihabitans cladoniiphilus sp nov., an actinobacterium of the family Microbacteriaceae isolated from lichen, and emended description of the genus Frondihabitans. International Journal of Systematic and Evolutionary Microbiology 61: 3033-3038.

Cole, J.R., Wang, Q., Cardenas, E., Fish, J., Chai, B., Farris, R.J. et al. (2009) The Ribosomal Database Project: improved alignments and new tools for rRNA analysis. Nucleic Acids Research 37: D141-D145.

Czeczuga, B., Bartel, R., Kiziewicz, B., Godlewska, A., and Muszynska, E. (2005) Zoosporic fungi growing on the eggs of sea trout (Salmo trutta m. trutta L.) in river water of varied trophicity. Polish Journal of Environmental Studies 14: 295-303.

Czerkies, P., Brzuzan, P., Kordalski, K., and Luczynski, M. (2001) Critical partial pressures of oxygen causing precocious hatching in Coregonus lavaretus and C. albula embryos. Aquaculture 196: 151-158.

Darriba, D., Taboada, G.L., Doallo, R., and Posada, D. (2012) jModelTest 2: more models, new heuristics and parallel computing. Nature Methods 9: 772-772.

Das, S., Ward, L.R., and Burke, C. (2008) Prospects of using marine actinobacteria as probiotics in aquaculture. Applied Microbiology and Biotechnology 81: 419-429.

DeAngelis, K.M., Brodie, E.L., DeSantis, T.Z., Andersen, G.L., Lindow, S.E., and Firestone, M.K. (2009) Selective progressive response of soil microbial community to wild oat roots. ISME Journal 3 : 168-178.

DeAngelis, K.M., Allgaier, M., Chavarria, Y., Fortney, J.L., Hugenholtz, P., Simmons, B. et al. (2011) Characterization of trapped lignin-degrading microbes in tropical forest soil. Plos One 6: e19306.

DeSantis, T.Z., Brodie, E.L., Moberg, J.P., Zubieta, I.X., Piceno, Y.M., and Andersen, G.L. (2007) High-density universal $16 \mathrm{~S}$ rRNA microarray analysis reveals broader diversity than typical clone library when sampling the environment. Microbial Ecology 53: 371-383.

Dharmaraj, S. (2010) Marine Streptomyces as a novel source of bioactive substances. World Journal of Microbiology \& Biotechnology 26: 2123-2139.

Eriksson, O.E., and Hawksworth, D.L. (2003) Saccharicola, a new genus for two Leptosphaeria species on sugar cane. Mycologia 95: 426-433.

Ernst, M., Neubert, K., Mendgen, K.W., and Wirsel, S.G.R. (2011) Niche differentiation of two sympatric species of Microdochium colonizing the roots of common reed. Bmc Microbiology 11:242.

Everard, A., Belzer, C., Geurts, L., Ouwerkerk, J.P., Druart, C., Bindels, L.B. et al. (2013) Cross-talk between Akkermansia muciniphila and intestinal epithelium controls diet-induced obesity. Proceedings of the National Academy of Sciences of the United States of America 110: 9066-9071.

Felsenstein, J. (1985) Confidence limits on phylogenies: an approach using the bootstrap. Evolution 39: 783-791.

Fernández-Benéitez, M.J., Ortiz-Santaliestra, M.E., Lizana, M., and Diéguez-Uribeondo, J. (2008) Saprolegnia diclina: another species responsible for the emergent disease 'Saprolegnia infections' in amphibians. FEMS Microbiology Letters 279: 23-29.

Fisher, M.C., Henk, D.A., Briggs, C.J., Brownstein, J.S., Madoff, L.C., McCraw, S.L. et al. (2012) Emerging fungal threats to animal, plant and ecosystem health. Nature 484: 186-194.

Frans, I., Michiels, C.W., Bossier, P., Willems, K.A., Lievens, B., and Rediers, H. (2011) Vibrio anguillarum as a fish pathogen: virulence factors, diagnosis and prevention. Journal of Fish Diseases 34: 643-661.

Gardes, M., and Bruns, T.D. (1993) ITS Primers with enhanced specificity for Basidiomycetes Application to the identification of Mycorrhizae and Rusts. Molecular Ecology 2: 113-118.

Greene, A.C., Euzeby, J.P., Tindall, B.J., and Patel, B.K.C. (2009) Proposal of Frondihabitans gen. nov to replace the illegitimate genus name Frondicola Zhang et al. 2007. International Journal of Systematic and Evolutionary Microbiology 59: 447-448. 
Hammer, Ø., Harper, D.A.T., and Ryan, P.D. (2001) PAST: Paleontological statistics software package for education and data analysis. Palaeontologia Electronica 4: 1-9.

Hansen, G.H., and Olafsen, J.A. (1999) Bacterial interactions in early life stages of marine cold water fish. Microbial Ecology 38: 1-26.

Harris, R.N., Brucker, R.M., Walke, J.B., Becker, M.H., Schwantes, C.R., Flaherty, D.C. et al. (2009) Skin microbes on frogs prevent morbidity and mortality caused by a lethal skin fungus. ISME Journal 3 : 818-824.

Hatai, K., and Hoshiai, G. (1992) Mass mortality in cultured coho salmon (Oncorhynchus kisutch) due to Saprolegnia parasitica coker. Journal of wildlife diseases 28: 532-536.

Hatai, K., and Hoshiai, G.-I. (1994) Pathogenicity of Saprolegnia parasitica Coker. Portland, Oregon: Bonneville Power Administration, Fiv. Fish and Wildlife.

Hayakawa, M., and Nonomura, H. (1987) Humic-acid vitamin agar, a new medium for the selective isolation of soil Actinomycetes. Journal of Fermentation Technology 65: 501-509.

Hazen, T.C., Dubinsky, E.A., DeSantis, T.Z., Andersen, G.L., Piceno, Y.M., Singh, N. et al. (2010) Deep-sea oil plume enriches indigenous oil-degrading bacteria. Science 330: 204-208.

Jeney, Z., and Jeney, G. (1995) Recent achievements in studies on diseases of common carp (Cyprinus carpio L.). Aquaculture 129: 397-420.

Kales, S.C., DeWitte-Orr, S.J., Bols, N.C., and Dixon, B. (2007) Response of the rainbow trout monocyte/macrophage cell line, RTS11 to the water molds Achlya and Saprolegnia. Molecular Immunology 44: 2303-2314.

Katoh, K., and Standley, D.M. (2013) MAFFT Multiple sequence alignment software version 7: improvements in performance and usability. Molecular Biology and Evolution 30: 772-780.

Kearse, M., Moir, R., Wilson, A., Stones-Havas, S., Cheung, M., Sturrock, S. et al. (2012) Geneious Basic: An integrated and extendable desktop software platform for the organization and analysis of sequence data. Bioinformatics 28: 1647-1649.

Kitancharoen, N., and Hatai, K. (1997) Aphanomyces frigidophilus sp. nov. from eggs of Japanese char, Salvelinus leucomaenis. Mycoscience 38: 135-140.

Krugner-Higby, L., Haak, D., Johnson, P.T.J., Shields, J.D., Jones, W.M., Reece, K.S. et al. (2010) Ulcerative disease outbreak in crayfish Orconectes propinquus linked to Saprolegnia australis in Big Muskellunge Lake, Wisconsin. Diseases of Aquatic Organisms 91: 57-66.

Kunin, V., Engelbrektson, A., Ochman, H., and Hugenholtz, P. (2010) Wrinkles in the rare biosphere: pyrosequencing errors can lead to artificial inflation of diversity estimates. Environmental Microbiology 12: $118-123$.

Lee, S.D. (2010) Frondihabitans peucedani sp nov., an actinobacterium isolated from rhizosphere soil, and emended description of the genus Frondihabitans Greene et al. 2009. International Journal of Systematic and Evolutionary Microbiology 60: 1740-1744.

Lovoll, M., Kilvik, T., Boshra, H., Bogwald, J., Sunyer, J.O., and Dalmo, R.A. (2006) Maternal transfer of complement components C3-1, C3-3, C3-4, C4, C5, C7, Bf, and Df to offspring in rainbow trout (Oncorhynchus mykiss). Immunogenetics 58: 168-179.

Martel, A., Spitzen-van der Sluijs, A., Blooi, M., Bert, W., Ducatelle, R., Fisher, M.C. et al. (2013) Batrachochytrium salamandrivorans sp. nov. causes lethal chytridiomycosis in amphibians. Proceedings of the National Academy of Sciences of the United States of America 110: 15325-15329.

Matsumoto, N. (2009) Snow molds: a group of fungi that prevail under snow. Microbes and Environments 24: 14-20.

Mazzola, M., Andrews, P.K., Reganold, J.P., and Levesque, C.A. (2002) Frequency, virulence, and metalaxyl sensitivity of Pythium spp. isolated from apple roots under conventional and organic production systems. Plant Disease 86: 669-675.

McDonald, D., Price, M.N., Goodrich, J., Nawrocki, E.P., DeSantis, T.Z., Probst, A. et al. (2012) An improved Greengenes taxonomy with explicit ranks for ecological and evolutionary analyses of bacteria and archaea. ISME Journal 6: 610-618.

McKenzie, V.J., Bowers, R.M., Fierer, N., Knight, R., and Lauber, C.L. (2012) Co-habiting amphibian species harbor unique skin bacterial communities in wild populations. ISME Journal 6: 588596.

Mendes, R., Garbeva, P., and Raaijmakers, J.M. (2013) The rhizosphere microbiome: significance of plant beneficial, plant pathogenic, and human pathogenic microorganisms. FEMS Microbiology Reviews 37: 634-663.

Mendes, R., Kruijt, M., de Bruijn, I., Dekkers, E., van der Voort, M., Schneider, J.H. et al. (2011) Deciphering the rhizosphere microbiome for disease-suppressive bacteria. Science 332: 1097-1100. 
Nilsson, R.H., Kristiansson, E., Ryberg, M., Hallenberg, N., and Larsson, K.-H. (2008) Intraspecific ITS variability in the kingdom fungi as expressed in the international sequence databases and its implications for molecular species identification. Evolutionary Bioinformatics 4: 193-201.

Nonomura, H., and Ohara, Y. (1969) Distribution of Actinomycetes in soil. (VI) A culture method effective for both preferential isolation and enumeration of Microbispora and Streptosporangium strains in soil (Part I). Journal of Fermentation Technology 47: 463-469.

Oidtmann, B. (2012) Review of biological factors relevant to import risk assessments for epizootic ulcerative syndrome (Aphanomyces invadans). Transboundary and Emerging Diseases 59: 26-39.

Phillips, A.J., Anderson, V.L., Robertson, E.J., Secombes, C.J., and van West, P. (2008) New insights into animal pathogenic oomycetes. Trends in Microbiology 16: 13-19.

Poorten, T.J., and Kuhn, R.E. (2009) Maternal transfer of antibodies to eggs in Xenopus laevis. Developmental and Comparative Immunology 33: 171-175.

Pounder, J.I., Simmon, K.E., Barton, C.A., Hohmann, S.L., Brandt, M.E., and Petti, C.A. (2007) Discovering potential pathogens among fungi identified as nonsporulating molds. Journal of Clinical Microbiology 45: 568-571.

Rambaut, A., and Drummond, A.J. (2007). Tracer v1.4. URL http://tree.bio.ed.ac.uk/software/tracer/. 160.

Ramette, A. (2007) Multivariate analyses in microbial ecology. Fems Microbiology Ecology 62: 142-

Ronquist, F., Teslenko, M., van der Mark, P., Ayres, D.L., Darling, A., Hohna, S. et al. (2012) MrBayes 3.2: efficient Bayesian phylogenetic inference and model choice across a large model space. Systematic Biology 61: 539-542.

Round, J.L., O'Connell, R.M., and Mazmanian, S.K. (2010) Coordination of tolerogenic immune responses by the commensal microbiota. Journal of Autoimmunity 34: J220-J225.

Sagvik, J., Uller, T., and Olsson, M. (2008) A genetic component of resistance to fungal infection in frog embryos. Proceedings of the Royal Society B: Biological Sciences 275: 1393-1396.

Saitou, N., and Nei, M. (1987) The neighbor-joining method: a new method for reconstructing phylogenetic trees. Molecular Biology and Evolution 4: 406-425.

Sandoval-Sierra, J.V., Martín, M.P., and Diéguez-Uribeondo, J. (2013) Species identification in the genus Saprolegnia (Oomycetes): defining DNA-based molecular operational taxonomic units. Fungal Biology 118: 559-578.

Sarmiento-Ramirez, J.M., Abella, E., Martin, M.P., Telleria, M.T., Lopez-Jurado, L.F., Marco, A. et al. (2010) Fusarium solani is responsible for mass mortalities in nests of loggerhead sea turtle, Caretta caretta, in Boavista, Cape Verde. FEMS Microbiology Letters 312: 192-200.

Schäfer, J., Jäckel, U., and Kämpfer, P. (2010) Development of a new PCR primer system for selective amplification of Actinobacteria. FEMS Microbiology Letters 311: 103-112.

Schneider, C.A., Rasband, W.S., Eliceiri, K.W. (2012) NIH Image to ImageJ: 25 years of image analysis. Nature Methods 9: 671-675.

Schulze, A.D., Alabi, A.O., Tattersall-Sheldrake, A.R., and Miller, K.M. (2006) Bacterial diversity in a marine hatchery: balance between pathogenic and potentially probiotic bacterial strains. Aquaculture 256: 50-73.

Silvestro, D., and Michalak, I. (2012) raxmIGUI: a graphical front-end for RAxML. Organisms Diversity \& Evolution 12: 335-337.

Sosa, E.R., Landsberg, J.H., Kiryu, Y., Stephenson, C.M., Cody, T.T., Dukeman, A.K. et al. (2007) Pathogenicity studies with the fungi Aphanomyces invadans, Achlya bisexualis, and Phialemonium dimorphosporum: induction of skin ulcers in striped mullet. Journal of Aquatic Animal Health 19: 41-48.

Stamatakis, A., Hoover, P., and Rougemont, J. (2008) A Rapid Bootstrap Algorithm for the RAxML Web Servers. Systematic Biology 57: 758-771.

Stamatakis, A., Blagojevic, F., Nikolopoulos, D.S., and Antonopoulos, C.D. (2007) Exploring new search algorithms and hardware for phylogenetics: RAxML meets the IBM cell. Journal of VIsi Signal Processing Systems for Signal Image and Video Technology 48: 271-286.

Stecher, B., Maier, L., and Hardt, W.-D. (2013) 'Blooming' in the gut: how dysbiosis might contribute to pathogen evolution. Nature Reviews Microbiology 11: 277-284.

Stueland, S., Hatai, K., and Skaar, I. (2005) Morphological and physiological characteristics of Saprolegnia spp. strains pathogenic to Atlantic salmon, Salmo salar L. Journal of Fish Diseases 28: 445-453.

Tambong, J.T., de Cock, A., Tinker, N.A., and Levesque, C.A. (2006) Oligonucleotide array for identification and detection of Pythium species. Applied and Environmental Microbiology 72: 2691-2706.

Tamura, K., and Nei, M. (1993) Estimation of the number of nucleotide substitutions in the control region of mitochondrial DNA in humans and chimpanzees. Molecular Biology and Evolution 10: 512-526. 
Tamura, K., Peterson, D., Peterson, N., Stecher, G., Nei, M., and Kumar, S. (2011) MEGA5: Molecular Evolutionary Genetics Analysis Using Maximum Likelihood, Evolutionary Distance, and Maximum Parsimony Methods. Molecular Biology and Evolution 28: 2731-2739.

Tobback, E., Decostere, A., Hermans, K., Haesebrouck, F., and Chiers, K. (2007) Yersinia ruckeri infections in salmonid fish. Journal of Fish Diseases 30: 257-268.

Turner, T.R., James, E.K., and Poole, P.S. (2013) The plant microbiome. Genome Biology 14: 209.

Van den Berg, A.H., McLaggan, D., Dieguez-Uribeondo, J., and Van West, P. (2013) The impact of the water moulds Saprolegnia diclina and Saprolegnia parasitica on natural ecosystems and the aquaculture industry. Fungal Biology 27: 33-42.

Verschuere, L., Rombaut, G., Sorgeloos, P., and Verstraete, W. (2000) Probiotic bacteria as biological control agents in aquaculture. Microbiology and Molecular Biology Reviews 64: 655-671.

Voglmayr, H. (2004) Spirosphaera cupreorufescens sp nov., a rare aeroaquatic fungus. Studies in Mycology: 221-228.

Vorholt, J.A. (2012) Microbial life in the phyllosphere. Nature Reviews Microbiology 10: 828-840.

Walke, J.B., Harris, R.N., Reinert, L.K., Rollins-Smith, L.A., and Woodhams, D.C. (2011) Social immunity in amphibians: evidence for vertical transmission of innate defenses. Biotropica 43: 396-400.

Wang, Z., Zhang, S., Tong, Z., Li, L., and Wang, G. (2009) Maternal transfer and protective role of the alternative complement components in zebrafish Danio rerio. Plos One 4: e4498.

Weiss, B., and Aksoy, S. (2011) Microbiome influences on insect host vector competence. Trends in Parasitology 27: 514-522.

White, T.J., Bruns, T., Lee, S., and Taylor, J. (1990) Amplification and direct sequencing of fungal ribosomal RNA genes for phylogenetics. In PCR protocols : a guide to methods and applications. Innis, M.A., Gelfand, D.H., Sninsky, J.J., and White, T.J. (eds). New York: Academic Press, pp. 315-322.

Woodhams, D.C., Bosch, J., Briggs, C.J., Cashins, S., Davis, L.R., Lauer, A. et al. (2011) Mitigating amphibian disease: strategies to maintain wild populations and control chytridiomycosis. Frontiers in Zoology 8: 8.

Zhang, J. (1990) Microbial Taxonomy. Shanghai: Fudan University Press.

Zhang, L., Xu, Z., and Patel, B.K.C. (2007) Frondicola australicus gen. nov., sp nov., isolated from decaying leaf litter from a pine forest. International Journal of Systematic and Evolutionary Microbiology 57: 1177-1182. 


\section{Supplementary Figures:}

\section{Experimental set-up}

1 Saprolegniosis diseased salmon eggs $(\mathrm{N}=6)$

2 Healthy salmon eggs $(\mathrm{N}=6)$

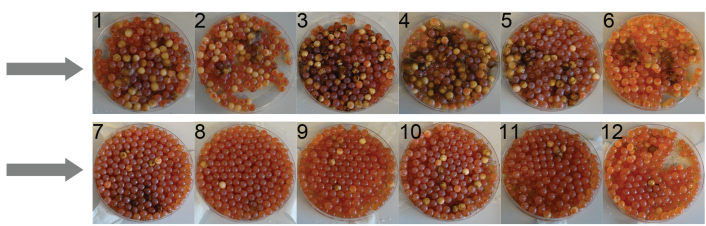

II Oomycete and fungal communities

1 ITS amplification with oomyceteand fungal- specific primers

2 Restriction digest with Haell and Hhal and fragment analysis (only for fungi)

3 Cloning into TOPO-TA vector, sequencing, identification and data analysis

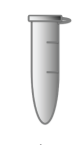

Oomycetes

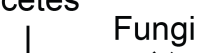

Bacteria \& Archaea

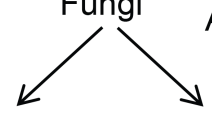
clone library

T-RFLP sequencing NMDS ANOSIM

\section{Bacterial and archaeal communities}

1 16S rRNA sequences amplification, fractionation and end-labelling with biotin

2 Hybridization, staining, washing and scanning, total of 12 chips ( 2 treatments, $\mathrm{N}=6$ )

3 Data analysis and selection of target groups

\section{Functional analysis (Oomycetes and Actinobacteria)}

1 Plating on specific media

2 Genetic and phenotypic characterisation (in vitro screening of isolated bacteria)

3 In vivo bioassays to test pathogenicity of oomycetes and disease suppression by bacterial isolates

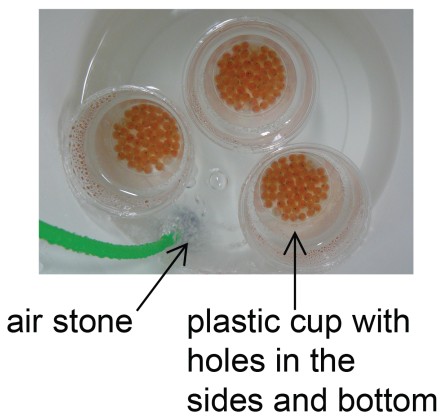

Figure S1 Overall strategy used to decipher the salmon egg microbiome and to identify commensal microorganisms that can mitigate Saprolegniosis. 
a

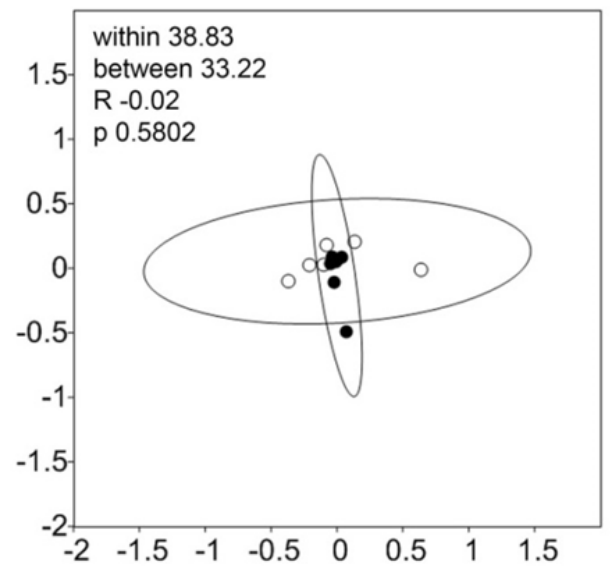

b

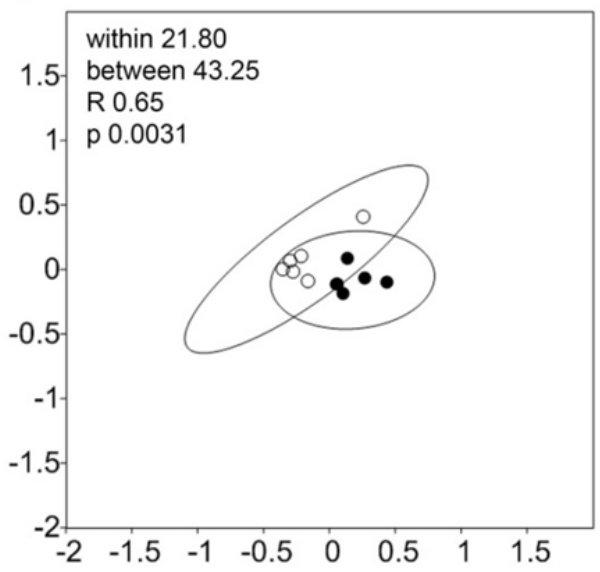

Figure S2 Non-metric multi-dimensional scaling (NMDS) plots of a, Fungal community T-RFLP analysis based on the presence/absence of individual T-RFs, and $\mathbf{b}$, Bacterial and archaeal operational taxonomic units (OTUs) in PhyloChip analysis. Ellipses indicate $95 \%$ confidence intervals for each treatment. Closed circles: diseased eggs; open circles: healthy eggs. $R$ and $p$ values along with mean ranks of all distances within and between treatments reported for analysis of similarity (ANOSIM) based on 10000 permutations. No significant difference found between fungal community in diseased and healthy egg batches $(P=0.5802)$. Although some overlap was observed $(R=0.65)$, bacterial community were significantly different between diseased and healthy batches of eggs $(P=0.0031)$. 


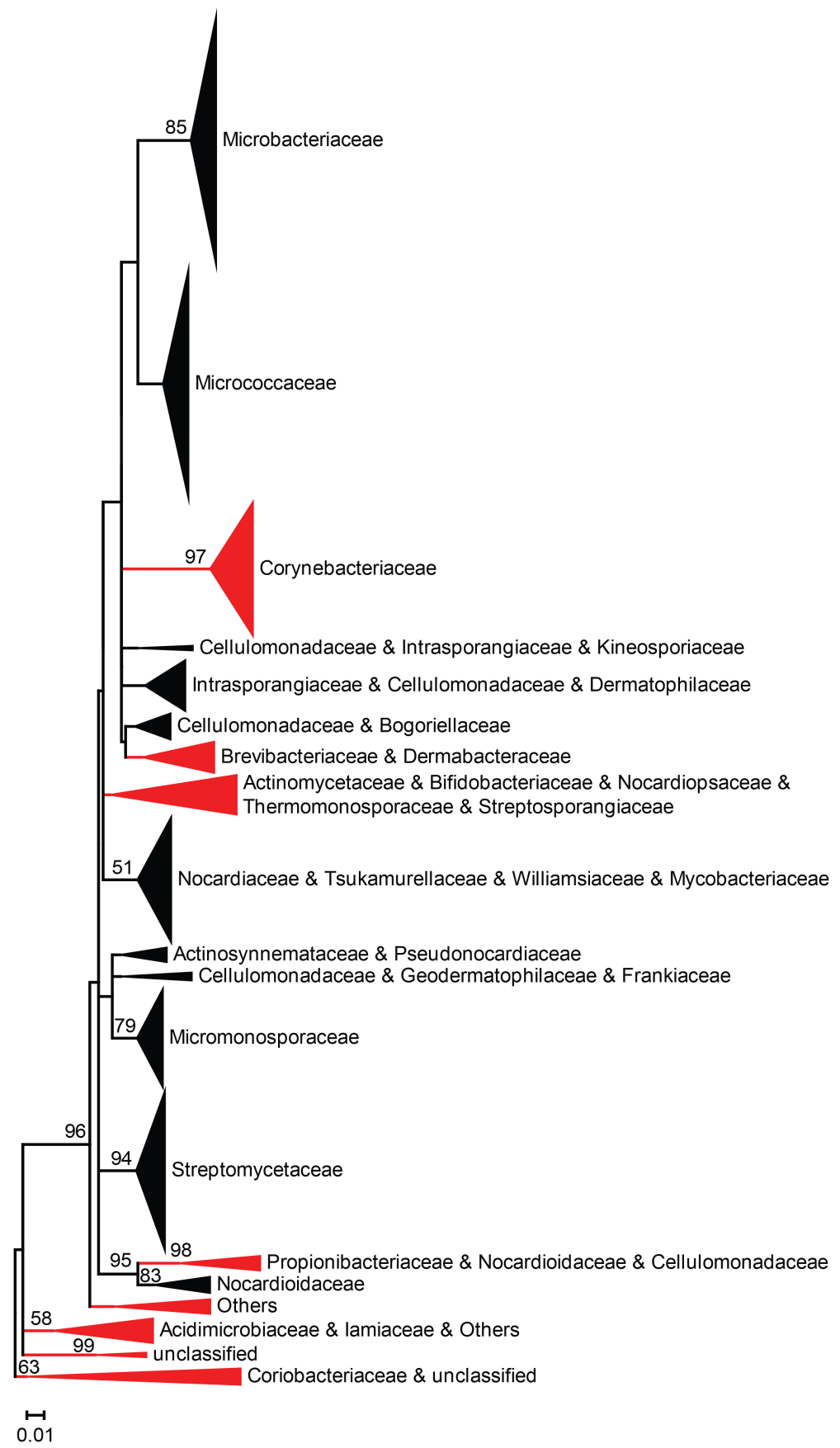

Figure S3 Phylogenetic tree of Actinobacterial 16S rRNA sequences ( $\geq 850 \mathrm{bp}$ ) of i) 354 isolates obtained by plating on semi-selective media and ii) 413 PhyloChip detected OTUs with a significant differential abundance between diseased and healthy egg samples. The bootstrap values indicated at the nodes are based on 1000 bootstrap replicates. Branch values lower than $50 \%$ were hidden. Clades indicated in black contain OTUs detected by PhyloChip and isolates obtained by plating on semiselective media. Clades indicated in red contain OTUs detected by PhyloChip only. 

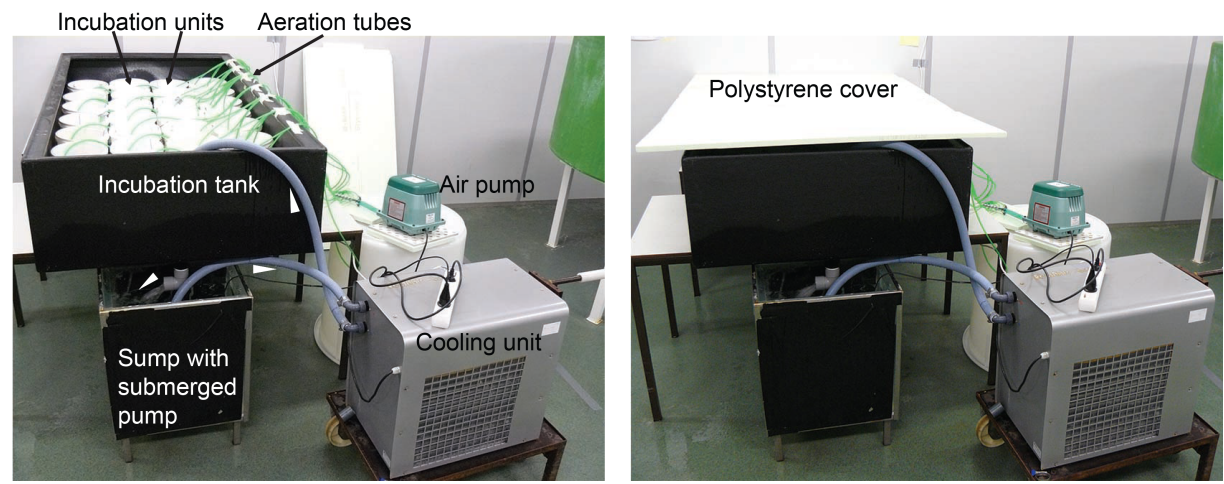

Figure S4 Set-up of the in vivo bioassay to determine the disease suppressive activity of the commensal Actinobacterial isolates. White arrows indicate the directions of water recirculation.

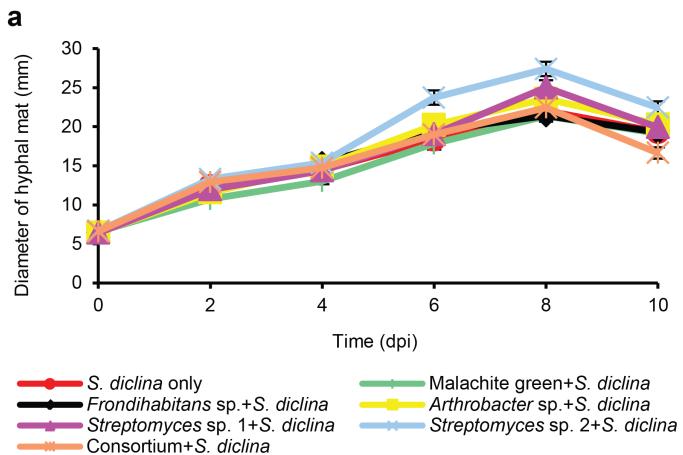

b

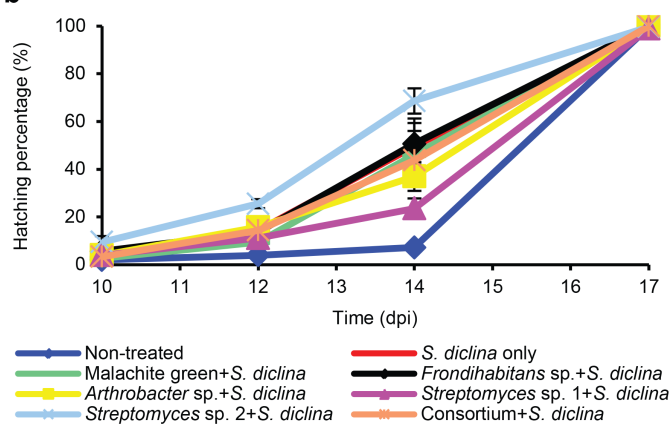

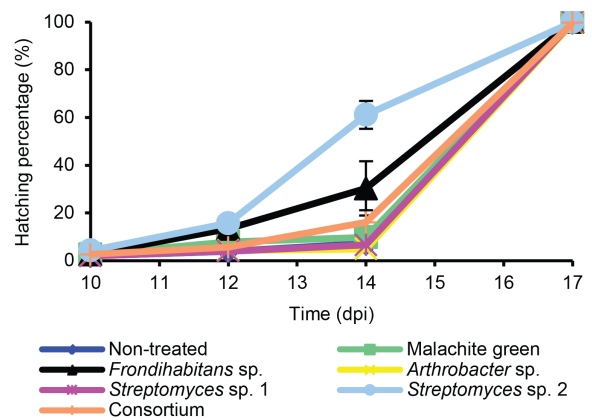

Figure S5 a, Saprolegnia hyphal expansion from infected salmon eggs in the in vivo bioassay. Area under hyphal expansion curve (AUHEC) was calculated and only the Streptomyces sp. 2 treatment was significantly different than the control, S. diclina only. $\mathbf{b}$ and $\mathbf{c}$, Hatching percentage of salmon eggs. In $\mathbf{b}$, eggs are non-treated, treated with only Saprolegnia, or with the combination of Saprolegnia and bacteria. None of the area under hatching percentage curves (AUHPCs) were statistically significant different compared to the control S. diclina alone. In c, eggs were non-treated or treated with bacteria. The AUHPC of Streptomyces sp. 2 treatment was significantly higher than the non-treated eggs. Statistical analyses were performed with Kruskal-Wallis one-way analysis of variance, $P<0.05$. The addition of $S$. diclina, bacterial suspensions or the combination of bacterial suspensions and $S$. diclina did not lead to stress-related hatching of salmon eggs in our experimental set-up, except for treatments with isolate Streptomyces sp. 2. The survival of eggs treated only with bacteria at $10 \mathrm{dpi}$ ranged between $99.7-100 \%$, indicating that the Actinobacteria tested did not adversely affect the salmon eggs. 


\section{Supplementary Tables}

Table S1 Details of the salmon egg samples of each incubator on the most recent formalin treatment, incubation temperature, and fertilization day before sampling.

\begin{tabular}{|c|c|c|c|c|c|c|}
\hline $\begin{array}{l}\text { Incubator } \\
\text { ID }\end{array}$ & $\begin{array}{l}\text { Health } \\
\text { status }\end{array}$ & $\begin{array}{l}\text { Days from } \\
\text { last formalin } \\
\text { treatment } \\
\text { prior to } \\
\text { sampling }\end{array}$ & $\begin{array}{c}\text { Average } \\
\text { incubation } \\
\text { temperature } \\
\text { per sample } \\
\left({ }^{\circ} \mathrm{C} \pm \text { standard }\right. \\
\text { deviation }) \\
\end{array}$ & $\begin{array}{c}\text { Average } \\
\text { incubation } \\
\text { temperature } \\
\left({ }^{\circ} \mathrm{C} \pm \text { standard }\right. \\
\text { deviation })\end{array}$ & $\begin{array}{l}\text { Days from } \\
\text { fertilization } \\
\text { (start of } \\
\text { incubation) } \\
\text { prior to } \\
\text { sampling } \\
\end{array}$ & $\begin{array}{l}\text { Average days } \\
\text { from fertilization } \\
\text { prior to sampling } \\
\text { (days } \pm \text { standard } \\
\text { deviation) }\end{array}$ \\
\hline 1 & \multirow{6}{*}{ Diseased } & 6 & $4.1 \pm 1.5$ & \multirow{6}{*}{$4.4 \pm 1.8$} & 103 & \multirow{6}{*}{$86 \pm 9$} \\
\hline 2 & & 6 & $3.6 \pm 0.7$ & & 87 & \\
\hline 3 & & 5 & $4.5 \pm 1.9$ & & 87 & \\
\hline 4 & & 13 & $4.8 \pm 2.0$ & & 80 & \\
\hline 5 & & 13 & $4.8 \pm 2.0$ & & 80 & \\
\hline 6 & & 12 & $4.8 \pm 2.0$ & & 80 & \\
\hline 7 & \multirow{6}{*}{ Healthy } & 6 & $3.5 \pm 0.7$ & \multirow{6}{*}{$3.5 \pm 0.7$} & 83 & \multirow{6}{*}{$84 \pm 2$} \\
\hline 8 & & 6 & $3.5 \pm 0.7$ & & 83 & \\
\hline 9 & & 6 & $3.5 \pm 0.7$ & & 83 & \\
\hline 10 & & 6 & $3.6 \pm 0.7$ & & 87 & \\
\hline 11 & & 6 & $3.5 \pm 0.7$ & & 83 & \\
\hline 12 & & 6 & $3.5 \pm 0.7$ & & 83 & \\
\hline
\end{tabular}

Table S2 Number and classification of fungal clones detected by clone library analysis. Sequences of at least 400 bp were analysed by BLASTn in the NCBI database. As identification criteria, hits should have at least $93 \%$ identity and a 400 bp alignment length.

\begin{tabular}{|c|c|c|c|c|}
\hline Kingdom & Phyla & Genera & Diseased & Healthy \\
\hline \multirow{13}{*}{ Fungi } & \multirow{6}{*}{ Ascomycota } & Microdochium/Monographella & 91 & 48 \\
\hline & & Clathrosphaerina & 2 & - \\
\hline & & Cadophora & 1 & - \\
\hline & & Geomyces & 1 & 1 \\
\hline & & Spirosphaera & - & 5 \\
\hline & & Saccharicola & - & 5 \\
\hline & \multirow[t]{2}{*}{ Zygomycota } & Mortierella & 14 & 4 \\
\hline & & Zygomycete genus & 1 & 9 \\
\hline & Chytridiomycota & Chytriomyces & 13 & - \\
\hline & \multirow{3}{*}{ Basidiomycota } & Heterobasidion & 1 & - \\
\hline & & Cryptococcus & - & 3 \\
\hline & & Deconica & - & 2 \\
\hline & Unknown fungi & - & - & 6 \\
\hline Animalia & Arthropoda & Eubosmina & - & 1 \\
\hline $\begin{array}{l}\text { Unknown } \\
\text { organisms }\end{array}$ & - & - & - & 1 \\
\hline & & Total & 124 & 85 \\
\hline
\end{tabular}


Table S3 Unique and shared number of operational taxonomic units (OTUs) in diseased and healthy salmon egg samples. PhyloChip analysis detected 31278 bacterial and 3 archaeal OTUs in diseased and healthy salmon egg samples.

\begin{tabular}{|c|c|c|c|c|}
\hline \multirow[t]{2}{*}{ Phyla } & \multirow[t]{2}{*}{ Families } & \multicolumn{3}{|c|}{ No. of OTUs } \\
\hline & & $\begin{array}{c}\text { Total } \\
\text { detected }\end{array}$ & $\begin{array}{c}\text { Diseased } \\
\text { only }\end{array}$ & $\begin{array}{c}\text { Healthy } \\
\text { only }\end{array}$ \\
\hline \multicolumn{5}{|l|}{ Unique } \\
\hline Actinobacteria & Glycomycetaceae & 1 & 1 & 0 \\
\hline Proteobacteria & Celerinatantimonadaceae & 1 & 1 & 0 \\
\hline Synergistetes & Thermovirgaceae & 1 & 1 & 0 \\
\hline Other phyla & unclassified & 3 & 3 & 0 \\
\hline \multirow[t]{5}{*}{ Actinobacteria } & Dermacoccaceae & 3 & 0 & 3 \\
\hline & Williamsiaceae & 2 & 0 & 2 \\
\hline & Actinospicaceae & 1 & 0 & 1 \\
\hline & Dermatophilaceae & 1 & 0 & 1 \\
\hline & Rarobacteraceae & 1 & 0 & 1 \\
\hline Cyanobacteria & Scytonemataceae & 2 & 0 & 2 \\
\hline Firmicutes & Thermodesulfobiaceae & 3 & 0 & 3 \\
\hline Other & Rs- 045 & 1 & 0 & 1 \\
\hline Others & unclassified & 21 & 0 & 21 \\
\hline \multicolumn{5}{|l|}{ Shared } \\
\hline \multirow{32}{*}{ Proteobacteria } & Enterobacteriaceae & 1711 & 1628 & 1438 \\
\hline & Comamonadaceae & 1464 & 1398 & 1445 \\
\hline & Pseudomonadaceae & 1207 & 1136 & 1185 \\
\hline & Burkholderiaceae & 472 & 437 & 468 \\
\hline & Rhodobacteraceae & 447 & 345 & 413 \\
\hline & Aquabacteriaceae & 408 & 390 & 399 \\
\hline & Sphingomonadaceae & 400 & 338 & 396 \\
\hline & Rhodospirillaceae & 320 & 268 & 316 \\
\hline & Rhizobiaceae & 320 & 260 & 317 \\
\hline & Xanthomonadaceae & 313 & 220 & 299 \\
\hline & Moraxellaceae & 255 & 178 & 248 \\
\hline & Bradyrhizobiaceae & 241 & 224 & 240 \\
\hline & Oxalobacteraceae & 236 & 222 & 235 \\
\hline & Chromatiaceae & 211 & 175 & 198 \\
\hline & Pelagibacteraceae & 208 & 139 & 193 \\
\hline & Phyllobacteriaceae & 203 & 158 & 197 \\
\hline & Vibrionaceae & 202 & 159 & 142 \\
\hline & Hyphomicrobiaceae & 197 & 155 & 192 \\
\hline & Alcaligenaceae & 195 & 183 & 185 \\
\hline & Neisseriaceae & 192 & 159 & 177 \\
\hline & Rhodocyclaceae & 191 & 157 & 181 \\
\hline & Acetobacteraceae & 165 & 119 & 157 \\
\hline & Pasteurellaceae & 159 & 140 & 151 \\
\hline & Halomonadaceae & 155 & 121 & 142 \\
\hline & Aeromonadaceae & 151 & 142 & 114 \\
\hline & Caulobacteraceae & 129 & 121 & 129 \\
\hline & Sinobacteraceae & 123 & 87 & 120 \\
\hline & Helicobacteraceae & 123 & 84 & 115 \\
\hline & Alteromonadaceae & 105 & 84 & 94 \\
\hline & Desulfobacteraceae & 101 & 70 & 94 \\
\hline & Others & 3275 & 2624 & 3050 \\
\hline & Subtotal & 13879 & 11921 & 13030 \\
\hline \multirow[t]{3}{*}{ Firmicutes } & Lachnospiraceae & 2188 & 1495 & 1855 \\
\hline & Ruminococcaceae & 1216 & 912 & 1010 \\
\hline & Bacillaceae & 804 & 522 & 713 \\
\hline
\end{tabular}




\begin{tabular}{|c|c|c|c|c|}
\hline & Streptococcaceae & 705 & 277 & 676 \\
\hline & Clostridiaceae & 508 & 465 & 391 \\
\hline & Staphylococcaceae & 367 & 192 & 341 \\
\hline & Veillonellaceae & 317 & 226 & 293 \\
\hline & Lactobacillaceae & 284 & 256 & 188 \\
\hline & Clostridiales Family XI. Incertae Sedis & 172 & 140 & 159 \\
\hline & Planococcaceae & 164 & 124 & 145 \\
\hline & Paenibacillaceae & 132 & 84 & 119 \\
\hline & Enterococcaceae & 110 & 76 & 92 \\
\hline & Others & 600 & 471 & 547 \\
\hline & Subtotal & 7567 & 5240 & 6529 \\
\hline \multirow[t]{9}{*}{ Bacteroidetes } & Flavobacteriaceae & 926 & 798 & 894 \\
\hline & Rikenellaceaell & 492 & 420 & 395 \\
\hline & Prevotellaceae & 397 & 155 & 390 \\
\hline & Chitinophagaceae & 173 & 157 & 164 \\
\hline & Flexibacteraceae & 104 & 89 & 102 \\
\hline & Sphingobacteriaceae & 104 & 93 & 100 \\
\hline & Porphyromonadaceae & 102 & 71 & 92 \\
\hline & Others & 416 & 325 & 381 \\
\hline & Subtotal & 2714 & 2108 & 2518 \\
\hline \multirow[t]{9}{*}{ Actinobacteria } & Corynebacteriaceae & 690 & 549 & 652 \\
\hline & Streptomycetaceae & 414 & 178 & 392 \\
\hline & Microbacteriaceae & 359 & 302 & 346 \\
\hline & Micrococcaceae & 336 & 270 & 332 \\
\hline & Mycobacteriaceae & 188 & 78 & 185 \\
\hline & Micromonosporaceae & 140 & 84 & 139 \\
\hline & Nocardiaceae & 121 & 41 & 119 \\
\hline & Others & 1355 & 892 & 1323 \\
\hline & Subtotal & 3603 & 2394 & 3488 \\
\hline \multirow[t]{4}{*}{ Acidobacteria } & Acidobacteriaceae & 266 & 202 & 264 \\
\hline & Solibacteraceae & 190 & 130 & 189 \\
\hline & Others & 214 & 161 & 208 \\
\hline & Subtotal & 670 & 493 & 661 \\
\hline \multirow[t]{3}{*}{ Verrucomicrobia } & Verrucomicrobiaceae & 223 & 166 & 195 \\
\hline & Others & 170 & 121 & 168 \\
\hline & Subtotal & 393 & 287 & 363 \\
\hline \multirow[t]{3}{*}{ Planctomycetes } & Planctomycetaceae & 163 & 110 & 159 \\
\hline & Others & 116 & 89 & 112 \\
\hline & Subtotal & 279 & 199 & 271 \\
\hline \multirow[t]{3}{*}{ Tenericutes } & Erysipelotrichaceae & 139 & 90 & 119 \\
\hline & Others & 179 & 148 & 153 \\
\hline & Subtotal & 318 & 238 & 272 \\
\hline \multirow[t]{3}{*}{ Chloroflexi } & Anaerolinaceae & 119 & 83 & 111 \\
\hline & Others & 163 & 109 & 159 \\
\hline & Subtotal & 282 & 192 & 270 \\
\hline \multirow[t]{3}{*}{ Spirochaetes } & Spirochaetaceae & 114 & 68 & 108 \\
\hline & Others & 61 & 53 & 52 \\
\hline & Subtotal & 175 & 121 & 160 \\
\hline Others & & 1360 & 1009 & 1295 \\
\hline Total & & 31281 & 24208 & 28892 \\
\hline
\end{tabular}


Table S4 Number of Actinobacterial isolates from each of the 12 salmon egg samples. To isolate Actinobacteria, incubation water of the salmon egg samples was spread plated on two semi-selective agar media, humic acid agar (HA) and starch agar (GA). On average 40 bacterial isolates were randomly picked from each culture medium of each sample. All the isolates were screened by an Actinobacterial specific primer pair. All isolates showing the expected amplification product for the Actinobacterial specific genes were sent for $16 \mathrm{~S}$ rRNA sequencing. Sequence identity was obtained by comparison to sequences deposited in the Greengenes database and Ribosomal Database Project (see supplementary materials and methods).

\begin{tabular}{cccc}
\hline Treatments & Sample ID & $\begin{array}{c}\text { No. of Actinobacterial isolates } \\
\text { HA }\end{array}$ & GA \\
\hline \multirow{5}{*}{ Diseased } & 1 & 3 & 9 \\
& 2 & 4 & 17 \\
& 3 & 17 & 26 \\
& 4 & 16 & 14 \\
Healthy & 5 & 12 & 18 \\
& 6 & 2 & 21 \\
\hline \multirow{5}{*}{} & 7 & 11 & 25 \\
& 8 & 12 & 20 \\
& 10 & 4 & 15 \\
& 11 & 15 & 26 \\
& 12 & 14 & 27 \\
& 10 & 8 & 18 \\
\hline
\end{tabular}

Table S5 Time line and experimental details of the in vivo bioassays with salmon eggs to assess the activity of four Actinobacterial isolates against Saprolegnia diclina.

\begin{tabular}{|c|c|c|}
\hline Day & dpi & Procedures \\
\hline-3 & & $\begin{array}{l}\text { Cultures of isolates Arthrobacter sp., Streptomyces sp. } 1 \text { and Streptomyces sp. } 2 \text { were } \\
\text { incubated at } 30^{\circ} \mathrm{C}\end{array}$ \\
\hline-1 & & Cultures of isolate Frondihabitans sp. were incubated at $30^{\circ} \mathrm{C}$ \\
\hline 0 & & Eggs arrived and were placed into incubation units \\
\hline 1 & & Incubation units inoculated with bacteria \\
\hline 2 & & Boiled eggs were placed on Saprolegnia hyphal culture and incubated at $25^{\circ} \mathrm{C}$ \\
\hline 3 & & Saprolegnia colonized eggs were transferred to $15^{\circ} \mathrm{C}$ \\
\hline 4 & 0 & $\begin{array}{l}\text { Eggs were plated on HA and GA media, Saprolegnia inocula were introduced into } \\
\text { incubation units, malachite green treatments, incubation units photographed }\end{array}$ \\
\hline 6 & 2 & Incubation units photographed \\
\hline 8 & 4 & Malachite green treatments, incubation units photographed \\
\hline 10 & 6 & Incubation units photographed \\
\hline 12 & 8 & Malachite green treatments, incubation units photographed \\
\hline 14 & 10 & $\begin{array}{l}\text { Incubation units photographed, determination of hyphal attachment percentage, eggs were } \\
\text { plated on } \mathrm{HA} \text { and GA media, hatching rate monitored }\end{array}$ \\
\hline 16 & 12 & Hatching rate monitored \\
\hline 18 & 14 & Hatching rate monitored \\
\hline 21 & 17 & Hatching rate monitored, bioassay terminated \\
\hline
\end{tabular}


Table S6 Composition of the well water (after iron removal) used in the in vivo bioassays at the research facility 'Carus' of the Department of Animal Sciences, Wageningen University.

\begin{tabular}{cc}
\hline Elements & Concentration \\
\hline $\mathrm{Cl}$ & $11.7 \mathrm{mg} / \mathrm{l}$ \\
$\mathrm{Al}$ & $0.02 \mathrm{mg} / \mathrm{l}$ \\
$\mathrm{Ca}$ & $28.4 \mathrm{mg} / \mathrm{l}$ \\
$\mathrm{Fe}$ & $0.02 \mathrm{mg} / \mathrm{l}$ \\
$\mathrm{K}$ & $0.5 \mathrm{mg} / \mathrm{l}$ \\
$\mathrm{Mg}$ & $1.97 \mathrm{mg} / \mathrm{l}$ \\
$\mathrm{Mn}$ & $0.010 \mathrm{mg} / \mathrm{l}$ \\
$\mathrm{Na}$ & $5.7 \mathrm{mg} / \mathrm{l}$ \\
$\mathrm{P}$ & $0.04 \mathrm{mg} / \mathrm{l}$ \\
$\mathrm{S}$ & $3.68 \mathrm{mg} / \mathrm{l}$ \\
$\mathrm{Zn}$ & $0.010 \mathrm{mg} / \mathrm{l}$ \\
$\mathrm{As}$ & $1.47 \mu \mathrm{gg} /$ \\
$\mathrm{Mo}$ & $0.36 \mu \mathrm{g} / \mathrm{l}$ \\
$\mathrm{Pb}$ & $0.07 \mu \mathrm{g} / \mathrm{l}$ \\
$\mathrm{Sn}$ & $0.5 \mu \mathrm{g} / \mathrm{l}$ \\
$\mathrm{Ti}$ & $0.08 \mu \mathrm{g} / \mathrm{l}$ \\
\hline
\end{tabular}

\section{Supplementary Movies}

Movie S1 Saprolegnia hyphal attachment was determined by lifting infection inocula with a pair of tweezers and counting the number of eggs attached to the hyphal patch.

Movie S2 Bacterial colonization of salmon egg surfaces was determined by rinsing the eggs with $1 \mathrm{ml}$ of sterile well water three consecutive times, draining briefly on sterile filter paper and rolling gently over the surface of semi-selective media. Colonies that were morphologically similar to the Actinobacterial isolates used for inoculation were subjected to $16 \mathrm{~S}$ rRNA sequencing.

Supplementary movies accompany this paper on The ISME Journal website (http://www.nature.com/ismej) 


\section{Chapter 3}

Phenotypic, genomic and metabolic characterization of aquatic Frondihabitans with activity against the oomycete fish pathogen Saprolegnia diclina

Yiying Liu, Desalegn Etalo, Victor de Jager, Víctor J. Carrión, Jos M. Raaijmakers and Irene de Bruijn 


\section{Abstract}

Among the aquatic oomycete pathogens, Saprolegnia species cause declines in populations of amphibians and fish. Understanding the diversity, dynamics and activities of microbiomes of aquatic ecosystems may provide alternative means to mitigate diseases caused by Saprolegnia and other emerging pathogens. Previously we studied the microbiome of salmon eggs and showed that Frondihabitans sp. $762 \mathrm{G} 35$ (Microbacteriaceae) significantly decreased attachment of Saprolegnia to salmon eggs (Liu et al., 2014). Here, phenotypic and phylogenetic analyses of twelve Frondihabitans isolates from healthy salmon eggs showed that they were closely related to known Frondihabitans and Frigoribacterium species and that they possessed lipase, protease, biofilm formation activities, and inhibited hyphal growth of Saprolegnia at low temperature $\left(5{ }^{\circ} \mathrm{C}\right)$. Subsequent analysis of the genome (3.4 Mb) of Frondihabitans sp. $762 \mathrm{G} 35$ and another publically available Frondihabitans genome sequence showed that only $57 \%$ of the genes were shared between the two genomes. In addition to a type III polyketide synthase gene cluster, two terpene biosynthesis gene clusters were identified, one of which was unique to aquatic Frondihabitans sp. 762G35. Subsequent liquid chromatography-mass spectrometry (LC-MS) of the extracellular cell-free culture supernatant of aquatic Frondihabitans sp. $762 \mathrm{G} 35$ identified accumulated furancarboxylic acid-derived metabolites which might be the potential active compounds involved in hyphal growth inhibition of Saprolegnia.

\section{Introduction}

Emerging fungal and oomycete diseases have detrimental effects on natural ecosystems and biodiversity as well as on food productivity in agriculture, horticulture and aquaculture (Fisher et al., 2012; Gozlan et al., 2014). For example, Fusarium solani and Fusarium falciforme cause high mortality of endangered sea turtle eggs (Fisher et al., 2012; Sarmiento-Ramírez et al., 2014) and Batrachochytrium dendrobatidis and Batrachochytrium salmandrivorans significantly reduce amphibian populations around the world (Woodhams et al., 2011; Martel et al., 2013). Among the oomycetes, Saprolegnia and Aphanomyces species cause a reduction in populations of amphibian, fish and crayfish in natural ecosystems and in aquaculture (van West, 2006; Fernández-Benéitez et al., 2008; Phillips et al., 2008; Krugner-Higby et al., 2010; Bruno et al., 2011; Fisher et al., 2012; van den Berg et al., 2013). Infections by Saprolegnia species cause Saprolegniosis, a wide spread aquatic disease characterized by white or grey cotton-like hyphal mats on the skin of amphibians, fish and fish eggs (van West, 2006). In aquaculture, Saprolegnia species frequently infect salmonids, like trout 
and salmon, during their freshwater life stage, but also non-salmonid fish including carp, catfish and perch (Bruno et al., 2011; Das et al., 2012). In Japan, Saprolegina infection induced annual mortality of at least $50 \%$ in Coho salmon (Hatai and Hoshiai, 1992; Hatai and Hoshiai, 1994; Bruno et al., 2011). In the USA, an economic loss of around $\$ 40$ million in channel catfish was caused by Saprolegnia infection, referred to as 'winter kill' (Bruno et al., 2011).

To control Saprolegniosis, formalin is widely applied in aquaculture but its use is expected to become restricted in the near future because of harmful effects on the environment (Bruno et al., 2011). Various efforts have been made to find effective and sustainable alternatives. For example, Pyceze ${ }^{\circledR}$ (bronopol), sea water flushes and $\mathrm{NaCl}$ applications are some of the recommended methods to suppress Saprolegniosis (Taylor and Bailey, 1979; Kitancharoen et al., 1997; Bruno et al., 2011). So far, none of these alternative strategies are as effective as the banned chemical malachite green (Bruno et al., 2011). A vaccine is not yet available for Saprolegniosis (van den Berg et al., 2013). Therefore, other sustainable remedies are needed to suppress Saprolegnia infections in aquaculture and natural ecosystems.

The use of protective microbes, such as Aeromonas and Pseudomonas, has been proposed as a promising measure to inhibit Saprolegniosis and other emerging diseases (Hatai and Willoughby, 1988; Bly et al., 1997; Hussein and Hatai, 2001; Lategan and Gibson, 2003; Lategan et al., 2004a, b; CarbajalGonzalez et al., 2011; Liu et al., 2014; Liu et al., 2015). In our previous work, 31,281 bacterial and archaeal operational taxonomic units (OTUs) were detected in Saprolegnia-infected (diseased) and non-infected (healthy) salmon egg samples from a commercial fish hatchery (Liu et al., 2014). The commensal Actinobacteria were significantly more enriched in healthy salmon egg samples and in particular Frondihabitans sp. $762 \mathrm{G} 35$ (Microbacteriaceae) effectively reduced hyphal attachment of Saprolegnia to live salmon eggs (Liu et al., 2014). Here we further characterized the commensal Frondihabitans strains isolated from healthy salmon eggs. Various phenotypic, genomic and metabolic traits of Frondihabitans sp. $762 \mathrm{G} 35$ were studied in detail.

\section{Materials and methods}

Isolation, identification and phylogeny of Frondihabitans isolates

Frondihabitans $\mathrm{sp}$. were isolated by plating the bacterial cell suspension retrieved from salmon eggs on humic acid-vitamin agar and starch-vitamin agar media and incubated at $30^{\circ} \mathrm{C}$. The isolates were selected at different time points within 6 weeks (Liu et al., 2014). Phylogenetic analyses of the $16 \mathrm{~S}$ rRNA sequences, including sequences of 12 Frondihabitans isolates from healthy salmon eggs and 204 strains including 35 type strains from Microbacteriaceae, were conducted with a similar method as 
described in Liu et al. (2015). The $16 \mathrm{~S}$ rRNA sequences ( $\geq 1200 \mathrm{bp}$ ) were downloaded from the Ribosomal Database Project (RDP) (Cole et al., 2014).

\section{Phenotypic characterization of Frondihabitans isolates}

The 12 Frondihabitans isolates obtained from healthy salmon eggs were grown, washed and resuspended in well water (Liu et al., 2014) to a final cell density of $1-3 \times 10^{9}$ cells $\mathrm{ml}^{-1}$. For each assay described below, 2-3 $\mu \mathrm{l}$ of bacterial suspension was inoculated and performed in triplicate, unless mentioned otherwise.

The lipase indicator medium (Sierra, 1957) consisted of tryptone soya broth (TSB, Oxoid Ltd., Hampshire, England) supplemented with 1.5-2\% agar (TSA; Merck KGaA, Darmstadt, Germany), 1\% Tween ${ }^{\circledast} 80$ (Merck Schuchardt OHG, Hohenbrunn, Germany) and $0.01 \% \mathrm{CaCl}_{2}$. The cell suspension of each Frondihabitans was spot-inoculated in the middle of the plate and the plates were incubated at 5 and $25^{\circ} \mathrm{C}$ up to four months with regular observation. The lipase activity was determined by observation of crystals around the inoculum.

The glucanase indicator medium consisted of TSA supplemented with $0.5 \%$ laminarin in a 24 -wells plate (Cellstar ${ }^{\circledR}$, Greiner bio-one, Frickenhausen, Germany) and the cell suspension of each Frondihabitans was spot-inoculated into each well. After incubation at 5 and $25{ }^{\circ} \mathrm{C}$ for about one month, the bacterial cells were removed by water and the medium was stained by congo red for 1-2 min and de-stained with water. The positive and negative glucanase activity was determined by observation of orange (reflecting degradation of laminarin) and red colour, respectively. This assay was conducted in duplicate per incubation temperature.

The protease indicator medium consisted of TSA supplemented with $1.5 \%$ skim milk powder and the cell suspension of each Frondihabitans was spot-inoculated at three different spots of the plate. After incubation at 5 and $25{ }^{\circ} \mathrm{C}$ for about 3-4 month, the protease activity was determined by observation of a clearing halo around the inoculum.

The chitinase indicator medium was prepared as follows: $10 \mathrm{ml}$ of TSA was poured in a petri dish and allowed solidification. $10 \mathrm{ml}$ of TSB supplemented with $0.2 \%(\mathrm{w} / \mathrm{v})$ colloidal chitin (Hsu and Lockwood, 1975; de Bruijn et al., 2015) and 1.2\% agar was poured on top of the solidified TSA. The cell suspension of each Frondihabitans isolate was spot-inoculated at three different places of the plate. After incubation at 5 and $25{ }^{\circ} \mathrm{C}$ for about 2-4 weeks, the chitinase activity was determined by observation of clearing halo around the bacterial inoculum.

The in vitro activity of the Frondihabitans isolates against Saprolegnia diclina, was tested on $1 / 5^{\text {th }}$ strength TSA, $1 / 5^{\text {th }}$ strength potato dextrose agar (Difco ${ }^{\mathrm{TM}}$, Becton, Dickinson and company, New Jersey, USA) and Pseudomonas minimal medium ( $2 \mathrm{gl}^{-1} \mathrm{glucose} 1 \mathrm{gl}^{-1} \mathrm{NH}_{4} \mathrm{H}_{2} \mathrm{PO}_{4} ; 0.2 \mathrm{gl}^{-1} \mathrm{KCl} ; 0.2 \mathrm{gl}^{-1}$ $\mathrm{MgSO}_{4} \cdot 7 \mathrm{H}_{2} \mathrm{O}$ ) dissolved in salmon egg water (50 salmon eggs were shaken in one litre of well water (Liu et al., 2014)) and $1 / 5^{\text {th }}$ strength malt extract broth (Difco ${ }^{\text {TM }}$, Becton, Dickinson and company, New Jersey, USA) supplemented with $1.6 \%$ agar (1/5MA). In addition, the activity of Frondihabitans sp. $762 \mathrm{G} 35$ was also tested on Pseudomonas agar $\mathrm{F}$ (Difco ${ }^{\mathrm{TM}}$, Becton, Dickinson and company, New Jersey, USA), TSA and salmon egg agar $(20,50$ or 100 homogenized salmon eggs per litre of well water and $1.5-2 \%$ agar). Each isolate was tested in duplicate or triplicate on each medium at 5 and 25 ${ }^{\circ} \mathrm{C}$. In the preliminary test on different media, each bacterial isolate was spot-inoculated at one spot of the petri dish and incubated for about one week at $25^{\circ} \mathrm{C}$ and four weeks at $5{ }^{\circ} \mathrm{C}$ prior to inoculation of a plug of $S$. diclina in the centre of each plate. For the tests on 1/5MA each bacterial isolate was spotinoculated at four different corners of the plate and incubated for about two week at $25{ }^{\circ} \mathrm{C}$ and four weeks at $5{ }^{\circ} \mathrm{C}$ prior to inoculation of $S$. diclina. Volatile activity was tested in two-compartment petri dishes (94x15, Greiner Bio-One Hungary Kft., Mosonmagyaròvàr, Hungary) with both compartments containing $1 / 5 \mathrm{MA}$ and each bacterial isolate was spot-inoculated at four spots in one compartment and incubated for about two weeks at $25{ }^{\circ} \mathrm{C}$ and four weeks at $5{ }^{\circ} \mathrm{C}$, respectively, prior to inoculation of a 
plug of $S$. diclina in the other compartment. Hyphal growth inhibition was monitored for all bacterial isolates during incubation for $4-7$ days at $25^{\circ} \mathrm{C}$ and $22-43$ days at $5{ }^{\circ} \mathrm{C}$.

The biofilm assay was conducted in 24-wells plates. $60 \mu \mathrm{l}$ of the aforementioned cell suspension of each isolate was added in $1140 \mu \mathrm{l}$ of TSB supplemented with $10 \%$ sucrose (TSBS) to reach the density of $1.5 \times 10^{8}$ cells $\mathrm{ml}^{-1}$. The standing cultures were incubated for 14 days at $5{ }^{\circ} \mathrm{C}$ and 56 days at $25{ }^{\circ} \mathrm{C}$. The biofilm formation activity was determined by observation of cell attachment on the side or at the bottom of solid surface.

The swimming and swarming media were prepared in TSB supplemented with $0.3 \%(\mathrm{w} / \mathrm{v})$ and $0.6 \%$ $(\mathrm{w} / \mathrm{v})$ of agar, respectively. In the centre of each plate, $5 \mu \mathrm{l}$ of the bacterial cell suspension of each isolate was spot-inoculated. After incubation at 5 and $25{ }^{\circ} \mathrm{C}$ for one to four weeks, the swimming and swarming activities were determined by observation of motile outgrowth from the inoculum point. This assay was conducted with one replicate per incubation temperature.

To test if the isolates grew at $37^{\circ} \mathrm{C}, 2 \mu \mathrm{l}$ of the bacterial cell suspension of each isolate was inoculated in $2 \mathrm{ml}$ fresh TSB and shaken for 11 days at $37^{\circ} \mathrm{C}$ at $200 \mathrm{rpm}$ before the cell density was measured by spectrophotometer at $600 \mathrm{~nm}$.

To test the growth of each isolate at $\mathrm{pH}$ ranges of 3-9, the International Streptomyces Project (ISP) medium 2 (Shirling and Gottlieb, 1966; Cardinale et al., 2011) was used. The medium contained $4 \mathrm{~g} \mathrm{I}^{-1}$ yeast extract, $10 \mathrm{~g} \mathrm{I}^{-1}$ malt extract, $4.4 \mathrm{~g} \mathrm{I}^{-1} \mathrm{D}(+)$-Glucose Monohydrate with the buffering system consisting of $0.05 \mathrm{M} \mathrm{NaH}_{2} \mathrm{PO}_{4} / \mathrm{Na}_{2} \mathrm{HPO}_{4}$. The $\mathrm{pH}$ values of ISP medium 2 were adjusted to $3,5,7$ and 9 by addition of $\mathrm{HCl}$ or $\mathrm{NaOH}$ and filter-sterilized through a $0.2 \mu \mathrm{m}$ filter $\left(\mathrm{Whatman}^{\mathrm{TM}}\right.$ ) before use. $2 \mu \mathrm{l}$ of each cell suspension was added into each well of 24 -wells plates containing $1 \mathrm{ml}$ of ISP medium 2 . The standing cultures were incubated for 4 weeks at $5{ }^{\circ} \mathrm{C}$ and $11-12$ days at $25{ }^{\circ} \mathrm{C}$ before the cell density was measured by spectrophotometer at $600 \mathrm{~nm}$.

\section{Growth curve and supernatant activity of Frondihabitans sp. 762G35}

To determine the growth and activity of Frondihabitans sp. 762G35, a pre-grown cell suspension was added to fresh $1 / 5 \mathrm{MB}$ with a final density of $10^{6}$ cells $\mathrm{ml}^{-1}$. The cultures were incubated at $300 \mathrm{rpm}$ at 5 ${ }^{\circ} \mathrm{C}$ and the cell density was determined at different time points by spectrophotometer at $600 \mathrm{~nm}$. The cultures of day $7,14,21$ and 27 were filter-sterilized through $0.2 \mu \mathrm{m}$ filters (Whatman ${ }^{\mathrm{TM}}$ ), lyophilized, redissolved in $1 / 5 \mathrm{MB}$ to 2.5 times concentrated level than the original culture and filter-sterilized again. Subsequently, 300-600 $\mu \mathrm{l}$ of this solution was added to a well of 24-wells or 48-wells plates (Cellstar ${ }^{\circledR}$, Greiner Bio-One $\mathrm{GmbH}$, Frickenhausen, Germany). One S. diclina 1152F4 hyphal plug of about $2 \mathrm{~mm}^{2}$ pregrown on $1 / 5 \mathrm{MB}$ with $1.5-2 \%$ agar was added into each well and the culture was incubated at $5{ }^{\circ} \mathrm{C}$. The effect on hyphal growth of $S$. diclina was monitored after 7-18 days and the diameter of hyphae was measured. Statistical significant differences were determined by independent-samples $t$-test $(P<0.05)$.

\section{Genomic DNA isolation and genome sequencing}

A single colony of a pregrown culture of Frondihabitans sp. 762G35 was inoculated in TSBS and the culture was incubated at $200 \mathrm{rpm}$ for 2 days at $25^{\circ} \mathrm{C}$. $2 \mathrm{ml}$ of the culture was centrifuged at $18400 \times \mathrm{g}$ for $2 \mathrm{~min}$ at room temperature and the cells were washed three times with sterile Milli-Q water. Subsequently, the genomic DNA was extracted by resuspending the cells in $660 \mu$ l solution of TrisEDTA buffer and lysozyme (10mM Tris, $10 \mathrm{mM}$ EDTA, $1.82 \mathrm{mg} \mathrm{ml}^{-1}$ ), and incubation for $30 \mathrm{~min}$ by shaking at $300 \mathrm{rpm}$ at $37^{\circ} \mathrm{C}$. SDS and proteinase $\mathrm{K}$ were added to the final concentration of $1.2 \%$ and $0.1 \mathrm{mg} \mathrm{ml}^{-1}$, respectively, mixed the contents by flipping the tube, and incubation for $15 \mathrm{~min}$ at $65^{\circ} \mathrm{C}$ at $300-450 \mathrm{rpm}$. Proteins were precipitated by adding $\mathrm{NaCl}$ to a final concentration of $0.7 \mathrm{M}$, mixing by flipping the tube, and $\mathrm{CTAB} / \mathrm{NaCl}$ to a final concentration of $1 \% \mathrm{CTAB}(\mathrm{w} / \mathrm{v})$ and $0.7 \mathrm{M} \mathrm{NaCl}$ and mixing by flipping the tube and incubation for $10 \mathrm{~min}$ at $65{ }^{\circ} \mathrm{C}$ at $300 \mathrm{rpm}$. The contaminating RNA was 
removed by adding DNase free RNase (dissolved in $10 \mathrm{mM}$ Tris ( $\mathrm{pH} \mathrm{7.6)} \mathrm{and} 15 \mathrm{mM} \mathrm{NaCl}$ ) to the final concentration of $0.1 \mathrm{mg} \mathrm{ml}^{-1}$. 90\% volume of chloroform:isoamylalcohol $(96: 4, \mathrm{v} / \mathrm{v})$ was added and mixed by flipping the tube for at least $15 \mathrm{sec}$, and the tubes were centrifuged at $18400 \times g$ for $10 \mathrm{~min}$ at room temperature. The aqueous layer was transferred to a new tube and the DNA was precipitated with an equal volume of isopropanol and mixed by inverting several times, and subsequent centrifugation at $18400 \times g$ for $15 \mathrm{~min}$ at $4{ }^{\circ} \mathrm{C}$. The supernatant was removed, $1 \mathrm{ml}$ ice cold $70 \%$ ethanol was added and the samples were centrifuged at $18400 \times g$ for $10 \mathrm{~min}$ at room temperature. The ethanol was removed and the DNA pellet was air dried and dissolved DNA in sterile Milli-Q water by incubation overnight at 4 ${ }^{\circ} \mathrm{C}$. Subsequently, the DNA solution was stored at $-20{ }^{\circ} \mathrm{C}$. The genomic DNA of Frondihabitans $\mathrm{sp}$. $762 \mathrm{G} 35$ was sequenced by the Pacific Biosciences RS II sequencing technology (Pacific Biosciences). A 10-kb insert library was prepared and sequenced using P4-C2 chemistry for 3 single-molecule realtime (SMRT) cells. Sequences were filtered using SMRT Analysis server v2.3.0.140936 using default settings. The RS_HGAP Assembly.2 (HGAP2) protocol (Chin et al., 2013) was used to assemble the filtered reads resulting in a single contig. The resulting assembly was subjected to read remapping using the RS_Resequencing. 1 module for sequence polishing up to $99.9999 \%$ consensus concordance with a mean coverage of 142.48 . The final assembly was circularized by overlapping the terminal repeats and rearranged to start at the $d n a A$ gene in the forward direction as proxy for the origin of replication (ORI) resulting in a chromosome of $3409251 \mathrm{nt}$ and $\mathrm{G}+\mathrm{C}$ content of $70.43 \%$. There was no evidence for plasmids in the sequence data.

\section{Whole genome phylogeny and bioinformatics analyses of Frondihabitans sp. $762 G 35$}

Annotation was performed with a modified version of Prokka (Seemann, 2014). A total of 3278 genes, 3212 CDSs, 50 tRNAs, 6 rRNAs and 1 tmRNA were annotated. No clustered interspaced short palindromic repeats (CRISPR) arrays were found. The annotation was manually curated and enriched by adding $X$ prophages predicted by PHAST (Zhou et al., 2011). COG annotations for the predicted proteins were determined using KOGnitor (http://www.ncbi.nlm.nih.gov/COG/grace/kognitor.html) (Snel et al., 2002). Pan-core genome analyses were performed by clustering together the protein coding genes from Frondihabitans sp. Leaf304, Frigoribacterium sp. Leaf415 and Frondihabitans sp. 762G35, with the protein coding genes of Clavibacter michiganensis subsp. sepedonicus ATCC33113 as an outgroup, using cd-hit (Huang et al., 2010) with word length 3 (-n 3), global identity (-G 1 and a minimal alignment coverage of $60 \%$ for the shortest protein (-aS 0.6). Cd-hit clusters were parsed into a presence-absence matrix from which the pan, core and variable genomes were parsed using custom scripts.

Analyses of genes and/or gene clusters encoding antibiotics and secondary metabolites were conducted in antiSMASH 3.0 (Weber et al., 2015).

For whole genome phylogeny, only those reference genomes of Microbacteriaceae with complete and/or scaffold level sequences from all the type strains, all Microbacterium strains characterized to species level and all strains from aquatic environments were downloaded from GenBank. Per genus, at least one strain was included. This resulted in a total of 24 genome sequences. Whole genome comparisons were conducted in Gegenees (Agren et al., 2012). In this program, the genome sequences are fragmented in $200 \mathrm{bp}$ fragments using overlap size of $100 \mathrm{bp}$, and all-against-all BLASTn comparison with a $20 \%$ cutoff threshold for non-conserved material is conducted. From the generated matrix a phylogenetic tree was made and visualised with Splitstree. Phylogenetic analyses of the housekeeping gene RpoB (DNA-directed RNA polymerase subunit beta) protein sequences including the sequence of Frondihabitans sp. 762G35 (genelD: FR762G35v2_01370) and the 24 Microbacteriaceae strains were conducted with a similar method as described in Liu et al. (2014). A maximum likelihood consensus tree was generated with the Whelan And Goldman model (Whelan and Goldman, 2001). The RpoB protein sequences of 24 Microbacteriaceae strains were approximately 1160 aa and downloaded from GenBank (Benson et al., 2013). 
Microbacteriaceae or Actinobacteria genes encoding protease, lipase or genes involved in biofilm formation were downloaded from GenBank and similar protein sequences in Frondihabitans sp. 762G35 were identified by BLASTp (e-value $<10^{-5}$ ). Next to the blast searches, the gene descriptions of Frondihabitans sp. $762 \mathrm{G} 35$ were searched for the terms 'protease', 'lipase' and 'biofilm'. The presence or absence of the identified genes in the Frondihabitans sp. Leaf304 and Frigoribacterium sp. Leaf415 genome sequences was also determined.

\section{HPLC fractionation and activity of fractions}

Frondihabitans sp. $762 \mathrm{G} 35$ was pregrown in $1 / 5 \mathrm{MB}$ for 21 days at $5^{\circ} \mathrm{C}$ at 250 or $300 \mathrm{rpm}$. The culture

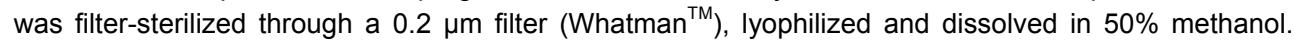
High Performance Liquid Chromatography (HPLC) analysis was performed by injection of $50 \mu \mathrm{l}$ sample on a HPLC (Thermo scientific, Dionex UltiMate 3000 including pump, autosampler, detector, RF2000 Fluorescence detector and automated fraction collector) equipped with a C18 reversed-phase column $\left(150 \times 4.6 \mathrm{~mm}, 3 \mu \mathrm{m}\right.$, Alltima $\left.{ }^{\mathrm{TM}}\right)$. Samples were analysed at a flow rate of $0.5 \mathrm{ml} / \mathrm{min}$ in a gradient running from $5-100 \%$ acetonitrile acidified with $0.1 \%(\mathrm{v} / \mathrm{v})$ trifluoroacetic acid in $45 \mathrm{~min}$. The HPLC fractions were collected every $5 \mathrm{~min}$ and subsequently 9 fractions were collected. Each fraction was airdried, lyophilized, dissolved in $50 \%$ methanol and added to fresh $1 / 5^{\text {th }}$ strength malt extract broth at 2.5 times concentrated level than the original culture. The activity of the extracts was tested by adding $300-$ $500 \mu \mathrm{l}$ of the concentrated extract to 48-wells plates. One S. diclina $1152 \mathrm{~F} 4$ hyphal plug of about $2 \mathrm{~mm}^{2}$ was added into each well and the culture was incubated at $5{ }^{\circ} \mathrm{C}$. The effect of HPLC fractions on hyphal growth of $S$. diclina was determined after 7-18 days.

\section{Metabolite extraction and liquid chromatography mass spectrometry (LC-MS) analyses}

24 cultures of $5 \mathrm{ml} 1 / 5 \mathrm{MB}$ were inoculated with $10^{6}$ cells $\mathrm{ml}^{-1}$ Frondihabitans sp. $762 \mathrm{G} 35$ and incubated at $5{ }^{\circ} \mathrm{C}$ at 250-300 rpm in each of the two different shakers. Six cultures of each shaker were collected on day $7,14,21$ and 27 , filter-sterilized, lyophilized and stored at $-20^{\circ} \mathrm{C}$. The lyophilized compounds of each tube was dissolved in $1 \mathrm{ml}$ of $50 \%$ methanol spiked with $0.1 \%$ formic acid, sonicated for $10 \mathrm{~min}$ at room temperature and centrifuged for $10 \mathrm{~min}$ at $21,000 \times \mathrm{g}$ at $15^{\circ} \mathrm{C}$. After centrifugation, the supernatant of each sample was transferred to a new tube. Samples from both shakers were pooled, dried by nitrogen air, redissolved in $1 \mathrm{ml}$ of $50 \%$ methanol spiked with $0.1 \%$ formic acid and filtered thought a Minisart SRP 4 syringe filter (PTFE-membrane, PP-housing, $0.45 \mu \mathrm{m}$ membrane, Sartorius Stedim Biotech $\mathrm{GmbH}$, Goettingen, Germany). In total six replicates per time point were considered for LC-MS analysis.

The LC-PDA-LTQ-Orbitrap-FTMS instrument consisted of an Accela HPLC system (Accela photodiode array (PDA) and autosampler), interfaced to an LTQ/Orbitrap hybrid mass spectrometer (Thermo Fisher Scientific) that was equipped with an ESI source (van der Hooft et al., 2011). A HS F5 analytical column (Sigma-Aldrich) was used for chromatographic separation. The mobile phase consisted of a binary eluent solvent system of degassed ultra-pure water (solvent $A$ ) and acetonitrile (solvent B), both containing $0.1 \% \mathrm{v} / \mathrm{v}$ formic acid. The sample injection volume was $5 \mu$ l, while keeping the column temperature at $40{ }^{\circ} \mathrm{C}$. The HPLC gradient was kept at $0 \%$ acetonitrile and linearly increased to $35 \%$ acetonitrile in $25 \mathrm{~min}$ with flow rate of the eluents at $0.1 \mathrm{ml} / \mathrm{min}$. The column was re-equilibrated for $18 \mathrm{~min}$ following the separation of each sample. The mass chromatograms that were generated by the Orbitrap-FTMS were processed (peak picking and baseline correction) using the MetAlign software package (Lommen, 2009). Extraction and reconstitution of compound mass spectra were performed according to the method described by (Tikunov et al., 2012). 1/5MB cultures without Frondihabitans inoculation were included as a control for determining the background. 
Nucleotide sequence accession numbers

All sequences of the Frondihabitans sp. isolates have been deposited in GenBank. The accession numbers for the $16 \mathrm{~S}$ rRNA sequences of isolates 762G35, 762H6, 734G14, 734G19, 734G114, 746H33, 746G4, 746G130, 746G131, 749G138, 749G139 and 762G34 are: KF741274, KT803428, KT803404, KT803158, КT803370, КT803275, КT803218, КT803179, КT803180, KT803170, КT803171 and KT803366, respectively. The accession number of the genome sequence of Frondihabitans sp. $762 \mathrm{G} 35$ is CP014619.

\section{Results and Discussion}

Identification and phylogeny of Frondihabitans isolates

From healthy salmon egg samples, we isolated several Actinobacterial genera of which 12 isolates were identified as Frondihabitans sp. based on 16S rRNA gene sequencing and phylogenetic analysis (Figure 1A). We previously showed that one of these aquatic isolates, designated Frondihabitans sp. 762G35, significantly reduced attachment of Saprolegnia diclina to salmon eggs (Liu et al., 2014). Nine of the twelve Frondihabitans isolates clustered phylogenetically with Frondihabitans australicus E1HC-02 and three to Frondihabitans peucedani RS-15 (Figure 1A). Frondihabitans (formerly named Frondicola) was originally isolated from leaf litter from a pine forest in Australia and belongs to the family Microbacteriaceae (Zhang et al., 2007; Greene et al., 2009). Subsequently it was also isolated from the rhizosphere of Peucedanum japonicum in Korea (Lee, 2010), from lichens in the Austrian Alps, Antarctic and Arctic areas (Cardinale et al., 2011; Lee et al., 2014; Vasileva-Tonkova et al., 2014), from sap of Acer mono in Korea (Kim et al., 2014), and from acid mine-impacted soil in Germany (Mayanna et al., 2015). Among relatives from the Microbacteriaceae family, Microbacterium has been reported to be associated with cod, yellowtail and bleak, and enhancing survival of cod larvae (Reid et al., 2009; Fjellheim et al., 2010; Ozaktas et al., 2012; Aguilera et al., 2013; Skjermo et al., 2015). To date, however, little is known about the ecology, genomics and metabolomics of Frondihabitans and their function(s) in aquatic ecosystems.

\section{Phenotypic characterization of Frondihabitans isolates}

For all 12 Frondihabitans isolates a range of in vitro assays were conducted to identify different phenotypic traits and to evaluate the effect of temperature on their activity. None of the 12 Frondihabitans isolates grew at $37^{\circ} \mathrm{C}$ (Table 1). All isolates grew at pH5 and $\mathrm{pH} 7$ at both $5{ }^{\circ} \mathrm{C}$ and $25^{\circ} \mathrm{C}$, whereas none of the isolates grew at $\mathrm{pH} 3$ and $\mathrm{pH} 9$ (Table 1). None of the isolates showed swimming or swarming activities under the growth conditions tested (Table 1), which is consistent with 
A

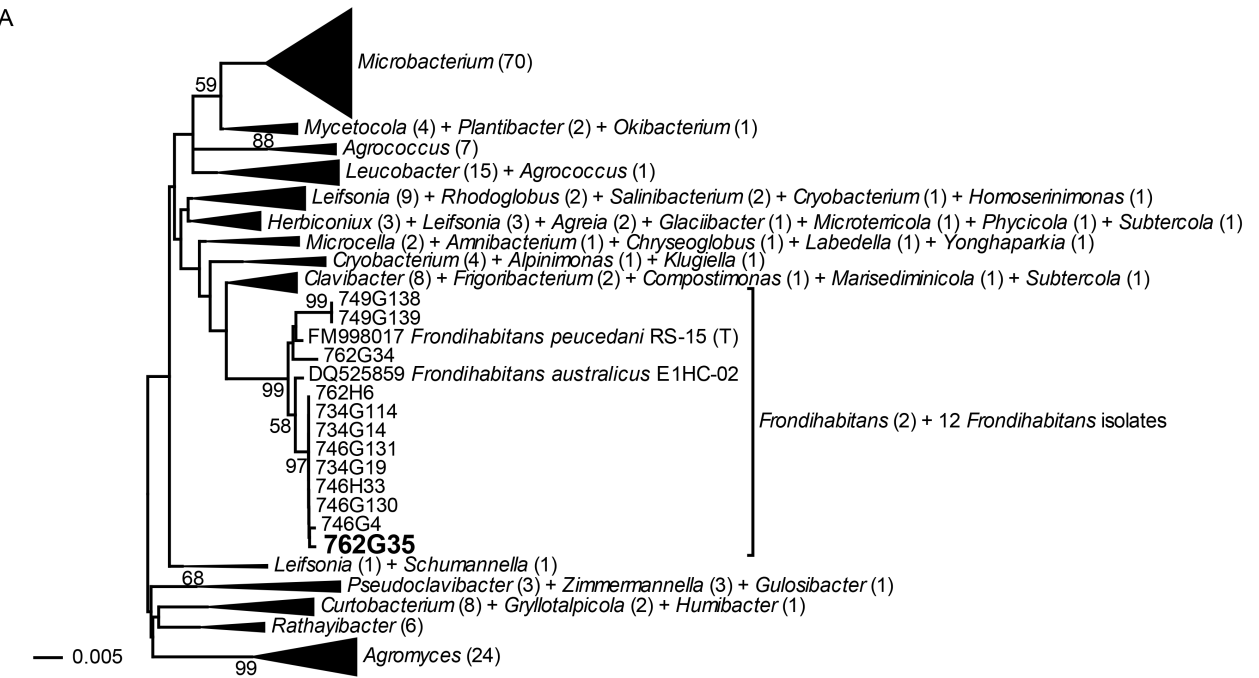

B

Frondihabitans sp. 762G35 (rpoB gene ID: FR762G35v2_01370)

93 - WP 055964899 Frondihabitans sp. Leaf 304

$100-$ KQT40048 Frigoribacterium sp. Leaf415

52 EYT66133 Curtobacterium flaccumfaciens UCD-AKU

CCE76521 Clavibacter michiganensis subsp. nebraskensis NCPPB 2581 (T)

100 CAQ00390 Clavibacter michiganensis subsp. sepedonicus ATCC 33113 (T)

64 100 WP 027692597 Rathayibacter toxicus DSM 7488 (T)

WP 055896823 Yonghaparkia sp. Root 332

98-WP 056653087 Agromyces sp. Root81

- WP 047405333 Herbiconiux sp. YR403

81 76 WP 018191996 Cryocola sp. 340MFSha3.1

[ AGW40609 Leifsonia xyli subsp. cynodontis

100 ERK71484 Leifsonia aquatica ATCC 14665 (T)

KQM15896 Plantibacter sp. Leaf1

95- KOS11972 Microbacterium chocolatum SIT 101
- BAJ73939 Microbacterium testaceum StLB037

- WP 029145630 Microbacterium luticocti DSM 19459 (T)

- WP 029150150 Microbacterium indicum DSM 19969 (T)

100 W 029153033 Microbacterium gubbeenense DSM 15944

1WP 010156380 Leucobacter chromiiresistens JG 31 (T)

WP 026372574 Agrococcus lahaulensis DSM 17612 (T)

WP 028245917 Psecus lahaulensis DSM 17612 (T)

WP_028245917 Pseudoclavibacter soli DSM 23366 (T)

100 W WP_026937638 Gulosibacter molinativorax DSM 13485 (T)

$-0.05$ AIC4̄8043 Rhodoluna lacicola MWH-Ta8 (T)

C

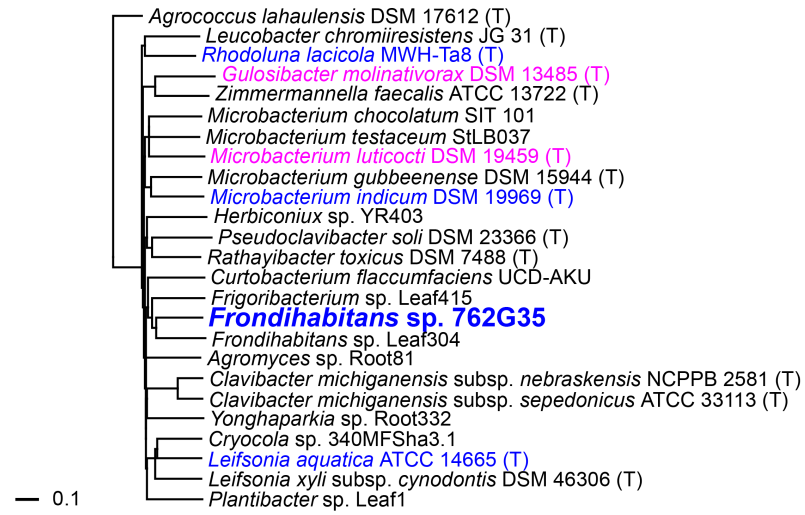

Figure 1 Phylogenetic trees of Frondihabitans and Microbacteriaceae isolates and reference strains. (A) Phylogenetic tree of $16 \mathrm{~S}$ rRNA sequences of 12 Frondihabitans isolates from healthy salmon eggs and 204 Microbacteriaceae sequences including 35 type strains. The $16 \mathrm{~S}$ rRNA sequences ( $\geq 1200 \mathrm{bp})$ of the reference strains were downloaded from the Ribosomal Database Project (RDP) (Cole et al., 2014). Each genus name is followed by the number of strains included in the same collapsed branch. Only the 
Frondihabitans subtree is expanded and displayed. Strain names of the two reference strains of Frondihabitans are preceded by the accession numbers. (B) Phylogenetic tree of RpoB protein sequences of aquatic Frondihabitans sp. 762G35 and 24 Microbacteriaceae strains. The sequences of strains approximately 1160 aa were downloaded from GenBank; the strain names are preceded by the accession numbers. (C) Phylogenetic tree based on whole genome sequences of Frondihabitans sp. $762 \mathrm{G} 35$ and other Microbacteriaceae strains. Only those reference genomes of Microbacteriaceae with complete and/or scaffold level sequences from type strains, Microbacterium strains characterized to species level and all strains from aquatic environments were downloaded from GenBank. Per genus, at least one strain was included. This resulted in a total of 24 strains. Whole genome comparisons were performed by Gegenees (Ågren et al., 2012) with fragmented alignment in BLASTn mode with settings $200 \mathrm{bp}$ fragments, $100 \mathrm{bp}$ overlap and a $20 \%$ cutoff threshold for non-conserved material. Black, blue and pink colours indicate strains isolated from terrestrial/plant, aquatic, or both sources of isolation, respectively. The scale bars in (A), (B) and (C) indicate an evolutionary distance of $0.005,0.05$ or 0.1 nucleotide substitution per sequence position, respectively. The bootstrap values indicated at the nodes in $(A)$ and $(B)$ are based on 1000 bootstrap replicates and branch values lower than $50 \%$ were hidden.

previous results for $F$. australicus, $F$. peucedani and Frondihabitans cladoniiphilus (Zhang et al., 2007; Greene et al., 2009; Lee, 2010; Cardinale et al., 2011). In contrast, Frondihabitans sucicola, isolated from sap of Acer mono, was reported to be motile (Kim et al., 2014).

We previously showed that Frondihabitans sp. $762 \mathrm{G} 35$ did not have in vitro activity against $S$. diclina in dual culture assays on $1 / 5^{\text {th }}$ strength potato dextrose agar at $25^{\circ} \mathrm{C}$ (Liu et al., 2014). Here, results showed that this isolate and almost all other Frondihabitans isolates could inhibit hyphal growth of $S$. diclina when grown on $1 / 5^{\text {th }}$ strength malt agar (1/5MA) but only when incubated at $5{ }^{\circ} \mathrm{C}$ and not at 25 ${ }^{\circ} \mathrm{C}$ (Table 1). For most isolates, this activity was not due to the production of volatile compounds, as only one isolate was active against $S$. diclina at $5{ }^{\circ} \mathrm{C}$ in a split-plate assay where Frondihabitans was physically separated from $\mathrm{S}$. diclina (Table 1).

To further elucidate this inhibitory activity, we tested the isolates for specific extracellular enzyme activities. None of the Frondihabitans isolates showed chitinase activity at the two temperatures tested (Table 1). However, most of the Frondihabitans isolates showed extracellular protease activity at both 5 and $25^{\circ} \mathrm{C}$, and glucanase activity at $25^{\circ} \mathrm{C}$. Lipase activity of the Frondihabitans isolates was mostly observed at $5{ }^{\circ} \mathrm{C}$ (Table 1). Extracellular lipase of Frondihabitans isolated from Arctic and Antarctic lichens, was produced at $10-20{ }^{\circ} \mathrm{C}$ and $20{ }^{\circ} \mathrm{C}$, respectively, but not at $4{ }^{\circ} \mathrm{C}$; the extracellular protease of one Arctic Frondihabitans isolate was produced at $10-20{ }^{\circ} \mathrm{C}$ (Lee et al., 2014). Enzymes active at cold and temperate conditions are potentially of great interests for industrial, medicinal, and biotechnological applications. Bacterial-derived lipases and proteases, such as proteases of Bacillus, Pyrococcus, Staphylothermus, Thermococcus and Thermotoga, have optimal temperatures ranging from $45-100{ }^{\circ} \mathrm{C}$ and are used as detergents in the food industry and leather production (Haki and Rakshit, 2003). 
Table 1 Phenotypic characterization of twelve aquatic Frondihabitans isolates obtained from healthy salmon eggs. Isolate $762 \mathrm{G} 35$ that reduced hyphal attachment of Saprolegnia diclina to salmon eggs (Liu et al. 2014) and from which the genome was sequenced. A range of in vitro assays were conducted and the effect of the temperature on the activity was evaluated. The images show examples of positive $(+)$ or negative (-) activity.

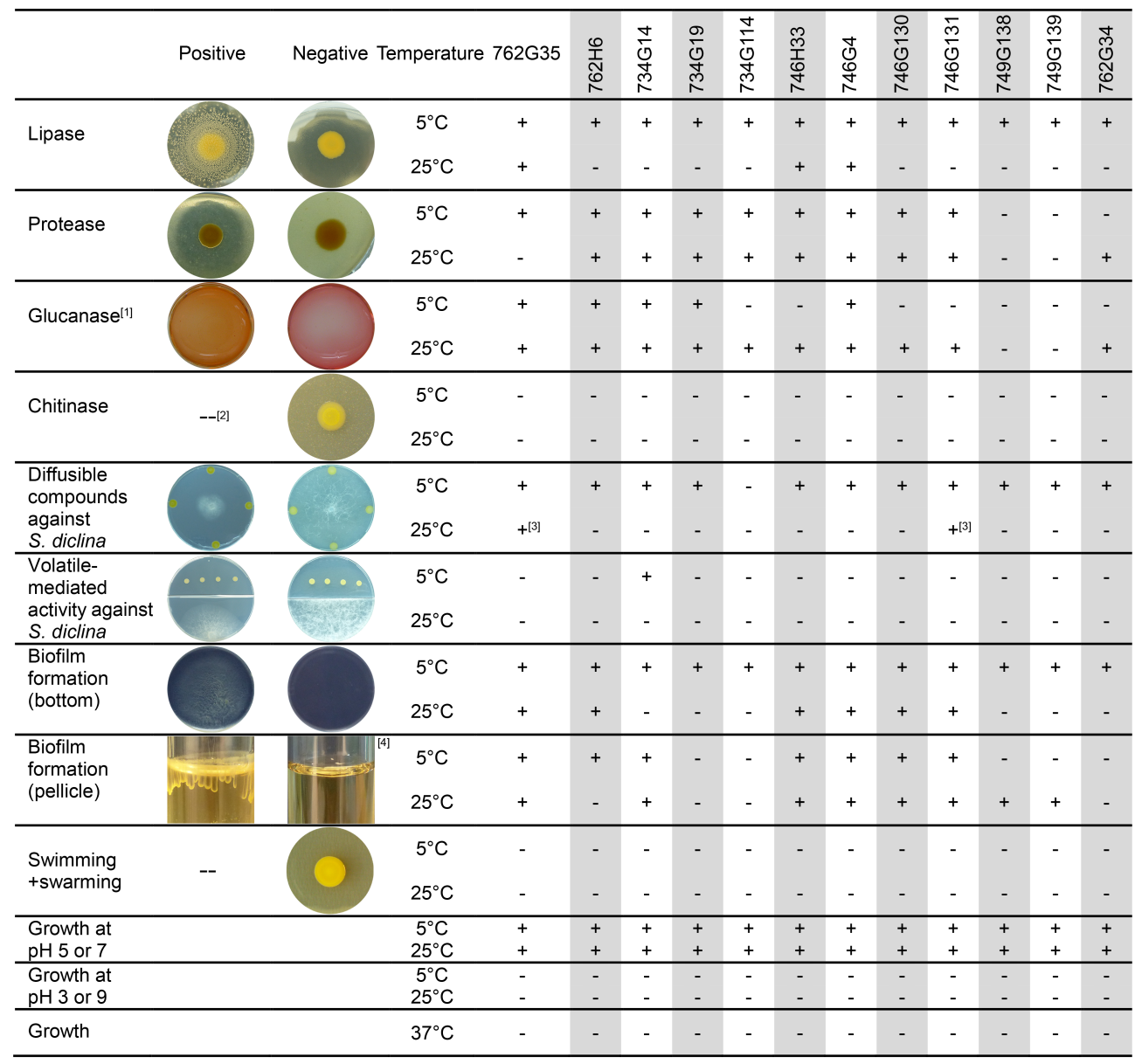

[1] When the colour of the medium was in-between orange and red after destaining, a negative glucanase activity was recorded.

[2] '--' no picture available.

${ }^{[3]}$ For the two Frondihabitans isolates $762 \mathrm{G} 35$ and $746 \mathrm{G} 131$ that inhibited hyphal growth of $\mathrm{S}$. diclina by diffusible compounds at $25^{\circ} \mathrm{C}$, the inhibition was not consistent between replicates.

${ }^{[4]}$ The images were taken from experiments conducted in a glass tube $(\varnothing 15 \mathrm{~mm})$. The left image shows biofilm formation containing $2 \mathrm{ml}$ tryptone soya medium and inoculated with Frondihabitans sp. 762G35 to an initial cell density of $10^{7}$ cells $\mathrm{ml}^{-1}$, incubated for 6 weeks at 5 and $25^{\circ} \mathrm{C}$. The right image shows the negative control, i.e. the same medium incubated for 6 weeks but not inoculated.

Microbial lipases from marine bacteria can be used to disrupt biofilm of pathogenic bacteria and remove corn oil from fabrics (Nerurkar et al., 2013; Seghal Kiran et al., 
2014). This indicates that the lipases and proteases produced by our aquatic Frondihabitans isolates may have potential for application at low temperature, as was suggested for marine bacteria (Kennedy et al., 2011).

In our previous work we postulated that one of the mechanisms by which Frondihabitans sp. $762 \mathrm{G} 35$ could suppress $S$. diclina disease may be via competitive niche exclusion (Liu et al., 2014). One potential mechanism contributing to competitive exclusion is the formation of biofilms. There are reports showing that bacterial biofilms can clean up organic wastes in water, protect the fish host against invasion by pathogenic species, improve attachment and aggregation of other community members, prevent desiccation and facilitate nutrient uptake (Burmølle et al., 2006; Ortega-Morales et al., 2007; lijima et al., 2009; Flemming and Wingender, 2010; Wesseling, 2015). The majority of the twelve aquatic Frondihabitans isolates that we characterized formed a biofilm at 5 ${ }^{\circ} \mathrm{C}$ at the bottom of the microtiter plate well wheras at the air-water interphase, biofilm (pellicle) formation varied between isolates and temperatures (Table 1). Biofilm-forming Microbacterium species were found in various environments, including drinking and recirculating waters, marine algae and seagrass, and diatom-associated biofilm in rivers (Makk et al., 2003; Burmølle et al., 2006; Ortega-Morales et al., 2007; Silbaq, 2009; Liu et al., 2011). Whether our aquatic Frondihabitans isolates also form biofilms on the salmon egg surface, thereby protecting against Saprolegnia invasion, remains to be investigated.

\section{Genome sequencing and bioinformatics analyses}

Since Frondihabitans sp. 762G35 significantly suppressed hyphal attachment of $S$. diclina to salmon eggs (Liu et al., 2014) and represents the largest phylogenetic group among the 12 Frondihabitans isolates (Figure $1 \mathrm{~A}$ ), we selected this isolate for genome sequencing. By PacBio sequencing and subsequent assembly we obtained a closed genome sequence of $3.4 \mathrm{Mb}$ with a GC content of $70 \%$ and 3212 coding DNA sequences (CDSs) (Table 2). The three largest groups of CDSs belonged to carbohydrate transport and metabolism (9.5\%), amino acid transport and metabolism (8.2\%), and transcription (8.3\%) (Figure 2).

Based on the housekeeping protein RpoB (Figure 1B) and whole genome (Figure 1C) phylogeny, Frondihabitans sp. $762 \mathrm{G} 35$ clustered closely with Frondihabitans sp. Leaf304, an isolate from the leaf of Arabidopsis thaliana (Bai et al., 2015), and Frigoribacterium, a bacterium isolated from diverse environments including air (Kämpfer et al., 2000; Murayama et al., 2010), soil (Dastager et al., 2008), plants (Nejad et al., 2006; Rijavec et al., 2007; Shen and Fulthorpe, 2015; Wang et al., 2015), animals (Rudolf et al., 2009), earthworm (Kim et al., 2011) and aquatic environments such as seaweed (Moore et al., 2002), nonsaline alkaline 
Table 2 Assembly statistics and features of the genome sequence of Frondihabitans sp. 762G35.

\begin{tabular}{ll}
\hline \multicolumn{2}{l}{ Frondihabitans sp. 762G35 genome sequence } \\
\hline Sequencing technology & PacBio P4-C2 \\
Assembly statistics & \\
\hline Genome size (Mb) & 3.4 \\
\# scaffolds & 1 \\
\# contigs & 1 \\
\# reads & 89853 \\
Mean subread length (bp) & 5476 \\
N50 read length (bp) & 7920 \\
GC\% & 70 \\
Genomic features & \\
\# coding DNA sequences (CDSs) & 3212 \\
\# hypothetical proteins & 1123 \\
\# rRNA genes & 6 \\
\# tRNA genes & 50 \\
\hline
\end{tabular}

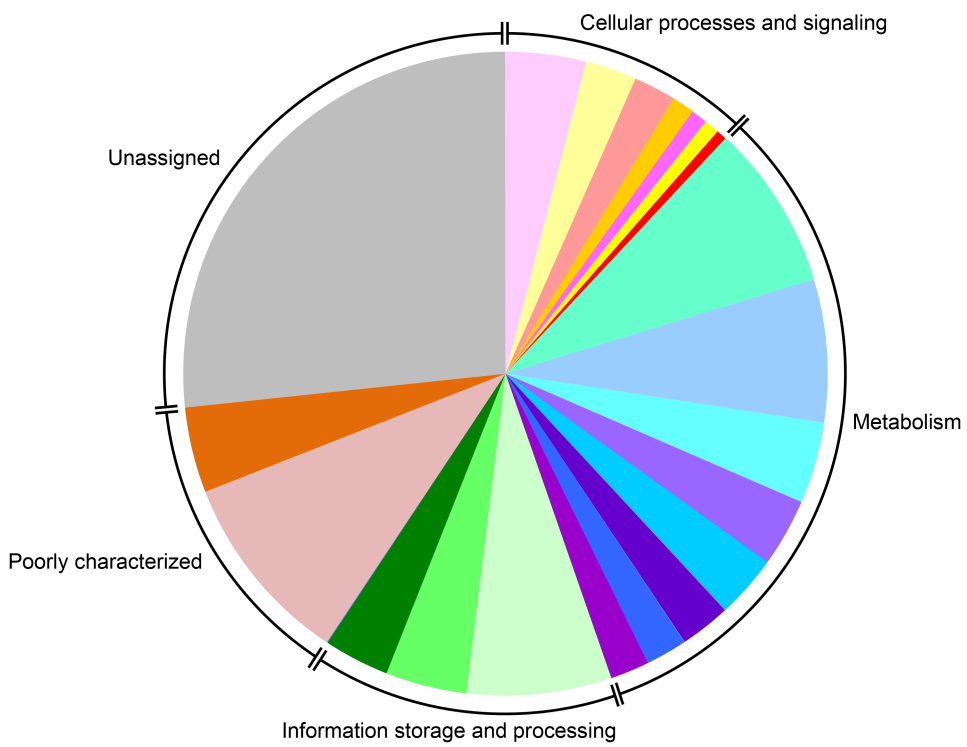

Cellular processes and signaling:

Cell wall/membrane/envelope biogenesis (148)

Signal transduction mechanisms (95)

- Post-translational modification, protein turnover, and chaperones (78)

- Intracellular trafficking, secretion, and vesicular transport (42)

- Cell motility (30)

Defense mechanisms (28)

- Cell cycle control, cell division, chromosome partitioning (19)

- Extracellular structures (0)

- Nuclear structure (0)

- Cytoskeleton $(0)$

\section{Metabolism:}

Carbohydrate transport and metabolism (306)

Amino acid transport and metabolism (264)

Inorganic ion transport and metabolism (150)

Energy production and conversion (126)

- Lipid transport and metabolism (116)

- Coenzyme transport and metabolism (94)

- Secondary metabolites biosynthesis, transport, and catabolism (77)

- Nucleotide transport and metabolism (72)
Information storage and processing: Transcription (267)

- Translation, ribosomal structure and biogenesis (150)

- Replication, recombination and repair (121)

घRA processing and modification (1)

- Chromatin structure and dynamics (0)

Poorly characterized:

๓ General function prediction only (357)

" Function unknown (158)

\section{Unassigned:}

Unassigned (982) 
Figure 2 Prediction of clusters of orthologous groups (COGs) in the genome of aquatic Frondihabitans sp. $762 \mathrm{G} 35$. In brackets the number of coding DNA sequences. COG annotations for the predicted proteins were determined using KOGnitor (http://www.ncbi.nlm.nih.gov/COG/grace/kognitor.html) (Snel et al., 2002).

groundwater (Tiago et al., 2004) and atmospheric water masses collected at the summit of a lava dome (Amato et al., 2007). Frigoribacterium harbours both (potential) pathogenic and beneficial species (Nejad et al., 2006; Rudolf et al., 2009; Pereira and Castro, 2014). For example, the psychrophilic Frigoribacterium faeni was pathogenic to willow because of its ice-nucleation activity (Nejad et al., 2006). Whether or not this activity is present in Frondihabitans still needs to be verified. Temperatures for optimal growth of Frigoribacterium can range from 2 to $10{ }^{\circ} \mathrm{C}$ (Kämpfer et al., 2000; Nejad et al., 2006) or from 25 to $30^{\circ} \mathrm{C}$ (Wang et al., 2015).

Pan-core genome analysis of Frondihabitans sp. 762G35, Frondihabitans sp. Leaf304 and Frigoribacterium sp. Leaf415 with the plant pathogen Clavibacter michiganensis subsp. sepedonicus ATCC 33113 as an outgroup, revealed 1292 core orthologous groups, representing $40-41 \%$ of each genome, and 5955 pan genome orthologous groups (Figure $3 \mathrm{~A}$ ). Only $57 \%$ of the number of CDSs was shared between the genome sequence of Frondihabitans sp. $762 \mathrm{G} 35$ and Frondihabitans sp. Leaf304, of which 529 orthologous groups were unique to the two Frondihabitans strains only, representing $16 \%$ of each genome. The number of unique orthologous groups for Frondihabitans sp. $762 \mathrm{G} 35$ was 1206, comprising 1213 CDSs and representing $37 \%$ of its genome. Among the unique orthologous groups, COGs could only be assigned to $52 \%$ of the CDSs and the three largest groups included transcription, carbohydrate transport and metabolism, and amino acid transport and metabolism, accounting for $8 \%, 7 \%$ and $4 \%$ of the total CDSs, respectively (Figure 3B).

\section{Genome mining for bioactive compounds}

Since Frondihabitans sp. $762 \mathrm{G} 35$ secretes compounds that inhibit hyphal growth of S. diclina (Table 1), we mined the annotated genome for genes or gene clusters encoding bioactive compounds. Several genes encoding proteases or lipases, or genes associated with biofilm formation were identified in the Frondihabitans sp. $762 \mathrm{G} 35$ genome sequence, several of which were also found in the Frondihabitans sp. Leaf304 and Frigoribacterium sp. Leaf415 genome sequences (Table S1). Whether these genes are encoding the enzymes involved in extracellular lipase or protease activity or contribute to biofilm formation remains to be investigated. 
A

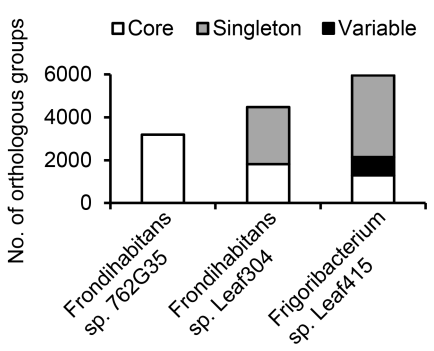

B

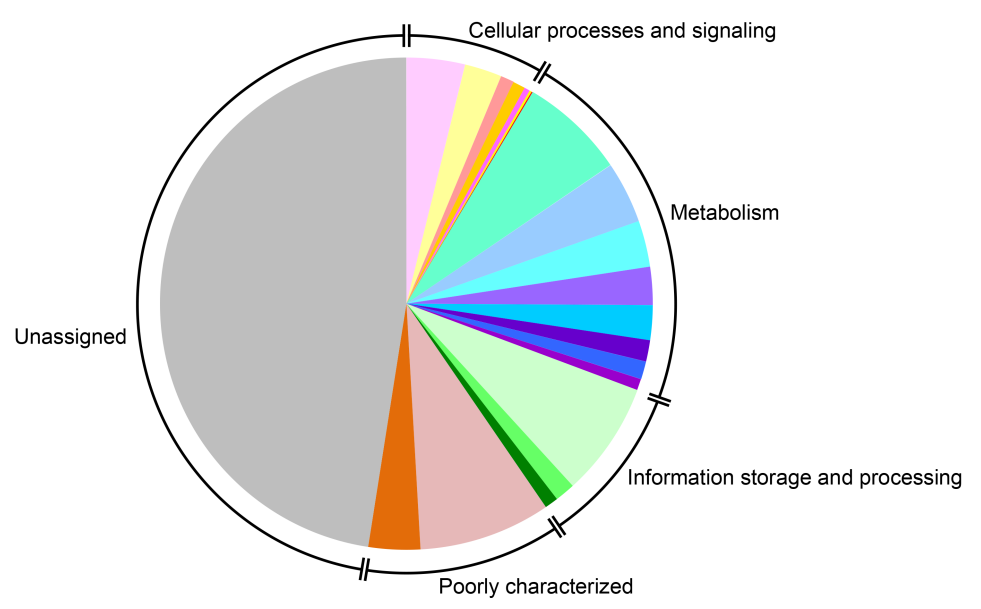

Cellular processes and signaling:

Cell wall/membrane/envelope biogenesis

(52)

Signal transduction mechanisms (33)

Defense mechanisms (12)

- Post-translational modification, protein turnover, and chaperones (11)

Intracellular trafficking, secretion, and vesicular transport (5)

Cell cycle control, cell division, chromosome partitioning (2)

- Cell motility (1)

- Extracellular structures (0)

= Nuclear structure $(0)$

- Cytoskeleton (0)
Metabolism:

- Carbohydrate transport and metabolism (94)

$\square$ Amino acid transport and metabolism (55)

- Lipid transport and metabolism (41)

- Inorganic ion transport and metabolism (34)

- Secondary metabolites biosynthesis, transport, and catabolism (31)

- Energy production and conversion (19)

- Coenzyme transport and metabolism (16)

- Nucleotide transport and metabolism (10)
Information storage and processing: Transcription (102)

- Replication, recombination and repair (18)

- Translation, ribosomal structure and biogenesis (12)

- RNA processing and modification (0)

- Chromatin structure and dynamics (0)

Poorly characterized:

- General function prediction only (117)

- Function unknown (46)

Unassigned:

- Unassigned (644)

Figure 3 Pan-core genome analysis of Frondihabitans. (A) Number of core, pan, unique and shared orthologous groups among aquatic Frondihabitans sp. 762G35, Frondihabitans sp. Leaf304 and Frigoribacterium sp. Leaf415. The number of shared and strain-specific gene clusters depends on which strain was added to the comparison (x-axis). Core gene clusters (white bars) appear in all strains, variable gene clusters (black bars) appear in more than one but not all strains and singleton gene clusters (grey bars) appear only in one strain. (B) Overview of the different clusters of orthologous groups (COGs) assigned to the coding DNA sequences (CDSs) that were unique for aquatic Frondihabitans sp. 762G35. In brackets the number of CDSs. 
Using antiSMASH (Weber et al., 2015), two gene clusters encoding terpene biosynthesis (Figure 4) were identified. The first terpene gene cluster appears to be unique to Frondihabitans sp. $762 \mathrm{G} 35$, while the second terpene gene cluster is partially present in the genome of Frondihabitans sp. Leaf304. Terpenes were originally identified in plants and later also in bacteria and animals (Gershenzon and Dudareva, 2007; Rabe et al., 2013), including actinomycetes (Actinobacteria) and cyanobacteria (Nagarajan et al., 2013; Rabe et al., 2013). Terpenes have low molecular weight and each of them consists of several isoprenes (Bakkali et al., 2008). Many of them, like gibberellic acid, artemisinin and altemicidin, are active in promoting plant growth, suppressing malaria and cancer, and protecting marine organisms from pathogen infection (Paul et al., 2006; Gershenzon and Dudareva, 2007; Olano et al., 2009; Rabe et al., 2013). Marine actinomycetes, mainly Streptomyces, Salinispora and Micromonospora species, are capable of producing various antitumor terpenes (Olano et al., 2009), and yellow to orange or yellow-red coloured terpenoids, called carotenoids, including canthaxanthin, lycopene, zeaxanthin (Romero et al., 2012). Collectively, these studies suggest a potential role of terpenes in the activity of Frondihabitans isolate 762G35 against $S$. diclina.

Beside the terpene clusters, a type III polyketide synthases (T3pks) gene cluster was identified in the genome of Frondihabitans sp. 762G35, which was partially present in the genome of Frondihabitans sp. Leaf304 (Figure 4). Polyketides comprise a wide variety of bioactive compounds, such as phenolic lipids, 1,3,6,8-tetrahydroxynaphthalene, the anticancer compound giganin, the anticholesterol compound herboxidiene, and the antibiotics balhimycin, tetracyclines, vancomycin and teicoplanin (Rohr, 1992; Fang et al., 1993; O'Hagan, 1995; Funa et al., 1999; Chen et al., 2001; Li et al., 2001; Pfeifer et al., 2001; Funa et al., 2002; Funa et al., 2006; Funabashi et al., 2008; Pokhrel et al., 2015). To elucidate which compound(s) the T3pks gene cluster and the terpene gene clusters are encoding and if these play a role in the activity of Frondihabitans sp. 762G35 against Saprolegnia, site-directed mutagenesis of the genes should be conducted in future studies, followed by chemical identification and in vivo bioassays to study gene transcription and the activities of T3pks- or terpene-deficient mutants should be compared to the wild type. 


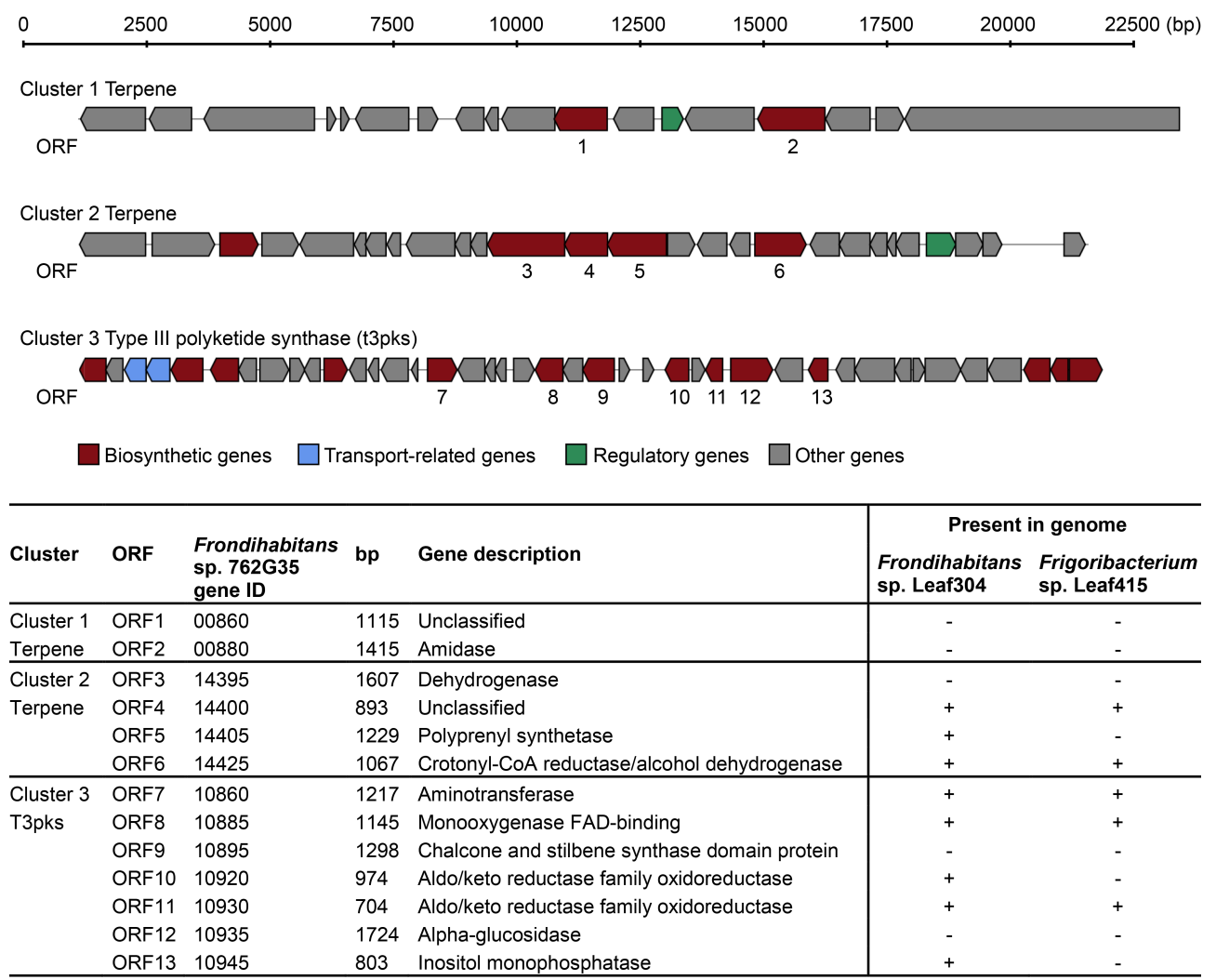

Figure 4 Gene clusters in the Frondihabitans sp. 762G35 genome predicted to encode antibiotics and secondary metabolites. The genome was analysed by antiSMASH 3.0 (Weber et al., 2015). Specific open reading frames (ORFs) of biosynthetic genes were numbered and described by gene ID, size (bp) and a short description. The presence ('+') or absence ('-') of these ORFs in the genome of Frondihabitans sp. Leaf304 and Frigoribacterium sp. Leaf415 is also indicated. The marker on top indicates the size $(\mathrm{bp})$ of the gene clusters.

\section{Chemical analyses of Frondihabitans sp. 762G35}

Frondihabitans sp. $762 \mathrm{G} 35$ was grown in $1 / 5 \mathrm{MB}$ at $5{ }^{\circ} \mathrm{C}$ and the supernatants were collected at several time points along the growth curve (Figure 5) and tested for activity against $S$. diclina. The supernatants of the lag phase (day 7 ), exponential phase (day 14) and stationary phase (days 21 and 27) showed increasing inhibitory activity on hyphal growth of $S$. diclina (Figure 5). As a first step to partially purify the bioactive compounds, HPLC analyses and fractionation were performed. Most compounds eluted in the first $15 \mathrm{~min}$ (Figure S1A and S1B). Among the nine fractions collected every 5 min over the 45 -min gradient, only compounds in the second fraction (5-10 min elution) inhibited hyphal growth of $S$. diclina when it was concentrated 2.5 times (Figure S1C). 
A

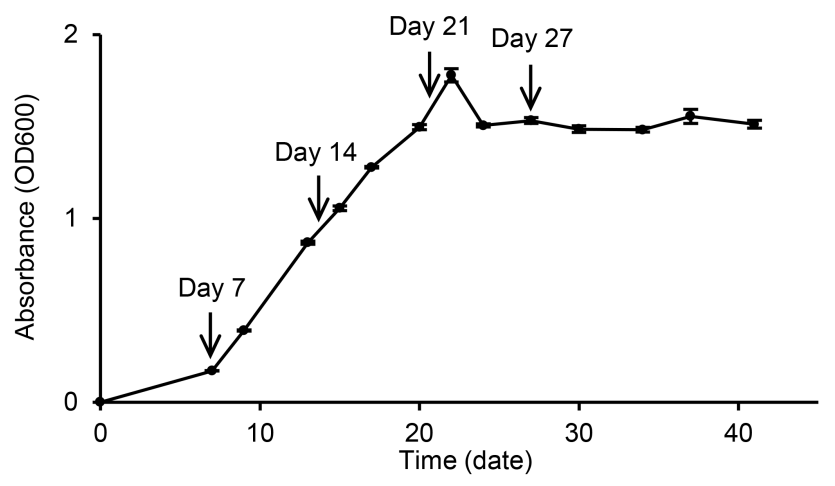

B

$\square$ Control $\square$ Frondihabitans sp. $762 \mathrm{G} 35$ culture filtrate
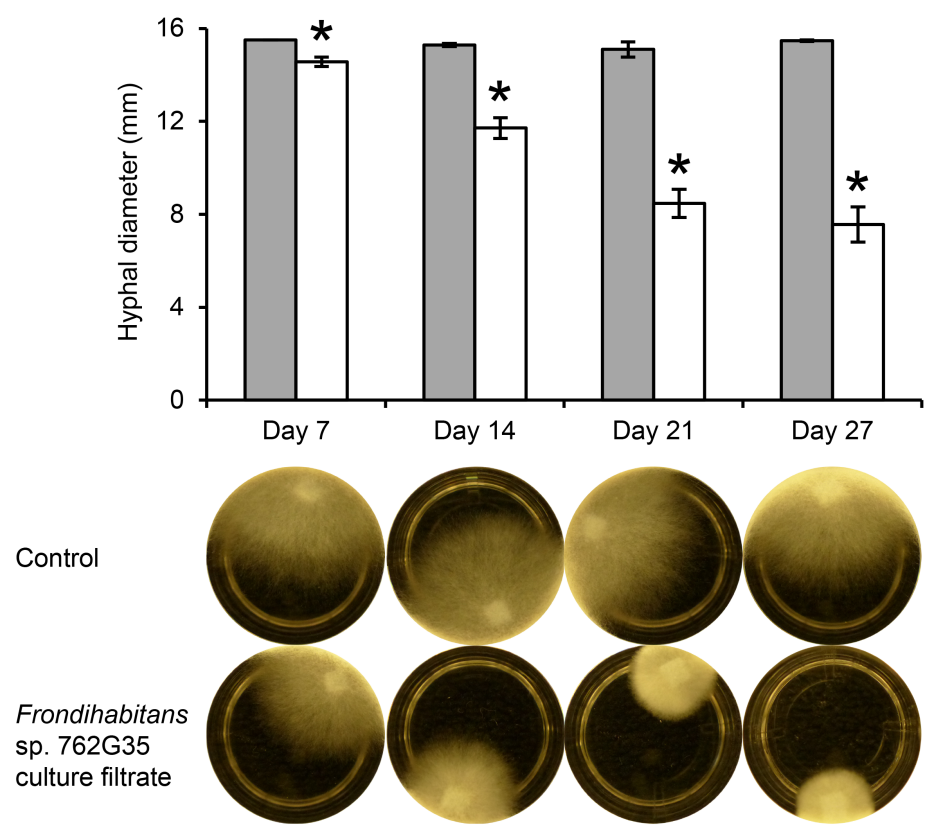

Figure 5 Growth of Frondihabitans sp. $762 \mathrm{G} 35$ at $5{ }^{\circ} \mathrm{C}$ and production of extracellular compounds inhibitory to hyphal growth of Saprolegnia diclina. (A) Growth curve of Frondihabitans sp. $762 \mathrm{G} 35$ over 41 days. A pregrown cell suspension was added to fresh $1 / 5^{\text {th }}$ strength malt broth $(1 / 5 \mathrm{MB})$ to obtain the density of $10^{6}$ cells $\mathrm{ml}^{-1}$. The cultures were incubated at $300 \mathrm{rpm}$ at $5{ }^{\circ} \mathrm{C}$ and the cell density of different time points was determined by spectrophotometer at $600 \mathrm{~nm}$. (B) Inhibitory activity of the cell-free culture supernatants on hyphal growth of $S$. diclina. The supernatants of day 7, 14, 21 and 27 were filter-sterilized through $0.2 \mu \mathrm{m}$ filters (Whatman ${ }^{\top \mathrm{M}}$ ), lyophilized, redissoved in $1 / 5 \mathrm{MB}$ to a 2.5 times concentrated level than the original culture and filter-sterilized again. Subsequently, 300-600 $\mu \mathrm{l}$ of this solution was added to a well of a 24-wells or 48-wells plate. One $S$. diclina $1152 \mathrm{~F} 4$ hyphal plug of approximately $2 \mathrm{~mm}^{2}$ was added into each well and the culture was incubated at $5{ }^{\circ} \mathrm{C}$. The effect on hyphal growth of $S$. diclina was determined by measuring the diameter of hyphal mat after 11 days of incubation. Error bars indicate S.E.M. $(N=2)$. An asterisk indicates a statistically significant difference compared to the medium control of the corresponding time point $(P<0.05$, independent-samples $t$-test). 
To monitor the temporal change in polar and semi-polar metabolites produced during the growth curve of Frondihabitans sp. 762G35, samples collected on day 7 , 14, 21 and 27 were subjected to LC-PDA-LTQ-Orbitrap-FTMS analysis in negative ionization mode. A total of 344 putative metabolites were detected across all the samples; 326 were significantly different at least under one of the conditions analysed $(P<0.05)$ and used for computing the hierarchical cluster analyses (Figure $6 \mathrm{~A})$. The metabolome profile of samples collected on day 14, 21 and 27 is more alike and clearly different from samples collected at day 7 and the control. The difference between these two groups is explained by different clusters of metabolites that showed variation in their abundance across the time points. The results suggest that metabolites in cluster I were consumed by Frondihabitans sp. 762G35 in the first week of culturing. Similarly, clusters II and III appear to be consumed in the second and third week of culturing, respectively. By contrast, metabolites in cluster IV showed accumulation from the second week onward. Metabolites in clusters I and II are depleted from the supernatant at the lag and exponential growth phases of Frondihabitans sp. 762G35 (day 7 and 14, respectively) and could be used for growth and normal metabolism of the microorganism. Instead, metabolites in cluster III showed drastic depletion at the stationary growth phase (day 21 and 27) and coincided with the accumulation of 65 metabolites in cluster IV. Based on this observation we assume that metabolites in cluster III might be used by Frondihabitans sp. 762G35 to produce metabolites in cluster IV.

The significance of the temporal accumulation of these 65 metabolites in cluster IV was assessed by comparing their accumulation in the supernatant obtained from different growth stages of Frondihabitans sp. $762 \mathrm{G} 35$ to the control using independent-samples $t$-test $(P<0.05)$ and fold-change in accumulation (fold-change $>2$ ). This resulted in 29 metabolites that were significantly accumulated at least under one of the growth stages when compared to the control (Figure 6B, Table S2). There were 7 core-metabolites that showed significant accumulation in all growth stages of Frondihabitans sp. 762G35 when compared to the control. Similarly, 17 metabolites showed significant accumulation both at the early and late (day 21 and 28, respectively) stationary growth phase of Frondihabitans sp. $762 \mathrm{G} 35$ and 4 other metabolites showed significant accumulation only at the late stationary growth phase (day 27). Only 1 metabolite significantly accumulated in the exponential growth phase (day 14) of Frondihabitans sp. 762G35 (Figure 6B). 

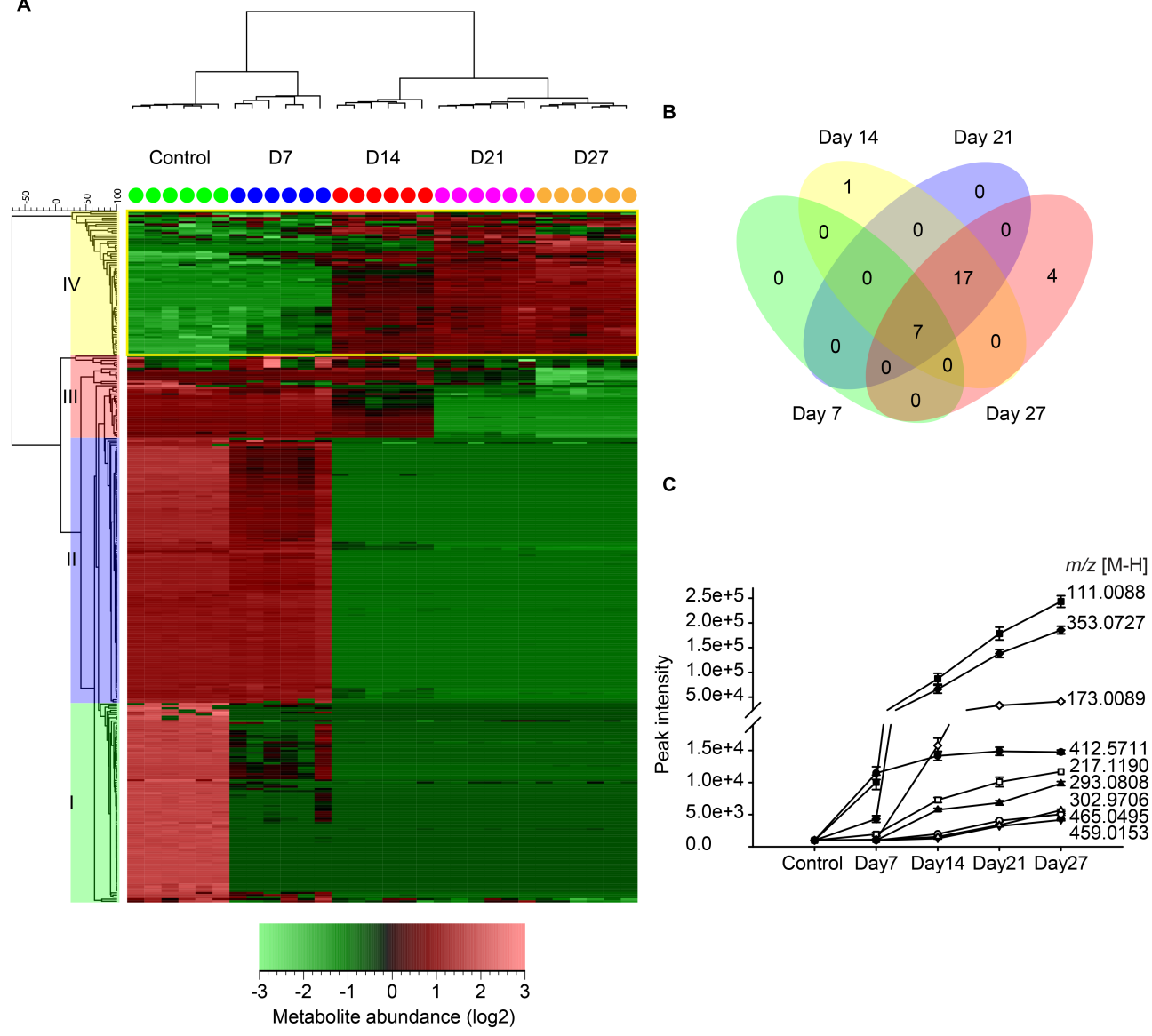

Figure 6 Hierarchical cluster analysis (HCA) of 344 metabolites detected from supernatant of Frondihabitans sp. $762 \mathrm{G} 35$ extract obtained on day $7,14,21$ and 27 in $1 / 5^{\text {th }}$ strength malt extract broth at $5{ }^{\circ} \mathrm{C}$. (A) Heat map based on 326 metabolites identified by liquid chromatography mass spectrometry (LC-MS) that are significantly different in abundance at least under one of the conditions analysed. D7, D14, D21 and D27 correspond to the six samples collected on day 7, 14, 21 and 27, respectively. To differentiate metabolites that are associated with the medium from the ones that are produced by Frondihabitans sp. $762 \mathrm{G} 35$, a set of $1 / 5^{\text {th }}$ strength malt extract broth cultures without Frondihabitans sp. 762G35 inoculation was included ('control'). There are four major clusters. Clusters I, II and III indicate metabolites in the medium that were consumed in the first, second and third week after inoculation, respectively. Cluster IV represents metabolites that accumulated from the second week onward. (B) Venn diagram showing the number and distribution of 29 significantly accumulated metabolites from cluster IV when their abundance is compared between the 4 growth stages (day 7, 14, 21 and 27) with the control $(P<0.05$ and fold change $>2)$. (C) The temporal accumulation pattern of 9 metabolites that eluted between 3-10 minutes of chromatographic separation that were among the 29 metabolites in cluster IV of panel A that showed significant accumulation at least under one of the growth stages when compared to the control. 
Supernatant obtained from the early and late stationary growth phase (day 21 and 27) of Frondihabitans sp. $762 \mathrm{G} 35$ showed the highest inhibitory activity against $S$. diclina (Figure 5) and this coincides with the accumulation of these 29 metabolites in the extract. Moreover, using bioactivity-guided fractionation from the extract of supernatant obtained on day 21, fractions collected between 5 and 10 minutes of HPLC run showed the highest inhibitory activity against $S$. diclina (Figure S1). Hence, using the elusion time window of 3-10 min we narrowed down the list of 29 metabolites to 9 potential candidates (Table S2). For these 9 metabolites, 3 were among the 7 core-metabolites (Figure 6B) and the others were evenly distributed among the 17 metabolites that are common to day 14, 21 and 27 and to those 4 metabolites that exclusively accumulated on day 27 (Figure 6B).

We used the accurate mass and the MS/MS $\left(\mathrm{MS}^{3}\right)$ fragmentation patterns of the parent ion of each of the selected 9 metabolites to give tentative identification. Out of the 9 metabolites only 3 were sufficient in abundance to be subjected for deep MS/MS analysis (Figure 6C). These 3 metabolites are represented by the parent ions $[\mathrm{M}-\mathrm{H}]^{-} \mathrm{m} / \mathrm{z} 111.0088,173.0089$ and 353.0721 (Table S2). Two of them $(\mathrm{m} / \mathrm{z} 111.0088$ and 353.0721$)$ were among the 7 core-metabolites that showed accumulation under all the growth stages and were $24 x$ and $43 x$ more abundant at day 27 compared to day 7 , respectively. M/z 173.0089 was among the 17 metabolites that showed significant accumulation on day 14, 21 and 27, which could not be detected at day 7 , and was $2.7 x$ more abundant at day 27 compared to day 14. Based on the accurate mass, the molecular formula $\mathrm{C}_{5} \mathrm{H}_{3} \mathrm{O}_{3}$ was assigned to the ion peak at $\mathrm{m} / \mathrm{z} 111.0088$. MS/MS analysis of $\mathrm{m} / \mathrm{z} 111.0088$ revealed a dominant furan ion peak at $\mathrm{m} / \mathrm{z} 67.0192\left(\mathrm{C}_{4} \mathrm{H}_{3} \mathrm{O}\right)$ with the loss of carboxyl group (COO). Both the accurate mass (sub-ppm accuracy) and the fragmentation pattern of $\mathrm{m} / \mathrm{z} 111.0088$ match with 2-furancarboxylic acid in the MassBank Database (http://www.massbank.jp/index.html). The ion peak at $\mathrm{m} / \mathrm{z}$ 173.0089 gave major fragment peaks at $\mathrm{m} / \mathrm{z} 111.0088(100 \%), 131.3856(60 \%)$ and $129.01913(20 \%)$. Similarly, the ion peak at $\mathrm{m} / \mathrm{z} 353.0721$ is characterized by major fragment ion peaks at $\mathrm{m} / \mathrm{z} 111.0088$ (100\%), $173.0092(50 \%)$ and 131.3772 (15\%). Therefore, based on the observed fragmentation pattern we assert that both $\mathrm{m} / \mathrm{z} 173.0089$ and 353.0721 are potentially derived from $\mathrm{m} / \mathrm{z} 111.0088$ because they showed a common fragment $\mathrm{m} / \mathrm{z}$ 111.0088, corresponding to 2furancarboxylic acid. The production of at least two of the three metabolites $(\mathrm{m} / \mathrm{z}$ 111.0088 and 353.0721), even at the lag (day 7) and exponential (day 14) growth phases of Frondihabitans sp. $762 \mathrm{G} 35$ (Figure 6B and C), is an indicator of the potential ecological role of these group of metabolites as antagonist against Saprolegnia. Interestingly, furancarboxylic acid-related compounds were previously described for the marine fungi Chaetomium and Penicillium and the plantassociated fungi Cephalosporium and Penicillium (Kobayashi and Ui, 1975; Abdel- 
Lateff, 2008; Kimura et al., 2009; Wang et al., 2016) and showed antibiotic, antifibrotic and phytotoxic activities (Kobayashi and Ui, 1975; Almeida et al., 2014; Wang et al., 2016). Several Actinomycetales, including Agromyces and Arthrobacter, can degrade toxic furanic compounds (Trifonova et al., 2008; Wierckx et al., 2010). Such microbes may be used as biodetoxifiers in industry (Wierckx et al., 2011). Besides, furan-2-yl acetate produced by marine Streptomyces inhibited in vitro the replication of fish nodavirus in fish cells. Hence, this class of compounds may contain promising candidates to control nodaviral diseases in marine aquaculture (Suthindhiran et al., 2011) and, based on the results of our study, Saprolegniosis of salmonids.

\section{Funding}

This work was financially supported by SAPRO (Sustainable Approaches to Reduce Oomycete (Saprolegnia) Infections in Aquaculture, 238550), a Marie Curie Initial Training Network funded by the European Commission under Framework Program 7, by ParaFishControl (Advanced Tools and Research Strategies for Parasite Control in European farmed fish, 634429), a Research and Innovation Program funded by the European Commission under HORIZON 2020, and by the Netherlands BEBasic Foundation (project number F07.003.01).

\section{Acknowledgments}

We appreciate the help and valuable advices from Menno van der Voort (Laboratory of Phytopathology, Wageningen University, The Netherlands) for the genomic DNA extraction and preparation for sequencing. We appreciate the help and valuable advices from Bert Schipper (Plant Research International, Wageningen University, The Netherlands) for the LC-MS and metabolomics analyses.

\section{Author Contributions}

Conceived and designed the experiments: YL IdB JMR. Performed the experiments: YL. Analyzed data and created figures: YL DE IdB. Wrote the paper: YL IdB DE VdJ JMR. Performed the bacterial isolations and characterization, phylogenetic and genome analyses, in vitro and HPLC experiments: YL. Performed LC-MS analyses: DE YL. Contributed to in vitro enzymatic activity tests: VJC. Contributed to genome analysis: IdB VdJ VJC. Contributed to HPLC analysis: IdB. Contributed to review of the manuscript: all authors.

\section{Competing Interests}

The authors have declared that no competing interests exist. 


\section{References}

Gegenees. URL http://www.gegenees.org/index.html.

Abdel-Lateff, A. (2008) Chaetominedione, a new tyrosine kinase inhibitor isolated from the algicolous marine fungus Chaetomium sp. Tetrahedron Letters 49: 6398-6400.

Ågren, J., Sundström, A., Håfström, T., and Segerman, B. (2012) Gegenees: fragmented alignment of multiple genomes for determining phylogenomic distances and genetic signatures unique for specified target groups. PLoS ONE 7: e39107.

Aguilera, E., Yany, G., and Romero, J. (2013) Cultivable intestinal microbiota of yellowtail juveniles (Seriola lalandi) in an aquaculture system. Latin American Journal of Aquatic Research 41: 395-403.

Almeida, C., El Aouad, N., Martin, J., Perez-Victoria, I., Gonzalez-Menendez, V., Platas, G. et al. (2014) Graminin B, a furanone from the fungus Paraconiothyrium sp. J Antibiot 67: 421-423.

Amato, P., Parazols, M., Sancelme, M., Laj, P., Mailhot, G., and Delort, A.M. (2007) Microorganisms isolated from the water phase of tropospheric clouds at the Puy de Dôme: major groups and growth abilities at low temperatures. FEMS Microbiol Ecol 59: 242-254.

Bai, Y., Müller, D.B., Srinivas, G., Garrido-Oter, R., Potthoff, E., Rott, M. et al. (2015) Functional overlap of the Arabidopsis leaf and root microbiota. Nature 528: 364-369.

Bakkali, F., Averbeck, S., Averbeck, D., and Waomar, M. (2008) Biological effects of essential oils A review. Food and Chemical Toxicology 46: 446-475.

Benson, D.A., Cavanaugh, M., Clark, K., Karsch-Mizrachi, I., Lipman, D.J., Ostell, J., and Sayers, E.W. (2013) GenBank. Nucleic Acids Res 41: D36-42.

Bly, J.E., Quiniou, S.M.A., Lawson, L.A., and Clem, L.W. (1997) Inhibition of Saprolegnia pathogenic for fish by Pseudomonas fluorescens. Journal of Fish Diseases 20: 35-40.

Bruno, D., van West, P., and Beakes, G. (2011) Saprolegnia and other oomycetes. In Fish diseases and disorders, viral, bacterial and fungal infections. Woo, P., and Bruno, D. (eds). Wallingford, UK: CABI: Wallingford, UK, pp. 669-720.

Burmølle, M., Webb, J.S., Rao, D., Hansen, L.H., Sorensen, S.J., and Kjelleberg, S. (2006) Enhanced biofilm formation and increased resistance to antimicrobial agents and bacterial invasion are caused by synergistic interactions in multispecies biofilms. Applied and Environmental Microbiology 72: 3916-3923.

Carbajal-Gonzalez, M.T., Fregeneda-Grandes, J.M., Suarez-Ramos, S., Rodriguez-Cadenas, F., and Aller-Gancedo, J.M. (2011) Bacterial skin flora variation and in vitro inhibitory activity against Saprolegnia parasitica in brown and rainbow trout. Diseases of Aquatic Organisms 96: 125-135.

Cardinale, M., Grube, M., and Berg, G. (2011) Frondihabitans cladoniiphilus sp. nov., an actinobacterium of the family Microbacteriaceae isolated from lichen, and emended description of the genus Frondihabitans. International Journal of Systematic and Evolutionary Microbiology 61: 30333038.

Chen, H., Tseng, C.C., Hubbard, B.K., and Walsh, C.T. (2001) Glycopeptide antibiotic biosynthesis: enzymatic assembly of the dedicated amino acid monomer (S)-3,5-dihydroxyphenylglycine. Proceedings of the National Academy of Sciences of the United States of America 98: 14901-14906.

Chin, C.S., Alexander, D.H., Marks, P., Klammer, A.A., Drake, J., and Heiner, C. (2013) Nonhybrid, finished microbial genome assemblies from long-read SMRT sequencing data. Nat Methods 10.

Cole, J.R., Wang, Q., Fish, J.A., Chai, B., McGarrell, D.M., Sun, Y. et al. (2014) Ribosomal Database Project: data and tools for high throughput rRNA analysis. Nucleic Acids Research 42: D633D642.

Das, S.K., Murmu, K., Das, A., Shakuntala, I., Das, R.K., Ngachan, S.V., and Majhi, S.K. (2012) Studies on the identification and control of pathogen Saprolegnia in selected Indian major carp fingerlings at mid hill altitude. Journal of Environmental Biology 33: 545-549. 
Dastager, S.G., Lee, J.-C., Ju, Y.-J., Park, D.-J., and Kim, C.-J. (2008) Frigoribacterium mesophilum sp nov., a mesophilic actinobacterium isolated from Bigeum Island, Korea. International Journal of Systematic and Evolutionary Microbiology 58: 1869-1872.

de Bruijn, I., Cheng, X., de Jager, V., Expósito, R.G., Watrous, J., Patel, N. et al. (2015) Comparative genomics and metabolic profiling of the genus Lysobacter. BMC Genomics 16: 1-16.

Fang, X.-p., Song, R., Gu, Z.-m., Rieser, M.J., Miesbauer, L.R., Smith, D.L., and McLaughlin, J.L. (1993) A new type of cytotoxic annonaceous acetogenin: Giganin from Goniothalamus giganteus. Bioorganic \& Medicinal Chemistry Letters 3: 1153-1156.

Fernández-Benéitez, M.J., Ortiz-Santaliestra, M.E., Lizana, M., and Diéguez-Uribeondo, J. (2008) Saprolegnia diclina: another species responsible for the emergent disease 'Saprolegnia infections' in amphibians. Fems Microbiology Letters 279: 23-29.

Fisher, M.C., Henk, D.A., Briggs, C.J., Brownstein, J.S., Madoff, L.C., McCraw, S.L., and Gurr, S.J. (2012) Emerging fungal threats to animal, plant and ecosystem health. Nature 484: 186-194.

Fjellheim, A.J., Klinkenberg, G., Skjermo, J., Aasen, I.M., and Vadstein, O. (2010) Selection of candidate probionts by two different screening strategies from Atlantic cod (Gadus morhua L.) larvae. Veterinary Microbiology 144: 153-159.

Flemming, H.-C., and Wingender, J. (2010) The biofilm matrix. Nat Rev Micro 8: 623-633.

Funa, N., Ohnishi, Y., Ebizuka, Y., and Horinouchi, S. (2002) Properties and substrate specificity of RppA, a chalcone synthase-related polyketide synthase in Streptomyces griseus. Journal of Biological Chemistry 277: 4628-4635.

Funa, N., Ozawa, H., Hirata, A., and Horinouchi, S. (2006) Phenolic lipid synthesis by type III polyketide synthases is essential for cyst formation in Azotobacter vinelandii. Proceedings of the National Academy of Sciences of the United States of America 103: 6356-6361.

Funa, N., Ohnishi, Y., Fujii, I., Shibuya, M., Ebizuka, Y., and Horinouchi, S. (1999) A new pathway for polyketide synthesis in microorganisms. Nature 400: 897-899.

Funabashi, M., Funa, N., and Horinouchi, S. (2008) Phenolic lipids synthesized by type III polyketide synthase confer penicillin resistance on Streptomyces griseus. Journal of Biological Chemistry 283: 13983-13991.

Gershenzon, J., and Dudareva, N. (2007) The function of terpene natural products in the natural world. Nat Chem Biol 3: 408-414.

Gozlan, R.E., Marshall, W., Lilje, O., Jessop, C., Gleason, F.H., and Andreou, D. (2014) Current ecological understanding of fungal-like pathogens of fish: what lies beneath? Frontiers in Microbiology 5 .

Greene, A.C., Euzeby, J.P., Tindall, B.J., and Patel, B.K.C. (2009) Proposal of Frondihabitans gen. nov to replace the illegitimate genus name Frondicola Zhang et al. 2007. International Journal of Systematic and Evolutionary Microbiology 59: 447-448.

Haki, G.D., and Rakshit, S.K. (2003) Developments in industrially important thermostable enzymes: a review. Bioresource Technology 89: 17-34.

Hatai, K., and Willoughby, L.G. (1988) Saprolegnia parasitica from rainbow trout inhibited by the bacterium Pseudomonas fluorescens. Bull Eur Ass Fish Pathol 8: 27-29.

Hatai, K., and Hoshiai, G. (1992) Mass mortality in cultured coho salmon (Oncorhynchus kisutch) due to Saprolegnia parasitica coker Journal of Wildlife Diseases 28: 532-536.

Hatai, K., and Hoshiai, G.-I. (1994) Pathogenicity of Saprolegnia parasitica Coker. In Salmon Saprolegniasis. Mueller, G.J. (ed). Portland, Oregon: U.S. Department of Energy, Bonneville Power Administration, Portland, Oregon.

Hsu, S.C., and Lockwood, J.L. (1975) Powdered chitin agar as a selective medium for enumeration of actinomycetes in water and soil. Appl Microbiol 29.

Huang, Y., Niu, B., Gao, Y., Fu, L., and Li, W. (2010) CD-HIT Suite: a web server for clustering and comparing biological sequences. Bioinformatics 26: 680-682.

Hussein, M.M.A., and Hatai, K. (2001) In vitro inhibition of Saprolegnia by bacteria isolated from lesions of salmonids with saprolegniasis. Fish Pathology 36: 73-78. 
lijima, S., Washio, K., Okahara, R., and Morikawa, M. (2009) Biofilm formation and proteolytic activities of Pseudoalteromonas bacteria that were isolated from fish farm sediments. Microbial biotechnology 2: 361-369.

Kämpfer, P., Rainey, F.A., Andersson, M.A., Lassila, E.L.N., Ulrych, U., Busse, H.J. et al. (2000) Frigoribacterium faeni gen. nov., sp nov., a novel psychrophilic genus of the family Microbacteriaceae. International Journal of Systematic and Evolutionary Microbiology 50: 355-363.

Kennedy, J., O'Leary, N.D., Kiran, G.S., Morrissey, J.P., O'Gara, F., Selvin, J., and Dobson, A.D.W. (2011) Functional metagenomic strategies for the discovery of novel enzymes and biosurfactants with biotechnological applications from marine ecosystems. Journal of Applied Microbiology 111: 787-799.

Kim, E.S., Hong, S.W., and Chung, K.S. (2011) Comparative analysis of bacterial diversity in the intestinal tract of earthworm (Eisenia fetida) using DGGE and pyrosequencing. Korean Journal of Microbiology and Biotechnology 39: 374-381.

Kim, S.-J., Lim, J.-M., Ahn, J.-H., Weon, H.-Y., Hamada, M., Suzuki, K.-i. et al. (2014) Description of Galbitalea soli gen. nov., sp. nov., and Frondihabitans sucicola sp. nov. International Journal of Systematic and Evolutionary Microbiology 64: 572-578.

Kimura, T., Takeuchi, T., Kumamoto-Yonezawa, Y., Ohashi, E., Ohmori, H., Masutani, C. et al. (2009) Penicilliols $A$ and $B$, novel inhibitors specific to mammalian $Y$-family DNA polymerases. Bioorganic \& Medicinal Chemistry 17: 1811-1816.

Kitancharoen, N., Ono, A., Yamamoto, A., and Hatai, K. (1997) The fungistatic effect of $\mathrm{NaCl}$ on rainbow trout egg Saprolegniasis. Fish Pathology 32: 159-162.

Kobayashi, K., and Ui, T. (1975) Isolation of phytotoxic substances produced by Cephalosporium gregatum allington and chamberlain. Tetrahedron Letters: 4119-4122.

Krugner-Higby, L., Haak, D., Johnson, P.T.J., Shields, J.D., Jones, W.M., III, Reece, K.S. et al. (2010) Ulcerative disease outbreak in crayfish Orconectes propinquus linked to Saprolegnia australis in Big Muskellunge Lake, Wisconsin. Diseases of Aquatic Organisms 91: 57-66.

Lategan, M.J., and Gibson, L.F. (2003) Antagonistic activity of Aeromonas media strain A199 against Saprolegnia sp., an opportunistic pathogen of the eel, Anguilla australis Richardson. Journal of Fish Diseases 26: 147-153.

Lategan, M.J., Torpy, F.R., and Gibson, L.F. (2004a) Biocontrol of saprolegniosis in silver perch Bidyanus bidyanus (Mitchell) by Aeromonas media strain A199. Aquaculture 235: 77-88.

Lategan, M.J., Torpy, F.R., and Gibson, L.F. (2004b) Control of saprolegniosis in the eel Anguilla australis Richardson, by Aeromonas media strain A199. Aquaculture 240: 19-27.

Lee, S.D. (2010) Frondihabitans peucedani sp nov., an actinobacterium isolated from rhizosphere soil, and emended description of the genus Frondihabitans Greene et al. 2009. International Journal of Systematic and Evolutionary Microbiology 60: 1740-1744.

Lee, Y.M., Kim, E.H., Lee, H.K., and Hong, S.G. (2014) Biodiversity and physiological characteristics of Antarctic and Arctic lichens-associated bacteria. World Journal of Microbiology \& Biotechnology 30: 2711-2721.

Li, T.-L., Choroba, O.W., Hong, H., Williams, D.H., and Spencer, J.B. (2001) Biosynthesis of the vancomycin group of antibiotics: characterisation of a type III polyketide synthase in the pathway to (S)3,5-dihydroxyphenylglycine. Chemical Communications: 2156-2157.

Liu, F., Zhao, C.C., Xia, L., Yang, F., Chang, X., and Wang, Y.Q. (2011) Biofouling characteristics and identification of preponderant bacteria at different nutrient levels in batch tests of a recirculating cooling water system. Environmental Technology 32: 901-910.

Liu, Y., Rzeszutek, E., van der Voort, M., Wu, C.-H., Thoen, E., Skaar, I. et al. (2015) Diversity of aquatic Pseudomonas species and their activity against the fish pathogenic oomycete Saprolegnia. PLOS ONE 10: e0136241.

Liu, Y., de Bruijn, I., Jack, A.L.H., Drynan, K., van den Berg, A.H., Thoen, E. et al. (2014) Deciphering microbial landscapes of fish eggs to mitigate emerging diseases. ISME J 8: 2002-2014.

Lommen, A. (2009) MetAlign: interface-driven, versatile metabolomics tool for hyphenated full-scan mass spectrometry data preprocessing. Analytical Chemistry 81: 3079-3086. 
Makk, J., Acs, E., Marialigeti, K., and Kovacs, G. (2003) Investigations on the Danube gravel-biofilm diatom-associated bacterial communities. Biologia 58: 729-742.

Martel, A., Spitzen-van der Sluijs, A., Blooi, M., Bert, W., Ducatelle, R., Fisher, M.C. et al. (2013) Batrachochytrium salamandrivorans sp. nov. causes lethal chytridiomycosis in amphibians. Proceedings of the National Academy of Sciences 110: 15325-15329.

Mayanna, S., Peacock, C.L., Schaeffner, F., Grawunder, A., Merten, D., Kothe, E., and Buechel, G. (2015) Biogenic precipitation of manganese oxides and enrichment of heavy metals at acidic soil pH. Chemical Geology 402: 6-17.

Moore, J.E., Xu, J., and Millar, B.C. (2002) Diversity of the microflora of edible macroalga (Palmaria palmata). Food Microbiology 19: 249-257.

Murayama, M., Kakinuma, Y., Maeda, Y., Rao, J.R., Matsuda, M., Xu, J. et al. (2010) Molecular identification of airborne bacteria associated with aerial spraying of bovine slurry waste employing $16 \mathrm{~S}$ rRNA gene PCR and gene sequencing techniques. Ecotoxicology and Environmental Safety 73: 443447.

Nagarajan, M., Maruthanayagam, V., and Sundararaman, M. (2013) SAR analysis and bioactive potentials of freshwater and terrestrial cyanobacterial compounds: a review. Journal of Applied Toxicology 33: 313-349.

Nejad, P., Ramstedt, M., Granhall, U., Roos, S., and Mclvor, I. (2006) Biochemical characterization and identification of ice-nucleation-active (INA) willow pathogens by means of BIOLOG (R) MicroPlate, INA gene primers and PCR-based 16S rRNA-gene analyses. Journal of Plant Diseases and Protection 113: 97-106.

Nerurkar, M., Joshi, M., Pariti, S., and Adivarekar, R. (2013) Application of lipase from marine bacteria Bacillus sonorensis as an additive in detergent formulation. Journal of Surfactants and Detergents 16: 435-443.

O'Hagan, D. (1995) Biosynthesis of fatty acid and polyketide metabolites. Natural Product Reports 12: 1-32.

Olano, C., Méndez, C., and Salas, J. (2009) Antitumor compounds from marine actinomycetes. Marine Drugs 7: 210.

Ortega-Morales, B.O., Santiago-Garcia, J.L., Chan-Bacab, M.J., Moppert, X., Miranda-Tello, E., Fardeau, M.L. et al. (2007) Characterization of extracellular polymers synthesized by tropical intertidal biofilm bacteria. Journal of Applied Microbiology 102: 254-264.

Ozaktas, T., Taskin, B., and Gozen, A.G. (2012) High level multiple antibiotic resistance among fish surface associated bacterial populations in non-aquaculture freshwater environment. Water Research 46: 6382-6390.

Paul, V.J., Puglisi, M.P., and Ritson-Williams, R. (2006) Marine chemical ecology. Natural Product Reports 23: 153-180.

Pereira, S.I.A., and Castro, P.M.L. (2014) Diversity and characterization of culturable bacterial endophytes from Zea mays and their potential as plant growth-promoting agents in metal-degraded soils. Environmental Science and Pollution Research 21: 14110-14123.

Pfeifer, V., Nicholson, G.J., Ries, J., Recktenwald, J., Schefer, A.B., Shawky, R.M. et al. (2001) A polyketide synthase in glycopeptide biosynthesis: the biosynthesis of the non-proteinogenic amino acid (S)-3,5-dihydroxyphenylglycine. J Biol Chem 276: 38370-38377.

Phillips, A.J., Anderson, V.L., Robertson, E.J., Secombes, C.J., and van West, P. (2008) New insights into animal pathogenic oomycetes. Trends in Microbiology 16: 13-19.

Pokhrel, A.R., Dhakal, D., Jha, A.K., and Sohng, J.K. (2015) Herboxidiene biosynthesis, production, and structural modifications: prospect for hybrids with related polyketide. Applied Microbiology and Biotechnology 99: 8351-8362.

Rabe, P., Citron, C.A., and Dickschat, J.S. (2013) Volatile terpenes from actinomycetes: a biosynthetic study correlating chemical analyses to genome data. Chembiochem 14: 2345-2354. 
Reid, H.I., Treasurer, J.W., Adam, B., and Birkbeck, T.H. (2009) Analysis of bacterial populations in the gut of developing cod larvae and identification of Vibrio logei, Vibrio anguillarum and Vibrio splendidus as pathogens of cod larvae. Aquaculture 288: 36-43.

Rijavec, T., Lapanje, A., Dermastia, M., and Rupnik, M. (2007) Isolation of bacterial endophytes from germinated maize kernels. Canadian Journal of Microbiology 53: 802-808.

Rohr, J. (1992) Comparison of multicyclic polyketides by folding analysis: a novel approach to recognize biosynthetic and/or evolutionary interrelationships of the natural products or intermediates and its exemplification on hepta-, octa-, and decaketides. The Journal of Organic Chemistry 57: 52175223.

Romero, F., Fernández-Chimeno, R., de la Fuente, J., and Barredo, J.-L. (2012) Selection and taxonomic identification of carotenoid-producing marine actinomycetes. In Microbial Carotenoids from Bacteria and Microalgae. Barredo, J.-L. (ed): Humana Press, pp. 13-20.

Rudolf, I., Mendel, J., Sikutova, S., Svec, P., Masarikova, J., Novakova, D. et al. (2009) 16S rRNA gene-based identification of cultured bacterial flora from host-seeking Ixodes ricinus, Dermacentor reticulatus and Haemaphysalis concinna ticks, vectors of vertebrate pathogens. Folia Microbiologica 54: 419-428.

Sarmiento-Ramírez, J.M., Abella-Pérez, E., Phillott, A.D., Sim, J., van West, P., Martín, M.P. et al. (2014) Global distribution of two fungal pathogens threatening endangered sea turtles. PLoS ONE 9: e85853.

Seemann, T. (2014) Prokka: rapid prokaryotic genome annotation. Bioinformatics 30: 2068-2069.

Seghal Kiran, G., Nishanth Lipton, A., Kennedy, J., Dobson, A.D., and Selvin, J. (2014) A halotolerant thermostable lipase from the marine bacterium Oceanobacillus sp. PUMB02 with an ability to disrupt bacterial biofilms. Bioengineered 5: 305-318.

Shen, S.Y., and Fulthorpe, R. (2015) Seasonal variation of bacterial endophytes in urban trees. Frontiers in Microbiology 6.

Shirling, E.B., and Gottlieb, D. (1966) Methods for characterization of Streptomyces species1. International Journal of Systematic and Evolutionary Microbiology 16: 313-340.

Sierra, G. (1957) A simple method for the detection of lipolytic activity of micro-organisms and some observations on the influence of the contact between cells and fatty substrates. Antonie van Leeuwenhoek 23: 15-22.

Silbaq, F.S. (2009) Viable ultramicrocells in drinking water. Journal of Applied Microbiology 106: 106-117.

Skjermo, J., Bakke, I., Dahle, S.W., and Vadstein, O. (2015) Probiotic strains introduced through live feed and rearing water have low colonizing success in developing Atlantic cod larvae. Aquaculture 438: 17-23.

Snel, B., Bork, P., and Huynen, M.A. (2002) The identification of functional modules from the genomic association of genes. Proceedings of the National Academy of Sciences 99: 5890-5895.

Suthindhiran, K., Sarath Babu, V., Kannabiran, K., Ishaq Ahmed, V.P., and Sahul Hameed, A.S. (2011) Anti-fish nodaviral activity of furan-2-yl acetate extracted from marine Streptomyces spp. Natural Product Research 25: 834-843.

Taylor, S.G., and Bailey, J.E. (1979) Saprolegnia - control of fungus on incubating eggs of pink salmon by treatment with seawater. Progressive Fish-Culturist 41: 181-183.

Tiago, I., Chung, A.P., and Verissimo, A. (2004) Bacterial diversity in a nonsaline alkaline environment: heterotrophic aerobic populations. Applied and Environmental Microbiology 70: 73787387.

Tikunov, Y.M., Laptenok, S., Hall, R.D., Bovy, A., and de Vos, R.C.H. (2012) MSClust: a tool for unsupervised mass spectra extraction of chromatography-mass spectrometry ion-wise aligned data. Metabolomics 8: 714-718.

Trifonova, R., Postma, J., Ketelaars, J.J.M.H., and van Elsas, J.D. (2008) Thermally treated grass fibers as colonizable substrate for beneficial bacterial inoculum. Microbial Ecology 56: 561-571. 
van den Berg, A.H., McLaggan, D., Dieguez-Uribeond, J., and van West, P. (2013) The impact of the water moulds Saprolegnia diclina and Saprolegnia parasitica on natural ecosystems and the aquaculture industry. Fungal Biology Reviews 27: 33-42.

van der Hooft, J.J.J., Vervoort, J., Bino, R.J., Beekwilder, J., and de Vos, R.C.H. (2011) Polyphenol identification based on systematic and robust high-resolution accurate mass spectrometry fragmentation. Analytical Chemistry 83: 409-416.

van West, P. (2006) Saprolegnia parasitica, an oomycete pathogen with a fishy appetite: new challenges for an old problem. Mycologist 20: 99-104.

Vasileva-Tonkova, E., Romanovskaya, V., Gladka, G., Gouliamova, D., Tomova, I., StoilovaDisheva, M., and Tashyrev, O. (2014) Ecophysiological properties of cultivable heterotrophic bacteria and yeasts dominating in phytocenoses of Galindez Island, maritime Antarctica. World Journal of Microbiology \& Biotechnology 30: 1387-1398.

Wang, H.-F., Zhang, Y.-G., Chen, J.-Y., Guo, J.-W., Li, L., Hozzein, W.N. et al. (2015) Frigoribacterium endophyticum sp nov., an endophytic actinobacterium isolated from the root of Anabasis elatior (C. A. Mey.) Schischk. International Journal of Systematic and Evolutionary Microbiology 65: 1207-1212.

Wang, W.-G., Li, A., Yan, B.-C., Niu, S.-B., Tang, J.-W., Li, X.-N. et al. (2016) LC-MS-guided isolation of penicilfuranone $A$ : a new antifibrotic furancarboxylic acid from the plant endophytic fungus Penicillium sp. sh18. Journal of Natural Products 79: 149-155.

Weber, T., Blin, K., Duddela, S., Krug, D., Kim, H.U., Bruccoleri, R. et al. (2015) antiSMASH 3.0-a comprehensive resource for the genome mining of biosynthetic gene clusters. Nucleic Acids Research 43: W237-W243.

Wesseling, W. (2015) Beneficial biofilms in marine aquaculture? Linking points of biofilm formation mechanisms in Pseudomonas aeruginosa and Pseudoalteromonas species. AIMS Bioengineering 2: 104-125.

Whelan, S., and Goldman, N. (2001) A general empirical model of protein evolution derived from multiple protein families using a maximum-likelihood approach. Mol Biol Evol 18: 691-699.

Wierckx, N., Koopman, F., Ruijssenaars, H.J., and de Winde, J.H. (2011) Microbial degradation of furanic compounds: biochemistry, genetics, and impact. Applied Microbiology and Biotechnology 92: 1095-1105.

Wierckx, N., Koopman, F., Bandounas, L., De Winde, J.H., and Ruijssenaars, H.J. (2010) Isolation and characterization of Cupriavidus basilensis HMF14 for biological removal of inhibitors from lignocellulosic hydrolysate. Microbial Biotechnology 3: 336-343.

Woodhams, D.C., Bosch, J., Briggs, C.J., Cashins, S., Davis, L.R., Lauer, A. et al. (2011) Mitigating amphibian disease: strategies to maintain wild populations and control chytridiomycosis. Frontiers in Zoology 8.

Zhang, L., Xu, Z., and Patel, B.K.C. (2007) Frondicola australicus gen. nov., sp nov., isolated from decaying leaf litter from a pine forest. International Journal of Systematic and Evolutionary Microbiology 57: 1177-1182.

Zhou, Y., Liang, Y., Lynch, K.H., Dennis, J.J., and Wishart, D.S. (2011) PHAST: a fast phage search tool. Nucleic Acids Research. 


\section{Supporting information}

Table S1 Identification of genes encoding proteases and lipases and genes associated with biofilm formation in the genome of Frondihabitans sp. 762G35. Microbacteriaceae or Actinobacteria reference genes were downloaded from GenBank and similar protein sequences in Frondihabitans sp. 762G35 were identified by BLASTp (e-value $<10^{-5}$ ). For each blast hit, the percentage of identity to Frondihabitans sp. $762 \mathrm{G} 35$ is indicated. Next to the blast searches, the terms 'protease' (including both intracellular and extracellular proteases), 'lipase' and 'biofilm' were searched in the gene descriptions of Frondihabitans sp. $762 \mathrm{G} 35$ and the corresponding genes are indicated in the table. The presence ('+') or absence ('-') of these genes in the reference genomes of Frondihabitans sp. Leaf304 and Frigoribacterium sp. Leaf415 is also indicated. NONE indicates gene name is not available.

\begin{tabular}{|c|c|c|c|c|c|}
\hline $\begin{array}{l}\text { Frondihabitans } \\
762 \text { G35 gene ID }\end{array}$ & $\begin{array}{l}\text { Gene name and } \\
\text { description }\end{array}$ & $\begin{array}{l}\text { Present } \\
\text { Frondihabitans } \\
\text { sp. Leaf304 }\end{array}$ & $\begin{array}{l}\text { in genome } \\
\text { Frigoribacterium } \\
\text { sp. Leaf415 }\end{array}$ & $\begin{array}{l}\text { Query (GenBank accession number, } \\
\text { name and organism) used in BLASTp }\end{array}$ & $\begin{array}{l}\% \\
\text { identity }\end{array}$ \\
\hline \multicolumn{6}{|l|}{ Lipase } \\
\hline 16115 & $\begin{array}{l}\text { nlhH_2|Carboxylesterase } \\
\mathrm{NlhH}\end{array}$ & - & - & $\begin{array}{l}\text { ACD89058 lipase [Brachybacterium } \\
\text { tyrofermentans] }\end{array}$ & 33,74 \\
\hline 16045 & $\begin{array}{l}\text { nlhH_1|Carboxylesterase } \\
\mathrm{NIhH}\end{array}$ & + & + & $\begin{array}{l}\text { ACD89058 lipase [Brachybacterium } \\
\text { tyrofermentans] }\end{array}$ & 33,19 \\
\hline 11900 & $\begin{array}{l}\text { lipR|Putative acetyl- } \\
\text { hydrolase LipR }\end{array}$ & - & - & $\begin{array}{l}\text { ACD89058 lipase [Brachybacterium } \\
\text { tyrofermentans] }\end{array}$ & 26,81 \\
\hline 11900 & $\begin{array}{l}\text { lipR|Putative acetyl- } \\
\text { hydrolase LipR }\end{array}$ & - & - & $\begin{array}{l}\text { ACD89059 lipase [Rhodococcus } \\
\text { erythropolis] }\end{array}$ & 31,61 \\
\hline 16045 & $\begin{array}{l}\text { nlhH_1|Carboxylesterase } \\
\text { NlhH }\end{array}$ & + & + & $\begin{array}{l}\text { ACD89059 lipase [Rhodococcus } \\
\text { erythropolis] }\end{array}$ & 31,51 \\
\hline 16115 & $\begin{array}{l}\text { nlhH_2|Carboxylesterase } \\
\mathrm{NIhH}\end{array}$ & - & - & $\begin{array}{l}\text { ACD89059 lipase [Rhodococcus } \\
\text { erythropolis] }\end{array}$ & 30,09 \\
\hline 04655 & NONE|Lipase 2 & - & - & - & - \\
\hline 13125 & NONE|Lipase 2 & - & - & - & - \\
\hline 13425 & $\begin{array}{l}\text { ytpA_1|Phospholipase } \\
\text { YtpA }\end{array}$ & + & + & - & - \\
\hline 15310 & $\begin{array}{l}\text { ytpA_2|Phospholipase } \\
\text { YtpA }\end{array}$ & - & - & - & - \\
\hline \multicolumn{6}{|l|}{ Protease } \\
\hline 04515 & $\begin{array}{l}\text { htrA_1|Putative serine } \\
\text { protease HtrA }\end{array}$ & + & - & $\begin{array}{l}\text { WP_025157174 serine protease } \\
\text { [Leifsonia aquatica] }\end{array}$ & 60,39 \\
\hline 06550 & $\begin{array}{l}\text { htrA_2|Putative serine } \\
\text { protease HtrA }\end{array}$ & + & + & $\begin{array}{l}\text { WP_025157174 serine protease } \\
\text { [Leifsonia aquatica] }\end{array}$ & 48,75 \\
\hline 00065 & $\begin{array}{l}\text { gluP|Rhomboid protease } \\
\text { GluP }\end{array}$ & + & + & - & - \\
\hline 00350 & $\begin{array}{l}\text { bepA|Beta-barrel } \\
\text { assembly-enhancing } \\
\text { protease }\end{array}$ & - & - & - & - \\
\hline 00360 & $\begin{array}{l}\text { ftsH_1|ATP-dependent } \\
\text { zinc metalloprotease } \\
\text { FtsH }\end{array}$ & - & - & - & - \\
\hline 00720 & $\begin{array}{l}\text { ftsH_2|ATP-dependent } \\
\text { zinc metalloprotease } \\
\text { Fts }\end{array}$ & + & + & - & - \\
\hline 00785 & $\begin{array}{l}\text { clpC1|ATP-dependent } \\
\text { Clp protease ATP- } \\
\text { binding subunit CIpC1 }\end{array}$ & + & + & - & - \\
\hline 01725 & $\begin{array}{l}\text { paiA_1|Protease } \\
\text { synthase and sporulation } \\
\text { negative regulatory } \\
\text { protein PAI } 1\end{array}$ & - & - & - & - \\
\hline 02055 & $\begin{array}{l}\text { clpS|ATP-dependent Clp } \\
\text { protease adapter protein } \\
\text { ClpS }\end{array}$ & + & - & - & - \\
\hline 03850 & $\begin{array}{l}\text { isp|Intracellular serine } \\
\text { protease }\end{array}$ & + & + & - & - \\
\hline 04490 & lon1|Lon protease 1 & + & + & - & - \\
\hline 04515 & $\begin{array}{l}\text { htrA_1|Putative serine } \\
\text { protease HtrA }\end{array}$ & + & - & - & - \\
\hline 04895 & $\begin{array}{l}\text { iga_1|lmmunoglobulin } \\
\text { A1 protease }\end{array}$ & - & - & - & - \\
\hline 05060 & $\begin{array}{l}\text { paiB|Protease synthase } \\
\text { and sporulation protein } \\
\text { PAI } 2\end{array}$ & - & - & - & - \\
\hline 05100 & $\begin{array}{l}\text { clpP2_1|ATP-dependent } \\
\text { Clp protease proteolytic } \\
\text { subunit } 2\end{array}$ & + & + & - & - \\
\hline 05105 & $\begin{array}{l}\text { clpP2_2|ATP-dependent } \\
\text { Clp protease proteolytic }\end{array}$ & - & + & - & - \\
\hline
\end{tabular}




\begin{tabular}{|c|c|c|c|c|c|}
\hline \\
\hline 05110 & $\begin{array}{l}\text { clpX|ATP-dependent Clp } \\
\text { protease ATP-binding } \\
\text { subunit ClpX }\end{array}$ & + & + & - & - \\
\hline 05445 & ptrB|Protease 2 & + & + & - & - \\
\hline 05530 & prsW|Protease PrsW & + & + & - & - \\
\hline 05610 & $\begin{array}{l}\text { NONE|putative zinc } \\
\text { protease }\end{array}$ & + & + & - & - \\
\hline 06280 & $\begin{array}{l}\text { iga_2|Immunoglobulin } \\
\text { A1 protease }\end{array}$ & - & + & - & - \\
\hline 06550 & $\begin{array}{l}\text { htrA_2|Putative serine } \\
\text { protease HtrA }\end{array}$ & + & + & - & - \\
\hline 06925 & $\begin{array}{l}\text { hflK|Modulator of FtsH } \\
\text { protease HflK }\end{array}$ & + & + & - & - \\
\hline 08795 & $\begin{array}{l}\text { rip1|Zinc metalloprotease } \\
\text { Rip1 }\end{array}$ & - & + & - & - \\
\hline 11620 & NONE|Protease 1 & + & - & - & - \\
\hline 12485 & $\begin{array}{l}\text { clpC|ATP-dependent Clp } \\
\text { protease ATP-binding } \\
\text { subunit ClpC }\end{array}$ & - & - & - & - \\
\hline 13830 & $\begin{array}{l}\text { paiA_2|Protease } \\
\text { synthase and sporulation } \\
\text { negative regulatory } \\
\text { protein PAI } 1\end{array}$ & + & - & - & - \\
\hline 14815 & $\begin{array}{l}\text { ftsH_3|ATP-dependent } \\
\text { zinc metalloprotease } \\
\text { FtsH }\end{array}$ & - & - & - & - \\
\hline \multicolumn{6}{|l|}{ Biofilm } \\
\hline 10225 & $\begin{array}{l}\text { birA_1|Bifunctional } \\
\text { ligase/repressor BirA }\end{array}$ & - & - & $\begin{array}{l}\text { WP_022893652 biofilm PGA synthesis } \\
\text { protein PgaB [Agromyces subbeticus] }\end{array}$ & 41,61 \\
\hline 10225 & $\begin{array}{l}\text { birA_1|Bifunctional } \\
\text { ligase/repressor BirA }\end{array}$ & - & - & $\begin{array}{l}\text { KRC52209 biofilm PGA synthesis protein } \\
\text { PgaB [Leifsonia sp. Root227] }\end{array}$ & 47,01 \\
\hline 10225 & $\begin{array}{l}\text { birA_1|Bifunctional } \\
\text { ligase/repressor BirA }\end{array}$ & - & - & $\begin{array}{l}\text { KQR52152 biofilm PGA synthesis protein } \\
\text { PgaB [Leifsonia sp. Leaf336] }\end{array}$ & 45,35 \\
\hline 10225 & $\begin{array}{l}\text { birA_1|Bifunctional } \\
\text { ligase/repressor BirA }\end{array}$ & - & - & $\begin{array}{l}\text { WP_022888292 biofilm PGA synthesis } \\
\text { protein PgaB [Agromyces italicus] }\end{array}$ & 44,14 \\
\hline 10225 & $\begin{array}{l}\text { birA_1|Bifunctional } \\
\text { ligase/repressor BirA }\end{array}$ & - & - & $\begin{array}{l}\text { WP_ } 022881549 \text { biofilm PGA synthesis } \\
\text { protein PgaB [Gryllotalpicola } \\
\text { ginsengisoli] }\end{array}$ & 50,17 \\
\hline 09490 & $\begin{array}{l}\text { bigR|Biofilm growth- } \\
\text { associated repressor }\end{array}$ & - & - & - & - \\
\hline 10200 & $\begin{array}{l}\text { brpA_1|Biofilm regulatory } \\
\text { protein } A\end{array}$ & - & + & - & - \\
\hline 13250 & $\begin{array}{l}\text { brpA_2|Biofilm regulatory } \\
\text { protein A }\end{array}$ & + & - & - & - \\
\hline
\end{tabular}


Table S2 Chemical analyses revealed 29 metabolites that were significantly accumulated at least under one of the growth stages when compared to the medium control. Statistical significant different metabolites were determined by independent-samples $t$-test $(P<0.05)$ and fold change in accumulation (fold change >2). Growth stages include growth of Frondihabitans sp. 762G35 on day 7, 14, 21 and 27.

\begin{tabular}{|c|c|c|c|c|c|c|c|c|c|}
\hline \multirow{2}{*}{$\begin{array}{l}\text { Mass } \\
\text { (Da) }[M-H)\end{array}$} & \multirow{2}{*}{$\begin{array}{l}\text { Retention } \\
\text { time (min) }\end{array}$} & \multicolumn{4}{|c|}{ Average intenstiy } & \multicolumn{4}{|c|}{ Independent-samples $t$-test } \\
\hline & & Day7 & Day14 & Day21 & Day27 & Day7 & Day14 & Day21 & Day27 \\
\hline 412.571 & 3.2 & 11462 & 14154 & 14871 & 14744 & 0 & 0 & 0 & 0 \\
\hline 217.119 & 5 & 2057 & 7279 & 10092 & 11699 & 0 & 0 & 0 & 0 \\
\hline $353.0727^{[3]}$ & 5.1 & 4322 & 66159 & 138145 & 185688 & 3.50E-05 & $5.00 \mathrm{E}-06$ & 0 & 0 \\
\hline $111.008^{[3]}$ & 5.1 & 10032 & 87117 & 178527 & 243188 & $5.00 \mathrm{E}-06$ & $6.00 \mathrm{E}-06$ & 0 & 0 \\
\hline 302.971 & 5.2 & $N D^{[1]}$ & ND & 3371 & 5686 & $\mathrm{NS}^{[2]}$ & $2.00 \mathrm{E}-06$ & 0 & 0 \\
\hline 459.016 & 5.3 & ND & ND & 3207 & 4179 & NS & 4.30E-03 & 0 & 0 \\
\hline 465.05 & 5.7 & ND & 2164 & 4046 & 5051 & NS & 0 & 0 & 0 \\
\hline 293.081 & 6.4 & ND & 5754 & 6845 & 9845 & NS & 0 & 0 & 0 \\
\hline $173.009^{[3]}$ & 6.4 & ND & 15761 & 33331 & 41357 & NS & 0 & 0 & 0 \\
\hline 345.094 & 10.8 & ND & 12328 & 18295 & 17269 & NS & 0 & 0 & 0 \\
\hline 284.125 & 19.7 & 4149 & 22947 & 29197 & 32026 & $5.20 \mathrm{E}-04$ & 0 & 0 & 0 \\
\hline 343.114 & 19.7 & ND & 11409 & 13926 & 15577 & NS & 0 & 0 & 0 \\
\hline 335.092 & 20.6 & ND & 3108 & 4955 & 4891 & NS & 0 & 0 & 0 \\
\hline 245.114 & 21.6 & 5073 & 10274 & 10718 & 10709 & 2.10E-02 & 0 & 0 & 0 \\
\hline 287.125 & 22.4 & ND & 9117 & 11969 & 13425 & NS & 0 & 0 & 0 \\
\hline 259.13 & 22.7 & 5164 & 12665 & 37918 & 52100 & NS & 0 & 0 & 0 \\
\hline 375.131 & 23.1 & ND & ND & 2678 & 3239 & NS & $6.80 \mathrm{E}-03$ & 3.30E-05 & 0 \\
\hline 295.13 & 24.9 & 2131 & 5318 & 8739 & 16270 & $2.60 \mathrm{E}-05$ & 0 & 0 & 0 \\
\hline 281.114 & 25.2 & ND & 4643 & 7330 & 7581 & NS & 0 & 0 & 0 \\
\hline 338.172 & 25.7 & 4032 & 14280 & 16094 & 17354 & $1.00 \mathrm{E}-06$ & 0 & 0 & 0 \\
\hline 349.161 & 26.6 & ND & 2859 & 3106 & 3222 & 1.10E-03 & 2.70E-05 & 0 & 0 \\
\hline 145.087 & 26.9 & ND & 8196 & 15356 & 22828 & NS & 0 & 0 & 0 \\
\hline 147.045 & 27.6 & ND & 5933 & 17795 & 23855 & NS & 0 & 0 & 0 \\
\hline 164.072 & 28.4 & 5261 & 16896 & 23881 & 19135 & $8.40 \mathrm{E}-04$ & 0 & 0 & 0 \\
\hline 326.172 & 28.6 & 2724 & 6842 & 7836 & 8555 & 3.00E-05 & 0 & 0 & 0 \\
\hline 480.246 & 30.1 & ND & 2194 & 2135 & 2163 & 7.70E-03 & $1.00 \mathrm{E}-06$ & 0 & 0 \\
\hline 411.167 & 30.1 & 2698 & 5823 & 6739 & 6800 & 1.00E-05 & 0 & 0 & 0 \\
\hline 173.024 & 31.4 & ND & 3133 & 5488 & 8495 & NS & 0 & 0 & 0 \\
\hline 491.251 & 33.1 & ND & 8325 & ND & ND & NS & $6.00 \mathrm{E}-06$ & NS & NS \\
\hline
\end{tabular}

["]ND, not detected

${ }^{[2]} \mathrm{NS}$, not significant $(P<0.05)$

${ }^{[3]}$ Metabolites that were subjected to $\mathrm{MS}^{3}$ analysis 


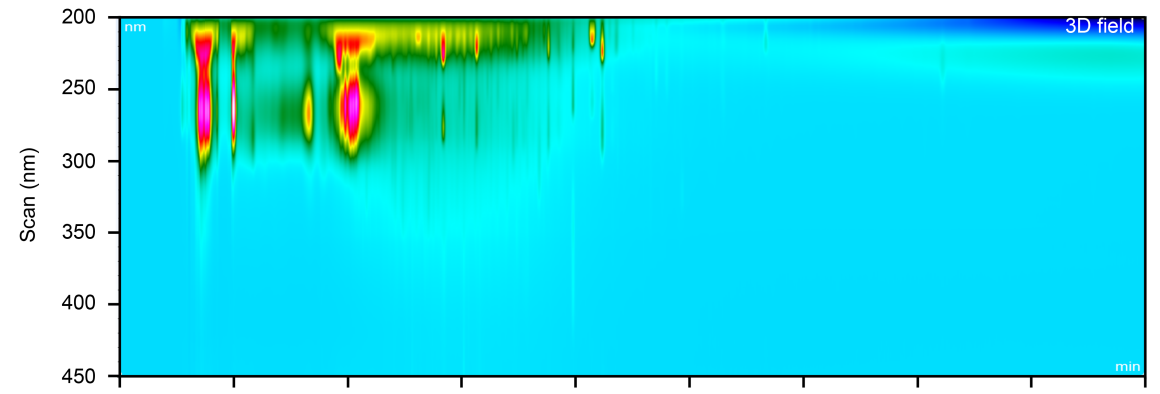

B

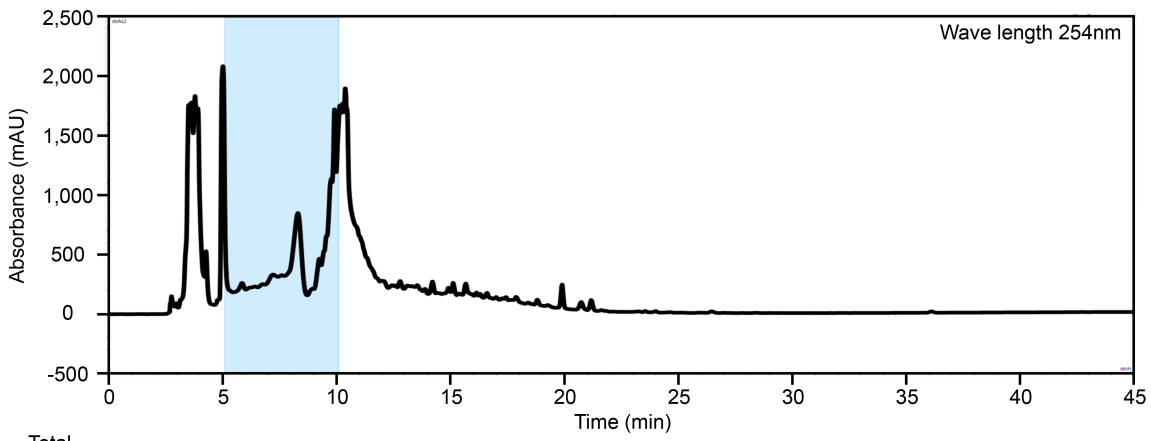

C

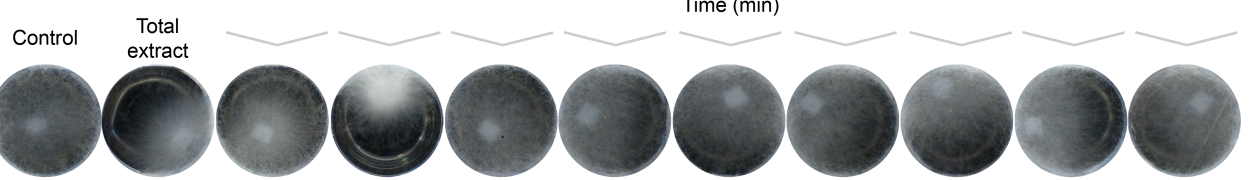

Figure S1 HPLC analyses of cell-free culture fractions from Frondihabitans $765 \mathrm{G} 35$ and their effect on Saprolegnia diclina 1152F4. 3D field (A) and chromatogram (B) of HPLC analyses of cell-free culture from Frondihabitans $765 \mathrm{G} 35$ collected after 21 days of incubation. The chromatogram was visualized at wave length of $254 \mathrm{~nm}$. (C) Effect of HPLC fractions on hyphal growth of S. diclina 1152F4. The HPLC fractions were collected every $5 \mathrm{~min}$ over $45 \mathrm{~min}$, air-dried, lyophilized, dissolved in $50 \%$ methanol and added to fresh $1 / 5^{\text {th }}$ strength malt extract broth at 2.5 times concentrated level than the original culture. The test was conducted with 300-500 $\mu \mathrm{l}$ of the fractions in each well of a 48 -wells plate. One S. diclina $1152 \mathrm{~F} 4$ hyphal plug of about $2 \mathrm{~mm}^{2}$ was added to each well and the culture was incubated at $5^{\circ} \mathrm{C}$. The effect of HPLC fractions on hyphal growth of $S$. diclina was determined after 7-18 days. The total lyophilized culture dissolved in 50\% methanol and 50\% methanol alone, were used as positive and negative controls, respectively. 


\section{Chapter 4}

\section{Diversity of aquatic Pseudomonas species and their activity against the fish pathogenic oomycete Saprolegnia}

Yiying Liu, Elzbieta Rzeszutek, Menno van der Voort, Cheng-Hsuan Wu, Even Thoen, Ida Skaar, Vincent Bulone, Pieter C. Dorrestein, Jos M. Raaijmakers and Irene de Bruijn

This chapter has been published as:

Yiying Liu, Elzbieta Rzeszutek, Menno van der Voort, Cheng-Hsuan Wu, Even Thoen, Ida Skaar, Vincent Bulone, Pieter C. Dorrestein, Jos M. Raaijmakers, Irene de Bruijn. (2015). Diversity of aquatic Pseudomonas species and their activity against the fish pathogenic oomycete Saprolegnia. PLoS ONE 10(8): e0136241. doi:10.1371/journal.pone.0136241. 


\section{Abstract}

Emerging fungal and oomycete pathogens are increasingly threatening animals and plants globally. Amongst oomycetes, Saprolegnia species adversely affect wild and cultivated populations of amphibians and fish, leading to substantial reductions in biodiversity and food productivity. With the ban of several chemical control measures, new sustainable methods are needed to mitigate Saprolegnia infections in aquaculture. Here, PhyloChip-based community analyses showed that the Pseudomonadales, particularly Pseudomonas species, represent one of the largest bacterial orders associated with salmon eggs from a commercial hatchery. Among the Pseudomonas species isolated from salmon eggs, significantly more biosurfactant producers were retrieved from healthy salmon eggs than from Saprolegnia-infected eggs. Subsequent in vivo activity bioassays showed that Pseudomonas isolate $\mathrm{H} 6$ significantly reduced salmon egg mortality caused by Saprolegnia diclina. Live colony mass spectrometry showed that strain H6 produces a viscosin-like lipopeptide surfactant. This biosurfactant inhibited growth of Saprolegnia in vitro, but no significant protection of salmon eggs against Saprolegniosis was observed. These results indicate that live inocula of aquatic Pseudomonas strains, instead of their bioactive compound, can provide new (micro)biological and sustainable means to mitigate oomycete diseases in aquaculture.

\section{Introduction}

Emerging fungal and fungal-like diseases are causing severe ecological disruptions and are recognised as a global threat to biodiversity and food security (Fisher et al., 2012; Gozlan et al., 2014). For example, Fusarium solani is involved in mass mortality of eggs of the endangered sea turtles in Cape Verde (SarmientoRamírez et al., 2014), and Batrachochytrium dendrobatidis and B. salmandrivorans are causing major amphibian declines globally (Woodhams et al., 2011; Martel et al., 2013). Amongst oomycetes, Aphanomyces and Saprolegnia species are causing significant declines in crayfish, fish and amphibian populations (van West, 2006; Fernández-Benéitez et al., 2008; Phillips et al., 2008; Krugner-Higby et al., 2010; Bruno et al., 2011; Fisher et al., 2012; van den Berg et al., 2013). Saprolegnia species are the causative agents of Saprolegniosis, a disease characterized by fluffy and filamentous white or grey mycelial patches on fish, fish eggs or amphibians (van West, 2006). In aquaculture, Saprolegnia species regularly infect freshwater cultured salmonids, including Atlantic salmon and rainbow trout, and non-salmonids like eel, perch, carp and catfish (Bruno et al., 2011; Das et al., 2012). In Japan, at least 50\% annual mortality in Coho salmon 
due to Saprolegniosis was reported (Hatai and Hoshiai, 1992; Hatai and Hoshiai, 1994; Bruno et al., 2011). Also the 'winter kill' by Saprolegnia species in channel catfish in the USA resulted in a substantial financial loss of approximately $\$ 40$ million (Bruno et al., 2011).

Formalin is now commonly used to control Saprolegniosis, but is expected to be banned soon due to adverse environmental effects (Bruno et al., 2011). Several treatments have been tested to prevent Saprolegniosis, such as hydrogen cyanide, Pyceze $^{\circledR}$ (bronopol), sea water flushes and $\mathrm{NaCl}$, but none of these measures exerted control to a level similar as obtained with malachite green, a chemical banned due to its carcinogenic properties (Bruno et al., 2011). Currently, no vaccination is available for Saprolegniosis (van den Berg et al., 2013). Therefore, new sustainable measures are urgently needed. A potential approach to control Saprolegniosis and other emerging diseases involves the application of beneficial microbes. A limited number of bacterial genera and species, including Aeromonas and Pseudomonas, have been reported as potential anti-pathogen agents in aquaculture, but a comprehensive understanding of the microbiome composition of fish eggs and their protective potential is still limited (Hatai and Willoughby, 1988; Bly et al., 1997; Hussein and Hatai, 2001; Lategan and Gibson, 2003; Lategan et al., 2004a, b; Carbajal-González et al., 2011).

In previous work, we detected 31,281 bacterial and archaeal operational taxonomic units (OTUs) on salmon eggs from a hatchery by PhyloChip metataxonomic analysis. The highest number of OTUs belonged to Proteobacteria (Liu et al., 2014). Based on this large-scale metataxonomic analysis, the diversity of salmon egg-associated Proteobacteria and their functional potential to protect fish eggs against Saprolegnia were investigated in this study. We focused specifically on the Pseudomonadales and isolated several Pseudomonas strains, assessed their genotypic diversity and tested their inhibitory activity against Saprolegnia species both in vitro and in vivo. Given the zoosporicidal activity of biosurfactants produced by Pseudomonas species (De Souza et al., 2003; Raaijmakers et al., 2006; de Bruijn et al., 2007), the isolates obtained from salmon eggs were also phenotypically screened for biosurfactant production. For the Pseudomonas isolate that provided the best protection against Saprolegniosis on salmon eggs, chemical profiling was performed by Nanospray Desorption ElectroSpray lonization (NanoDESI) live colony mass spectrometry followed by MS/MS analysis for partial identification of the biosurfactant. 


\title{
Materials and Methods
}

\author{
Isolation of bacteria associated with salmon eggs
}

Healthy and Saprolegnia-infected salmon eggs ( $N=6$ for healthy and $N=6$ for diseased eggs) and their corresponding incubation water was collected from a commercial hatchery (Liu et al., 2014). To release bacteria from the surface of eggs, approximately 30 eggs and $20 \mathrm{ml}$ of incubation water of each sample was transferred into a glass tube, vortexed for one minute, sonicated for one minute and vortexed again for one minute. The total culturable bacteria were isolated and enumerated by plating on $1 / 10^{\text {th }}$ strength tryptone soya broth (Oxoid) with 15-20 $\mathrm{gl}^{-1}$ agar (1/10TSA) supplemented with $100 \mathrm{\mu g} \mathrm{ml}^{-1}$ Delvocid (DSM, Delft, Netherlands) to inhibit fungal growth. Pseudomonas strains were isolated and enumerated on semi-selective Pseudomonas agar F (PSA, Difco ${ }^{\mathrm{TM}}$ ) supplemented with $100 \mathrm{\mu g} \mathrm{ml}^{-1}$ Delvocid, 12.5 $\mu \mathrm{g} \mathrm{ml}^{-1}$ chloramphenicol and $50 \mathrm{\mu g} \mathrm{ml}^{-1}$ ampicillin. Both media were incubated at $25^{\circ} \mathrm{C}$ for 4 days. From each replicate sample and each growth medium, approximately 40 bacterial isolates were randomly selected and stored, which resulted in a total of approximately 900 random bacterial isolates.

\section{In vitro activity and biosurfactant production by the bacterial isolates}

All bacterial isolates were tested for activity against Saprolegnia diclina strain VS20 and Saprolegnia parasitica strain CBS 223.65 (C65) according to Liu et al. (2014). Bacteria were spot-inoculated at the edge of plates of $1 / 5^{\text {th }}$ strength potato dextrose broth (Difco ${ }^{\mathrm{TM}}$ ) with $15-20 \mathrm{~g} \mathrm{I}^{-1}$ agar (1/5PDA) and incubated for $2-4$ days at $25^{\circ} \mathrm{C}$ prior to inoculation of a plug of Saprolegnia in the centre of a 1/5PDA plate. Hyphal growth inhibition was monitored for all bacterial isolates during incubation for 4-5 days at $18^{\circ} \mathrm{C}$. All bacterial isolates were also screened for biosurfactant production by the drop collapse assay according to the method described by de Bruijn et al. (2007).

\section{Identification and phylogeny of bacterial isolates}

Pseudomonas isolates inhibiting Saprolegnia hyphal growth and/or producing biosurfactants were subjected to BOX-PCR fingerprinting using primer BOX A1R (Versalovic et al., 1994; Rademaker et al., 1998). Representative isolates from the BOX groups with at least 4 isolates for diseased or for healthy salmon egg samples were chosen for phylogenetic analysis. Therefore, a total of 27 representative isolates (S1 Table) were selected and identified by $16 \mathrm{~S}$ rRNA sequencing. Phylogenetic analyses, including the 16S rRNA sequences of 29 known reference strains (Loper et al., 2012), was performed according to Liu et al. (2014). The evolutionary distances were calculated using the Kimura 2-parameter method (Kimura, 1980).

\section{In vivo bioassays to test disease suppression by Proteobacteria}

The representative isolates were chosen for activity testing in salmon egg bioassays (Table S1). From the shared representative isolates, Pseudomonas isolates S1 and S2, which belonged to the largest shared BOX group and originated from both healthy and diseased salmon eggs were selected. Collectively, a total of 11 representative isolates were selected for activity testing in salmon egg bioassays (Table S1).

The experimental set-up of the in vivo bioassays was similar to that described by Liu et al. (2014). For bioassay 1 conducted in Norway in 2012, salmon eggs used in this bioassay were 385 degree-days at the day of shipment. Each treatment was conducted in a separate incubation unit containing three perforated cups with 30 live salmon eggs per cup. The 11 representative isolates described above were pre-grown on PSA for 2 days at $25^{\circ} \mathrm{C}$, washed with sterile de-mineralized water and added to each salmon egg incubation unit to a final cell density of $10^{8} \mathrm{CFU} \mathrm{\textrm {ml } ^ { - 1 }}$. S. diclina $765 \mathrm{~F} 3$ and bacteria were added to the incubation units with 2.5 litre of de-chlorinated Norwegian tap water on day 0 ( 0 day post inoculation) and egg mortality was scored on day 6 ( 6 days post inoculation, dpi) and expressed as a percentage of the total number of salmon eggs. To further study the activity spectrum of the Pseudomonas isolates, a similar experiment was conducted with S. parasitica 762F4 (Liu et al., 2014). To check if the bacterial isolates alone were pathogenic to salmon eggs, a similar bioassay as 
described above was conducted with the bacterial inoculum only. Also here, the percentage of egg mortality was determined at 6 dpi.

For bioassay 2 conducted in The Netherlands in 2014, the experimental design was adjusted to monitor the disease progress over a longer period of time. Therefore, the salmon eggs were 'younger' than those in bioassay 1, i.e. 321 degree-days at the day of shipment. Each treatment was conducted in two separate incubation units; each incubation unit contained three perforated cups with $51 \pm 2$ live salmon eggs per cup. Spontaneous rifampicin resistant mutants of the Pseudomonas isolates were generated to allow monitoring of their population dynamics. The Pseudomonas isolates were added to each salmon egg incubation unit filled with 2 litres of well water (Liu et al., 2014) to the final cell density of $10^{7} \mathrm{CFU} \mathrm{ml}{ }^{-1}$. S. diclina 1152F4 (Liu et al., 2014) was used in bioassay 2. Salmon eggs not treated with the bacterial isolates or exposed to $S$. diclina only served as the controls. The egg incubation water of each incubation unit was sampled on day 1, day $4(0 \mathrm{dpi})$ and day $24(20 \mathrm{dpi})$ and dilution-plated on PSA+rifampicin to determine the density of the introduced isolates in the water. Colonization of the applied Pseudomonas isolates on the salmon egg surface was determined by rolling one to two eggs from each cup on PSA+rifampicin at 0 and $20 \mathrm{dpi}$ as described by Liu et al. (2014). The percentage of salmon eggs to which hyphae of $S$. diclina were attached was determined at $20 \mathrm{dpi}$ according to Liu et al. (2014).

S. diclina $765 \mathrm{~F} 3$ from the healthy sample and $S$. diclina $1152 \mathrm{~F} 4$ from the diseased sample were used as pathogen source in the bioassay 1 in 2012 and bioassay 2 in 2014, respectively. These two $S$. diclina isolates showed similar pathogenicity on salmon eggs in 2012 (Liu et al., 2014).

\section{Nucleotide sequence accession numbers}

The 16S rRNA sequences of Pseudomonas strains D1, D2, D3, S1, S2, H1, H2, H3, H4, H5, H6 and S3-S18 have been deposited in GenBank under accession numbers KP890304-KP890314 and KT223371-KT223386, respectively.

\section{Live colony NanoDESI MS/MS data acquisition and molecular networking}

The most antagonistic Pseudomonas isolate $\mathrm{H} 6$ was subjected to chemical profiling by Nanospray Desorption ElectroSpray lonization (NanoDESI) live colony mass spectrometry as described previously (Watrous et al., 2012; Nguyen et al., 2013). P. fluorescens SS101 and P. fluorescens SBW25 (Nguyen et al., 2013) were used as references. Pseudomonas strains were cultured in Luria-Bertani broth by shaking overnight at $28^{\circ} \mathrm{C}$. For Pseudomonas $\mathrm{H} 6$, four cultures $(0.5 \mu \mathrm{l}$ each) were spot-inoculated on ISP2 agar and incubated for 48 hours at $30^{\circ} \mathrm{C}$ (Nguyen et al., 2013). P. fluorescens SS101 and $P$. fluorescens SBW25 were streaked on $1 / 5^{\text {th }}$ strength NBY agar $\left(1 \mathrm{gl}^{-1}\right.$ glucose, $1.6 \mathrm{gl}^{-1}$ nutrient broth, 0.4 $\mathrm{gl}^{-1}$ yeast extract and $15 \mathrm{gl}^{-1}$ agar) and cultured for 48 hours at $25^{\circ} \mathrm{C}$. Data collection with a datadependent MS/MS method was conducted on a hybrid 6.4T LTQ-FT (Thermo Electron) mass spectrometer according to Nguyen et al. (2013).

The MS/MS data of strains Pseudomonas H6, P. fluorescens SS101 and P. fluorescens SBW25 were combined with data obtained by Nguyen et al. (2013) for 18 other Pseudomonads and 42 Bacilli. Metabolic networks were generated by clustering as described previously (Pierce et al., 2007) using the GNPS website (http://gnps.ucsd.edu/). Algorithms were the same as described by Nguyen et al. (2013). Networks were visualized using Cytoscape (v 3.1.1). The two plugins used for aiding data visualization and sequence tagging were described previously by Nguyen et al. (2013).

\section{HPLC analysis}

Pseudomonas H6, P. fluorescens SS101 and $P$. fluorescens SBW25 were pre-grown on PSA for 3-6 days at $25^{\circ} \mathrm{C}$. Extraction of biosurfactants was conducted according to De Souza et al. (2003). After lyophilization, the biosurfactant was dissolved in Milli-Q water. Reversed-Phase High Performance Liquid Chromatography (RP-HPLC) analysis was performed by injection of $100 \mu \mathrm{l}$ sample on a Waters 996 HPLC equipped with a Symmetry C18 Column (100 $\AA, 5 \mu \mathrm{m}, 3.9 \mathrm{~mm} \times 150 \mathrm{~mm}$, Waters) as described previously (Cheng et al., 2015). Samples were analysed at a flow rate of $0.5 \mathrm{ml} / \mathrm{min}$ for 50 $\min$ in an isocratic mobile phase of $45: 40: 15$ acetonitrile:methanol:Milli- $Q$ water with $0.1 \%(\mathrm{v} / \mathrm{v})$ trifluoroacetic acid. 
The biosurfactant of Pseudomonas $\mathrm{H} 6$ was tested for activity against hyphae of $S$. diclina $1152 \mathrm{~F} 4$ and $S$. parasitica $\mathrm{C} 65$ by adding the biosurfactant to $1 \mathrm{ml} 1 / 5^{\text {th }}$ strength potato dextrose broth (1/5PDB) in 24well cell-culture plates (Greiner Bio-One, Kremsmünster, Austria) to final concentrations of $15,40,100$, $200 \mu \mathrm{g} \mathrm{ml}^{-1}$, respectively. The lipopeptide surfactant massetolide A produced by $P$. fluorescens SS101 was used as a standard. An agar plug of pre-grown S. diclina 1152F4 or S. parasitica C65 of approximately $0.2 \mathrm{~cm}^{2}$ was added to each well and incubated at $25^{\circ} \mathrm{C}$. Hyphal growth inhibition was scored after 3 days for $S$. diclina 1152F4 or 2 days for S. parasitica C65. Morphological abnormalities were monitored under an Olympus SZX12 stereomicroscope and image capture was accomplished using a Zeiss AxioCam MRc 5 camera with Zeiss AxioVision software (AxioVs40 V 4.8.2.0). ImageJ $1.47 \mathrm{v}$ (Schneider et al., 2012) was used to measure the diameter of 10 hyphae in each treatment.

\section{In vivo effects of biosurfactants on Saprolegniosis}

The salmon eggs had been incubated at $0.92^{\circ} \mathrm{C}$ on average at AquaGen AS (Trondheim, Norway) and their age was 135 degree-days at the day of shipment. The set-up of the salmon egg bioassay was similar to that of bioassay 2 described above. The biosurfactants from Pseudomonas H6 and SS101 were tested at concentrations of $15 \pm 3 \mu \mathrm{g} \mathrm{ml}^{-1}$ and $40 \pm 8 \mathrm{~g} \mathrm{~m} \mathrm{~m}^{-1}$. Malachite green $\left(2.5 \pm 0.5 \mathrm{~g} \mathrm{~m} \mathrm{ml}^{-1}(\mathrm{ppm})\right)$ was used as a chemical reference. All treatments were performed with three separate incubation units (biological replicates), except for the treatments without S. diclina 1152F4 where one incubation unit with three incubation cups (technical reps) was used; each cup contained $51 \pm 2$ live salmon eggs. Application of biosurfactants or malachite green was conducted every 2-3 days by reducing the water level to $600 \pm 100 \mathrm{ml}$ and exposing the salmon eggs to the corresponding chemicals for 90-120 min with aeration. Afterwards, the treated water was removed. Each incubation unit was rinsed by $100-200 \mathrm{ml}$ fresh well water and finally 2 litres of fresh well water was added. The percentage of hyphal attachment of $S$. diclina to the salmon eggs was determined on $18 \mathrm{dpi}$.

\section{Results and Discussion}

\section{PhyloChip-based community profiling}

Previously we analysed the bacterial community compositions of healthy salmon eggs and Saprolegnia-infected salmon eggs (referred to as diseased salmon eggs) by PhyloChip-based profiling (Liu et al., 2014). Healthy eggs harboured more OTUs belonging to the Proteobacteria than diseased eggs (Liu et al., 2014). Amongst the phylum Proteobacteria, the class Gammaproteobacteria was most represented (Figure 1A). Within the Gammaproteobacteria, most OTUs belonged to the orders Enterobacteriales and Pseudomonadales (Figure 1B), accounting for $6.57 \%$ and $6.71 \%$ of the total bacterial OTUs detected on average on salmon eggs, respectively. The majority of OTUs of the family Pseudomonadaceae belonged to Pseudomonas, representing 935 OTUs on average. No significant differences were found in the number of Pseudomonas OTUs between diseased and healthy salmon eggs. Given that Pseudomonas species (Pseudomonadales) are considered as potential aquaculture probiotics (Verschuere et al., 2000), a more indepth analysis was conducted here to unravel the genotypic and functional diversity of Pseudomonas species associated with healthy and diseased salmon eggs (Figure S1). 
A

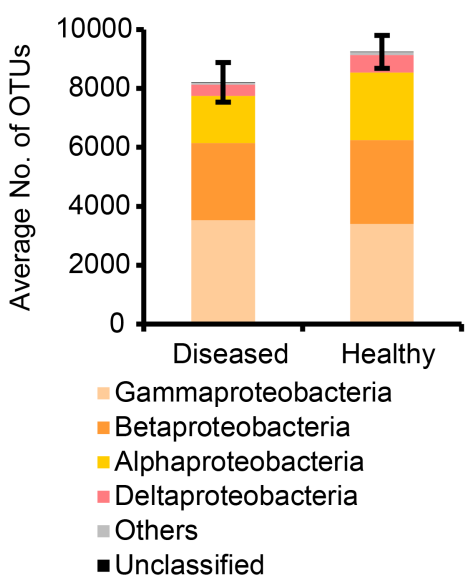

B

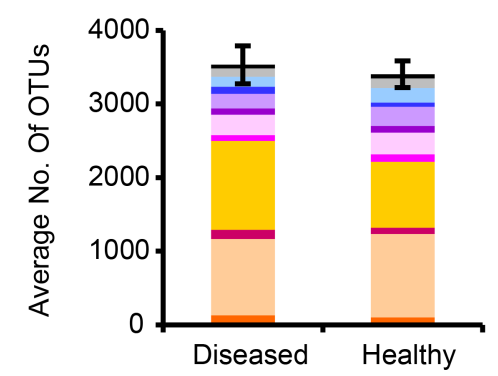

-Alteromonadales $\backsim$ Pseudomonadales

-Aeromonadales Enterobacteriales

- Legionellales

- Pasteurellales

-Vibrionales

-Others
Oceanospirillales

- Chromatiales

Xanthomonadales

- Unclassified

Figure 1 Proteobacteria (A) and Gammaproteobacteria (B) community analyses of diseased and healthy salmon eggs by PhyloChip-based analyses. Salmon eggs were sampled from a commercial hatchery (Liu et al., 2014). Indicated is the average number of OTUs at different taxonomic levels: the phylum Proteobacteria $(A)$ and the class Gammaproteobacteria (B). Error bars represent S.E.M $(N=6)$.

\section{Isolation, in vitro activity and phylogeny of aquatic Pseudomonas}

The bacteria attached to the salmon eggs were released by vortexing and sonication in the incubation water from the hatchery. The total count of culturable aerobic bacteria was approximately $3 \times 10^{7} \mathrm{CFU} \mathrm{ml}{ }^{-1}$ for both healthy and diseased salmon eggs (Figure S2). Amongst 440 randomly selected isolates, $7 \%$ and $13 \%$ inhibited hyphal growth of Saprolegnia diclina VS20 and Saprolegnia parasitica C65, respectively. Drop collapse assays further revealed that $3 \%$ of the $1 / 10$ TSA isolates produced biosurfactants under the experimental conditions tested. For both the healthy and diseased salmon egg samples, the putative Pseudomonas population density enumerated on semi-selective PSA medium was approximately $10^{6} \mathrm{CFU} \mathrm{ml}{ }^{-1}$ (Figure S2). Amongst 465 randomly selected Pseudomonas isolates, $60-69 \%$ of the isolates from the diseased salmon eggs and $72-80 \%$ of the isolates from the healthy salmon eggs inhibited hyphal growth of S. diclina VS20 and/or S. parasitica C65. No statistically significant difference was observed between diseased and healthy salmon eggs in the percentage of isolates with in vitro growth-inhibiting activities (Figure 2A). However, based on the results obtained in drop collapse assays, healthy eggs harboured a significantly higher frequency (64 $\pm 7 \%$ ) of biosurfactant-producing Pseudomonas isolates than diseased salmon eggs $(34 \pm 8 \%)$ (Figure $2 \mathrm{~B}$ ). A marine biosurfactant-producing Lactobacillus pentosus provided protection for the crustacean Artemia against pathogenic Vibrio alginolyticus, suggesting a potential role of biosurfactants in disease suppression (Garces et al., 2015). 
A

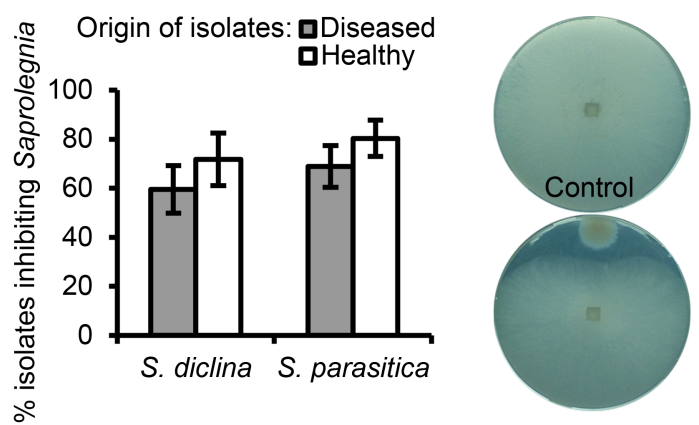

B

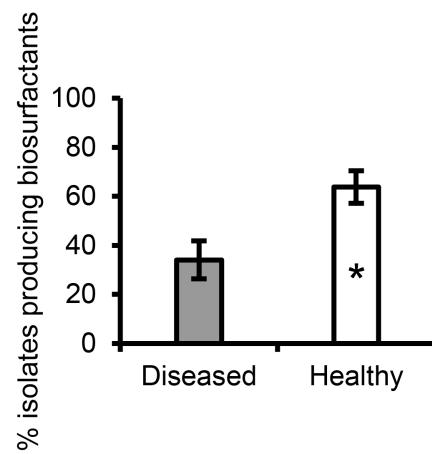

C
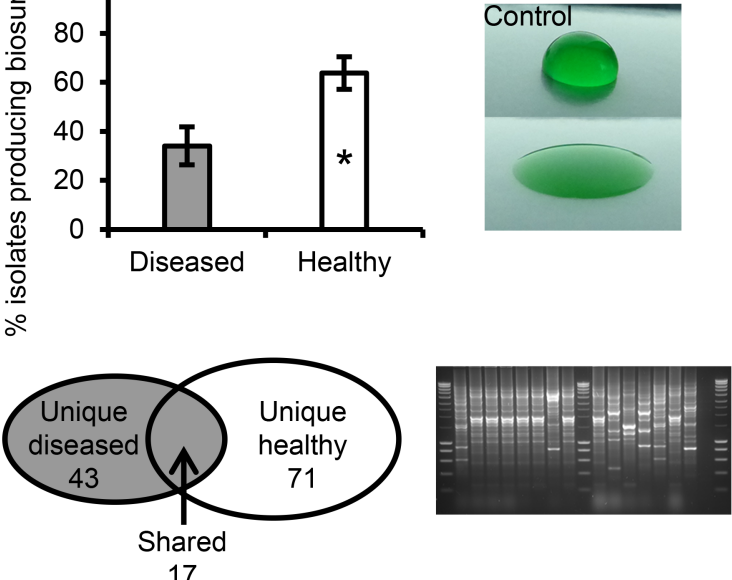

Figure 2 Phenotypic and genotypic analysis of Pseudomonas isolates. The isolates were obtained from healthy salmon egg samples and salmon eggs infected with Saprolegnia. (A) Mean percentage of the number of bacterial isolates that were inhibitory to hyphal growth of Saprolegnia diclina VS20 and Saprolegnia parasitica CBS 223.65, tested by observation of an inhibition halo around the bacterial colony (right panel insert). (B) Mean percentage of the number of bacterial isolates that produce biosurfactants based on the drop collapse assay (right panel insert). Error bars represent the S.E.M. $(N=6)$. The asterisk indicates a statistically significant difference $(P<0.05$, Student's $t$-test). (C) Genotypic BOX-PCR grouping of bacterial isolates that inhibiting Saprolegnia hyphal growth and/or producing biosurfactants. The Venn diagram (left panel insert) shows the total number of BOX groups obtained for isolates from either diseased, healthy or both samples. An example of the DNA profiles obtained by BOX-PCR is shown in agarose gel (right panel insert).

Genotypic profiling by BOX-PCR of the Pseudomonas isolates that inhibited Saprolegnia hyphal growth in vitro and/or produced biosurfactants, resulted in 131 BOX groups with 43 and 71 unique groups from diseased $(D)$ or healthy $(H)$ salmon egg samples, respectively, and 17 groups with isolates found in both diseased and healthy samples (referred to as 'shared' isolates (S)) (Figure 2C). Representative isolates from BOX groups that consisted of at least 4 isolates 
unique for diseased $(\mathrm{D})$ or healthy $(\mathrm{H})$ samples, as well as 18 isolates from the 9 'shared' (S) BOX groups (Table S1) were subjected to phylogenetic analyses. No distinct differences were observed in the 16S rRNA-based phylogenetic delineation of Pseudomonas isolates from diseased or healthy salmon eggs. Most of the isolates belonged to the $P$. fluorescens clade, including the isolates from the shared BOX groups, except isolate S13 and S14 that clustered with $P$. syringae (Figure 3).

\section{Bioactivity of aquatic Pseudomonas in vivo}

When Pseudomonas isolates were applied at an initial density of $10^{7} \mathrm{CFU} \mathrm{ml^{-1 }}$ to the incubation water in vivo, seven out of eleven Pseudomonas isolates significantly reduced hyphal attachment of $S$. diclina to salmon eggs (Figure 4). Strains originally isolated from healthy salmon egg samples showed a better control efficacy than those originally isolated from diseased salmon egg samples (Figure 4), suggesting that the healthy salmon eggs harbour Pseudomonas strains with stronger activity against Saprolegnia. The bacterial density in the incubation water decreased from $10^{6}-10^{7} \mathrm{CFU} \mathrm{ml^{-1 }}$ on $0 \mathrm{dpi}$ to $10^{3}-10^{5} \mathrm{CFU} \mathrm{ml^{-1 }}$ on $20 \mathrm{dpi}$. When tested against another $S$. diclina isolate and $S$. parasitica isolate under different temperatures and bacterial densities, only Pseudomonas strain $\mathrm{H} 6$ showed the most consistent activity against Saprolegnia in all cases (Figure S3 and S4A). Hence, strain $\mathrm{H} 6$ was selected for further characterization.

\section{Chemical profiling of aquatic Pseudomonas strain $\mathrm{H} 6$}

To elucidate which compounds Pseudomonas strain H6 produces, live colony mass spectrometry and MS/MS analyses were performed with two phylogenetically related strains $P$. fluorescens SS101 and SBW25 as references. A Cytoscape network with spectra of in total 21 Pseudomonads and 42 Bacilli strains (Nguyen et al., 2013) showed that Pseudomonas $\mathrm{H} 6$ produces a predominant compound with a parent mass-to-charge ratio of $\mathrm{m} / \mathrm{z} 1148.65$, which clustered together with the lipopeptides massetolide $A(m / z 1162.69)$ and viscosin $(m / z ~ 1148.67)$ produced by strains SS101 and SBW25, respectively (Figure 5A). Further examination of the raw MS/MS data showed that mass shifts could be linked to specific amino acids, which created identical sequence tags of 87-113-87-113 Da (Ser-Leu/lle-SerLeu/lle) for the lipopeptide surfactants produced by Pseudomonas H6, P. fluorescens SS101 and SBW25 (Figure 5B) (Nguyen et al., 2013). These results suggest that Pseudomonas $\mathrm{H} 6$ produces a lipopeptide surfactant with a peptide moiety that is, most likely, structurally similar to that of massetolide $A$ and viscosin. 


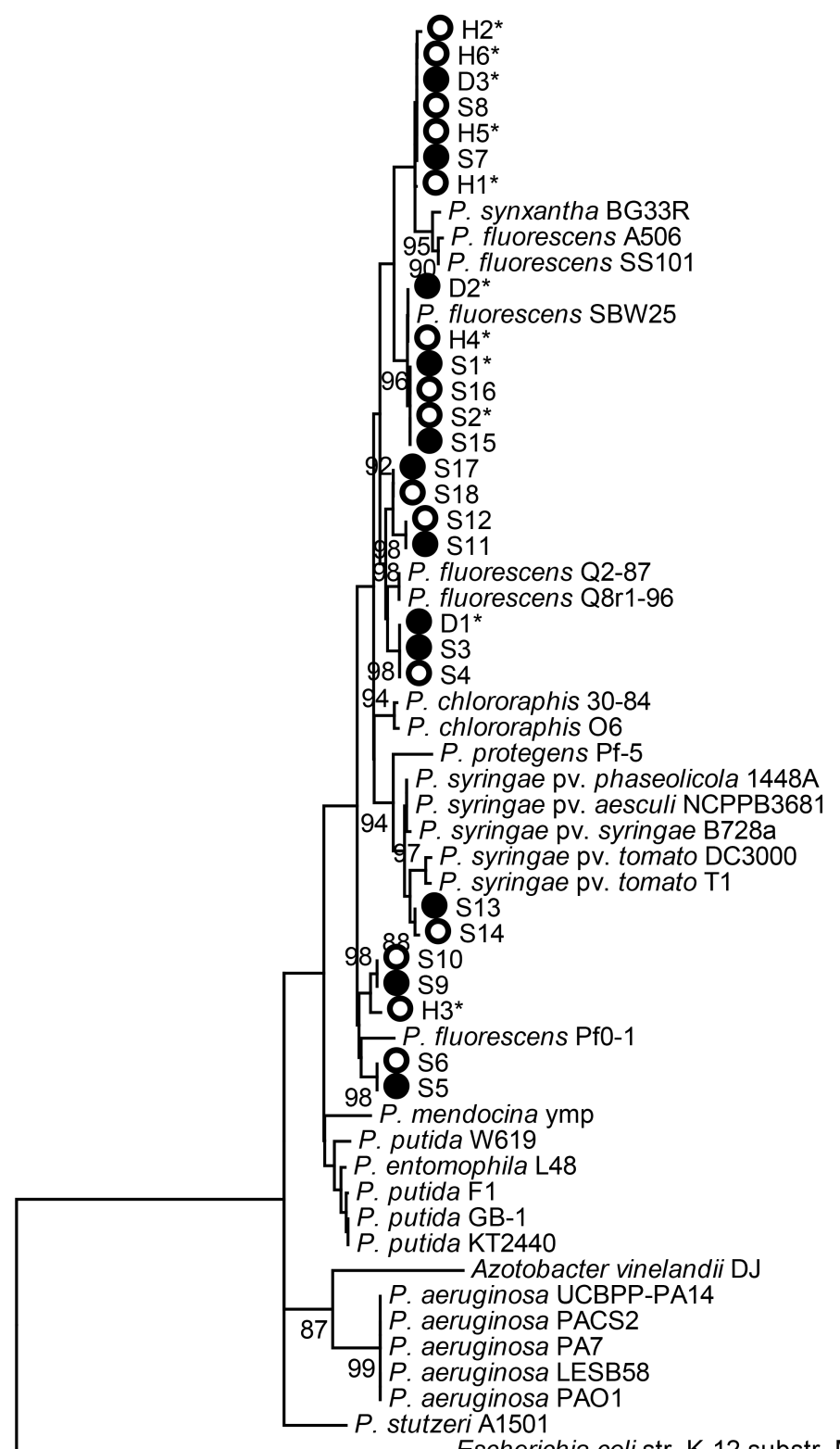

Escherichia coli str. K-12 substr. MG1655

\section{$0 . \mathrm{H}_{02}$ Origin of isolates: Diseased $\mathrm{O}$ Healthy}

Figure 3 Phylogenetic tree of $16 \mathrm{~S}$ rRNA sequences of Pseudomonas strains representative of $18 \mathrm{BOX}$ PCR groups. The $16 \mathrm{~S}$ rRNA sequences were approximately $960 \mathrm{bp}$. The BOX-PCR groups were identified among the Pseudomonas isolates from healthy and diseased salmon eggs (Table S1). A total of 29 reference Pseudomonas species/strains were included to delineate the 27 aquatic Pseudomonas strains obtained in this study. Bootstrap values at the nodes are based on 1000 replications. Only those branch values higher than $80 \%$ are shown. Asterisks indicate the isolates selected for salmon egg bioassays. 


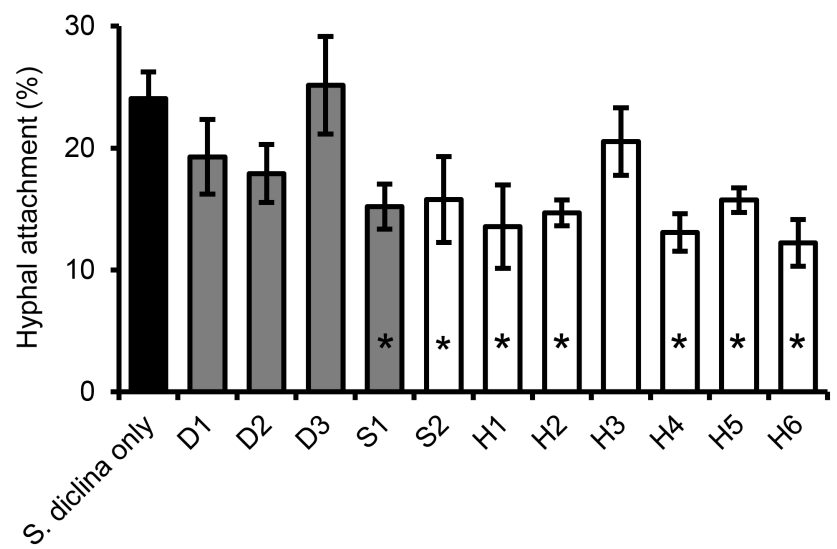

Figure 4 In vivo activity of 11 Pseudomonas strains against $S$. diclina $1152 F 4$. In bioassay 2 , the mean percentage of eggs to which of $S$. diclina $1152 \mathrm{~F} 4$ hyphae attached was determined at 20 days post inoculation (dpi) (Liu et al., 2014). Bacterial strains were introduced at an initial cell density of $10^{7} \mathrm{CFU}$ $\mathrm{ml}^{-1}$. The incubation temperature was $5-7^{\circ} \mathrm{C}$. Error bars represent S.E.M. $(N=6)$. Asterisks indicate statistically significant differences with the control, S. diclina only, based on a one-way analysis of variance and post hoc LSD analysis $(P<0.05)$.

RP-HPLC analysis of the lipopeptide surfactants extracted from these three strains revealed a difference in retention time of the biosurfactants from Pseudomonas $\mathrm{H} 6$, P. fluorescens SS101 and SBW25 (Figure 5C), suggesting that the lipopeptide biosurfactant produced by Pseudomonas $\mathrm{H} 6$ is structurally not identical to massetolide $A$ or viscosin. The small shift in retention could also be due to a structural difference in the lipid moiety.

\section{Activity profiling of lipopeptide surfactant from aquatic Pseudomonas strain $\mathrm{H} 6$}

We tested the effect of the purified lipopeptide surfactants of Pseudomonas $\mathrm{H} 6$ and $P$. fluorescens SS101 on hyphal growth of S. diclina 1152F4 (Figure 6A). Both surfactants showed growth-inhibitory activity at $15 \mathrm{\mu g} \mathrm{ml}^{-1}$, the lowest concentration tested. Hyphal growth was almost completely inhibited at $100 \mathrm{\mu g} \mathrm{ml}^{-1}$ for the biosurfactant of Pseudomonas $\mathrm{H} 6$ and at $200 \mathrm{mg} \mathrm{ml}^{-1}$ for massetolide A of $P$. fluorescens SS101 (Figure 6A). The biosurfactant of $\mathrm{H} 6$ also showed a stronger activity compared to massetolide $A$ against hyphal growth of S. parasitica (Figure 7A). Lipopeptide surfactants are known to cause hyphal swelling, hyphal branching, zoospore lysis and inhibition of cyst germination of plant pathogenic oomycetes (de Bruijn et al., 2007; de Bruijn et al., 2008; van de Mortel et al., 2009). When we 
A
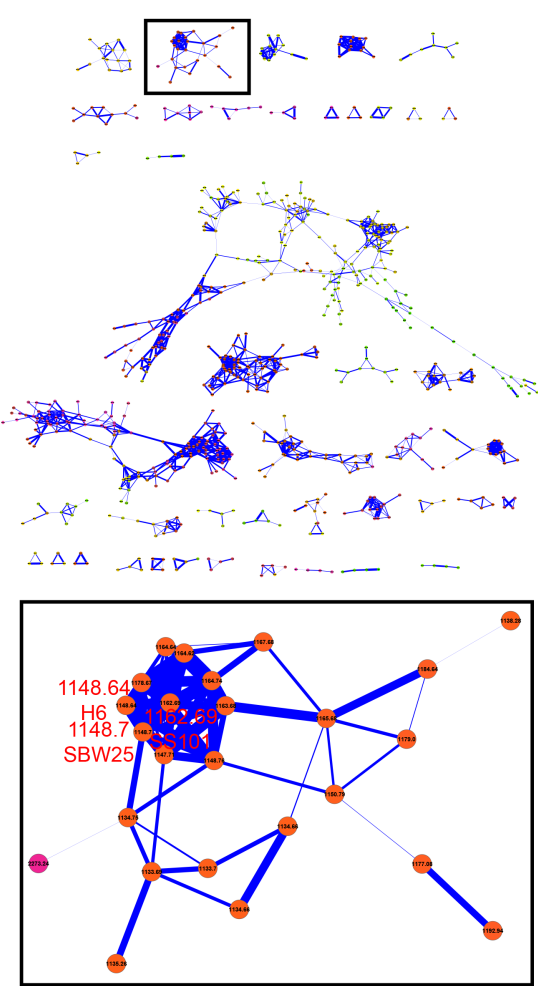

$132.10 \quad 2343.52$

$\mathrm{m} / \mathrm{z}$
B

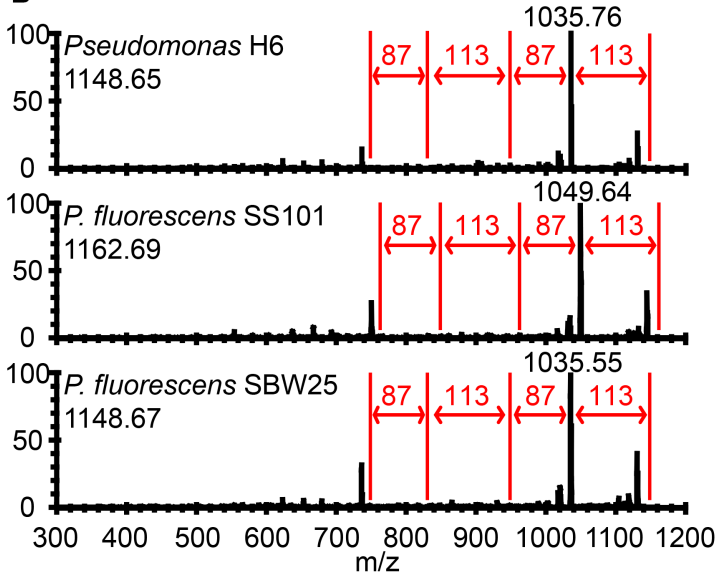

C

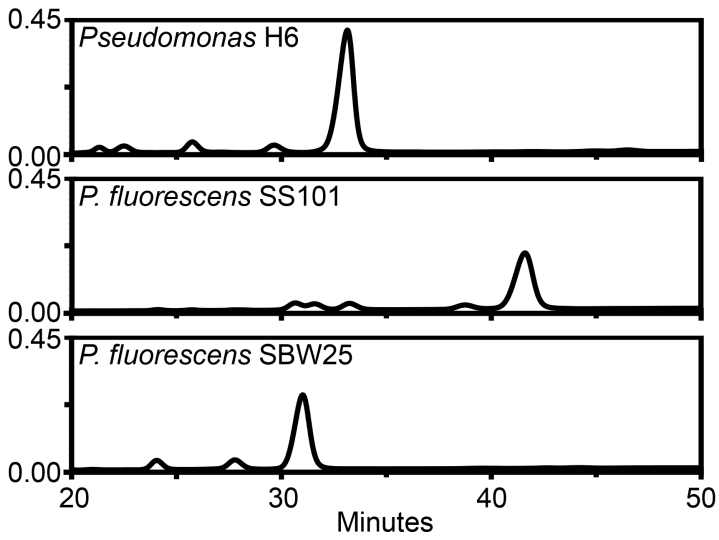

Figure 5 Live colony mass spectrometry and MS/MS networking. (A) Molecular network of Pseudomonas H6, P. fluorescens SS101, P. fluorescens SBW25 and 18 other Pseudomonads and 42 Bacilli (Nguyen et al., 2013). The viscosin-like cluster was boxed and enlarged. (B) Selection of nodes of Pseudomonas H6, P. fluorescens SS101 and SBW25 for MS/MS raw spectra analyses and generation of amino acid sequence tag. The sequence tag is created by analysing the mass shifts between adjacent ions in the MS/MS spectra, which are corresponding to the mass of an amino acid. The value of the parent mass ions for Pseudomonas H6 and P. fluorescens SBW25 in Figure 5B is not completely matching to the parent mass ion as indicated in Figure $5 \mathrm{~A}$, because during network analyses a mass tolerance setting of 0.3 Da was used. (C) Reversed-phase HPLC chromatograms of cell-free culture extracts of lipopeptide surfactants from Pseudomonas H6, P. fluorescens SS101 and SBW25. 

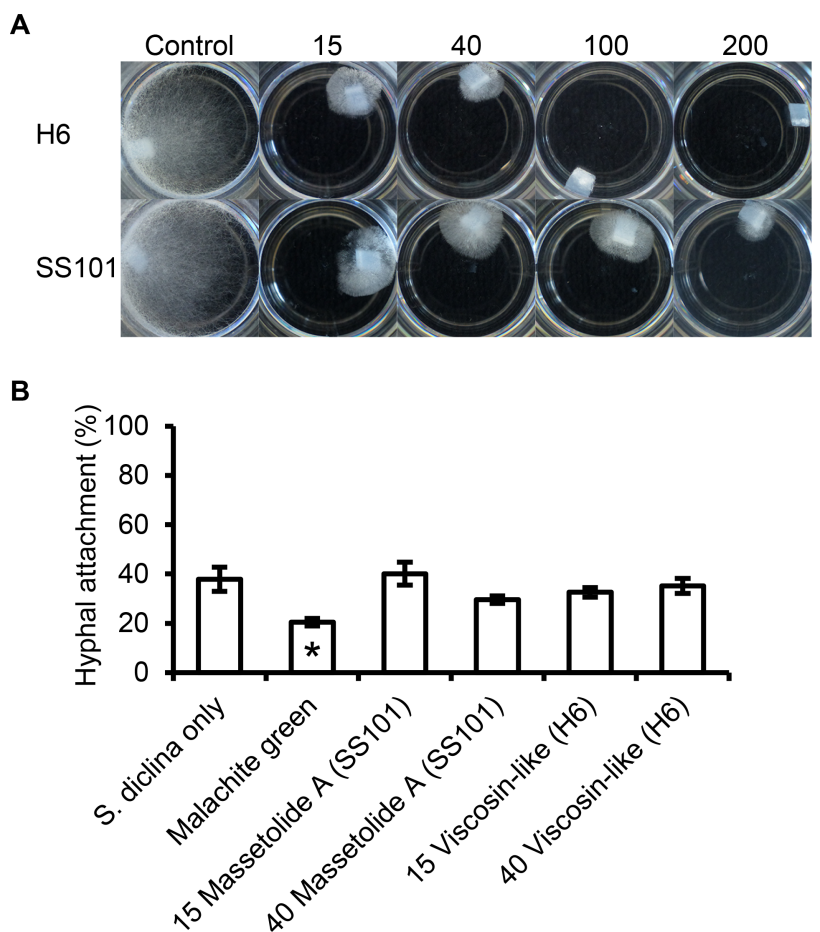

Figure 6 Effect of biosurfactants from Pseudomonas $\mathrm{H} 6$ and $P$. fluorescens SS101 on S. diclina 1152F4. (A) S. diclina 1152F4 hyphal plugs were incubated for 3 days in 1/5PDB supplemented with biosurfactants from Pseudomonas H6 or P. fluorescens SS101 (massetolide A) at concentrations ranging from 15 to $200 \mu \mathrm{g} \mathrm{ml}^{-1}$. (B) The activity of the biosurfactants against $S$. diclina under in vivo condition was assessed by determining the mean percentage of salmon eggs to which $S$. diclina 1152F4 hyphae were attached at $18 \mathrm{dpi}$. Salmon eggs were treated with biosurfactants from Pseudomonas $\mathrm{H} 6$ and $P$. fluorescens SS101 at $15 \pm 3 \mu \mathrm{g} \mathrm{ml}^{-1}$ and $40 \pm 8 \mu \mathrm{g} \mathrm{ml}^{-1}$. Eggs exposed to $S$. diclina only were used as negative control. Eggs treated with $2.5 \pm 0.5 \mathrm{\mu g} \mathrm{ml}^{-1}(\mathrm{ppm})$ malachite green and $S$. diclina were used as the chemical reference. Error bars represent S.E.M. $(N=9)$. The asterisk indicates a statistically significant difference from the negative control ( $S$. diclina only) based on oneway analysis of variance and post hoc LSD analysis $(P<0.05)$.

investigated the effect of the lipopeptide surfactants of strains H6 and SS101 microscopically, the diameter of $S$. parasitica hyphae grown in the presence of biosurfactants was larger (Table S2) and exhibited a higher number of branches compared to the control. This phenotypic effect intensified with increasing biosurfactant concentrations; furthermore, massetolide $A$ induces more hyphal branching than the Pseudomonas $\mathrm{H} 6$ biosurfactant (Figure 7B).

The lipopeptide surfactants from Pseudomonas $\mathrm{H} 6$ and P. fluorescens SS101 were tested in an in vivo bioassay at concentrations of $15 \pm 3 \mathrm{\mu g} \mathrm{ml}^{-1}$ and $40 \pm 8 \mu \mathrm{g}$ $\mathrm{ml}^{-1}$ of incubation water. Because the set-up of the in vivo bioassays involved large volumes and the yield of biosurfactants was relatively low, higher biosurfactant 
A

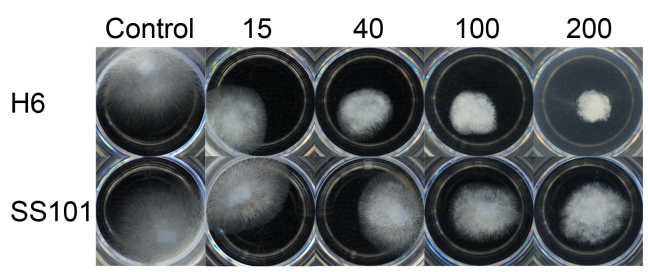

B
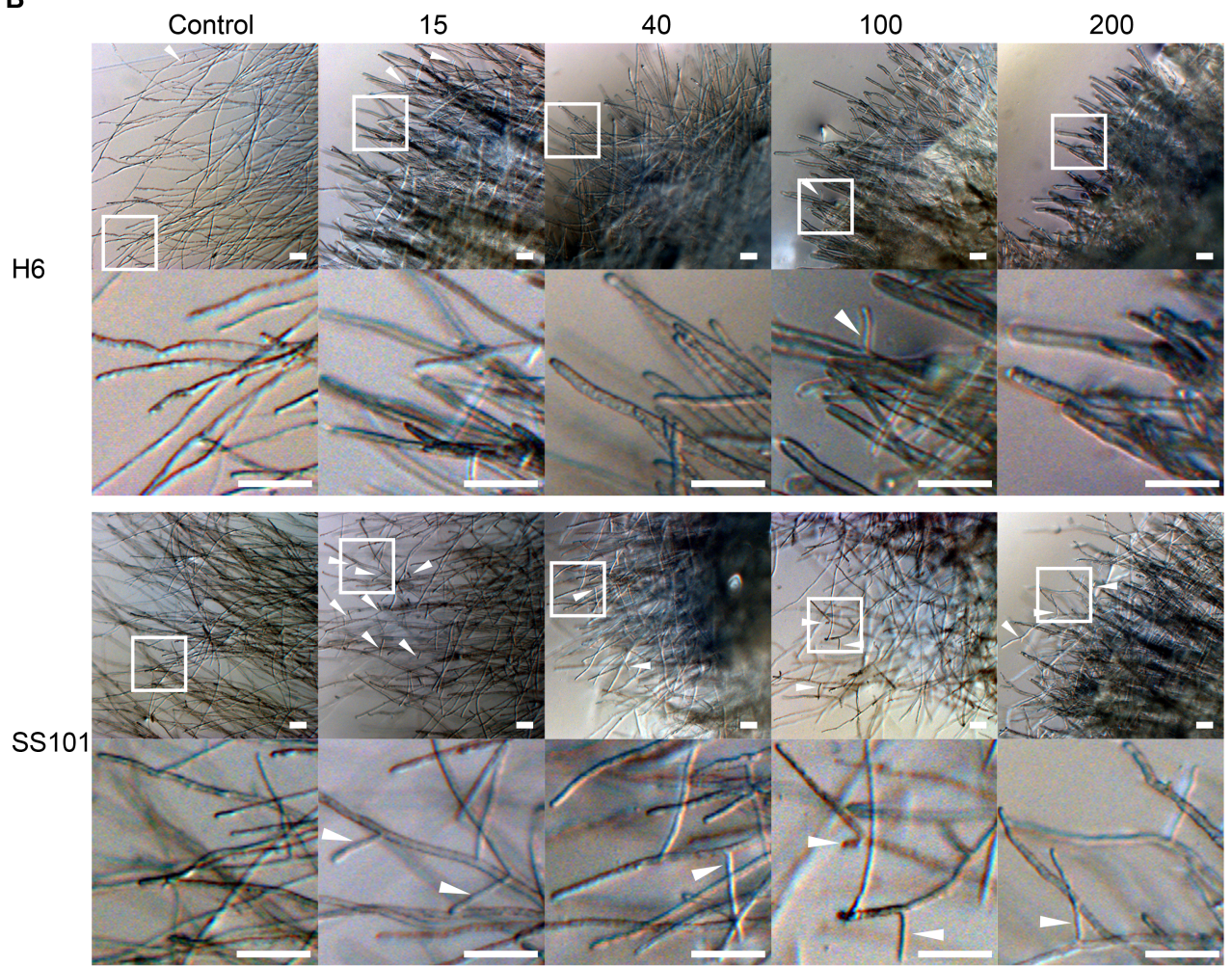

Figure 7 Effect of biosurfactants from Pseudomonas H6 and P. fluorescens SS101 on S. parasitica CBS 223.65. The effect was according to hyphal growth (A) and hyphal morphology (B). S. parasitica hyphal plugs were grown for 48 hours in 1/5PDB supplemented with biosurfactants from Pseudomonas $\mathrm{H} 6$ or $P$. fluorescens SS101 (massetolide A) at concentrations ranging from 15 to $200 \mathrm{\mu g} \mathrm{ml}^{-1}$. The bottom row shows the enlargement of the area indicated in the top row. White arrows indicate branching hyphae. The scale bars in the pictures of panel B represent $100 \mu \mathrm{m}$.

concentrations were not tested. At the concentrations tested, no significant reductions in attachment of $S$. diclina hyphae to salmon eggs were found, whereas the chemical control (malachite green) did significantly reduce hyphal attachment (Figure 6B). Although the lipopeptide surfactants were applied every 2-3 days for a duration of 90-120 min each time, instability (e.g. degradation) and/or a too short exposure time may have caused a lack of in vivo activity. Biosurfactants have been shown to be degraded in aquatic systems and non-sterile soil (Abd-Allah and Srorr, 
1998; Nielsen and Sørensen, 2003; Abu-Ghunmi et al., 2014) and the same may have occurred in the salmon egg incubation units. The fate of the biosurfactants could not be analysed by RP-HPLC analysis, since the applied concentrations were below the detection limit. Although the biosurfactants alone did not affect hyphal attachment by Saprolegnia in vivo, this does not exclude that these compounds may play a role in the activity of the producing bacterial strain, an aspect that remains to be further investigated. Lipopeptide surfactants are wellknown for their role in biofilm formation (de Bruijn et al., 2007; de Bruijn et al., 2008) and may have enabled Pseudomonas $\mathrm{H} 6$ to colonize the salmon egg surface to form a protective biofilm that avoids hyphal attachment by Saprolegnia. Also the biosurfactant produced by Lactobacillus pentosus was suggested to facilitate the adhesion to the Artemia gut, thereby excluding the colonization of pathogenic Vibrio alginolyticus (Garces et al., 2015). The bacterial biofilm provides an ecological niche in which the bacterial cells produce a protective extracellular matrix that is beneficial to their growth and development by excluding other microbes (Verschuere et al., 2000). Whether the biosurfactants are actually produced in the egg incubation units or on the egg surfaces by the introduced Pseudomonas strains is not known. Recently, Song and colleagues (Song et al., 2014) showed that massetolide A production by $P$. fluorescens SS101 increased at lower temperatures, indicating that the low temperatures $\left(5-10^{\circ} \mathrm{C}\right)$ used in the salmon egg assays may be favourable for biosurfactant production. To provide more evidence for a role of the lipopeptide surfactant of Pseudomonas $\mathrm{H} 6$ in in situ production and protection against Saprolegniosis, site-directed mutagenesis of the biosynthetic genes should be performed in future studies, followed by in vivo bioassays where gene transcriptional analyses are conducted and activities of surfactant-deficient mutants are compared to those of the wild type strain $\mathrm{H6}$. Additionally, even though $P$. fluorescens is recognized as a beneficial microbe against Saprolegnia (Bly et al., 1997), it is also known to be pathogenic to a wide range of fish species, mostly to carps (Austin and Austin, 2007) but also to salmonids like rainbow trout (Oncorhynchus mykiss) (Austin and Austin, 2007) and Chinook salmon (Oncorhynchus tshawytscha) (Loch et al., 2012). For some of the Pseudomonas isolates tested here, except $\mathrm{H} 6$, we indeed observed adverse effects on the salmon eggs (Figure S4B). Further studies should also look into effects of $P$. fluorescens $\mathrm{H} 6$ on the life-cycle of salmon post hatching.

\section{Conclusions}

Aquaculture is one of the fastest growing animal food sectors (FAO, 2014), partly as a response to the increasing demand for fish protein and regulations to prevent overfishing from wild populations (Bruno et al., 2011). Considering the long-term 
importance of aquaculture for food production and economic development, sustainable measures are urgently needed to mitigate emerging diseases including Saprolegniosis. Although the biosurfactant from Pseudomonas $\mathrm{H} 6$ did not show activity in vivo, the bacterial strain itself did provide promising antagonistic activity against Saprolegnia infections of salmon eggs. Our research provides a framework for selecting beneficial bacteria that can suppress Saprolegniosis and possibly other emerging diseases in aquaculture.

\section{Funding}

This work was financially supported by SAPRO (Sustainable Approaches to Reduce Oomycete (Saprolegnia) Infections in Aquaculture, 238550), a Marie Curie Initial Training Network funded by the European Commission under Framework Program 7; ParaFishControl (Advanced Tools and Research Strategies for Parasite Control in European farmed fish, 634429), a Research and Innovation action funded by the European Commission under HORIZON 2020; and BE-Basic Foundation (project number F07.003.01). The funders had no role in study design, data collection and analysis, decision to publish, or preparation of the manuscript.

\section{Acknowledgements}

We appreciate the help and valuable advices from Menno ter Veld and Geert Wiegertjes (Animal Sciences, Wageningen University, The Netherlands) for the in vivo experiments. This manuscript is publication number 5912 of Netherlands Institute of Ecology (NIOO-KNAW).

\section{Author Contributions}

Conceived and designed the experiments: YL ER IdB MvdV VB JMR. Performed the experiments: YL ER MvdV CHW ET. Analyzed the data: YL ER CHW MvdV IdB. Wrote the paper: YL ER IdB MvdV VB JMR. Performed the strain isolations and characterization, genomic fingerprinting, phylogenetic analyses, in vitro and in vivo experiments: YL. Performed tests of massetolide A against S. parasitica: YL ER. Performed live colony mass spectrometry analysis: MvdV CHW PCD. Created Figures: YL ER CHW MvdV IdB. Contributed to HPLC analysis: MvdV. Contributed to design of bioassays: ET IS. Contributed to performance of bioassays: ET. Contributed to review of the manuscript: all authors.

\section{Competing Interests}

The authors have declared that no competing interests exist. 


\section{References}

Abd-Allah, A.M.A., and Srorr, T. (1998) Biodegradation of anionic surfactants in the presence of organic contaminants. Water Research 32: 944-947.

Abu-Ghunmi, L., Badawi, M., and Fayyad, M. (2014) Fate of Triton X-100 applications on water and soil environments: a review. Journal of Surfactants and Detergents 17: 833-838.

Austin, B., and Austin, D.A. (2007) Bacterial fish pathogens: disease of farmed and wild fish: Springer Science \& Business Media.

Bly, J.E., Quiniou, S.M.A., Lawson, L.A., and Clem, L.W. (1997) Inhibition of Saprolegnia pathogenic for fish by Pseudomonas fluorescens. Journal of Fish Diseases 20: 35-40.

Bruno, D., van West, P., and Beakes, G. (2011) Saprolegnia and other oomycetes. In Fish Diseases and Disorders, Viral, Bacterial and Fungal Infections. Woo, P., and Bruno, D. (eds). Wallingford, UK: CABI: Wallingford, UK, pp. 669-720.

Carbajal-González, M.T., Fregeneda-Grandes, J.M., Suárez-Ramos, S., Rodríguez-Cadenas, F., and Aller-Gancedo, J.M. (2011) Bacterial skin flora variation and in vitro inhibitory activity against Saprolegnia parasitica in brown and rainbow trout. Diseases of Aquatic Organisms 96: 125-135.

Cheng, X., van der Voort, M., and Raaijmakers, J.M. (2015) Gac-mediated changes in pyrroloquinoline quinone biosynthesis enhance the antimicrobial activity of Pseudomonas fluorescens SBW25. Environmental Microbiology Reports: n/a-n/a.

Das, S.K., Murmu, K., Das, A., Shakuntala, I., Das, R.K., Ngachan, S.V. et al. (2012) Studies on the identification and control of pathogen Saprolegnia in selected Indian major carp fingerlings at mid hill altitude. Journal of environmental biology / Academy of Environmental Biology, India. 33: 545-549.

de Bruijn, I., de Kock, M.J.D., de Waard, P., van Beek, T.A., and Raaijmakers, J.M. (2008) Massetolide a biosynthesis in Pseudomonas fluorescens. Journal of Bacteriology 190: 2777-2789.

de Bruijn, I., de Kock, M.J.D., Yang, M., de Waard, P., van Beek, T.A., and Raaijmakers, J.M. (2007) Genome-based discovery, structure prediction and functional analysis of cyclic lipopeptide antibiotics in Pseudomonas species. Molecular Microbiology 63: 417-428.

De Souza, J.T., De Boer, M., De Waard, P., Van Beek, T.A., and Raaijmakers, J.M. (2003) Biochemical, genetic, and zoosporicidal properties of cyclic lipopeptide surfactants produced by Pseudomonas fluorescens. Applied and Environmental Microbiology 69: 7161-7172.

FAO (2014) The state of world fisheries and aquaculture 2014. Rome, Italy.223 p.

Fernández-Benéitez, M.J., Ortiz-Santaliestra, M.E., Lizana, M., and Diéguez-Uribeondo, J. (2008) Saprolegnia diclina: another species responsible for the emergent disease 'Saprolegnia infections' in amphibians. FEMS Microbiology Letters 279: 23-29.

Fisher, M.C., Henk, D.A., Briggs, C.J., Brownstein, J.S., Madoff, L.C., McCraw, S.L. et al. (2012) Emerging fungal threats to animal, plant and ecosystem health. Nature 484: 186-194.

Garces, M.E., Sequeiros, C., and Olivera, N.L. (2015) Marine Lactobacillus pentosus H16 protects Artemia franciscana from Vibrio alginolyticus pathogenic effects. Diseases of Aquatic Organisms 113: 41-50.

Gozlan, R.E., Marshall, W., Lilje, O., Jessop, C., Gleason, F.H., and Andreou, D. (2014) Current ecological understanding of fungal-like pathogens of fish: what lies beneath? Frontiers in Microbiology 5

Hatai, K., and Willoughby, L.G. (1988) Saprolegnia parasitica from rainbow trout inhibited by the bacterium Pseudomonas fluorescens. Bulletin of the European Association of Fish Pathologists 8: 2729.

Hatai, K., and Hoshiai, G. (1992) Mass mortality in cultured coho salmon (Oncorhynchus kisutch) due to Saprolegnia parasitica coker. Journal of Wildlife Diseases 28: 532-536.

Hatai, K., and Hoshiai, G.-I. (1994) Pathogenicity of Saprolegnia parasitica Coker. In Salmon Saprolegniasis. Mueller, G.J. (ed). Portland, Oregon: U.S. Department of Energy, Bonneville Power Administration, Portland, Oregon.

Hussein, M.M.A., and Hatai, K. (2001) In vitro inhibition of Saprolegnia by bacteria isolated from lesions of salmonids with saprolegniasis. Fish Pathology 36: 73-78.

Kimura, M. (1980) A simple method for estimating evolutionary rates of base substitutions through comparative studies of nucleotide sequences. Journal of Molecular Evolution 16: 111-120.

Krugner-Higby, L., Haak, D., Johnson, P., Shields, J., Jones, W.I., Reece, K. et al. (2010) Ulcerative disease outbreak in crayfish Orconectes propinquus linked to Saprolegnia australis in Big Muskellunge Lake, Wisconsin. Diseases of Aquatic Organisms 91: 57-66.

Lategan, M.J., and Gibson, L.F. (2003) Antagonistic activity of Aeromonas media strain A199 against Saprolegnia sp., an opportunistic pathogen of the eel, Anguilla australis Richardson. Journal of Fish Diseases 26: 147-153. 
Lategan, M.J., Torpy, F.R., and Gibson, L.F. (2004a) Biocontrol of saprolegniosis in silver perch Bidyanus bidyanus (Mitchell) by Aeromonas media strain A199. Aquaculture 235: 77-88.

Lategan, M.J., Torpy, F.R., and Gibson, L.F. (2004b) Control of saprolegniosis in the eel Anguilla australis Richardson, by Aeromonas media strain A199. Aquaculture 240: 19-27.

Liu, Y., de Bruijn, I., Jack, A.L.H., Drynan, K., van den Berg, A.H., Thoen, E. et al. (2014) Deciphering microbial landscapes of fish eggs to mitigate emerging diseases. The ISME Journal 8: 2002-2014.

Loch, T.P., Scribner, K., Tempelman, R., Whelan, G., and Faisal, M. (2012) Bacterial infections of Chinook salmon, Oncorhynchus tshawytscha (Walbaum), returning to gamete collecting weirs in Michigan. Journal of Fish Diseases 35: 39-50.

Loper, J.E., Hassan, K.A., Mavrodi, D.V., Davis, E.W., II, Lim, C.K., Shaffer, B.T. et al. (2012) Comparative genomics of plant-associated Pseudomonas spp.: insights into diversity and inheritance of traits involved in multitrophic interactions. PLoS Genetics 8: e1002784.

Martel, A., Spitzen-van der Sluijs, A., Blooi, M., Bert, W., Ducatelle, R., Fisher, M.C. et al. (2013) Batrachochytrium salamandrivorans sp. nov. causes lethal chytridiomycosis in amphibians. Proceedings of the National Academy of Sciences of the United States of America 110: 15325-15329.

Nguyen, D.D., Wu, C.-H., Moree, W.J., Lamsa, A., Medema, M.H., Zhao, X. et al. (2013) MS/MS networking guided analysis of molecule and gene cluster families. Proceedings of the National Academy of Sciences. doi: 10.1073/pnas.1303471110

Nielsen, T.H., and Sørensen, J. (2003) Production of cyclic lipopeptides by Pseudomonas fluorescens strains in bulk soil and in the sugar beet rhizosphere. Applied and Environmental Microbiology 69: 861-868.

Phillips, A.J., Anderson, V.L., Robertson, E.J., Secombes, C.J., and van West, P. (2008) New insights into animal pathogenic oomycetes. Trends in Microbiology 16: 13-19.

Pierce, C.Y., Barr, J.R., Cody, R.B., Massung, R.F., Woolfitt, A.R., Moura, H. et al. (2007) Ambient generation of fatty acid methyl ester ions from bacterial whole cells by direct analysis in real time (DART) mass spectrometry. Chemical Communications: 807-809. doi: 10.1039/B613200F

Raaijmakers, J.M., de Bruijn, I., and de Kock, M.J.D. (2006) Cyclic lipopeptide production by plantassociated Pseudomonas spp.: diversity, activity, biosynthesis, and regulation. Molecular Plant-Microbe Interactions 19: 699-710.

Rademaker, J.L.W., Louws, F.J., and de Bruijn, F.J. (1998) Characterization of the diversity of ecologically important microbes by rep-PCR genomic fingerprinting. In Molecular Microbial Ecology Manual. Akkermans, A.D.L., van Elsas, J.D., and de Bruijn, F.J. (eds). Dordrecht: Kluwer, pp. 1-26.

Sarmiento-Ramírez, J.M., Abella-Pérez, E., Phillott, A.D., Sim, J., van West, P., Martín, M.P. et al. (2014) Global distribution of two fungal pathogens threatening endangered sea turtles. PLOS ONE 9: e85853.

Schneider, C.A., Rasband, W.S., and Eliceiri, K.W. (2012) NIH Image to ImageJ: 25 years of image analysis. Nature Methods 9: 671-675.

Song, C., Aundy, K., van de Mortel, J., and Raaijmakers, J.M. (2014) Discovery of new regulatory genes of lipopeptide biosynthesis in Pseudomonas fluorescens. FEMS Microbiology Letters 356: 166175.

van de Mortel, J.E., Ha, T., Govers, F., and Raaijmakers, J.M. (2009) Cellular responses of the late blight pathogen Phytophthora infestans to cyclic lipopeptide surfactants and their dependence on $G$ proteins. Applied and Environmental Microbiology 75: 4950-4957.

van den Berg, A.H., McLaggan, D., Diéguez-Uribeondo, J., and van West, P. (2013) The impact of the water moulds Saprolegnia diclina and Saprolegnia parasitica on natural ecosystems and the aquaculture industry. Fungal Biology Reviews 27: 33-42.

van West, P. (2006) Saprolegnia parasitica, an oomycete pathogen with a fishy appetite: new challenges for an old problem. Mycologist 20: 99-104.

Versalovic, J., Schneider, M., de Bruijn, F.J., and Lupski, J.R. (1994) Genomic fingerprinting of bacteria using repetitive sequence-based polymerase chain reaction. Methods in Molecular and Cellular Biology 5: 25-40.

Verschuere, L., Rombaut, G., Sorgeloos, P., and Verstraete, W. (2000) Probiotic bacteria as biological control agents in aquaculture. Microbiology and Molecular Biology Reviews 64: 655-671.

Watrous, J., Roach, P., Alexandrov, T., Heath, B.S., Yang, J.Y., Kersten, R.D. et al. (2012) Mass spectral molecular networking of living microbial colonies. Proceedings of the National Academy of Sciences.

Woodhams, D.C., Bosch, J., Briggs, C.J., Cashins, S., Davis, L.R., Lauer, A. et al. (2011) Mitigating amphibian disease: strategies to maintain wild populations and control chytridiomycosis. Frontiers in Zoology 8. 


\section{Supporting Information}

\section{Experimental set-up}

1 Saprolegnia-infected salmon eggs $(N=6)$

2 Healthy salmon eggs $(N=6)$

II Bacterial and archaeal communities

PhyloChip-based analysis and selection of target groups

III Functional analysis (Pseudomonas)

1 Phenotypic and genotypic characterisation (in vitro screening and phylogeny)

2 In vivo bioassays to test disease suppression by bacterial isolates

3 Chemical characterisation (LCMS, MS/MS, RP-HPLC )

\section{Functional analysis (biosurfactant)}

1 In vitro test against Saprolegnia hyphal growth

2 In vivo bioassays to test disease suppression by biosurfactant

Figure S1 Overall strategy used to decipher diversity of aquatic Pseudomonas species and their activity against the fish pathogenic oomycete Saprolegnia.

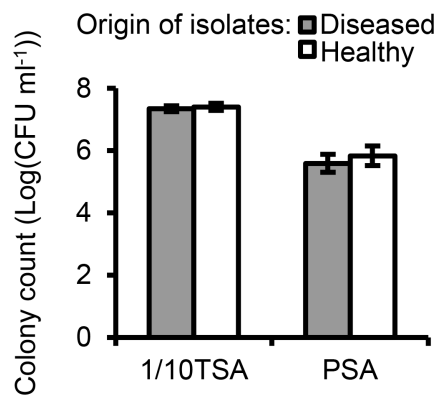

Figure S2 Colony count of salmon egg incubation water dilution-plated on 1/10TSA and PSA. Error bars represent S.E.M. $(N=6)$. 


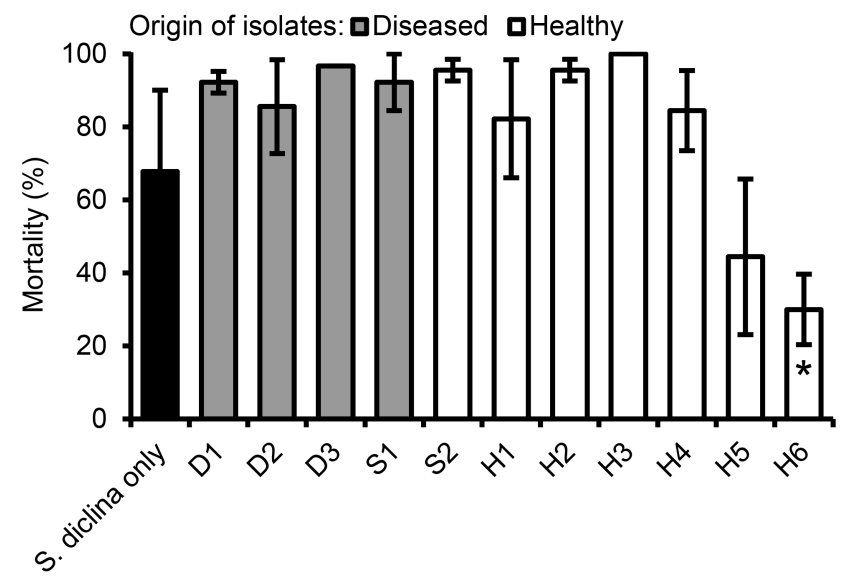

Figure S3 In vivo activity of the 11 aquatic Pseudomonas strains against $S$. diclina on salmon eggs. The mean percentage of egg mortality caused by $S$. diclina $765 \mathrm{~F} 3$ was determined at 6 days post inoculation (dpi) of this oomycete pathogen. Pseudomonas strains D1-D3 and S1 originated from diseased salmon eggs, whereas strains $\mathrm{S} 2$ and $\mathrm{H} 1-\mathrm{H} 6$ originated from healthy salmon eggs. All strains were introduced at an initial cell density of $10^{8} \mathrm{CFU} \mathrm{ml}{ }^{-1}$. The incubation temperature was $10 \pm 1^{\circ} \mathrm{C}$. Error bars represent S.E.M. $(N=3)$. The asterisk indicates a statistically significant difference from the control (S. diclina only) based on a one-way analysis of variance and post hoc LSD analysis $(P<0.05)$.

A

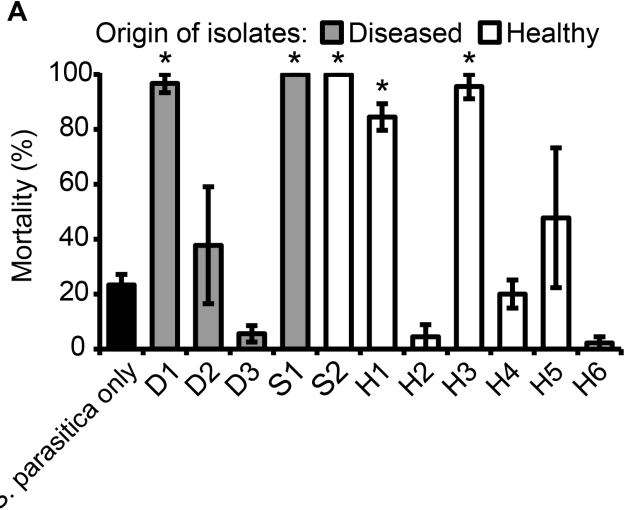

B Origin of isolates: $\square$ Diseased $\square$ Healthy

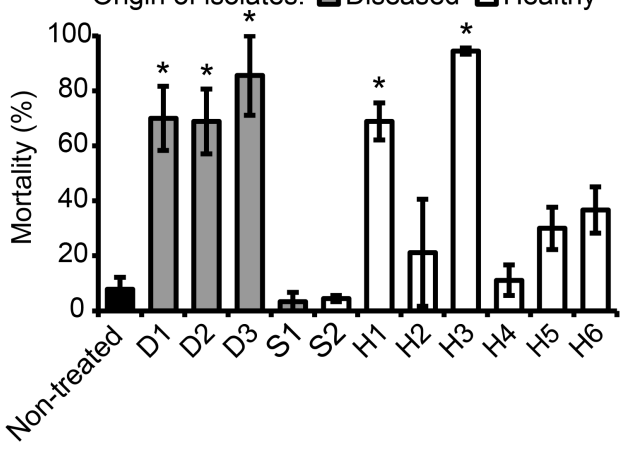

Figure S4 In vivo activity of 11 Pseudomonas isolates against S. parasitica and their effect on salmon egg mortality. In bioassay 1 , the initial bacterial density was $10^{8} \mathrm{CFU} \mathrm{ml^{-1 }}$ and incubation temperature was $10 \pm 1^{\circ} \mathrm{C}$. (A) Mean percentage of egg mortality was determined at 6 dpi of S. parasitica $762 \mathrm{~F} 4$ (Liu et al., 2014). Pseudomonas $\mathrm{H} 6$ reduced $(P=0.062)$ mortality compared to the control with $S$. parasitica only. (B) Mean percentage of egg mortality inoculated with cell suspensions of 11 Pseudomonas strains only. Error bars represent S.E.M. $(N=3)$. Asterisks indicate statistically significant differences from the controls, S. parasitica only (A) or non-treated (B) based on one-way analysis of variance and post hoc LSD analysis on ArcSin square root transformed data $(P<0.05)$. 
Table S1 BOX-PCR genotypic grouping of bacteria isolated from diseased and healthy salmon eggs by plating incubation water on the Pseudomonas semi-selective medium PSA. Only the BOX groups that consisted of at least 4 isolates from either diseased or healthy salmon egg samples are shown. One representative isolate from each BOX group was selected for activity testing in salmon egg bioassays. From the shared representative isolates, Pseudomonas isolates S1 and S2, which belonged to the largest shared BOX group and originated from both healthy and diseased salmon eggs were selected.

\begin{tabular}{ccc|cccc}
\hline $\begin{array}{c}\text { BOX } \\
\text { groups }\end{array}$ & No. of isolates & $\begin{array}{c}\text { Isolates } \\
\text { selected } \\
\text { for } \\
\text { phylogeny } \\
\text { analysis }\end{array}$ & $\begin{array}{c}\text { Positive } \\
\text { against } \\
\text { Saproelgnia } \\
\text { hyphal } \\
\text { growth }\end{array}$ & $\begin{array}{c}\text { Capable of } \\
\text { producing } \\
\text { biosurfactants }\end{array}$ & $\begin{array}{c}\text { Isolates } \\
\text { selected for } \\
\text { testing in } \\
\text { salmon egg } \\
\text { bioassays }\end{array}$ \\
\hline 1 & 9 & 0 & $\mathrm{D} 1$ & Yes & No & $\mathrm{D} 1$ \\
2 & 7 & 0 & $\mathrm{D} 2$ & Yes & Yes & $\mathrm{D} 2$ \\
3 & 6 & 0 & $\mathrm{D} 3$ & Yes & Yes & $\mathrm{D} 3$ \\
\hline 4 & 0 & 23 & $\mathrm{H} 1$ & Yes & Yes & $\mathrm{H} 1$ \\
5 & 0 & 7 & $\mathrm{H} 2$ & Yes & Yes & $\mathrm{H} 2$ \\
6 & 0 & 5 & $\mathrm{H} 3^{\mathrm{a}}$ & Yes & Yes & $\mathrm{H} 3^{\mathrm{a}}$ \\
7 & 0 & 5 & $\mathrm{H} 4$ & Yes & Yes & $\mathrm{H} 4$ \\
8 & 0 & 4 & $\mathrm{H} 5$ & Yes & Yes & $\mathrm{H} 5$ \\
9 & 0 & 4 & $\mathrm{H} 6$ & Yes & Yes & $\mathrm{H} 6$ \\
\hline 10 & 30 & 15 & $\mathrm{~S} 1, \mathrm{~S} 2^{\mathrm{a}}$ & Yes & No & $\mathrm{S} 1, \mathrm{~S} 2^{\mathrm{a}}$ \\
11 & 10 & 9 & $\mathrm{~S} 3, \mathrm{~S} 4$ & Yes & No & \\
12 & 11 & 7 & $\mathrm{~S} 5, \mathrm{~S} 6$ & Yes & Yes & \\
13 & 10 & 4 & $\mathrm{~S} 7, \mathrm{~S} 8$ & Yes & Yes & \\
14 & 10 & 1 & $\mathrm{~S} 9, \mathrm{~S} 10$ & Yes & No & \\
15 & 3 & 8 & $\mathrm{~S} 11, \mathrm{~S} 12$ & Yes & $\mathrm{S} 11$ : No; S12: Yes & \\
16 & 7 & 1 & $\mathrm{~S} 13, \mathrm{~S} 14$ & Yes & Yes & \\
17 & 5 & 1 & $\mathrm{~S} 15, \mathrm{~S} 16$ & Yes & No & \\
18 & 2 & 4 & $\mathrm{~S} 17, \mathrm{~S} 18$ & Yes & No & \\
\hline
\end{tabular}

${ }^{\mathrm{a}}$ Isolates $\mathrm{H} 3$ and S2 were obtained from 1/10TSA, not from PSA.

Table S2 Effect of biosurfactants from Pseudomonas $\mathrm{H} 6$ and $P$. fluorescens SS101 on hyphal diameter of S. parasitica CBS 223.65. Diameter of $10 \mathrm{~S}$. parasitica hyphae of each treatment was measured by Image J $1.47 \mathrm{v}$. Mean diameter and standard error of the mean are shown. Asterisks indicate statistically significant differences compared to the controls, based on a one-way analysis of variance and post hoc LSD analysis $(P<0.05)$.

\begin{tabular}{cc|llllll}
\hline & & Control & 15 & 40 & 100 & 200 & $\left(\mu \mathrm{g} \mathrm{ml}^{-1}\right)$ \\
\hline Hyphal & $\mathrm{H} 6$ & $0.009 \pm$ & $0.012 \pm$ & $0.014 \pm$ & $0.017 \pm$ & $0.017 \pm$ & $(\mathrm{mm})$ \\
& & 0.0005 & $0.0007^{*}$ & $0.0008^{*}$ & $0.0014^{*}$ & $0.0008^{*}$ & \\
thickness & $\mathrm{SS} 101$ & $0.007 \pm$ & $0.011 \pm$ & $0.013 \pm$ & $0.011 \pm$ & $0.013 \pm$ & $(\mathrm{mm})$ \\
& & 0.0006 & $0.0008^{*}$ & $0.0007^{*}$ & $0.0008^{*}$ & $0.0007^{*}$ & \\
\hline
\end{tabular}





\section{Chapter 5}

\section{Elucidating the diversity of aquatic}

Microdochium and Trichoderma species and their activity against the fish pathogen Saprolegnia diclina

Yiying Liu, Christin Zachow, Jos M. Raaijmakers and Irene de Bruijn

This chapter has been published as:

Yiying Liu, Christin Zachow, Jos M. Raaijmakers and Irene de Bruijn. (2016). Elucidating the diversity of aquatic Microdochium and Trichoderma species and their activity against the fish pathogen Saprolegnia diclina. International Journal of Molecular Sciences. 17, 140; doi:10.3390/ijms17010140. 


\section{Abstract}

Animals and plants are increasingly threatened by emerging fungal and oomycete diseases. Amongst oomycetes, Saprolegnia species cause population declines in aquatic animals, especially fish and amphibians, resulting in significant perturbation in biodiversity, ecological balance and food security. Due to the prohibition of several chemical control agents, novel sustainable measures are required to control Saprolegnia infections in aquaculture. Previously, fungal community analysis by terminal restriction fragment length polymorphism (T-RFLP) revealed that the Ascomycota, specifically the genus Microdochium, was an abundant fungal phylum associated with salmon eggs from a commercial fish farm. Here, phylogenetic analyses showed that most fungal isolates obtained from salmon eggs were closely related to Microdochium lycopodinum/Microdochium phragmitis and Trichoderma viride species. Phylogenetic and quantitative PCR analyses showed both a quantitative and qualitative difference in Trichoderma population between diseased and healthy salmon eggs, which was not the case for the Microdochium population. In vitro antagonistic activity of the fungi against Saprolegnia diclina was isolate-dependent; for most Trichoderma isolates, the typical mycoparasitic coiling around and/or formation of papilla-like structures on $S$. diclina hyphae were observed. These results suggest that among the fungal community associated with salmon eggs, Trichoderma species may play a role in Saprolegnia suppression in aquaculture.

\section{Introduction}

Saprolegniosis, caused by Saprolegnia species, results in tremendous losses in wild and cultured fish species including salmonids such as salmon and trout, and non-salmonids such as tilapia, catfish, carp, and eel (Bruno et al., 2011). The typical symptoms of Saprolegniosis are white or grey fungal-like hyphal mats on fish or their eggs (van West, 2006). Yield losses of $10 \%$ to more than $50 \%$ have been reported in eggs and young fish (Hatai and Hoshiai, 1992; Hatai and Hoshiai, 1993; Bruno et al., 2011).

To control Saprolegniosis, formalin is now commonly applied but is expected to be banned soon due to adverse effects on the environment (Bruno et al., 2011). A limited number of chemical and non-chemical alternative treatments have been tested to control Saprolegniosis, including hydrogen peroxide, sea water flushes and ultraviolet irradiation, but none of these are as effective as the banned malachite green (Bruno et al., 2011). Also, no vaccine is currently available to control this disease (Bruno et al., 2011; van den Berg et al., 2013).

Bacterial genera such as Bacillus, Enterococcus and Lactobacillus have been shown to reduce specific diseases in aquaculture and several of these beneficial 
bacteria are being commercialized (Chang and Liu, 2002; Irianto and Austin, 2002; Lara-Flores et al., 2003; Taoka et al., 2006; Gatesoupe, 2008). As a sustainable measure to combat Saprolegniosis, the bacterial genera Aeromonas, Frondihabitans and Pseudomonas have been proposed (Hatai and Willoughby, 1988; Bly et al., 1997; Hussein and Hatai, 2001; Lategan and Gibson, 2003; Lategan et al., 2004a, b; Bruno et al., 2011; Carbajal-González et al., 2011; Liu et al., 2014). Alike the probiotic bacteria, several beneficial fungi and/or their bioactive compounds are applied to control diseases. These fungal species are isolated either randomly or systematically (Campbell, 1947; Sandys-Winsch et al., 1993; Sallenave-Namont et al., 2000; Vargas Gil et al., 2009; Mulaw et al., 2013; Lopez et al., 2014; Kasa et al., 2015). Amongst commercialized fungi, Aspergillus oryzae, Coniothyrium minitans, Phlebiopsis gigantea and Trichoderma (teleomorph Hypocrea (Druzhinina et al., 2011)) spp., are able to suppress diseases and promote the growth of various hosts, mainly terrestrial crops and some animals such as cattle (Kmet et al., 1993; de Vrije et al., 2001; Wolken et al., 2003). For fish, Trichoderma viride enhanced body weight and reduced mortality of Nile tilapia exposed to Saprolegnia sp. (Abdelhamid et al., 2007). The commercial product HetroNex, containing Trichoderma viride and Trichoderma harzianum, has been developed to control fungal and oomycete diseases caused by Fusarium, Lagenidium and Saprolegnia in aquaculture ponds of fish, prawn and shrimp (Neospark).

In a fungal diversity study of the marine sponge Dragmacidon reticulatum, Trichoderma represented one of the most abundant genera among the isolated fungi (Passarini et al., 2013). To date, however, still little is known about the fungal community in aquaculture or aquatic environments (Dörr et al., 2012; Liu et al., 2014). Previously, we showed by clone library analyses that the oomycete community associated with Saprolegnia-infected (diseased) and healthy salmon eggs from a commercial fish hatchery were dominated by Saprolegnia with no difference in the number and pathogenicity of the Saprolegnia isolates present in either diseased or healthy salmon egg batches (Liu et al., 2014). Based on terminal restriction fragment length polymorphism (T-RFLP) analysis and clone library sequencing, also no obvious differences were observed in the fungal community composition between the diseased and healthy salmon egg batches (Liu et al., 2014). The clone library consisted of 209 fungal clones, the majority of which belonged to the Ascomycota. More specifically, 139 clones were classified as Microdochium (teleomorph Monographella) (Alford, 2008; Horst, 2008; Liu et al., 2014). To elucidate the role of fungi in the protection of salmon eggs against Saprolegniosis, we isolated and (phylogenetically) characterized fungi from diseased and healthy salmon eggs. Their abundance in diseased and healthy salmon egg batches and their activity against Saprolegnia diclina were investigated here. 


\section{Materials and Methods}

\section{Phylogenetic analysis of Microdochium and Trichoderma isolates}

Fungal isolation from salmon eggs was described previously by Liu et al. (2014). DNA isolation, internal transcribed spacer (ITS) rRNA sequencing and phylogenetic analyses of fungal isolates were conducted as described by Liu et al. (2014). For Trichoderma isolates, additional phylogenetic analysis was conducted with translation elongation factor 1 alpha (tef1) sequences. The tef1 gene was amplified by primer set EF1-728F (Cortinas et al., 2006) and TEF1LLErev (Nagy et al., 2007). The evolutionary distances of the phylogenetic trees were computed using the Kimura 2-parameter method (Kimura, 1980) for Microdochium ITS sequences, Tamura 3-parameter method (Tamura, 1992) for Trichoderma ITS sequences and Tamura-Nei method (Tamura and Nei, 1993) for tef1 sequences.

\section{Culture filtrate activity of Microdochium and Trichoderma isolates}

One agar plug of each Microdochium and Trichoderma isolate was pregrown in $6 \mathrm{~mL} 1 / 5$ th strength potato dextrose broth (1/5PDB, Difco ${ }^{\mathrm{TM}}$, Franklin Lakes, NJ, USA) for one week at $20-25{ }^{\circ} \mathrm{C}$. Each culture was lyophilized, the pellet dissolved in $6 \mathrm{~mL}$ fresh 1/5PDB and filter-sterilized through a $0.2 \mu \mathrm{m}$ filter (Whatman ${ }^{\mathrm{TM}}$, Freiburg, Germany). $1 \mathrm{~mL}$ culture filtrate solution was added into a well of 24 well suspension culture plate (Greiner bio-one, Cellstar ${ }^{\circledR}$, Frickenhausen, Germany) and one agar plug of Saprolegnia diclina $1152 \mathrm{~F} 4$ was added into each well. After incubation at $14-15{ }^{\circ} \mathrm{C}$ for four days the effect of the culture filtrates on hyphal growth of $S$. diclina was determined.

\section{Dual culture assay}

One agar plug of each of the Microdochium or Trichoderma isolates and one agar plug of $S$. diclina were placed at two opposite sides of 1/5th strength potato dextrose agar (1/5PDA). After incubation for 6 days at $20-25^{\circ} \mathrm{C}$, inhibition of hyphal growth of $S$. diclina was determined and plates were stored for one to two months at $4{ }^{\circ} \mathrm{C}$ until microscopic analyses were performed. Hyphal interactions were observed under a Nikon 90i epifluorescence microscope (Nikon Instruments Europe BV, Amsterdam, The Netherlands) with brightfield settings and accomplished with Nikon NIS-elements.

\section{Quantification of total fungi, Microdochium and Trichoderma in salmon egg incubation water}

DNA extraction from salmon egg samples and storage was described in Liu et al. (2014). All DNA samples were thawed on ice and normalized to $5 \pm 1 \mathrm{ng} \cdot \mu \mathrm{L}^{-1}$. To quantify total fungi in the water samples, ITS rRNA genes were amplified with ITS4 (White et al., 1990) and ITS9 (Ihrmark et al., 2012) primers in $12 \mu \mathrm{L}$ volumes, each consisted of $5 \mu \mathrm{L}$ of DNA template, $5.8 \mu \mathrm{L}$ BIOLINE 2x SensiFAST SYBR No-ROX mix, $0.1 \mu \mathrm{L}$ ITS4 primer $(10 \mathrm{mM}), 0.1 \mu \mathrm{L}$ ITS9 primer $(10 \mathrm{mM})$ and $1 \mu \mathrm{L}$ BSA $(0.1$ $\left.\mathrm{mg} \cdot \mathrm{mL}^{-1}\right)$. The quantitative PCR program consisted of 1 cycle at $95^{\circ} \mathrm{C}$ for $5 \mathrm{~min}, 45$ cycles at $95^{\circ} \mathrm{C}$ for 20 $\mathrm{s}, 55^{\circ} \mathrm{C}$ for $20 \mathrm{~s}, 72{ }^{\circ} \mathrm{C}$ for $30 \mathrm{~s}, 82^{\circ} \mathrm{C}$ for $15 \mathrm{~s}$. To quantify Microdochium lycopodinum/Microdochium phragmitis in the water samples, MPF (5'-AAGGTACCCGAAAGGGTGCTGG-3') and MPR (5'GAATTACTGCGCTCAGAGT ACGT-3') primers were designed and firstly the accuracy was verified by PCR using the genomic DNA isolated from M. phragmitis CBS 285.71 and Microdochium nivale var. nivale CBS 110.94 as template (Supplementary Material, Figure S2). The quantitative PCR program consisted of 1 cycle at $95^{\circ} \mathrm{C}$ for $5 \mathrm{~min}, 45$ cycles at $95^{\circ} \mathrm{C}$ for $20 \mathrm{~s}, 60^{\circ} \mathrm{C}$ for $20 \mathrm{~s}, 72{ }^{\circ} \mathrm{C}$ for $30 \mathrm{~s}, 82{ }^{\circ} \mathrm{C}$ for $15 \mathrm{~s}$. To quantify Trichoderma in the water samples, Trichoderma specific genes were amplified with ITS1TrF and ITS4TrR primers (Meincke et al., 2010) and QIAGEN Rotor-Gene ${ }^{\circledR}$ SYBR $^{\circledR}$ Green PCR Master Mix 2x was used. The quantitative PCR program consisted of 1 cycle at $95^{\circ} \mathrm{C}$ for $5 \mathrm{~min}, 45$ cycles at $95{ }^{\circ} \mathrm{C}$ for $10 \mathrm{~s}, 51{ }^{\circ} \mathrm{C}$ for $10 \mathrm{~s}, 72{ }^{\circ} \mathrm{C}$ for $20 \mathrm{~s}, 82^{\circ} \mathrm{C}$ for $10 \mathrm{~s}$. Genomic DNA of Trichoderma isolates $1152 \mathrm{~F} 1$ and $762 \mathrm{~F} 1 \mathrm{~b}$, and Microdochium isolates $736 \mathrm{~F} 1 \mathrm{a}$ and $749 \mathrm{~F} 1$ was isolated with PowerSoil $^{\circledR}$ DNA isolation kit (MO BIO Laboratories, Inc., Carlsbad, CA, USA) according to the manufacturer's instructions. Dilution series of DNA of each strain was prepared at $5,5 \times 10^{-1}, 5 \times 10^{-2}$, $5 \times 10^{-3}, 5 \times 10^{-4}, 5 \times 10^{-5}, 5 \times 10^{-6}, 5 \times 10^{-7} \mathrm{ng} \cdot \mu^{-1}$ and used as standards (Supplementary Material, Figure S3). 
All DNA sequences have been deposited in GenBank. The accession numbers for the internal transcribed spacer sequences of Trichoderma, Microdochium and Mortierella are KU202214-22, KU202223-31 and KU202232-33, respectively. The accession numbers for the sequences of translation elongation factor 1 alpha of Trichoderma isolates are KU202234-42.

\section{Results and Discussion}

Isolation of fungi from diseased and healthy salmon eggs

Previously, Saprolegnia-infected (diseased) and healthy salmon eggs and their corresponding incubation water were sampled from a commercial fish farm $(N=6$ for diseased eggs and $N=6$ for healthy eggs) (Liu et al., 2014). Per sample, one or two salmon eggs were placed on potato dextrose agar to allow fungal outgrowth (Figure 1). We obtained and purified 20 fungal isolates in total and by ITS sequencing identified three different genera, Microdochium, Trichoderma (both Ascomycota) and Mortierella (Zygomycota). Microdochium and Mortierella were the most represented genera in our previous clone library sequence analysis. Interestingly, Trichoderma was not detected in the previous analysis, probably due to the limited number of sequenced clones, the specificity of the primers or the efficiency of the PCR reaction (Liu et al., 2014). The two Mortierella isolates (BLAST identity of $100 \%$ in Genbank database) were isolated from only one healthy salmon egg sample. Here we aimed at comparing isolates obtained from multiple replicate samples of diseased and healthy eggs. Therefore, we focused on the Ascomycota isolates for the subsequent analyses described below.

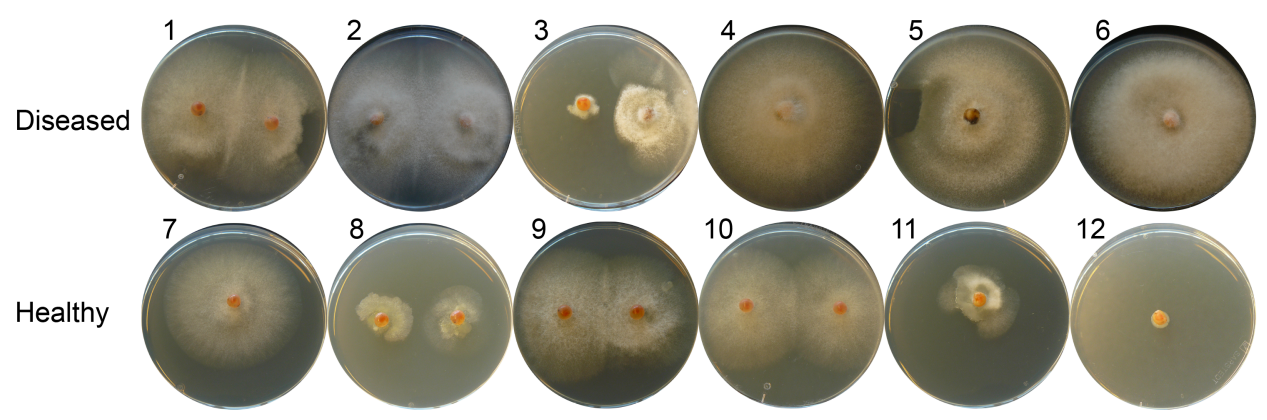

Figure 1 Isolation of salmon egg-associated fungi and oomycetes on potato dextrose agar plates. One or two salmon eggs from a Saprolegnia-infected batch (diseased, replicate No. 1-6) or a healthy batch (replicate No. 7-12) were placed onto the agar plates to allow fungal outgrowth. 


\section{Microdochium}

Microdochium species are known as snow molds, and some are pathogenic to plants (Cook, 1981; Mediha et al., 1986; Daamen et al., 1991; Simpson et al., 2000; Hong et al., 2008; Matsumoto, 2009; Xu and Nicholson, 2009; Rapacz et al., 2014). Microdochium nivale and Microdochium majus are two of the main causative agents of Fusarium head blight (Xu and Nicholson, 2009), whereas Microdochium lycopodinum and Microdochium phragmitis were isolated from plants without causing disease (Ernst et al., 2011; Jaklitsch and Voglmayr, 2012). M. phragmitis was endophytic in common reed and was more present in flooded habitats than the closely related Microdochium bolleyi (Ernst et al., 2011). Some Microdochium species were antagonistic to the plant pathogen Verticillium dahliae (Berg et al., 2005). Amongst our nine Microdochium isolates, five were isolated from diseased and four from healthy salmon eggs (Table 1). The origin of our Microdochium isolates was possibly from the catchment area, which was the water source for the salmon egg incubators (Liu et al., 2014). Based on the phylogenetic analyses of internal transcribed spacer (ITS) sequences, all the nine Microdochium isolates are closely related to $M$. lycopodinum and $M$. phragmitis, and no distinct separation is observed between isolates from diseased or healthy salmon eggs (Figure 2). Quantitative PCR using M. lycopodinum/M. phragmitis specific primers showed and confirmed that $M$. lycopodinum/M. phragmitis was detected in equal amounts in total DNA samples obtained from diseased and healthy salmon egg samples (Figure 3). One Microdochium isolate (749F1) inhibited the hyphal growth of Saprolegnia diclina on 1/5th strength potato dextrose agar (1/5PDA) (Table 1, Figure $4 a)$ suggesting the secretion of enzymes or other bioactive metabolites.

Table 1 In vitro activity of Microdochium or Trichoderma isolates against hyphal growth of Saprolegnia diclina 1152F4. The fungal isolates were retrieved from Saprolegnia-infected (diseased) or healthy salmon egg samples.

\begin{tabular}{|c|c|c|c|c|c|}
\hline Genus & $\begin{array}{c}\text { Strain } \\
\text { no. }\end{array}$ & $\begin{array}{c}\text { Salmon egg } \\
\text { sample }\end{array}$ & $\begin{array}{c}\text { Activity of } \\
\text { culture filtrate }\end{array}$ & $\begin{array}{c}\text { Dual culture } \\
\text { assay on 1/5PDA }\end{array}$ & $\begin{array}{l}\text { Hyphal interaction with } \\
\text { S. diclina microscopically }\end{array}$ \\
\hline \multirow{9}{*}{ Microdochium } & $41 \mathrm{~F} 2$ & Diseased & Not inhibitory & Not inhibitory & Not observed \\
\hline & $684 \mathrm{~F} 5$ & Diseased & Not inhibitory & Not inhibitory & Not observed \\
\hline & $736 \mathrm{~F} 1 \mathrm{a}$ & Diseased & Not inhibitory & Not inhibitory & Not observed \\
\hline & $736 \mathrm{~F} 1 \mathrm{~b}$ & Diseased & Not inhibitory & Not inhibitory & Not observed \\
\hline & $1056 \mathrm{~F} 2$ & Diseased & Not inhibitory & Not inhibitory & Not observed \\
\hline & $765 \mathrm{~F} 1 \mathrm{a}$ & Healthy & Not inhibitory & Not inhibitory & Not observed \\
\hline & $765 \mathrm{~F} 1 \mathrm{~b}$ & Healthy & Not inhibitory & Not inhibitory & Not observed \\
\hline & $749 F 1$ & Healthy & Not inhibitory & Inhibitory & Not observed \\
\hline & $749 \mathrm{~F} 2$ & Healthy & Not inhibitory & Not inhibitory & Not observed \\
\hline \multirow{9}{*}{ Trichoderma } & $684 \mathrm{~F} 1$ & Diseased & Not inhibitory & Not inhibitory & Coiling, papilla-like structure \\
\hline & 1056F1 & Diseased & Not inhibitory & Not inhibitory & Papilla-like structure \\
\hline & $1152 F 1$ & Diseased & Not inhibitory & Not inhibitory & Inconclusive \\
\hline & $762 \mathrm{~F} 1 \mathrm{a}$ & Healthy & Not inhibitory & Not inhibitory & Coiling \\
\hline & $762 \mathrm{~F} 1 \mathrm{~b}$ & Healthy & Not inhibitory & Not inhibitory & Coiling \\
\hline & $762 \mathrm{~F} 2$ & Healthy & Not inhibitory & Not inhibitory & Papilla-like structure \\
\hline & $764 \mathrm{~F} 1$ & Healthy & Inhibitory & Not inhibitory & Papilla-like structure \\
\hline & $764 \mathrm{~F} 2$ & Healthy & Not inhibitory & Not inhibitory & Coiling, papilla-like structure \\
\hline & $764 \mathrm{~F} 3$ & Healthy & Not inhibitory & Not inhibitory & Coiling, papilla-like structure \\
\hline
\end{tabular}




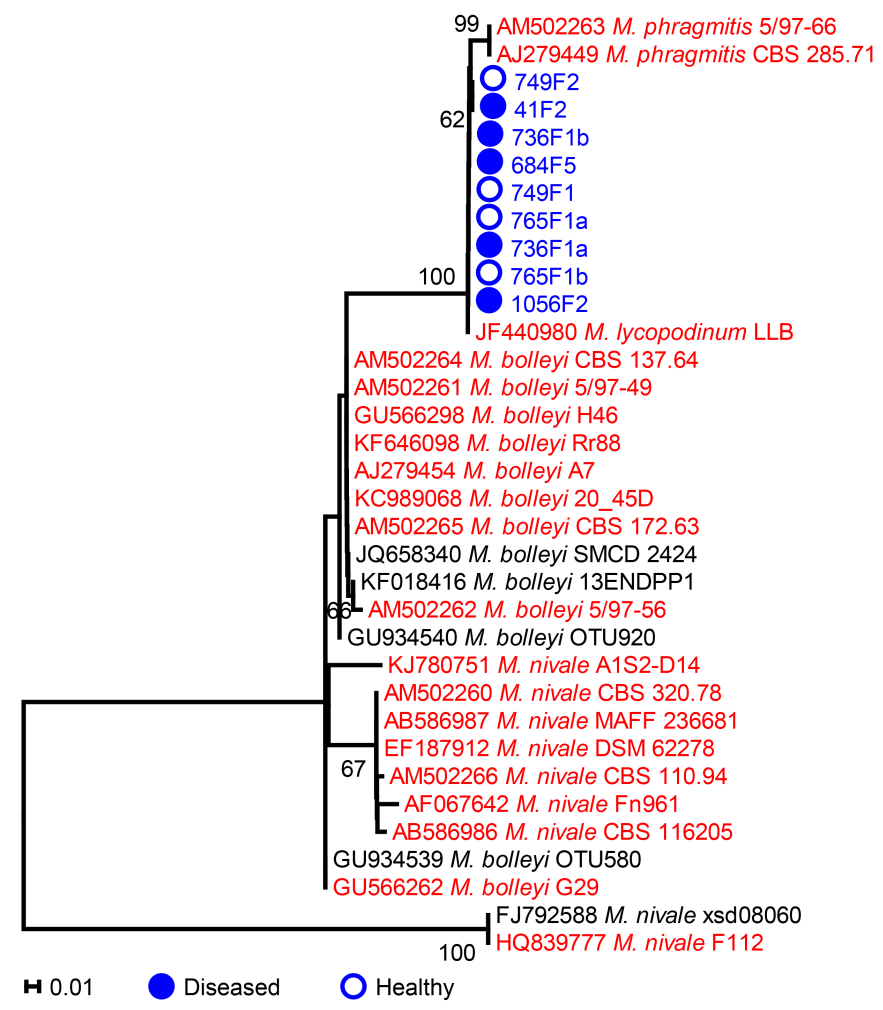

Figure 2 Phylogenetic tree of ITS rRNA sequences of nine Microdochium isolates from salmon eggs and reference strains. The phylogenetic analyses were conducted in Mega 5 using the Kimura 2parameter method (Kimura, 1980) to compute evolutionary distances. The bootstrap values indicated at the nodes are based on 1000 bootstrap replicates. Branch values lower than $50 \%$ are hidden. Closed and open circles indicate Microdochium isolates from Saprolegnia-infected (diseased) or healthy salmon egg samples, respectively. Red, blue and black colors indicate strains from terrestrial/plant, aquatic and unknown sources of isolation, respectively. The scale bar indicates an evolutionary distance of 0.01 nucleotide substitution per sequence position. Twenty-five ITS sequences of good quality and at least $550 \mathrm{bp}$ of reference strains of Microdochium were downloaded from GenBank; their strain names are preceded by the accession numbers.

To date, not much is known about Microdochium in aquatic environments, aquaculture or aquatic animals (Liu et al., 2014). Also not much is known about the bioactive compounds produced by Microdochium. Bhosale et al. (2011) reported that the active compound cyclosporine A, extracted from an estuarine M. nivale, has the potential to be applied pharmaceutically to control diseases caused by some dermatophytes and Aspergillus species in human and animals (Bhosale et al., 2011); Santiago et al. (2012) reported that the extract of M. phragmitis, which was isolated from Antarctic angiosperms, showed cytotoxic activity against a human tumoral cell line (Santiago et al., 2012). Therefore, further experiments are needed to decipher the bioactive potential capacity of our Microdochium isolates, especially their interaction with pathogens from cold water environments, like Saprolegnia spp. 


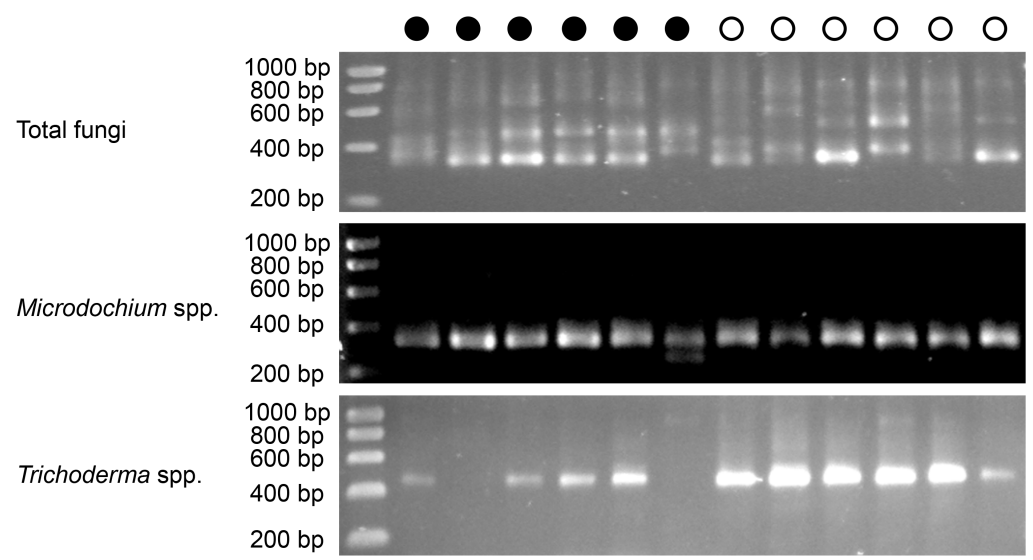

Figure 3 Detection of total fungi, Microdochium and Trichoderma in salmon egg samples by quantitative PCR. Total fungal community was detected using ITS4-ITS9 primers, Microdochium lycopodinum/Microdochium phragmitis species were detected by MPF-MPR primers, and Trichoderma species were detected by ITS1TrF-ITS4TrR primers. The concentration of DNA template of each sample was normalized at $5 \pm 1 \mathrm{ng} \cdot \mu \mathrm{L}-1$. Closed and open circles indicate DNA samples extracted from Saprolegnia-infected (diseased) or healthy samples, respectively. The lane on the left is the size marker and the band size (bp) is indicated next to each band.

\section{Trichoderma}

Most Trichoderma species are applied in agriculture as biocontrol agents against various plant-associated bacterial, fungal and oomycete pathogens, such as Clavibacter, Fusarium and Phytophthora (Verma et al., 2007; Schuster and Schmoll, 2010; Druzhinina et al., 2011). Trichoderma species are capable of producing a range of extracellular compounds to suppress plant pathogens, such as enzymes, fungicidal compounds and antibiotics; they can also promote plant growth via symbiotic association with plant hosts (Schirmböck et al., 1994; Harman et al., 2004; Schuster and Schmoll, 2010; Druzhinina et al., 2011; Harman, 2011). Trichoderma is commonly isolated from terrestrial environments, such as soil and wood (Druzhinina et al., 2011), but also from aquatic environments like freshwater (drinking water) and marine water (Miao and Qian, 2005; Hageskal et al., 2008; Gal-Hemed et al., 2011; Zhou et al., 2011; Passarini et al., 2013; Wu et al., 2014). Marine Trichoderma atroviride and Trichoderma asperelloides suppressed disease caused by Rhizoctonia solani on beans and enhanced defence responses against pathogenic Pseudomonas syringae pv. Lachrimans on cucumber seedlings (GalHemed et al., 2011). Some other marine-derived Trichoderma strains were capable of producing antagonistic compounds against cancer, diabetes, cancer cell lines or pathogenic Staphylococcus epidermidis; such compounds include tandyukisins from Trichoderma harzianum OUPS-111D-4, pyridones from Trichoderma sp. MF106, and trichoketides from Trichoderma sp. TPU1237 (Wu et al., 2014; Yamada et al., 2015; Yamazaki et al., 2015). 
S. diclina alone Microdochium 749F1 alone

$+$
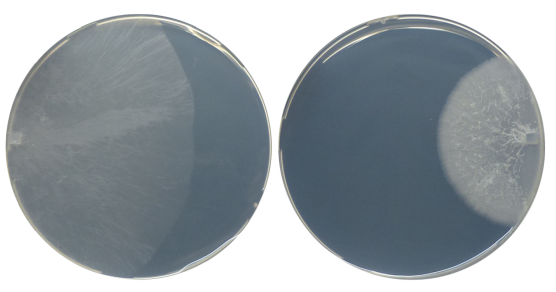

Microdochium 749F1

S. diclina alone Trichoderma $762 \mathrm{~F} 1 \mathrm{~b}$ alone

S. diclina

$+$

Trichoderma $762 \mathrm{~F} 1 \mathrm{~b}$
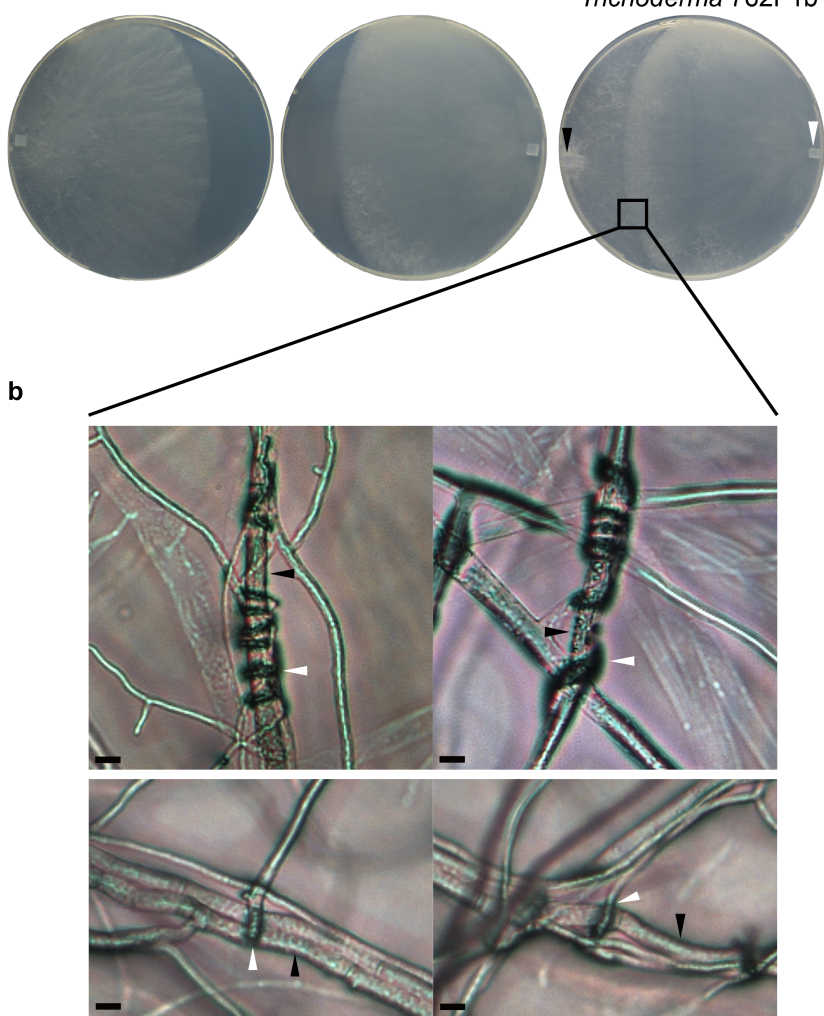

Figure 4 In vitro activities of Microdochium and Trichoderma isolates. (a) Dual culture of Microdochium isolate $749 \mathrm{~F} 1$ or Trichoderma isolate $762 \mathrm{~F} 1 \mathrm{~b}$ with Saprolegnia diclina $1152 \mathrm{~F} 4$ on $1 / 5$ th strength potato dextrose agar (1/5PDA). S. diclina and the fungal isolates were pre-grown on 1/5PDA. A hyphal plug of $S$. diclina was inoculated on the left side of the fresh 1/5PDA and a hyphal plug of Microdochium isolate $749 \mathrm{~F} 1$ or Trichoderma isolate $762 \mathrm{~F} 1 \mathrm{~b}$ was inoculated on the right side. The dual cultures were incubated for six days at $20-25{ }^{\circ} \mathrm{C}$. The black arrows indicate $S$. diclina plugs and the white arrows indicate Microdochium or Trichoderma plugs; (b) Microscopic pictures of the hyphal interaction between Trichoderma and S. diclina. The black arrows indicate hyphae of $S$. diclina. The white arrows indicate the coiling of Trichoderma hyphae around S. diclina hyphae (top pictures) or the formation of papilla-like structure of Trichoderma hyphae around S. diclina hyphae (bottom pictures). Scale bars represent 10 $\mu \mathrm{m}$. 
It was suggested that Trichoderma may have the potential to also control infectious diseases in aquaculture (Citarasu, 2012). Among our nine Trichoderma isolates, three were isolated from diseased and six from healthy salmon eggs (Table 1). Quantitative PCR with Trichoderma-specific primers showed that Trichoderma was present in higher abundance in total DNA samples of healthy than of diseased salmon eggs (Figure 3), although some variation in results were observed between replicated PCR reactions on the same DNA samples (Supplementary Material, Figure S1). The total fungal community did not differ in abundance between healthy and diseased salmon eggs (Figure 3). Collectively, these results suggest that Trichoderma is more enriched in healthy salmon egg samples than in diseased salmon egg samples. Phylogenetic analyses based on ITS sequences showed that all nine Trichoderma isolates belonged to the Trichoderma section (Druzhinina and Kopchinskiy) and no apparent separation was observed between isolates from diseased or healthy salmon eggs based on ITS sequences (Figure 5). However, phylogeny based on sequences of the translation elongation factor 1 alpha (tef1) clearly separated the Trichoderma isolates from diseased and healthy salmon eggs (Figure 6). Our nine Trichoderma isolates and the Trichoderma viride reference strains (Jaklitsch et al., 2006; Jaklitsch, 2011) formed three clades of Trichoderma viride. These results suggest that next to a quantitative difference also a qualitative difference in Trichoderma populations from diseased and healthy salmon eggs.

In terms of extracellular activity, we observed that the culture filtrate of only one Trichoderma isolate showed inhibition of hyphal growth of $S$. diclina (Table 1). Dual culture assays did not show inhibition of hyphal growth of $S$. diclina by any of the Trichoderma isolates tested (Table 1, Figure 4a). However, the hyphae of most Trichoderma isolates coiled around or produced a papilla-like structure on the hyphae of S. diclina (Table 1 and Figure 4b) (Druzhinina et al., 2011). The coiling and papilla-like structures suggest attachment of Trichoderma hyphae to S. diclina hyphae. Coiling is required for mycoparasitism but not all coiling leads to mycoparasitism (Harman et al., 2004; Lu et al., 2004; Druzhinina et al., 2011; Harman, 2011). The formation of papilla-like structures in the interaction with $S$. diclina could indicate the start of mycoparasitic invasion by Trichoderma; these structures have been shown to induce hyphal breakdown of various hosts (RochaRamírez et al., 2002; Harman et al., 2004; Chacón et al., 2007; Druzhinina et al., 2011; Harman, 2011). 


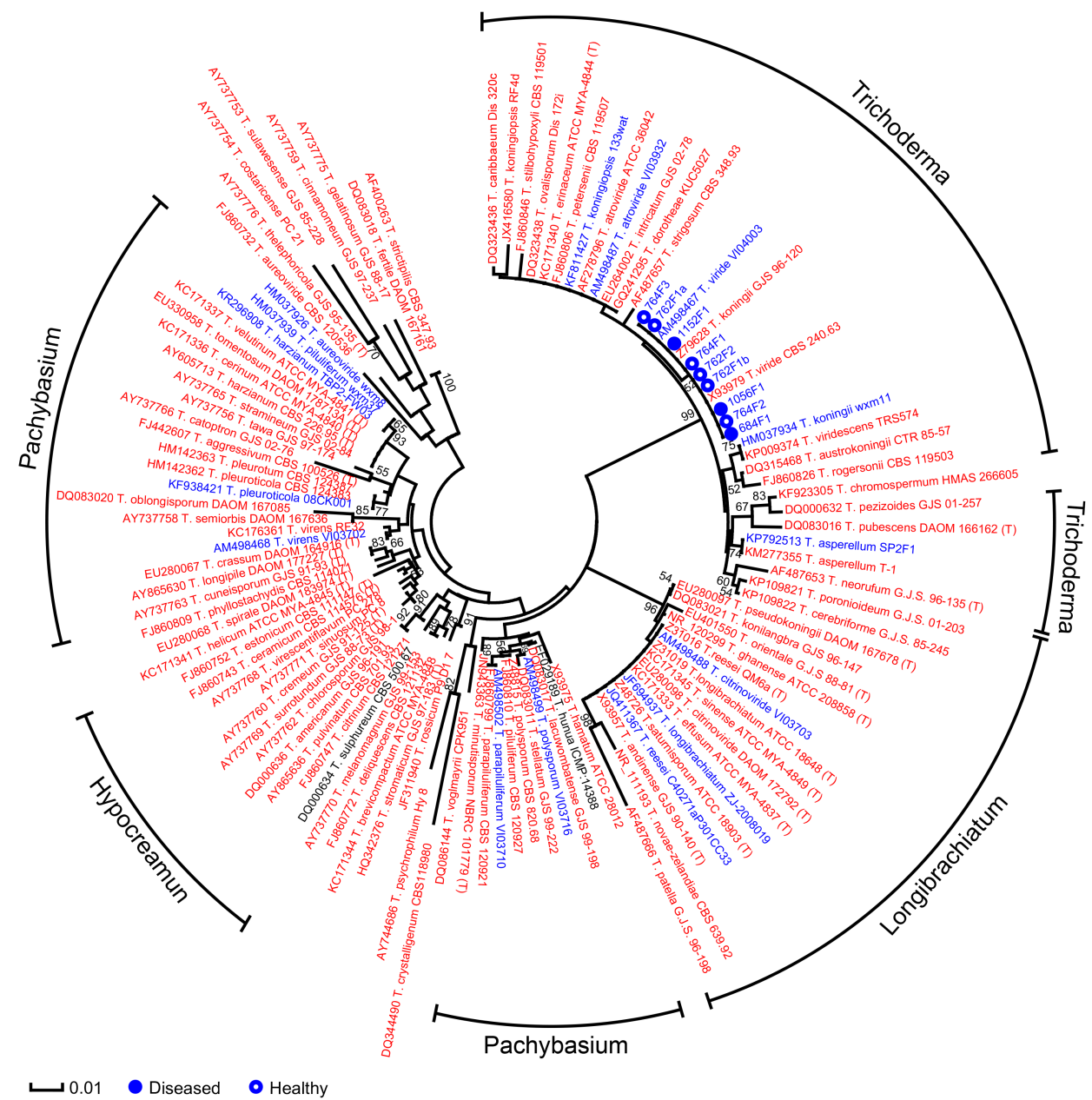

Figure 5 Phylogenetic tree of ITS rRNA sequences of nine Trichoderma isolates and reference strains. The phylogenetic analyses were conducted in Mega 5 using the Tamura 3-parameter method (Tamura, 1992) to compute evolutionary distances. The bootstrap values indicated at the nodes are based on 1000 bootstrap replicates. Branch values lower than $50 \%$ are hidden. Closed and open circles indicate isolates from Saprolegnia-infected (diseased) or healthy samples, respectively. Red, blue and black colors indicate strains from terrestrial/plant, aquatic and unknown sources of isolation, respectively. The scale bar indicates an evolutionary distance of 0.01 nucleotide substitution per sequence position. Outer labels describe section names based on the list of species in ISTH website (Druzhinina and Kopchinskiy) and only sections contained at least five strains are indicated. 104 ITS sequences of good quality and at least $550 \mathrm{bp}$ of reference strains of Trichoderma were downloaded from GenBank; their corresponding strain names are preceded by the accession numbers. Strain names followed by "( $T)$ " indicate type strains. 


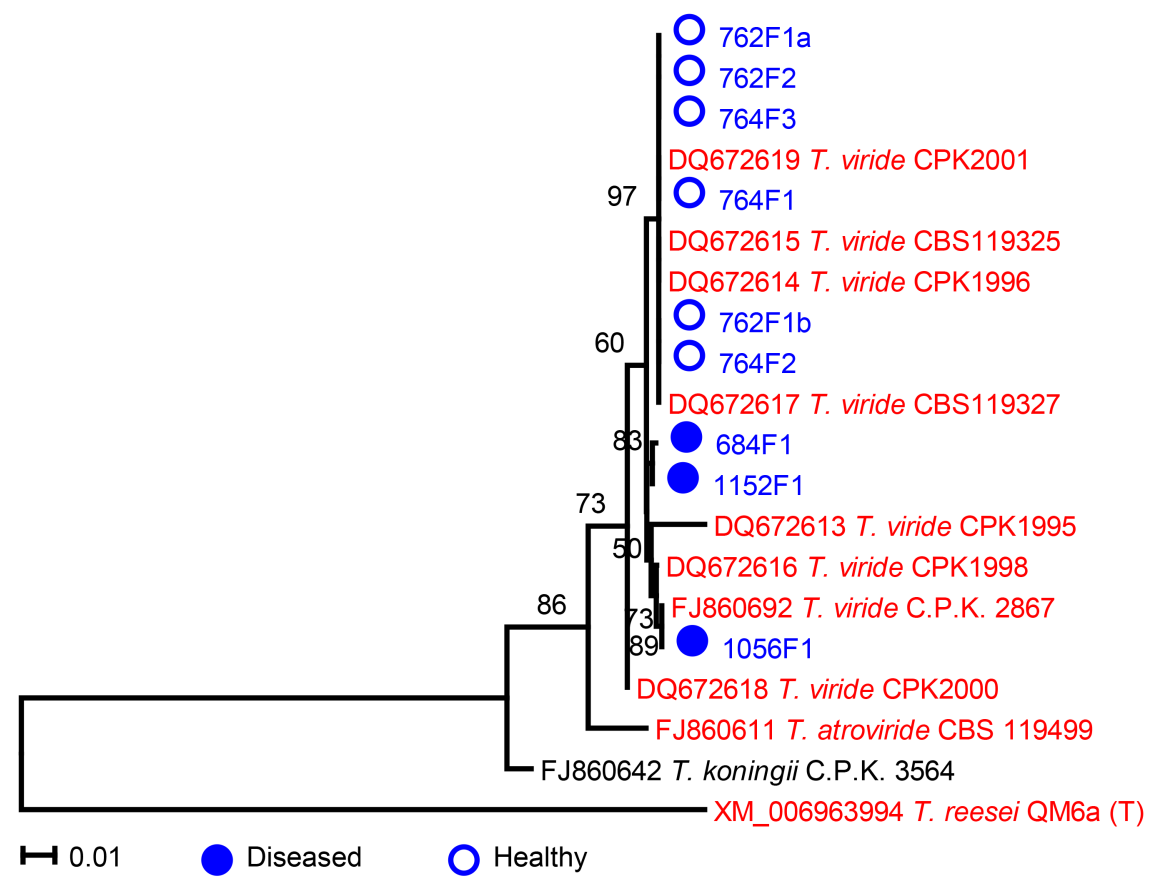

Figure 6 Phylogenetic tree of tef1 sequences of nine Trichoderma viride isolates and reference strains. The phylogenetic analyses were conducted in Mega 5 using the Tamura-Nei method (Tamura and Nei, 1993) to compute evolutionary distances. The bootstrap values indicated at the nodes are based on 1000 bootstrap replicates. Branch values lower than $50 \%$ are hidden. Closed and open circles indicate isolates from Saprolegnia-infected (diseased) or healthy samples, respectively. Red, blue and black colors indicate strains from terrestrial/plant, aquatic and unknown sources of isolation, respectively. The scale bar indicates an evolutionary distance of 0.01 nucleotide substitution per sequence position. 11 sequences of good quality and at least $1200 \mathrm{bp}$ of reference strains of Trichoderma were downloaded from GenBank; their strain names are preceded by the accession numbers. Strain name followed by "(T)" indicates type strain.

Even though Trichoderma species are commonly considered beneficial fungi, some Trichoderma strains, including $T$. harzianum, Trichoderma koningii, Trichoderma longibrachiatum, Trichoderma pseudokoningii and Trichoderma viride, maybe pathogenic to human (Escudero Gil et al., 1976; Loeppky et al., 1983; Jacobs et al., 1992; Gautheret et al., 1995; Seguin et al., 1995; Tanis et al., 1995; Campos-Herrero et al., 1996; Guiserix et al., 1996; Munoz et al., 1997; Furukawa et al., 1998; Guarro et al., 1999; Richter et al., 1999; Rota et al., 2000; Chouaki et al., 2002; Myoken et al., 2002; De Miguel et al., 2005). Some marine Trichoderma were associated to contaminated mussels and some were even toxic to aquatic animals, such as Artemia larvae (Sallenave-Namont et al., 2000; Marrouchi et al., 2013). Therefore, evaluations of the adverse effects of our Trichoderma isolates on the environment and humans are needed. 
Previous work by Abdelhamid et al. (2007) indicated that $T$. viride can enhance body weight and reduce mortality of Nile tilapia treated with Saprolegnia sp. (Abdelhamid et al., 2007). Our isolates belong to the $T$. viride clade and are, to our knowledge, the first characterized Trichoderma from salmon eggs. Collectively, our results pointed to both quantitative and qualitative differences in Trichoderma population between diseased and healthy salmon eggs. These analyses suggest a potential role of Trichoderma species in the protection of salmon eggs from $S$. diclina. Hence, our Trichoderma isolates and/or their metabolites, especially isolate 764F1 and its bioactive compounds, may have the potential to be applied in aquaculture. To this end, in vivo experiments should be conducted to determine the beneficial effects of our Trichoderma isolates in controlling Saprolegniosis and other aquaculture diseases.

\section{Conclusions}

Aquaculture has become one of the fastest developing animal food sectors (FAO, 2014), partly due to regulations to protect wild fish populations from overfishing and the increased demand for fish products (Bruno et al., 2011). To support this increase in food demand, aquaculture production is gradually intensifying, but effective and sustainable strategies are needed to suppress emerging diseases including Saprolegniosis. Very few studies have demonstrated the beneficial activity of fungi against aquatic pathogens (Abdelhamid et al., 2007; Woodhams et al., 2014). Our study is, to our knowledge, the first to establish correlations between the frequency/occurrence of indigenous fungal communities (Trichoderma and Microdochium species) and the health status of salmon eggs in a commercial hatchery. Our study is also the first to assess the diversity among Trichoderma and Microdochium isolates from aquaculture samples. The traditional plate assays provided informative results showing the potential antagonistic activity of our Trichoderma isolates obtained from salmon eggs against the pathogen Saprolegnia diclina. These results demonstrated the basic characters of our Trichoderma isolates, which provide a good starting point for future analyses on the molecular basis of Trichoderma-Saprolegnia interactions. Further in vitro and in vivo tests are needed to confirm their beneficial protective activity in situ. The role of Trichoderma in Saprolegnia disease suppression is especially interesting, since Trichoderma was shown to be more abundant in healthy salmon eggs than in diseased ones and showed a mycoparasitic interaction with Saprolegnia. Our study provides a framework to isolate and monitor putative protective fungi in Saprolegnia control and possibly other emerging diseases in aquaculture. 


\section{Acknowledgments}

This work was financially supported by SAPRO (Sustainable Approaches to Reduce Oomycete (Saprolegnia) Infections in Aquaculture, 238550), a Marie Curie Initial Training Network funded by the European Commission under Framework Program 7; ParaFishControl (Advanced Tools and Research Strategies for Parasite Control in European farmed fish, 634429), a Research and Innovation action funded by the European Commission under HORIZON 2020. The funds for covering the costs to publish in open access are received from ParaFishControl. We thank Klaas Bouwmeester (Wageningen University) for his help with microscopic work. We thank Emilia Hannula, Rosalinde M. Keijzer, Saskia Gerards, Agata Pijl (NIOO-KNAW) and Johnny Soares (Agronomic Institute-IAC, Brazil) for their advices in quantitative PCR. This manuscript is publication number 6010 of Netherlands Institute of Ecology (NIOOKNAW).

\section{Author contributions}

Conceived and designed the experiments: Yiying Liu, Christin Zachow, Irene de Bruijn and Jos M Raaijmakers. Performed the experiments: Yiying Liu. Analyzed the data: Yiying Liu, Christin Zachow, Irene de Bruijn. Created figures: Yiying Liu, Irene de Bruijn. Wrote the paper: Yiying Liu, Irene de Bruijn, Jos M Raaijmakers. Contributed to phylogenetic analyses, microscopic observation and quantitative PCR design: Christin Zachow. Designed M. lycopodinum/M. phragmitis specific primers: Yiying Liu, Irene de Bruijn. Contributed to review of the manuscript: all authors.

\section{Conflicts of Interest}

The authors declare no conflict of interest.

\section{References}

BioZyme, Inc. Available online: http://vitaferm.com/products/amaferm-digest-more/ (accessed on 4 December 2015).

Abdelhamid, A.M., Shabana, Y.M., and Gomaa, S.S.A. (2007). Aquatic fungi and fish production in Egypt, II - In vivo studies. Available online: http://en.engormix.com/MA-aquaculture/articles/aquaticfungi-fish-production-t460/MYC-p0.htm (accessed on 4 December 2015).

Alford, D.V. (2008) Pest and Disease Management Handbook: Wiley: Hoboken, NJ, USA.

Berg, G., Zachow, C., Lottmann, J., Gotz, M., Costa, R., and Smalla, K. (2005) Impact of plant species and site on rhizosphere-associated fungi antagonistic to Verticillium dahliae kleb. Applied and Environmental Microbiology 71: 4203-4213.

Bhosale, S.H., Patil, K.B., Parameswaran, P.S., Naik, C.G., and Jagtap, T.G. (2011) Active pharmaceutical ingredient (api) from an estuarine fungus, Microdochium nivale (Fr.). Journal of Environmental Biology 32: 653-658.

Bly, J.E., Quiniou, S.M.A., Lawson, L.A., and Clem, L.W. (1997) Inhibition of Saprolegnia pathogenic for fish by Pseudomonas fluorescens. Journal of Fish Diseases 20: 35-40.

Bruno, D., van West, P., and Beakes, G. (2011) Saprolegnia and other oomycetes. In Fish diseases and disorders, viral, bacterial and fungal infections. Woo, P., and Bruno, D. (eds). CABI: Wallingford, UK, pp. 669-720. 195.

Campbell, W.A. (1947) A new species of Coniothyrium parasitic on sclerotia. Mycologia 39: 190-

Campos-Herrero, M., Bordes, A., Perera, A., Ruiz, M., and Fernández, A. (1996) Trichoderma koningii peritonitis in a patient undergoing peritoneal dialysis. Clinical Microbiology Newsletter 18: 150152.

Carbajal-González, M.T., Fregeneda-Grandes, J.M., Suárez-Ramos, S., Rodríguez-Cadenas, F., and Aller-Gancedo, J.M. (2011) Bacterial skin flora variation and in vitro inhibitory activity against Saprolegnia parasitica in brown and rainbow trout. Diseases of Aquatic Organisms 96: 125-135. 
Chacón, M.R., Rodríguez-Galán, O., Benítez, T., Sousa, S., Rey, M., Llobell, A., et al. (2007) Microscopic and transcriptome analyses of early colonization of tomato roots by Trichoderma harzianum. International Microbiology 10: 19-27.

Chang, C.I., and Liu, W.Y. (2002) An evaluation of two probiotic bacterial strains, Enterococcus faecium SF68 and Bacillus toyoi, for reducing edwardsiellosis in cultured European eel, Anguilla anguilla L. Journal of Fish Diseases 25: 311-315.

Chouaki, T., Lavarde, V., Lachaud, L., Raccurt, C.P., and Hennequin, C. (2002) Invasive infections due to Trichoderma species: report of 2 cases, findings of in vitro susceptibility testing, and review of the literature. Clinical Infectious Diseases 35: 1360-1367.

Citarasu, T. (2012) Natural antimicrobial compounds for use in aquaculture. In Infectious Disease in Aquaculture. Austin, B. (ed): Woodhead Publishing: Cambridge, UK, pp. 419-456.

Cook, R.J. (1981) Fusarium diseases of wheat and other small grains in North America. In Fusarium diseases, biology, and taxonomy. Nelson, P.E., Toussoun, T.A., and Cook, R.J. (eds). Pennsylvania State University Press: University Park, PA, USA, pp. 39-52.

Cortinas, M.-N., Crous, P.W., Wingfield, B.D., and Wingfield, M.J. (2006) Multi-gene phylogenies and phenotypic characters distinguish two species within the Colletogloeopsis zuluensis complex associated with Eucalyptus stem cankers. Studies in mycology 55: 133-146.

Daamen, R.A., Langerak, C.J., and Stol, W. (1991) Surveys of cereal diseases and pests in The Netherlands .3. Monographella nivalis and Fusarium spp. in winter-wheat fields and seed lots. Netherlands Journal of Plant Pathology 97: 105-114.

De Miguel, D., Gomez, P., Gonzalez, R., Garcia-Suarez, J., Cuadros, J.A., Banas, M.H. et al. (2005) Nonfatal pulmonary Trichoderma viride infection in an adult patient with acute myeloid leukemia: report of one case and review of the literature. Diagnostic Microbiology and Infectious Disease 53: 3337.

de Vrije, T., Antoine, N., Buitelaar, R.M., Bruckner, S., Dissevelt, M., Durand, A. et al. (2001) The fungal biocontrol agent Coniothyrium minitans: production by solid-state fermentation, application and marketing. Applied Microbiology and Biotechnology 56: 58-68.

Dörr, A.J.M., Elia, A.C., Rodolfi, M., Garzoli, L., Picco, A.M., D'Amen, M., et al. (2012) A model of co-occurrence: segregation and aggregation patterns in the mycoflora of the crayfish Procambarus clarkii in Lake Trasimeno (central Italy). Journal of Limnology 71: 135-143.

Druzhinina, I., and Kopchinskiy, A. International Subcommission on Trichoderma and Hypocrea Taxonomy. Available online: http://isth.info/ (accessed on 4 December 2015).

Druzhinina, I.S., Seidl-Seiboth, V., Herrera-Estrella, A., Horwitz, B.A., Kenerley, C.M., Monte, E. et al. (2011) Trichoderma: the genomics of opportunistic success. Nature Reviews Microbiology 9: 749759.

Ernst, M., Neubert, K., Mendgen, K.W., and Wirsel, S.G.R. (2011) Niche differentiation of two sympatric species of Microdochium colonizing the roots of common reed. Bmc Microbiology 11.

Escudero Gil, M.R., Pino Corral, E., and Munoz Munoz, R. (1976) Pulmonary mycoma cause by Trichoderma viride. Actas Dermo-Sifiliográficas 67: 673-680.

FAO (2014) The state of world fisheries and aquaculture 2014. Food and Agriculture Organization of the United Nations: Rome, Italy, 2014; p. 223

Furukawa, H., Kusne, S., Sutton, D.A., Manez, R., Carrau, R., Nichols, L. et al. (1998) Acute invasive sinusitis due to Trichoderma longibrachiatum in a liver and small bowel transplant recipient. Clinical Infectious Diseases 26: 487-489.

Gal-Hemed, I., Atanasova, L., Komon-Zelazowska, M., Druzhinina, I.S., Viterbo, A., and Yarden, O. (2011) Marine isolates of Trichoderma spp. As potential halotolerant agents of biological control for aridzone agriculture. Applied and Environmental Microbiology 77: 5100-5109.

Gatesoupe, F.-J. (2008) Updating the importance of lactic acid bacteria in fish farming: Natural occurrence and probiotic treatments. Journal of Molecular Microbiology and Biotechnology 14: 107-114.

Gautheret, A., Dromer, F., Bourhis, J.H., and Andremont, A. (1995) Trichoderma pseudokoningii as a cause of fatal infection in a bone marrow transplant recipient. Clinical Infectious Diseases 20: 10631064.

Guarro, J., Antolín-Ayala, M.I., Gené, J., Gutiérrez-Calzada, J., Nieves-Díez, C., and Ortoneda, M. (1999) Fatal case of Trichoderma harzianum infection in a renal transplant recipient. Journal of Clinical Microbiology 37: 3751-3755.

Guiserix, J., Ramdane, M., Finielz, P., Michault, A., and Rajaonarivelo, P. (1996) Trichoderma harzianum peritonitis in peritoneal dialysis. Nephron 74: 473-474.

Hageskal, G., Vrålstad, T., Knutsen, A.K., and Skaar, I.D.A. (2008) Exploring the species diversity of Trichoderma in Norwegian drinking water systems by DNA barcoding. Molecular Ecology Resources 8: 1178-1188. 
Harman, G.E. (2011) Multifunctional fungal plant symbionts: new tools to enhance plant growth and productivity. New Phytologist 189: 647-649.

Harman, G.E., Howell, C.R., Viterbo, A., Chet, I., and Lorito, M. (2004) Trichoderma species opportunistic, avirulent plant symbionts. Nature Reviews Microbiology 2: 43-56.

Hatai, K., and Willoughby, L.G. (1988) Saprolegnia parasitica from rainbow trout inhibited by the bacterium Pseudomonas fluorescens. Bulletin of the European Association of Fish Pathologists 8: 2729.

Hatai, K., and Hoshiai, G. (1992) Mass mortality in cultured coho salmon (Oncorhynchus kisutch) due to Saprolegnia parasitica coker. Journal of Wildlife Diseases 28: 532-536.

Hatai, K., and Hoshiai, G.-I. (1993) Characteristics of two Saprolegnia species isolated from coho salmon with Saprolegniosis. Journal of Aquatic Animal Health 5: 115-118.

Hong, S.K., Kim, W.G., Choi, H.W., and Lee, S.Y. (2008) Identification of Microdochium bolleyi associated with basal rot of creeping bent grass in Korea. Mycobiology 36: 77-80.

Horst, R.K. (2008) Westcott's Plant Disease Handbook. Springer: Berlin, Germany; Heidelberg, Germany, 2008.

Hussein, M.M.A., and Hatai, K. (2001) In vitro inhibition of Saprolegnia by bacteria isolated from lesions of salmonids with saprolegniasis. Fish Pathology 36: 73-78.

Ihrmark, K., Bödeker, I.T.M., Cruz-Martinez, K., Friberg, H., Kubartova, A., Schenck, J. et al. (2012) New primers to amplify the fungal ITS2 region - evaluation by 454-sequencing of artificial and natural communities. FEMS Microbiology Ecology 82: 666-677.

Irianto, A., and Austin, B. (2002) Probiotics in aquaculture. Journal of Fish Diseases 25: 633-642.

Jacobs, F., Byl, B., Bourgeois, N., Coremans-Pelseneer, J., Florquin, S., Depre, G. et al. (1992)

Trichoderma viride infection in a liver transplant recipient. Mycoses 35: 301-303.

Jaklitsch, W., and Voglmayr, H. (2012) Phylogenetic relationships of five genera of Xylariales and Rosasphaeria gen. nov. (Hypocreales). Fungal Diversity 52: 75-98.

Jaklitsch, W.M. (2011) European species of Hypocrea part II: species with hyaline ascospores. Fungal Diversity 48: 1-250.

Jaklitsch, W.M., Samuels, G.J., Dodd, S.L., Lu, B.S., and Druzhinina, I.S. (2006) Hypocrea rufa/Trichoderma viride: a reassessment, and description of five closely related species with and without warted conidia. Studies in Mycology 56: 135-177.

Kasa, P., Modugapalem, H., and Battini, K. (2015) Isolation, screening, and molecular characterization of plant growth promoting rhizobacteria isolates of Azotobacter and Trichoderma and their beneficial activities. Journal of Natural Science, Biology, and Medicine 6: 360-363.

Kimura, M. (1980) A simple method for estimating evolutionary rate of base substitutions through comparative studies of nucleotide sequences. Journal of Molecular Evolution 16: 111-120.

Kmet, V., Flint, H.J., and Wallace, R.J. (1993) Probiotics and manipulation of rumen development and function. Archives of animal nutrition 44: 1-10.

Lara-Flores, M., Olvera-Novoa, M.A., Guzmán-Méndez, B.z.E., and López-Madrid, W. (2003) Use of the bacteria Streptococcus faecium and Lactobacillus acidophilus, and the yeast Saccharomyces cerevisiae as growth promoters in Nile tilapia (Oreochromis niloticus). Aquaculture 216: 193-201.

Lategan, M.J., and Gibson, L.F. (2003) Antagonistic activity of Aeromonas media strain A199 against Saprolegnia sp., an opportunistic pathogen of the eel, Anguilla australis Richardson. Journal of Fish Diseases 26: 147-153.

Lategan, M.J., Torpy, F.R., and Gibson, L.F. (2004a) Biocontrol of saprolegniosis in silver perch Bidyanus bidyanus (Mitchell) by Aeromonas media strain A199. Aquaculture 235: 77-88.

Lategan, M.J., Torpy, F.R., and Gibson, L.F. (2004b) Control of saprolegniosis in the eel Anguilla australis Richardson, by Aeromonas media strain A199. Aquaculture 240: 19-27.

Liu, Y., de Bruijn, I., Jack, A.L.H., Drynan, K., van den Berg, A.H., Thoen, E. et al. (2014) Deciphering microbial landscapes of fish eggs to mitigate emerging diseases. The ISME Journal 8: 2002-2014.

Loeppky, C.B., Sprouse, R.F., Carlson, J.V., and Everett, E.D. (1983) Trichoderma viride peritonitis. Southern Medical Journal 76: 798-799.

Lopez, L.L.M.A., Aganon, C.P., and Juico, P.P. (2014) Isolation of Trichoderma species from carabao manure and evaluation of its beneficial uses. International journal of scientific and technology research 3: 190-199.

Lu, Z.X., Tombolini, R., Woo, S., Zeilinger, S., Lorito, M., and Jansson, J.K. (2004) In vivo study of Trichoderma-pathogen-plant interactions, using constitutive and inducible green fluorescent protein reporter systems. Applied and Environmental Microbiology 70: 3073-3081.

Marrouchi, R., Benoit, E., Le Caer, J.-P., Belayouni, N., Belghith, H., Molgó, J., et al. (2013) Toxic C17-sphinganine analogue mycotoxin, contaminating Tunisian mussels, causes flaccid paralysis in rodents. Marine Drugs 11: 4724. 
Matsumoto, N. (2009) Snow molds: a group of fungi that prevail under snow. Microbes and Environments 24: 14-20.

Mediha, H., Al-Hashimi, and Perry, D.A. (1986) Fungal antagonists of Gerlachia nivalis. Journal of Phytopathology 116: 106-112.

Meincke, R., Weinert, N., Radl, V., Schloter, M., Smalla, K., and Berg, G. (2010) Development of a molecular approach to describe the composition of Trichoderma communities. Journal of Microbiological Methods 80: 63-69.

Miao, L., and Qian, P.Y. (2005) Antagonistic antimicrobial activity of marine fungi and bacteria isolated from marine biofilm and seawaters of Hong Kong. Aquatic Microbial Ecology 38: 231-238.

Mulaw, T.B., Druzhinina, I.S., Kubicek, C.P., and Atanasova, L. (2013) Novel endophytic Trichoderma spp. isolated from healthy Coffea arabica roots are capable of controlling coffee Tracheomycosis. Diversity 5: 750-766.

Munoz, F.M., Demmler, G.J., Travis, W.R., Ogden, A.K., Rossmann, S.N., and Rinaldi, M.G. (1997) Trichoderma longibrachiatum infection in a pediatric patient with aplastic anemia. Journal of Clinical Microbiology 35: 499-503.

Myoken, Y., Sugata, T., Fujita, Y., Asaoku, H., Fujihara, M., and Mikami, Y. (2002) Fatal necrotizing stomatitis due to Trichoderma longibrachiatum in a neutropenic patient with malignant lymphoma: a case report. International Journal of Oral and Maxillofacial Surgery 31: 688-691.

Nagy, V., Seidl, V., Szakacs, G., Komofl-Zelazowska, M., Kubicek, C.P., and Druzhinina, I.S. (2007) Application of DNA bar codes for screening of industrially important fungi: the haplotype of Trichoderma harzianum sensu stricto indicates superior chitinase formation. Applied and Environmental Microbiology 73: 7048-7058.

Neospark. Available online: http://www.neospark.com/hetronex-abtp.html (accessed on 4 December 2015).

Passarini, M.R.Z., Santos, C., Lima, N., Berlinck, R.G.S., and Sette, L.D. (2013) Filamentous fungi from the Atlantic marine sponge Dragmacidon reticulatum. Archives of Microbiology 195: 99-111.

Rapacz, M., Ergon, A., Hoglind, M., Jorgensen, M., Jurczyk, B., Ostrem, L. et al. (2014) Overwintering of herbaceous plants in a changing climate. Still more questions than answers. Plant Science 225: 34-44.

Richter, S., Cormican, M.G., Pfaller, M.A., Lee, C.K., Gingrich, R., Rinaldi, M.G., et al. (1999) Fatal disseminated Trichoderma longibrachiatum infection in an adult bone marrow transplant patient: species identification and review of the literature. Journal of Clinical Microbiology 37: 1154-1160.

Rocha-Ramírez, V., Omero, C., Chet, I., Horwitz, B.A., and Herrera-Estrella, A. (2002) Trichoderma atroviride G-protein alpha-subunit gene tga1 is involved in mycoparasitic coiling and conidiation. Eukaryotic Cell 1: 594-605.

Rota, S., Marchesi, D., Farina, C., and de Bievre, C. (2000) Trichoderma pseudokoningii peritonitis in automated peritoneal dialysis patient successfully treated by early catheter removal. Peritoneal Dialysis International 20: 91-93.

Sallenave-Namont, C., Pouchus, Y.F., Robiou du Pont, T., Lassus, P., and Verbist, J.F. (2000) Toxigenic saprophytic fungi in marine shellfish farming areas. Mycopathologia 149: 21-25.

Sandys-Winsch, C., Whipps, J.M., Gerlagh, M., and Kruse, M. (1993) World distribution of the sclerotial mycoparasite Coniothyrium minitans. Mycological Research 97: 1175-1178.

Santiago, I.F., Alves, T.M.A., Rabello, A., Sales Junior, P.A., Romanha, A.J., Zani, C.L. et al. (2012) Leishmanicidal and antitumoral activities of endophytic fungi associated with the Antarctic angiosperms Deschampsia antarctica Desv. and Colobanthus quitensis (Kunth) Bartl. Extremophiles 16: 95-103.

Schirmböck, M., Lorito, M., Wang, Y.L., Hayes, C.K., Arisanatac, I., Scala, F. et al. (1994) Parallel formation and synergism of hydrolytic enzymes and peptaibol antibiotics, molecular mechanisms involved in the antagonistic action of Trichoderma harzianum against phytopathogenic fungi. Applied and Environmental Microbiology 60: 4364-4370.

Schuster, A., and Schmoll, M. (2010) Biology and biotechnology of Trichoderma. Applied Microbiology and Biotechnology 87: 787-799.

Seguin, P., Degeilh, B., Grulois, I., Gacouin, A., Maugendre, S., Dufour, T. et al. (1995) Successful treatment of a brain abscess due to Trichoderma longibrachiatum after surgical resection. European Journal of Clinical Microbiology \& Infectious Diseases 14: 445-448.

Simpson, D.R., Rezanoor, H.N., Parry, D.W., and Nicholson, P. (2000) Evidence for differential host preference in Microdochium nivale var. majus and Microdochium nivale var. nivale. Plant Pathology 49: 261-268.

Tamura, K. (1992) Estimation of the number of nucleotide substitutions when there are strong transition-transversion and G + C-content biases. Molecular Biology and Evolution 9: 678-687. 
Tamura, K., and Nei, M. (1993) Estimation of the number of nucleotide substitutions in the control region of mitochondrial DNA in humans and chimpanzees. Molecular Biology and Evolution 10: 512526.

Tanis, B.C., van der Pijl, H., van Ogtrop, M.L., Kibbelaar, R.E., and Chang, P.C. (1995) Fatal fungal peritonitis by Trichoderma longibrachiatum complicating peritoneal dialysis. Nephrology Dialysis Transplantation 10: 114-116.

Taoka, Y., Maeda, H., Jo, J.-Y., Jeon, M.-J., Bai, S.C., Lee, W.-J. et al. (2006) Growth, stress tolerance and non-specific immune response of Japanese flounder Paralichthys olivaceus to probiotics in a closed recirculating system. Fisheries Science 72: 310-321.

van den Berg, A.H., McLaggan, D., Diéguez-Uribeondo, J., and van West, P. (2013) The impact of the water moulds Saprolegnia diclina and Saprolegnia parasitica on natural ecosystems and the aquaculture industry. Fungal Biology Reviews 27: 33-42.

van West, P. (2006) Saprolegnia parasitica, an oomycete pathogen with a fishy appetite: new challenges for an old problem. Mycologist 20: 99-104.

Vargas Gil, S., Pastor, S., and March, G.J. (2009) Quantitative isolation of biocontrol agents Trichoderma spp., Gliocladium spp. and actinomycetes from soil with culture media. Microbiological Research 164: 196-205.

Verma, M., Brar, S.K., Tyagi, R.D., Surampalli, R.Y., and Valero, J.R. (2007) Antagonistic fungi, Trichoderma spp.: Panoply of biological control. Biochemical Engineering Journal 37: 1-20.

White, T.J., Bruns, T., Lee, S., and Taylor, J. (1990) Amplification and direct sequencing of fungal ribosomal RNA genes for phylogenetics. In PCR protocols : a guide to methods and applications. Innis, M.A., Gelfand, D.H., Sninsky, J.J., and White, T.J. (eds). Academic Press: New York, NY, USA, pp. 315-322.

Wolken, W.A.M., Tramper, J., and van der Werf, M.J. (2003) What can spores do for us? Trends in Biotechnology 21: 338-345.

Woodhams, D.C., Brandt, H., Baumgartner, S., Kielgast, J., Küpfer, E., Tobler, U. et al. (2014) Interacting symbionts and immunity in the amphibian skin mucosome predict disease risk and probiotic effectiveness. PLOS ONE 9: e96375.

Wu, B., Oesker, V., Wiese, J., Schmaljohann, R., and Imhoff, J.F. (2014) Two new antibiotic pyridones produced by a marine fungus, Trichoderma sp. strain MF106. Marine Drugs 12: 1208-1219.

$\mathrm{Xu}, \mathrm{X}$., and Nicholson, P. (2009) Community ecology of fungal pathogens causing wheat head blight. Annual Review of Phytopathology, 47: 83-103.

Yamada, T., Umebayashi, Y., Kawashima, M., Sugiura, Y., Kikuchi, T., and Tanaka, R. (2015) Determination of the chemical structures of Tandyukisins $B-D$, isolated from a marine sponge-derived fungus. Marine Drugs 13: 3231.

Yamazaki, H., Saito, R., Takahashi, O., Kirikoshi, R., Toraiwa, K., Iwasaki, K. et al. (2015) Trichoketides $A$ and $B$, two new protein tyrosine phosphatase $1 B$ inhibitors from the marine-derived fungus Trichoderma sp. The Journal of Antibiotics 68: 628-632.

Zhou, K., Zhang, X., Zhang, F., and Li, Z. (2011) Phylogenetically diverse cultivable fungal community and polyketide synthase (PKS), non-ribosomal peptide synthase (NRPS) genes associated with the South China Sea sponges. Microbial Ecology 62: 644-654. 


\section{Supplementary Materials}

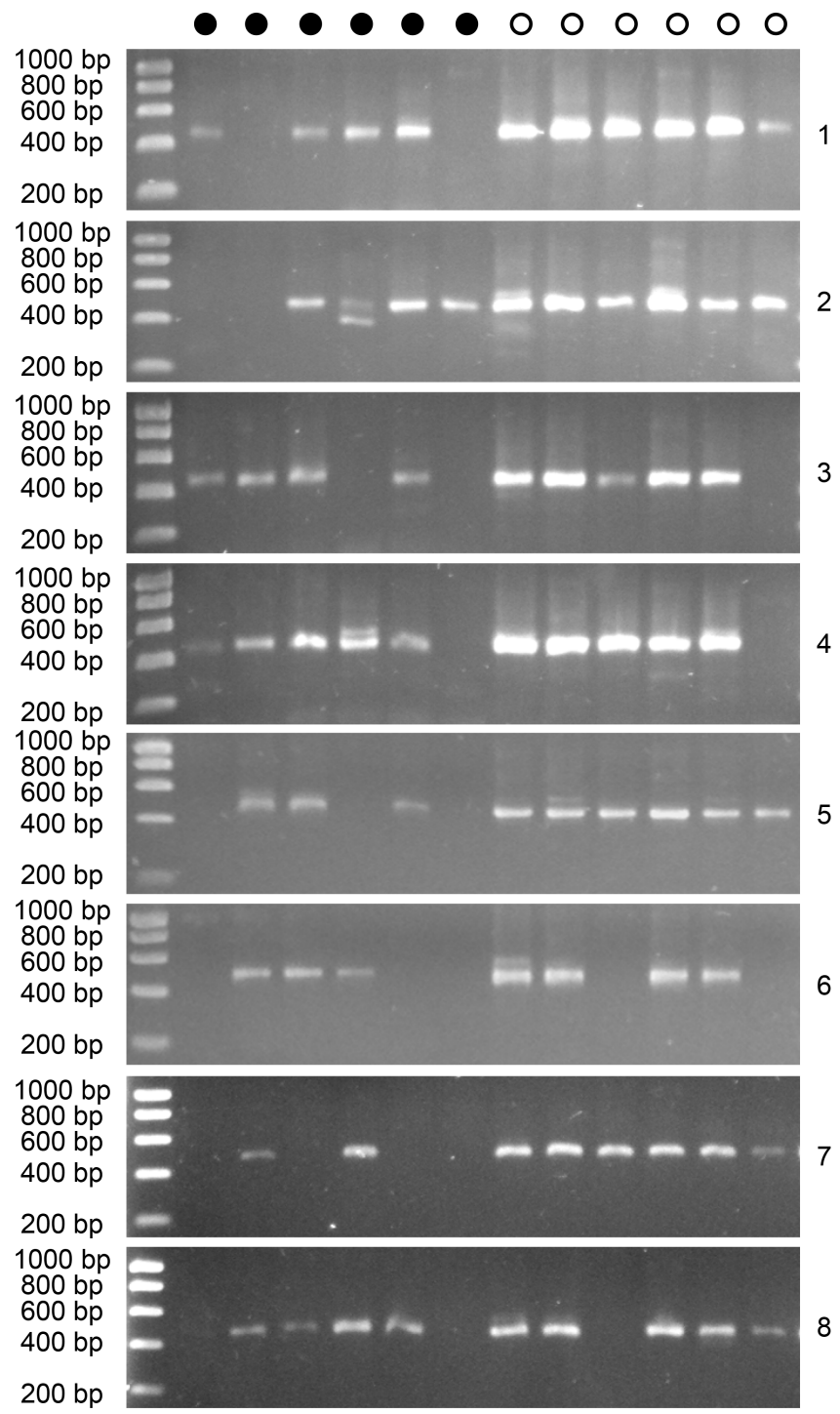

Figure S1 Reproducibility of quantitative PCR based detection of Trichoderma species in salmon egg samples. Eight independent quantitative PCRs were run for each salmon egg sample to show the variation of amplification. The concentration of DNA template of each sample was normalized at $5 \pm 1$ $\mathrm{ng} \cdot \mu \mathrm{L}-1$. Closed and open circles indicate Saprolegnia-infected (diseased) or healthy salmon egg samples, respectively. The expected band size is around $500 \mathrm{bp}$. 


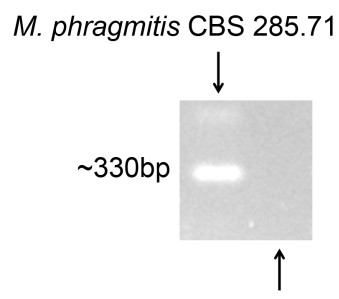

M. nivale var. nivale CBS 110.94

Figure S2 Amplification of Microdochium lycopodinum/Microdochium phragmitis specific gene by primer set MPF-MPR using M. phragmitis CBS 285.71 as positive control and M. nivale var. nivale CBS 110.94 as negative control.

$$
10^{0} 10^{-1} 10^{-2} 10^{-3} \quad 10^{-4} \quad 10^{-5} \quad 10^{-6} \quad 10^{-7} \text { fold dilution }
$$

a ITS4-ITS9:

$$
\text { Trichoderma } 762 \mathrm{~F} 1 \mathrm{~b}
$$$$
\sim 400 \mathrm{bp}
$$
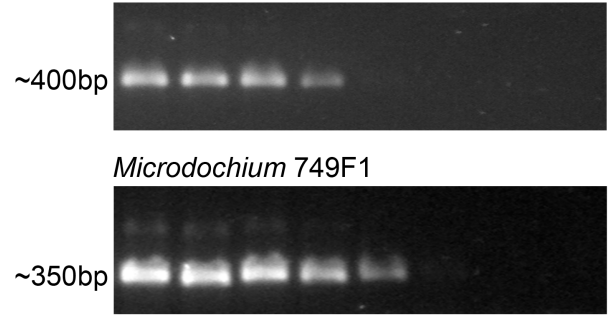

b MPF-MPR: $\quad$ Microdochium 736F1a
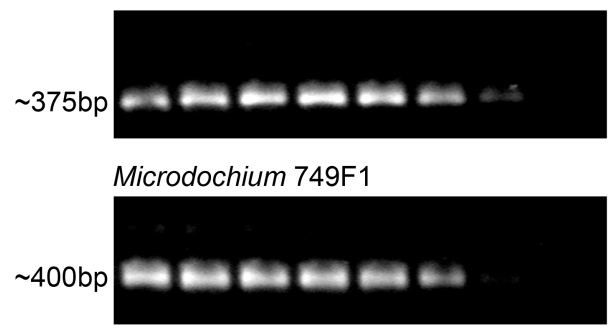

c ITS1TrF-ITS4TrR: Trichoderma 1152F1
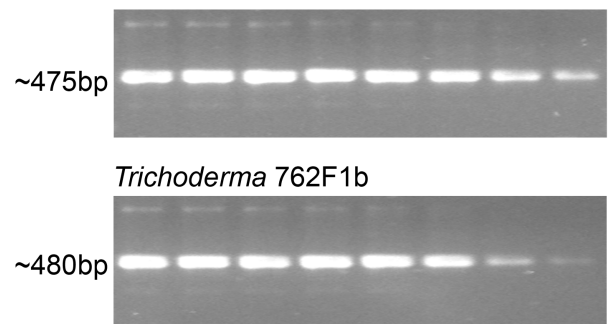

Figure S3 Standards of the quantitative PCR to determine the detection limits. The genomic DNA of the indicated fungal strains was set at $5 \mathrm{ng} \cdot \mu \mathrm{L}-1$ and diluted in 10-fold steps. Each dilution, indicated at the top, was used as template for the PCR using the primer sets ITS4-ITS9 (a), MPF-MPR (b) and ITS1TrFITS4TrR (c). 


\section{Chapter 6}

Summarizing discussion and future perspectives 
Emerging pathogens of plants and animals are increasingly threatening global ecosystem functioning, biodiversity and food security (Fisher et al., 2012, Gozlan et al., 2014). Introduction of protective microbes and habitat bioaugmentation have been proposed as novel strategies to protect wild and farmed aquatic animals from emerging disease. Both strategies need profound knowledge of the microbial communities associated with aquatic animals. In recent years, several studies have shown that microbiomes play a vital role in the protection against pathogens in a variety of eukaryotes including humans, insects and plants (Round et al., 2010, Mendes et al., 2011, Weiss \& Aksoy, 2011, Everard et al., 2013, Stecher et al., 2013, Turner et al., 2013). For aquatic animals, such as fish and amphibians, large-scale metagenomics-based microbiome studies have only been initiated recently (Cahill, 1990, Hansen \& Olafsen, 1999, Schulze et al., 2006, McKenzie et al., 2012, Merrifield \& Rodiles, 2015) and little is known on the diversity, richness, dynamics and functions of microbes associated with fish eggs (Hansen \& Olafsen, 1999, Olafsen, 2001). Fish eggs have an immature adaptive immune system and depend on nonspecific innate defences for protection against pathogen infections. In this thesis, the salmon egg associated microbiomes (bacteria, oomycetes and fungi) were analysed by both classic and state-of-the-art 'omics technologies. Potential beneficial microbes were subsequently isolated and characterised for their genotypic, phenotypic and metabolic diversity as well as their protective activity on salmon eggs against the oomycete pathogen Saprolegnia diclina.

The microbiome of Atlantic salmon eggs was unravelled by using various metataxonomic analyses including PhyloChip, clone library sequencing and terminal restriction fragment length polymorphism (T-RFLP; chapter 2). The results of these analyses showed that healthy and Saprolegnia-infected (diseased) salmon eggs are home to diverse oomycete, fungal, bacterial and archaeal communities. The oomycete community in both diseased and healthy salmon egg samples from a commercial fish hatchery, consisted mainly of Saprolegnia, Achlya and Aphanomyces, three genera in the order Saprolegniales. Even though Achlya and Aphanomyces have been described to be pathogenic on fish, no reports have described that these are pathogenic for Atlantic salmon. Virulent Saprolegnia isolates were found in both diseased and healthy salmon eggs, indicating that the difference in incidence of Saprolegniosis between the two sets of salmon egg samples cannot be explained by differences in population structure or pathogenicity of the Saprolegnia species present in both sample sets.

Analysis of the bacterial community composition revealed a total of 31,278 bacterial and 3 archaeal operational taxonomic units (OTUs). The most dominant bacterial phyla for the salmon egg samples were the Proteobacteria, Actinobacteria, Firmicutes and Bacteroidetes (chapter 2). A low incidence of Saprolegniosis was correlated with a significant higher abundance and richness of 
specific commensal Actinobacteria. Subsequent isolation of Actinobacteria and functional bioassays showed that an Actinobacterial isolate, classified as Frondihabitans (Microbacteriaceae), significantly inhibited hyphal attachment of $S$. diclina to live salmon eggs (chapter 2).

The culturable Frondihabitans population associated with healthy salmon eggs was further investigated (chapter 3 ) and results showed that most Frondihabitans isolates inhibited growth in vitro of $\mathrm{S}$. diclina, formed biofilms and had extracellular protease and lipase activities at low temperature $\left(5^{\circ} \mathrm{C}\right)$. When grown at $25^{\circ} \mathrm{C}$, the enzymatic activity was more variable between isolates and only one isolate inhibited growth of $S$. diclina. This suggests that Frondihabitans is producing enzymes and antimicrobial compounds in a temperature-dependent manner. Enzymes active at cold-temperate conditions are potentially of great interest for industrial, medical, biotechnological and domestic applications. The Frondihabitans sp. $762 \mathrm{G} 35$ that inhibited hyphal attachment of $S$. diclina to salmon eggs was selected for genome sequencing. Its genome is $3.4 \mathrm{Mb}$ in size with a GC content of $70 \%$ and 3212 coding DNA sequences (CDS). An in-depth study was conducted to further analyse the genome of Frondihabitans sp. 762G35. Among the clusters of orthologous groups (COGs), the categories carbohydrate and amino acid transport and metabolism, and transcription were the three largest COGs. Whole genome phylogeny showed that Frondihabitans sp. $762 \mathrm{G} 35$ is related to Frondihabitans sp. Leaf304 and Frigoribacterium sp. Leaf415, two bacteria isolated from leaves of Arabidopsis thaliana (Bai et al., 2015). Pan-core genome analyses of Frondihabitans sp. 762G35, Frondihabitans sp. Leaf304 and Frigoribacterium sp. Leaf415 showed a core genome of 1292 orthologous groups, representing only $40 \%$ of each genome and with a pan genome of 5955 orthologous groups. More than one-third of the Frondihabitans sp. $762 \mathrm{G} 35$ genome, comprising 1206 orthologous groups, was not found in the other two closely related bacterial strains. Mining for biosynthetic gene clusters by antiSMASH (Weber et al., 2015) showed that Frondihabitans sp. $762 \mathrm{G} 35$ harboured two terpene gene clusters and one type III polyketide synthase gene cluster. High performance liquid chromatography (HPLC) analysis and fractionation of the extracellular culture filtrate of Frondihabitans sp. $762 \mathrm{G} 35$ resulted in a polar fraction that was capable of inhibiting $S$. diclina growth (chapter 3 ). Since this fraction still consisted of multiple compounds, liquid chromatography-mass spectrometry (LC-MS) was performed and this resulted in the identification of furancarboxylic acid-derived metabolites in the cell-free supernatant that might be involved in the activity of Frondihabitans sp. $762 \mathrm{G} 35$ against $S$. diclina. Additional fractionations and liquid chromatographytandem mass spectrometry (LC-MS/MS) and nuclear magnetic resonance (NMR) analyses are required to further identify these active compounds from 
Frondihabitans sp. $762 \mathrm{G} 35$. Such compounds may provide a basis for the further development of alternative measures to control Saprolegniosis in aquaculture.

Based on the PhyloChip-based metataxonomic analyses, Pseudomonas (Pseudomonadales) represented one of the most abundant bacterial genera associated with the salmon eggs (chapter 2). No distinct difference was observed in the 16S rRNA-based phylogenetic delineation of 440 Pseudomonas isolates from diseased or healthy salmon eggs, nor in the percentage of isolates with in vitro activities against Saprolegnia (chapter 4). However, a significantly higher frequency of biosurfactant-producing Pseudomonas was found among the isolates from healthy salmon eggs than among those from diseased eggs. Biosurfactants have been suggested to play a role in disease suppression (Raaijmakers et al., 2010, Garces et al., 2015). When tested against S. diclina and S. parasitica, only Pseudomonas strain $\mathrm{H} 6$ consistently inhibited hyphal attachment to live salmon eggs and reduced salmon egg mortality. Live colony mass spectrometry showed that Pseudomonas $\mathrm{H} 6$ produces a viscosin-like compound, a biosurfactant belonging to the class of cyclic lipopeptides. This biosurfactant inhibited hyphal growth of $S$. diclina and $S$. parasitica in vitro, but no significant effects were observed in protection of salmon eggs against Saprolegnia infection (chapter 4). Although the biosurfactant alone did not affect hyphal attachment of S. diclina to salmon eggs, this compound may still have a role in the activity and ecology of the producing bacterial strain, an aspect that remains to be investigated. For example, lipopeptide surfactants are well-known for their role in biofilm formation (de Bruijn et al., 2007, de Bruijn et al., 2008) and may have enabled Pseudomonas $\mathrm{H} 6$ to colonize the salmon egg surface to form a protective biofilm that prevents hyphal attachment by Saprolegnia.

Very few studies to date have addressed the beneficial activity of fungi against aquatic pathogens (Abdelhamid et al., 2007, Woodhams et al., 2014). Our analysis showed that the fungal community of the salmon eggs was dominated by Ascomycota, and mainly Microdochium species. Furthermore, no apparent difference was found in the fungal microbiome composition between diseased and healthy salmon eggs (chapter 2). Subsequent isolation and characterization of the salmon egg-associated fungi showed that most isolates were closely related to Microdochium lycopodinum/Microdochium phragmitis, and also to Trichoderma viride (chapter 5). Microdochium species are known as snow molds and some are pathogenic to plants (Cook, 1981, Mediha et al., 1986, Daamen et al., 1991, Simpson et al., 2000, Hong et al., 2008, Matsumoto, 2009, Xu \& Nicholson, 2009, Rapacz et al., 2014). To date, not much is known about Microdochium in aquatic environments, aquaculture or aquatic animals (Liu et al., 2014). Several Trichoderma species are applied in agriculture as biocontrol agents against various plant-associated bacterial, fungal and oomycete pathogens, such as Clavibacter, 
Fusarium and Phytophthora (Verma et al., 2007, Schuster \& Schmoll, 2010, Druzhinina et al., 2011). Trichoderma species are capable of producing a range of extracellular compounds to suppress plant pathogens, such as enzymes, fungicidal compounds and antibiotics, and they can also promote growth of plant hosts (Schirmböck et al., 1994, Harman et al., 2004, Schuster \& Schmoll, 2010, Druzhinina et al., 2011, Harman, 2011). Trichoderma is commonly isolated from terrestrial environments, such as soil and wood (Druzhinina et al., 2011), but also from aquatic environments both fresh and marine water (Miao \& Qian, 2005, Hageskal et al., 2008, Gal-Hemed et al., 2011, Zhou et al., 2011, Passarini et al., 2013, Wu et al., 2014). In our study, quantitative PCR and phylogenetic analyses revealed both qualitative and quantitative differences in the Trichoderma community associated with diseased and healthy salmon eggs, differences that were not observed for the Microdochium community. Only few fungal isolates showed in vitro antagonistic activity against $S$. diclina. For most Trichoderma isolates, the typical mycoparasitic coiling around and/or formation of papilla-like structures on S. diclina hyphae were observed (chapter 5), suggesting attachment of Trichoderma hyphae to $S$. diclina hyphae. Coiling is required for mycoparasitism but not always leads to mycoparasitism (Harman et al., 2004, Lu et al., 2004, Druzhinina et al., 2011, Harman, 2011). These results imply that among the commensal fungal microbiome of salmon eggs, Trichoderma species may be important to suppress Saprolegnia infection in aquaculture.

Overall, my research project demonstrated that the fundamental study of the microbiome of salmon eggs provides a framework for identifying beneficial microbes and their metabolites. This study together with other microbiome studies may ultimately be used to mitigate emerging diseases of aquatic animals in farmed and natural ecosystems. Future studies are needed to identify the genes and bioactive compounds involved in disease suppression and to unravel the underlying mechanisms. To this end, in-depth metabolomic analyses will help to understand the identities and activities of the bioactive compounds. Mutagenesis of biosynthetic genes encoding these compounds should be conducted, followed by in vivo bioassays complemented with transcriptomic analyses and activity profiling in which compound-deficient mutants are compared to wild type strains. Further large-scale tests under farming conditions are needed to assess the in situ activity of the beneficial bacterial and fungal isolates that were identified in this thesis. 


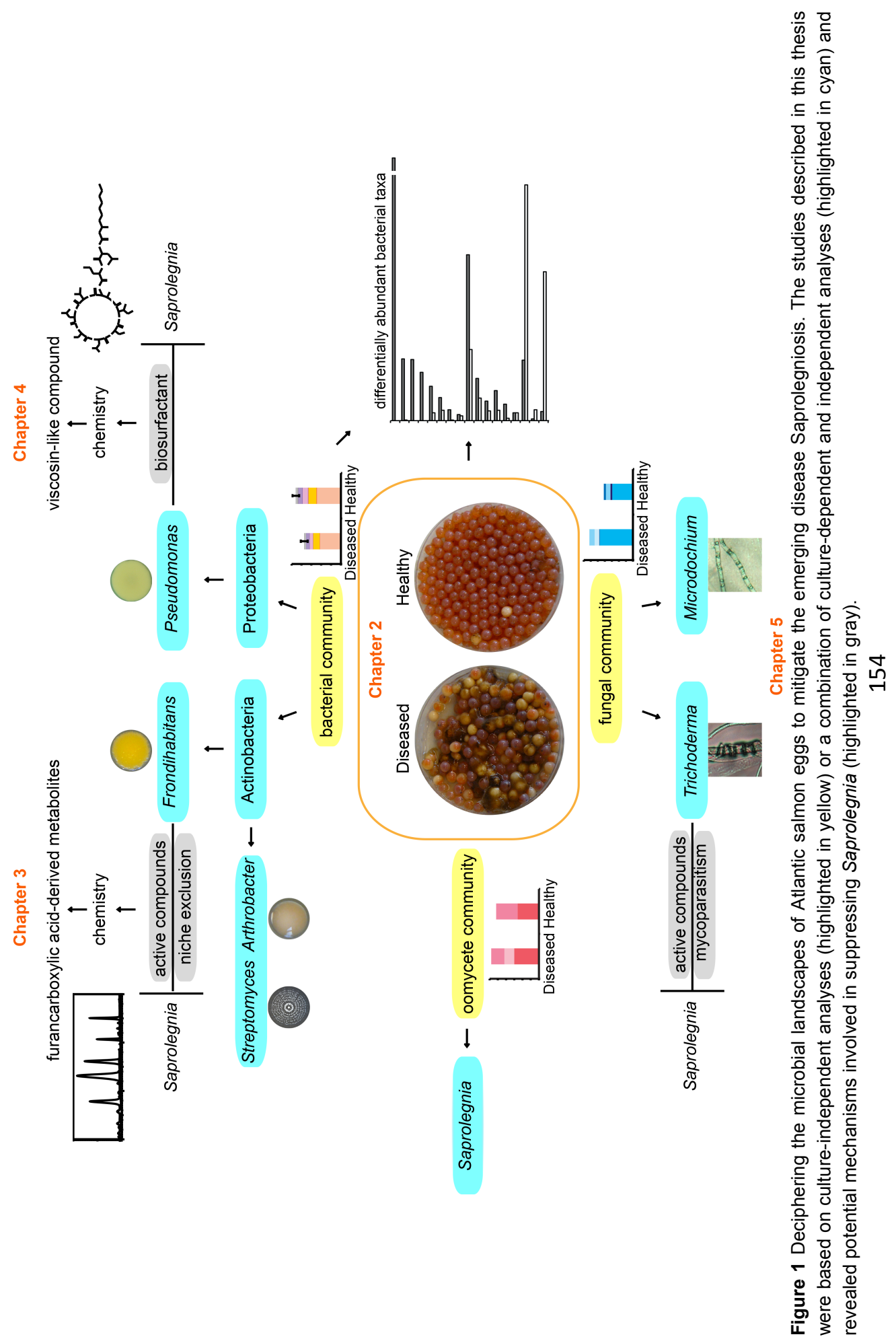




\section{Future perspectives}

Aquaculture is one of the fastest-growing food sectors in the world and important for the growing human population, human health and the economy by providing high value of animal proteins (FAO, 2014). Diseases threaten the development and productivity of aquaculture and need to be addressed in a sustainable manner. Amongst the existing and promising sustainable measures, probiotics and prebiotics are proposed as environmental friendly remedies to suppress diseases and to enhance productivity in aquaculture and agriculture. Our research provides a fundamental framework for the identification of the diversity and dynamics of microbial communities associated with fish eggs. This fundamental knowledge is needed to target specific microbial groups or microbial consortia for isolation, characterization and evaluation as protective microbiota for mitigation of emerging diseases in farmed and natural ecosystems. The bacterial and fungal isolates that we identified in this study, especially Frondihabitans, Pseudomonas and Trichoderma isolates, and their bioactive metabolites, are proposed as effective candidates to tackle the (re-)emerging disease Saprolegniosis. Although numerous studies have demonstrated the beneficial effects of microorganisms, very few are commercialized in aquaculture to date, largely due to concerns on long-term safety for the environment as well as other issues such as limited shelf-life, costs, stringent storage and transport conditions of the microbial inoculants. Also consistency of performance under different environmental conditions and their relatively narrow activity spectrum and compatibility with application processes are points of concern for the industry. International programs on disease control have been initiated with the aim to obtain more in depth knowledge and to gain experience with the application of probiotics (Verschuere et al., 2000, Pandiyan et al., 2013, Velivelli et al., 2014). One example is the ParaFishControl program funded by the European Commission (http://www.parafishcontrol.eu/) in which there is strong focus on the underlying protective mechanisms of probiotics, the synergistic effects of probiotic strain mixtures, the population dynamics of the applied microbial strains and their effects on the resident microbial community. Additionally, the feasibility of applying beneficial microbes on a large industrial scale should be evaluated under strict guidelines and regulations (Verschuere et al., 2000). Last but not least, the knowledge on probiotics should be accessible to fish farmers by conveying research findings and novel, sustainable technologies and products.

\section{References}

Abdelhamid AM, Shabana YM \& Gomaa SSA (2007) Aquatic fungi and fish production in Egypt, II In vivo studies. p.^pp. 
Bai Y, Müller DB, Srinivas G, et al. (2015) Functional overlap of the Arabidopsis leaf and root microbiota. Nature 528: 364-369.

Cahill MM (1990) Bacterial flora of fishes: A review. Microbial ecology 19: 21-41.

Cook RJ (1981) Fusarium diseases of wheat and other small grains in North America. Fusarium diseases, biology, and taxonomy,(Nelson PE, Toussoun TA \& Cook RJ, eds.), p.^pp. 39-52. Pennsylvania State University Press, University Park, USA.

Daamen RA, Langerak CJ \& Stol W (1991) Surveys of cereal diseases and pests in the netherlands .3. Monographella nivalis and Fusarium spp. in winter-wheat fields and seed lots. Netherlands Journal of Plant Pathology 97: 105-114.

de Bruijn I, de Kock MJD, de Waard P, van Beek TA \& Raaijmakers JM (2008) Massetolide a biosynthesis in Pseudomonas fluorescens. Journal of Bacteriology 190: 2777-2789.

de Bruijn I, de Kock MJD, Yang M, de Waard P, van Beek TA \& Raaijmakers JM (2007) Genomebased discovery, structure prediction and functional analysis of cyclic lipopeptide antibiotics in Pseudomonas species. Molecular Microbiology 63: 417-428.

Druzhinina IS, Seidl-Seiboth V, Herrera-Estrella A, Horwitz BA, Kenerley CM, Monte E, Mukherjee PK, Zeilinger S, Grigoriev IV \& Kubicek CP (2011) Trichoderma: the genomics of opportunistic success. Nat Rev Micro 9: 749-759.

Everard A, Belzer C, Geurts L, et al. (2013) Cross-talk between Akkermansia muciniphila and intestinal epithelium controls diet-induced obesity. Proceedings of the National Academy of Sciences of the United States of America 110: 9066-9071.

FAO (2014) The state of world fisheries and aquaculture 2014. Rome, Italy.

Fisher MC, Henk DA, Briggs CJ, Brownstein JS, Madoff LC, McCraw SL \& Gurr SJ (2012) Emerging fungal threats to animal, plant and ecosystem health. Nature 484: 186-194.

Gal-Hemed I, Atanasova L, Komon-Zelazowska M, Druzhinina IS, Viterbo A \& Yarden O (2011) Marine isolates of Trichoderma spp. As potential halotolerant agents of biological control for arid-zone agriculture. Applied and Environmental Microbiology 77: 5100-5109.

Garces ME, Sequeiros C \& Olivera NL (2015) Marine Lactobacillus pentosus H16 protects Artemia franciscana from Vibrio alginolyticus pathogenic effects. Diseases of Aquatic Organisms 113: 41-50.

Gozlan RE, Marshall WL, Lilje O, Jessop CN, Gleason FH \& Andreou D (2014) Current ecological understanding of fungal-like pathogens of fish: what lies beneath? Frontiers in microbiology 5: 62.

Hageskal G, Vrålstad T, Knutsen AK \& Skaar IDA (2008) Exploring the species diversity of Trichoderma in Norwegian drinking water systems by DNA barcoding. Molecular Ecology Resources 8: 1178-1188.

Hansen GH \& Olafsen JA (1999) Bacterial Interactions in Early Life Stages of Marine Cold Water Fish. Microbial ecology 38: 1-26.

Harman GE (2011) Multifunctional fungal plant symbionts: new tools to enhance plant growth and productivity. New Phytologist 189: 647-649.

Harman GE, Howell CR, Viterbo A, Chet I \& Lorito M (2004) Trichoderma species - opportunistic, avirulent plant symbionts. Nat Rev Micro 2: 43-56.

Hong SK, Kim WG, Choi HW \& Lee SY (2008) Identification of Microdochium bolleyi associated with basal rot of creeping bent grass in Korea. Mycobiology 36: 77-80.

Liu Y, de Bruijn I, Jack ALH, et al. (2014) Deciphering microbial landscapes of fish eggs to mitigate emerging diseases. ISME J 8: 2002-2014.

Lu ZX, Tombolini R, Woo S, Zeilinger S, Lorito M \& Jansson JK (2004) In vivo study of Trichoderma-pathogen-plant interactions, using constitutive and inducible green fluorescent protein reporter systems. Applied and Environmental Microbiology 70: 3073-3081.

Matsumoto N (2009) Snow molds: a group of fungi that prevail under snow. Microbes and Environments 24: 14-20.

McKenzie VJ, Bowers RM, Fierer N, Knight R \& Lauber CL (2012) Co-habiting amphibian species harbor unique skin bacterial communities in wild populations. The ISME Journal 6: 588-596. 
Mediha H, Al-Hashimi \& Perry DA (1986) Fungal antagonists of Gerlachia nivalis. Journal of Phytopathology 116: 106-112.

Mendes R, Kruijt M, de Bruijn I, et al. (2011) Deciphering the rhizosphere microbiome for diseasesuppressive bacteria. Science (New York, NY) 332: 1097-1100.

Merrifield DL \& Rodiles A (2015) 10 - The fish microbiome and its interactions with mucosal tissues. Mucosal Health in Aquaculture,(Peatman BHB, ed.) p.^pp. 273-295. Academic Press, San Diego.

Miao L \& Qian PY (2005) Antagonistic antimicrobial activity of marine fungi and bacteria isolated from marine biofilm and seawaters of Hong Kong. Aquatic Microbial Ecology 38: 231-238.

Olafsen JA (2001) Interactions between fish larvae and bacteria in marine aquaculture. Aquaculture 200: 223-247.

Pandiyan P, Deivasigamani B, Rajasekar T, Jothi EG, Kumaran S, Sakthivel M \& Balamurugan S (2013) Probioitcs in aquaculture. Drug invention today.

Passarini MRZ, Santos C, Lima N, Berlinck RGS \& Sette LD (2013) Filamentous fungi from the Atlantic marine sponge Dragmacidon reticulatum. Archives of Microbiology 195: 99-111.

Raaijmakers JM, de Bruijn I, Nybroe O \& Ongena M (2010) Natural functions of lipopeptides from Bacillus and Pseudomonas: more than surfactants and antibiotics. Fems Microbiology Reviews 34: 1037-1062.

Rapacz M, Ergon A, Hoglind M, Jorgensen M, Jurczyk B, Ostrem L, Rognli OA \& Tronsmo AM (2014) Overwintering of herbaceous plants in a changing climate. Still more questions than answers. Plant Science 225: 34-44.

Round JL, O'Connell RM \& Mazmanian SK (2010) Coordination of tolerogenic immune responses by the commensal microbiota. Journal of autoimmunity 34: J220-225.

Schirmböck M, Lorito M, Wang YL, Hayes CK, Arisanatac I, Scala F, Harman GE \& Kubicek CP (1994) Parallel formation and synergism of hydrolytic enzymes and peptaibol antibiotics, molecular mechanisms involved in the antagonistic action of Trichoderma harzianum against phytopathogenic fungi. Applied and Environmental Microbiology 60: 4364-4370.

Schulze AD, Alabi AO, Tattersall-Sheldrake AR \& Miller KM (2006) Bacterial diversity in a marine hatchery: Balance between pathogenic and potentially probiotic bacterial strains. Aquaculture 256: 5073.

Schuster A \& Schmoll M (2010) Biology and biotechnology of Trichoderma. Applied Microbiology and Biotechnology 87: 787-799.

Simpson DR, Rezanoor HN, Parry DW \& Nicholson P (2000) Evidence for differential host preference in Microdochium nivale var. majus and Microdochium nivale var. nivale. Plant Pathology 49: 261-268.

Stecher B, Maier L \& Hardt WD (2013) 'Blooming' in the gut: how dysbiosis might contribute to pathogen evolution. Nature reviews Microbiology 11: 277-284.

Turner TR, James EK \& Poole PS (2013) The plant microbiome. Genome biology 14: 209.

Velivelli SLS, De Vos P, Kromann P, Declerck S \& Prestwich BD (2014) Biological control agents: from field to market, problems, and challenges. Trends in Biotechnology 32: 493-496.

Verma M, Brar SK, Tyagi RD, Surampalli RY \& Valero JR (2007) Antagonistic fungi, Trichoderma spp.: Panoply of biological control. Biochemical Engineering Journal 37: 1-20.

Verschuere L, Rombaut G, Sorgeloos P \& Verstraete W (2000) Probiotic bacteria as biological control agents in aquaculture. Microbiology and Molecular Biology Reviews 64: 655-+.

Weber T, Blin K, Duddela S, et al. (2015) antiSMASH 3.0-a comprehensive resource for the genome mining of biosynthetic gene clusters. Nucleic Acids Research 43: W237-W243.

Weiss B \& Aksoy S (2011) Microbiome influences on insect host vector competence. Trends in parasitology 27: 514-522.

Woodhams DC, Brandt H, Baumgartner S, et al. (2014) Interacting symbionts and immunity in the amphibian skin mucosome predict disease risk and probiotic effectiveness. PLOS ONE 9: e96375.

Wu B, Oesker V, Wiese J, Schmaljohann R \& Imhoff JF (2014) Two new antibiotic pyridones produced by a marine fungus, Trichoderma sp. strain MF106. Marine Drugs 12: 1208-1219. 
Xu X \& Nicholson P (2009) Community ecology of fungal pathogens causing wheat head blight. Annual Review of Phytopathology, Vol. 47 p.^pp. 83-103.

Zhou K, Zhang X, Zhang F \& Li Z (2011) Phylogenetically diverse cultivable fungal community and polyketide synthase (PKS), non-ribosomal peptide synthase (NRPS) genes associated with the South China Sea sponges. Microbial Ecology 62: 644-654. 


\section{Summary}

Emerging diseases caused by oomycete, fungal, bacterial and viral pathogens increasingly threaten natural ecosystems, biodiversity and food security. In aquaculture, disease control is pivotal to the success of this industry. Recent studies in a variety of eukaryotes, in particular in humans, insects and plants, have demonstrated that their microbiomes play an essential role in protection against diseases. Therefore, habitat bioaugmentation and introduction of beneficial microbes have been suggested as novel sustainable measures to mitigate emerging diseases of fish and amphibians. Both measures require profound knowledge of the microbiomes associated with their aquatic hosts. However, largescale metataxonomic studies for aquatic animals are still in its infancy and little is known on the diversity, ecology and functional potential of fish microbiomes. Fish eggs have an immature immune system and hence, for disease protection they likely rely on other defence mechanisms.

In my thesis, I studied the microbiome of Atlantic salmon (Salmo salar L.) eyed eggs and analysed the effects of infections by the oomycete pathogen Saprolegnia on the microbial architecture, in particular diversity and richness (chapter 2). By combining classic microbiological and state-of-the-art 'omics techniques, the composition and activities of oomycete, fungal, bacterial and archaeal communities associated with Saprolegnia-infected (diseased) and healthy salmon eggs were studied. A low incidence of Saprolegniosis was correlated with a relatively high abundance and richness of specific commensal Actinobacteria. Subsequent isolation of Actinobacteria and bioassays showed that an Actinobacterial isolate, classified as Frondihabitans sp. 762G35 (Microbacteriaceae), significantly inhibited hyphal attachment of Saprolegnia diclina to live salmon eggs. The culturable Frondihabitans population associated with healthy salmon eggs was further investigated (chapter 3 ) and showed that most Frondihabitans isolates inhibited growth in vitro of $S$. diclina, formed biofilms and had protease and lipase activities at low temperature $\left(5{ }^{\circ} \mathrm{C}\right)$. The genome of Frondihabitans sp. $762 \mathrm{G} 35$ was sequenced and genome mining revealed gene clusters potentially involved in production of terpene and type III polyketide synthase. Chemical characterization of cell-free supernatant of Frondihabitans sp. $762 \mathrm{G} 35$ by high performance liquid chromatography (HPLC) and liquid chromatography-mass spectrometry (LC-MS) identified furancarboxylic acid-derived metabolites that may be involved in the $S$. diclina hyphal growth inhibiting activity. 
Among the bacterial community, Pseudomonas (Pseudomonadales) represented one of the most abundant bacterial genera associated with the salmon eggs. No distinct difference was observed in abundance nor in in vitro activities against Saprolegnia spp. between Pseudomonas isolates from diseased or healthy salmon eggs (chapter 4). However, a significantly higher frequency of biosurfactant-producing Pseudomonas was found among the isolates from healthy salmon eggs. In vivo salmon egg bioassays revealed that Pseudomonas isolate $\mathrm{H} 6$ significantly inhibited hyphal attachment of $S$. diclina to salmon eggs and reduced salmon egg mortality. Live colony mass spectrometry showed that this isolate produced a viscosin-like lipopeptide surfactant. Although this biosurfactant inhibited hyphal growth of Saprolegnia spp. in vitro, no significant protective effect on salmon eggs against $S$. diclina was observed for this bacterial metabolite.

Among the fungal community, Microdochium (Ascomycota) represented the most abundant fungal genus associated with salmon eggs. Subsequent isolation and phylogenetic analyses showed that most fungal isolates obtained from salmon eggs were indeed closely related to Microdochium lycopodinum/Microdochium phragmitis but also to Trichoderma viride (chapter 5). Phylogenetic and quantitative PCR analyses showed both a quantitative and qualitative difference in the Trichoderma population between diseased and healthy salmon eggs, which was not the case for the Microdochium population. Only few fungal isolates showed in vitro antagonistic activity against $S$. diclina and most Trichoderma isolates showed typical coiling around and/or formation of papilla-like structures on the hyphae of $S$. diclina. These results suggest that among the fungal community associated with salmon eggs, mycoparasitic Trichoderma species play a role in Saprolegnia suppression in aquaculture.

In conclusion, my $\mathrm{PhD}$ thesis provides a scientific framework for studying the diversity and dynamics of microbial communities associated with fish eggs. This fundamental knowledge is needed to target specific microbial groups or microbial consortia for evaluation as protective microbiota for mitigation of emerging diseases in aquaculture and natural ecosystems. The bacterial and fungal isolates, especially Frondihabitans, Pseudomonas and Trichoderma, and/or their bioactive metabolites, are proposed as effective candidates to control the emerging disease Saprolegniosis. 


\section{Samenvatting}

Nieuwe ziektes veroorzaakt door (pseudo)schimmels, bacteriën en virussen zijn in opkomst en vormen niet alleen een bedreiging voor de biodiversiteit van natuurlijke ecosystemen maar ook voor onze voedselvoorziening. In de aquacultuur, de bestrijding van deze ziektes is van cruciaal belang en bepalend voor het succes van deze sector. Recente studies in onder andere mensen, insecten en planten hebben aangetoond dat de microbiële gemeenschappen die leven in associatie met deze organismen een belangrijke rol spelen bij de bescherming van de gastheer tegen ziekteverwekkers. Dit suggereert dat het toedienen van beschermende microben een duurzame methode kan zijn voor het onderdrukken van ziekteverwekkers in de aquacultuur. Dit vereist echter een grondige kennis van de diversiteit en ecologie van de natuurlijk aanwezige microbiële gemeenschappen in/op vissen en amfibieën en hun functies voor de gastheer. Viseieren hebben een onderontwikkeld immuunsysteem en zijn afhankelijk van andere manieren van verdediging tegen ziekteverwekkers. De rol van de microbiële gemeenschappen op viseieren is tot op heden niet uitgebreid bestudeerd.

In dit proefschrift beschrijf ik de samenstelling van de microbiële gemeenschappen, het zogenaamde microbioom, van zalmeieren. Door middel van klassieke en moderne technieken heb ik de effecten onderzocht van Saprolegniainfecties op de diversiteit, samenstelling en activiteit van het zalmei-microbioom. Een lage ziekte incidentie was gecorreleerd met een verhoogde aanwezigheid van specifieke Actinobacteriën. Isolatie en activiteit-analyses toonden aan dat tenminste één Actinobacterieel isolaat, geclassificeerd als Frondihabitans sp. 762 G35 (Microbacteriaceae), de aanhechting van Saprolegnia diclina aan zalmeieren significant kon verminderen. Meerdere Frondihabitans isolaten zijn vervolgens fenotypisch en genetisch gekarakteriseerd en hieruit bleek dat de meeste isolaten myceliumgroei van $S$. diclina kunnen remmen en een biofilm kunnen vormen, en dat ze bij lage temperaturen $\left(5^{\circ} \mathrm{C}\right)$ extracellulaire protease en lipase activiteit bezitten. Het genoom van Frondihabitans sp. $762 \mathrm{G} 35$ werd vervolgens gesequenced en uit analyses bleek dat dit isolaat twee genclusters bevat die coderen voor de biosynthese van terpenen en één voor een type III polyketide synthase. Chemische karakterisatie van het cultuur supernatant van dit isolaat resulteerde in de identificatie van 9 stoffen die mogelijk betrokken zijn bij de activiteit tegen Saprolegnia. 
Het genus Pseudomonas (Pseudomonodales) vormde één van de grootste groepen binnen de bacteriële gemeenschap geassocieerd met zalmeieren. $\mathrm{Er}$ waren overigens geen verschillen in diversiteit, aantallen of activiteit tegen Saprolegnia tussen de Pseudomonas isolaten afkomstig van gezonde of zieke zalmeieren. Echter, Pseudomonas isolaten afkomstig van gezonde zalmeieren hadden vaker het vermogen om oppervlakte spanning-verlagende stoffen (biosurfactants) te produceren dan die afkomstig van zieke zalmeieren. Uit chemische analyse bleek dat de biosurfactant een viscosin-achtig cyclische lipopetide is. Ondanks de waarneming dat dit lipopeptide de myceliumgroei van Saprolegnia in vitro kon onderdrukken, was er geen beschermend effect van deze stof tegen infectie van Saprolegnia op de zalmeieren.

Ook de schimmelpopulatie werd bestudeerd en de Ascomyceet Microdochium bleek het meest abundant op basis van DNA analyse en isolatie. Verdere karakterisering van de schimmelisolaten liet zien dat de meeste isolaten sterk gerelateerd zijn aan Microdochium lycopodinum of Microdochium phragmitis. Daarnaast werden ook meerdere Trichoderma isolaten gevonden. Fylogenetische en kwantitatieve PCR lieten een kwantitatief en kwalitatief verschil zien tussen Trichoderma populaties verkregen van zieke en gezonde zalmeieren, wat niet het geval was voor de Microdochium isolaten. Slechts enkele schimmel-isolaten lieten in vitro activiteit zien tegen Saprolegnia, terwijl de meeste Trichoderma isolaten wel de typische wikkeling rondom Saprolegnia-hyfen vertoonden en/of papilla-achtige structuren vormden op de hyfen. Deze resultaten suggereren dat mycoparasitaire Trichoderma soorten een rol kunnen spelen in de bescherming van zalmeieren tegen Saprolegnia.

Concluderend geeft mijn onderzoek een wetenschappelijk raamwerk voor microbioom-analyses van viseieren. Deze fundamentele kennis is nodig om de potentie te evalueren van specifieke microbiële groepen of consortia voor toepassing in een meer duurzame bescherming tegen opkomende ziektes in de aquacultuur en mogelijk in natuurlijke ecosystemen. De bacteriële isolaten Frondihabitans en Pseudomonas en hun bioactieve stoffen alsook de schimmel Trichoderma zijn potentiële kandidaten voor de bescherming van zalmeieren tegen Saprolegnia. 


\section{Acknowledgements}

I would like to express my sincere acknowledgment to Jos Raaijmakers. Jos, your patience in mentoring students, your logic of shaping scientific stories, your ambition and efforts to combine multifaceted research domains, your enthusiasm for international research collaborations and your communication skills have had a great impact on my career development. Your typical comments on manuscripts, such as 'more meat' and 'more spicy', were very crucial to boost the quality of our papers. I appreciate that you are always very strict, critical and picky to all my experiments, presentations and manuscripts, because I know, as you said to me, 'I want to make you shine'.

Irene de Bruijn, I still remember you showed me the microscopic morphology of Saprolegnia when we met for the first time in Aberdeen. I was lucky to have you as my daily supervisor. You took the responsibility to ensure that our research plans were clear, and had time for discussions whenever I needed you. You were extremely efficient in giving comments on manuscripts, which largely accelerated the writing progress. Without your help I would have missed the deadline for submitting my thesis. Thanks also for caring about my future career.

Francine Govers, it was very nice to chat occasionally with you about science, career and life. I enjoyed a lot the long discussion with you on the propositions. Thanks for your comments on the thesis and your efforts to ensure the thesis was submitted on time.

Detmer Sipkema, thanks for attending my oral and poster presentations and for the nice discussions on my $\mathrm{PhD}$ project.

Menno van der Voort, you were (or pretended to be) very strict and critical to almost all my questions. You forced me to answer my own questions, but you always gave me detailed and clear answers the next day. You were worried about the writing of the HPLC experiments and live colony mass spectrometry and eventually you wrote the first draft of these parts yourself. You were very critical in our discussions, but all your concerns were important to improve the quality of our papers.

Víctor Carrión, you started helping me immediately since we met - you helped me to move from my old place to my current place. You forced me to let you clean up the waste from my experiments, and to eat your well-prepared meals and fruits. Thanks for sending me the newly-generated phylogenetic tree at 1 a.m. and for saying 'I will not stop helping you', even when I bothered you many times.

Ruth Gómez Expósito, you were my safety guard when I worked alone in the lab. You cared about me and contacted me whenever you didn't see me at work at 10 a.m. on weekdays. Thanks for explaining complicated scientific concept and techniques in a way that was easily understandable to me. 
Viviane Cordovez, You were my caretaker. You made me calm when I was stressed. You gave me a warm greeting card when I was writing my thesis during the Christmas holidays. Thanks for giving me $0.5 \mathrm{~kg}$ of my favorite candies and for your explanation on how to culture and characterize Actinobacteria.

Paolo Di Lonardo and Saskia Gerards, thanks for the scientific discussions and for caring about me.

I sincerely appreciate all my research collaborators. Your crucial support, timely responses and critical suggestions were essential to make the research and manuscripts more logical and complete. Even Thoen, you always gave priority to my requests about work. I appreciate your teaching of morphology and farming of salmon eggs, and your concerns about my career development. Thanks for searching for soft silicon tubes to protect my fingers at $-20^{\circ} \mathrm{C}$, in dark and snowy Oslo. Allison Jack, it was great to work with you in the aquarium and thanks for teaching me English. Cheng-Hsuan Wu, thanks for the long discussions on the data analyses, for sending me the newly-obtained results even in late evenings or early mornings and for the figures drawn according to my picky requests. Desalegn Etalo, thanks for teaching me the in-depth chemical knowledge and techniques, and for running the LC-MS analyses even during the weekend, which allowed me to have the thesis submitted before the deadline. Vladimir SandovalSierra, thanks for the phylogenetic tree which I could directly embed into the figure. Mark Mazzola, thanks for the timely T-RFLP and clone library analyses. Christin Zachow, thanks for the discussions; your expertise was of great benefit for the chapter in which we described the fungal isolates from salmon eggs. Albert $\mathbf{H}$ van den Berg, thanks for the sampling and the microscopic pictures. Ida Skaar, it was a great pleasure to work in your lab. Elzbieta Rzeszutek, the microscopic work was very well done. Victor de Jager, thanks for the genome analysis. Pieter van West and Javier Diéguez-Uribeondo, thanks for teaching me the knowledge on Saprolegniosis in natural and farming environments. Menno ter Veld and Geert Wiegertjes, thanks for your help and valuable advices for the salmon egg bioassays. Many thanks also to Vincent Bulone, Pieter C Dorrestein, Keith Drynan and Rodrigo Mendes.

I would like to thank all members of SAPRO and ParaFishControl projects. Shimaa E Ali, Mwansa M Songe and Amada Pérez-Traba, thanks for taking good care of me when I was doing my secondment in Norway. I very much enjoyed playing with your sweet kids. Hugo Mélida, thanks for giving me tailor-made lectures on chemistry.

Thanks to all the colleagues in Phytopathology (WUR) and Microbial Ecology (NIOO-KNAW). Special acknowledgements to Chunxu Song and Xu Cheng, you have helped me a lot since the first day I arrived Wageningen. Also thanks for inviting me to the Chinese dinners at your places. Judith van de Mortel, thanks for 
helping me to settle down soon after I arrived Wageningen and for taking care of everybody of our group, including me. Cuong $\mathbf{N}$ Le, thanks for the introduction of BOX-PCR. Yan Wang, it was nice to chat with you when we were cycling home after work. Klaas Bouwmeester and Chenlei Hua, thanks for your help with microscopic work and for your teaching of morphology of oomycetes. Emilia Hannula, Johnny Soares and Rosalinde M Keijzer, thanks for you advices in quantitative PCR. Henk Martens, thanks for teaching me how to analyze BOXPCR profiles. Laurens Deurhof, thanks for teaching me how to run an agarose gel. Noriko Cassman, thanks for the English corrections on my manuscripts. Lisha Zhang and Chenlei Hua, thanks for the nice dinner and barbecue at your place. Agata Pijl, thanks for helping me even when you didn't have time. Many thanks to the amazing technicians and secretaries: Ester Dekkers, Ciska Raaijmakers, Ali Ormel and Gerda Giesen-Peters. Thanks also to Jordi Boshoven, Emilie Chapelle, Kay Moisan, Je Seung Jeon, Juan Pérez Jaramillo and Lucas Mendes.

I would also like to take this opportunity to thank all my MSc aquaculture classmates in Ghent. Before the start of my MSc project, I didn't know what 'aquaculture', 'tilapia' and 'Artemia' stood for. ALL of you helped me to quickly digest the fundamental knowledge of aquaculture. Edward Manda Ackson Chilolo and Mphatso Edda Takamani Chapotera, thanks for being my free private caretakers and English teachers, and for studying with me during the entire two-year MSc project. Patrick Sorgeloos, thanks for your help with the Master Grant application. I could not have completed my MSc project without that grant. It arrived just in time, right after all my money was spent. Tom Defoirdt and Peter Bossier, thanks for stimulating my intrinsic interests in the domain of biocontrol of diseases in aquaculture. You helped me to develop my research skills and conceptual thinking.

衰心感謝媚姐, 外婆, 爸爸, 媽媽, 弟弟, 陳應怡和王衛芳一直以來給予我的教 誨, 栽培, 關懷, 鼓勵, 支持和無盡的愛! 


\section{Curriculum vitae}

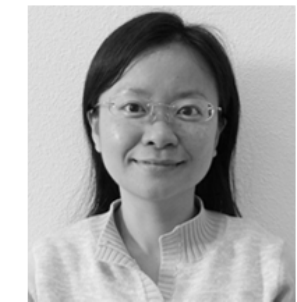

Yiying Liu (劉懿瑩) was born in 1982 in Guangdong, China. She obtained a BSc degree in Biotechnology at Shaoguan University, China. In 2007, she started her MSc studies in Aquaculture at Ghent University, Belgium. In 2008, she was awarded with a Master Grant from Ghent University. Under the supervision of Dr. Tom Defoirdt and Prof. Peter Bossier, she conducted her MSc thesis research and published a paper entitled 'PHBdegrading bacteria isolated from the gastrointestinal tract of aquatic animals as protective actors against luminescent vibriosis'. In 2010, she started her PhD research at Wageningen University, The Netherlands, in the Laboratory of Phytopathology, under the supervision of Dr. Irene de Bruijn, Prof. Jos M Raaijmakers and Prof. Francine PM Govers. In 2014 the research group of Jos M Raaijmakers moved to the Netherlands Institute of Ecology (KNAW-NIOO), also in Wageningen, where Yiying continued her $\mathrm{PhD}$ project. The results of her $\mathrm{PhD}$ research are described in this thesis.

Email: liuyyy2016@gmail.com 


\section{Publications}

Liu Y., Etalo D., de Jager V., Carrión V.J., Raaijmakers J.M. and de Bruijn I. Phenotypic, genomic and metabolic characterization of aquatic Frondihabitans with activity against the oomycete fish pathogen Saprolegnia diclina. (in preparation).

Liu Y., Raaijmakers J.M. and de Bruijn I. The fish microbiome: for better or for worse? (submitted).

Liu Y., Zachow C., Raaijmakers J.M. and de Bruijn I. (2016). Elucidating the diversity of aquatic Microdochium and Trichoderma species and their activity against the fish pathogen Saprolegnia diclina. International Journal of Molecular Sciences. 17, 140; doi:10.3390/ijms17010140.

Liu Y., Rzeszutek E., van der Voort M., Wu C.-H., Thoen E., Skaar I., Bulone V., Dorrestein P.C., Raaijmakers J.M. and de Bruijn I. (2015). Diversity of aquatic Pseudomonas species and their activity against the fish pathogenic oomycete Saprolegnia. PLoS ONE 10(8): e0136241. doi:10.1371/journal.pone.0136241.

Liu Y.*, de Bruijn I.*, Jack A.L.H., Drynan K., van den Berg A.H., Thoen E., Sandoval-Sierra V., Skaar I., van West P., Diéguez-Uribeondo J., van der Voort M., Mendes R., Mazzola M. and Raaijmakers J.M. (2014). Deciphering microbial landscapes of fish eggs to mitigate emerging diseases. The ISME Journal 8 (10), 2002-2014; doi:10.1038/ismej.2014.44.

Liu Y. ", De Schryver P. *, Van Delsen B., Maignien L., Boon N., Sorgeloos P., Verstraete W., Bossier P. and Defoirdt T. (2010). PHB-degrading bacteria isolated from the gastrointestinal tract of aquatic animals as protective actors against luminescent vibriosis. FEMS Microbiology Ecology. 74: 196204; doi:10.1111/j.1574-6941.2010.00926.x.

*Shared first author. 


\section{Education Statement of the Graduate School Experimental Plant Sciences}

Issued to: Yiying Liu

Date: 13 June 2016

Phytopathology

University: Wageningen University \& Research Centre

\begin{tabular}{|lc|}
\hline 1) Start-up phase & date \\
& First presentation of your project \\
Title: Biological control of Saprolegnia species \\
Writing or rewriting a project proposal \\
Title: Biological control of Saprolegnia species \\
Writing a review or book chapter \\
MSc courses \\
Laboratory use of isotopes
\end{tabular}

\begin{tabular}{|c|c|c|}
\hline 2) & $\begin{array}{l}\text { ific Exposure } \\
\text { EPS PhD student days }\end{array}$ & $\underline{\text { date }}$ \\
\hline & EPS PhD student days, Leiden University & Nov 29, 2013 \\
\hline & EPS Get2Gether, Soest (NL) & Jan 29-30, 2015 \\
\hline$\checkmark$ & EPS theme symposia & \\
\hline & $\begin{array}{l}\text { EPS theme } 4 \text { symposium 'Genome Biology', Radboud } \\
\text { University Nijmegen }\end{array}$ & \\
\hline & EPS theme 4 symposium 'Genome Biology', Wageningen & Dec 07,2012 \\
\hline & University & Dec 13, 2013 \\
\hline 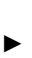 & $\begin{array}{l}\text { Annual EPS Meetings (Lunteren) and other National } \\
\text { Platforms }\end{array}$ & \\
\hline & Molecular Genetics meeting, Lunteren & Oct 06-07, 2011 \\
\hline & WIAS Science Day 2013 & Feb 28,2013 \\
\hline & NIOO Science Days 2015 & Nov 11-12, 2015 \\
\hline 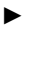 & $\begin{array}{l}\text { Seminars (series), workshops and symposia } \\
\text { PSG Seminars: Angus Dawe, Rays Jiang, Peter C. }\end{array}$ & \\
\hline & Dorrestein & May \& Oct 2011, Aug 2013 \\
\hline & NIOO Seminars: Noah Fierer, Jos M Raaijmakers, Detmer & \\
\hline & Sipkema & Nov 2011, Jan 2014 \& 2016 \\
\hline & Farewell symposia: Pierre J.G.M. de Wit \& J.A. Hans van & \\
\hline & Veen & 05 \& 27 June, 2014 \\
\hline & Workshops: Citizen science \& Writing for impact & Nov 11, 2015 \\
\hline & $\begin{array}{l}\text { Inaugural speeches: Shirley Pomponi, Jos M. Raaijmakers, } \\
\text { Liesje Mommer }\end{array}$ & Sep 2013, Nov 2015, Feb \\
\hline & Seminar plus & \\
\hline 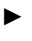 & International symposia and congresses & \\
\hline & EU SAPRO consortium meetings, Scotland and The & $1-128 \operatorname{lnct} 312$ \\
\hline & EU SAPRO mid-term review meeting, Norway & Oct 25,2011 \\
\hline & EU SAPRO consortium meetings, Spain and Sweden & Mar 26 \& Sep 03, 2012 \\
\hline & EU SAPRO consortium meeting, Norway & May 22, 2013 \\
\hline & BE-Basic Symposium 2014 & Feb 05, 2014 \\
\hline & BE-Basic Symposium 2015 & Mar 31-Apr 01, 2015 \\
\hline & EU ParaFishControl kick-off meeting & May 26-29, 2015 \\
\hline & Aquaculture Europe 2015 International Conference and & \\
\hline & Exposition (NL) & Oct 20-23, 2015 \\
\hline 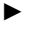 & Presentations & \\
\hline & SAPRO consortium meetings (Talks) & Apr 12 \& Oct 31, 2011 \\
\hline & Molecular Genetics ALW meeting (Poster) & Oct 06-07, 2011 \\
\hline & SAPRO mid-term review meeting (Talk) & Oct 25, 2011 \\
\hline & EPS Autumn School 'Host-Microbe Interactomics' (Poster) & Nov 01-03, 2011 \\
\hline & SAPRO consortium meetings and Summer School (Talks) & Mar 26 \& Sep 03, 2012 \\
\hline & SAPRO consortium meeting (Talk) & May 22, 2013 \\
\hline & PhD course Diseases in Salmonid Aquaculture, Norway & \\
\hline & (Poster) & May 23, 2013 \\
\hline & Phytopathology Friday labmeetings (Talks) & Oct 2011 \& May 2013 \\
\hline & Microbial Ecology department meetings (Talks) & Apr 28, 2014 \& Mar 14, 2016 \\
\hline
\end{tabular}




\begin{tabular}{|lc|}
\hline BE-Basic Symposium 2014 \& 2015 (Posters) & Feb 05, 2014 \& Mar 31-Apr \\
ParaFishControl Kick-off meeting (Talk) & May 28, 2015 \\
Aquaculture Europe 2015 International Conference and & \\
Exposition (Talk) & Oct 21, 2015 \\
NIOO Science Days 2015 (Reused poster from BE-Basic & Nov 12, 2015 \\
Symposium 2015) & \\
IAB interview & \\
Meeting with a member of the International Advisory Board of & Dec 03, 2014 \\
EPS & Mar 27, 2012 \\
Excursions & Subtotal Scientific Exposure
\end{tabular}

\begin{tabular}{|lc|}
\hline 3) In-Depth Studies & $\underline{\text { date }}$ \\
EPS courses or other PhD courses & Nov 01-03, 2011 \\
EPS Autumn School 'Host-Microbe Interactomics' & Sep 03-05, 2012 \\
Initial Training Network SAPRO Summer School, Sweden & May 23-24, 2013 \\
PhD course Diseases in Salmonid Aquaculture, Norway & \\
Journal club & \\
Literature discussion,Bacterial Ecology \& Genomics Group of & $2011-2013$ \\
Phytopathology,Wageningen University & $2014-2016$ \\
Literature discussion, Microbial Ecology Department meeting, & Jan-Apr 2012 \\
NIOO-KNAW, Wageningen & 6.9 credits* \\
\hline
\end{tabular}

\begin{tabular}{|c|c|}
\hline $\begin{array}{l}\text { 4) Personal development } \\
\text { Skill training courses } \\
\text { WGS Course Ethics and Philosophy in Life Sciences } \\
\text { Career Orientation } \\
\text { Project and Time Management } \\
\text { BE-Basic Innovation Centre training course: Business } \\
\text { Awareness Workshop } \\
\text { The last Stretch of the PhD Programme at Wageningen } \\
\text { University } \\
\text { Organisation of PhD students day, course or conference } \\
\text { Membership of Board, Committee or PhD council }\end{array}$ & $\begin{array}{c}\frac{\text { date }}{} \\
\text { Jun 20-22, 2012 } \\
\text { Mar 01, 08, 15, 22, 28, } 2013 \\
\text { Apr 02 \& 18, May 14, } 2013 \\
\text { Mar 20, } 2014 \\
\text { Sep 25, } 2015\end{array}$ \\
\hline Subtotal Personal Development & 3.6 credits $^{*}$ \\
\hline
\end{tabular}

Herewith the Graduate School declares that the PhD candidate has complied with the educational requirements set by the Educational Committee of EPS which comprises of a minimum total of 30 ECTS credits

${ }^{*}$ A credit represents a normative study load of 28 hours of study. 
The research described in this thesis was conducted in the Laboratory of Phytopathology of Wageningen University and the Department of Microbial Ecology of the Netherlands Institute of Ecology (NIOO-KNAW). It was financially supported by SAPRO (Sustainable Approaches to Reduce Oomycete (Saprolegnia) Infections in Aquaculture, 238550), a Marie Curie Initial Training Network funded by the European Commission under Framework Program 7, by ParaFishControl (Advanced Tools and Research Strategies for Parasite Control in European farmed fish, 634429), a Research and Innovation Program funded by the European Commission under HORIZON 2020, and by the Netherlands BE-Basic Foundation (project number F07.003.01).

This is NIOO-KNAW thesis 125 .

Front cover: salmon eggs decorated with the structures of cis-aconitic acid (left) and 2-furancarboxylic acid (right).

Back cover: salmon eggs decorated with the structure of the lipopeptide viscosin.

Cover design: Yiying Liu, Desalegn Etalo, Viviane Cordovez, Ruth Gómez Expósito, Ruth Schmidt, Paolo Di Lonardo.

Printed by: Uitgeverij BOXpress || proefschriftmaken.nl. 


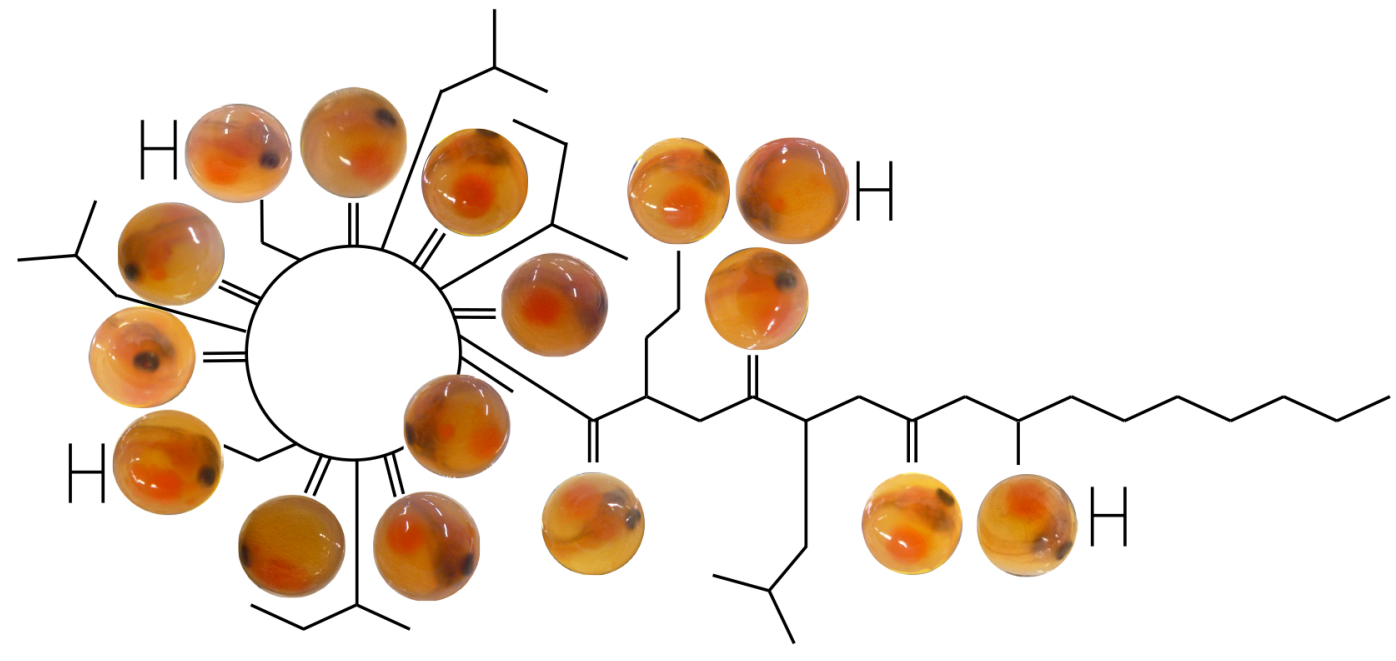

